\title{
CONTROLLED DESIGN ASSUMPTIONS DOCUMENT
}

\author{
Document \\ B00000000-01717-4600-00032, Rev. 4
}

September 12, 1996

Prepared for:

U.S. Department of Energy

Office of Radioactive Waste Management 1000 Independence Avenue, S.W.

Washington, D.C. 20585

Prepared by:

TRW Environmental Safety Systems Inc. 101 Convention Center Drive

Las Vegas, Nevada 89109

Under Contract Number

DE-AC01-91RWOO134 
WBS: 1.2 .1

SCPB: N/A

QA: L

\section{Civilian Radioactive Waste Management System Management and Operating Contractor}

\section{Controlled Design Assumptions Document}

B00000000-01717-4600-00032 REV 04, ICN 3

November 6, 1997

CONTROLLED COPY LAS VEGAS DOCUMENT CONTROL

$$
\text { COPY NO } \frac{101762}{\text { THS IS ARED STAMP }}
$$

Prepared for:

U.S. Department of Energy

Yucca Mountain Site Characterization Office P.O. Box 30307

North Las Vegas, Nevada 89036-0307

Prepared by:

TRW Environmental Safety Systems Inc. 1180 Town Center Drive Las Vegas, Nevada 89134

Under Contract Number DE-AC01-RW00134 


\title{
Civilian Radioactive Waste Management System Management and Operating Contractor
}

\author{
Controlled Design Assumptions Document
}

\section{B00000000-01717-4600-00032 REV 04, ICN 3}

November 6, 1997

Approvals:

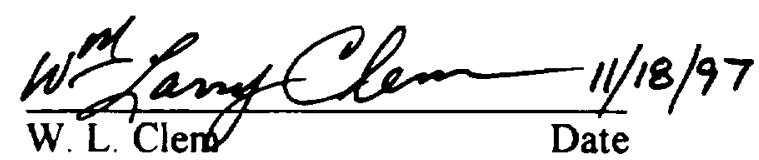

Document Preparer

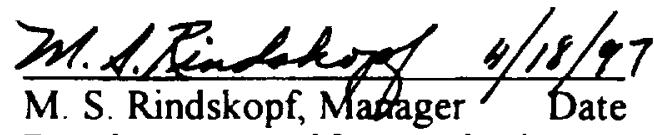

Requirements and Integration'

Configuration Management

Senior Management Concurrence:
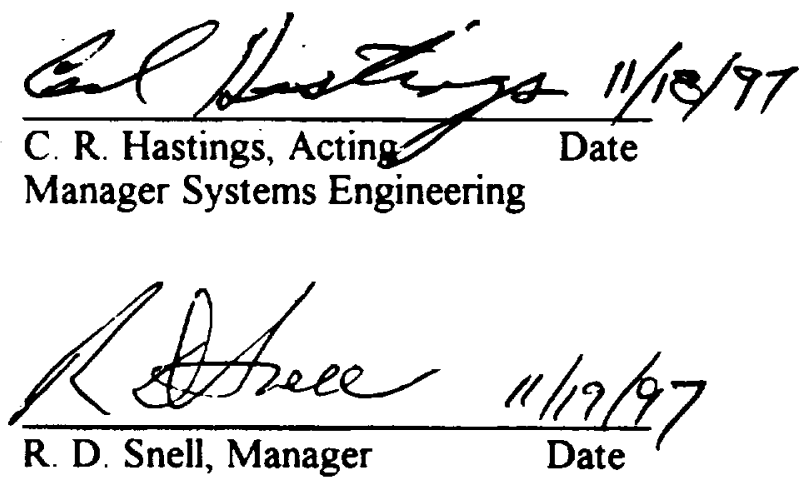

Engineering and Integration

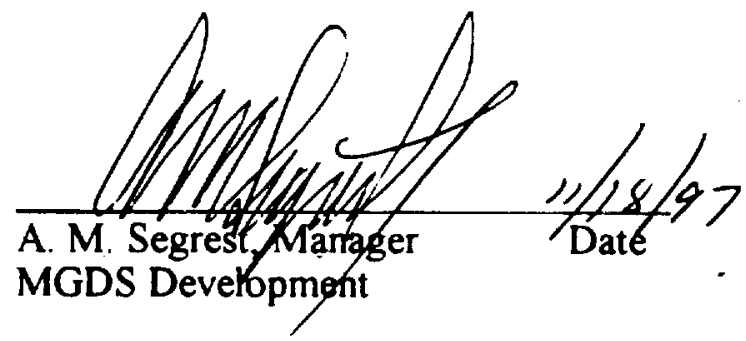
Operations

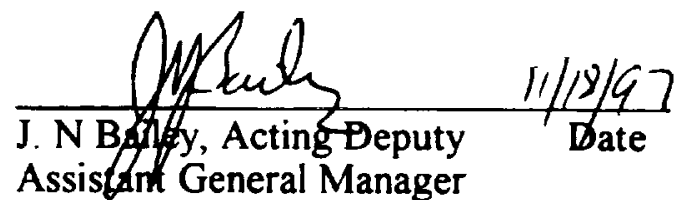




\section{CONTROLLED DESIGN ASSUMPTIONS -}

\section{ENGINEERING ORGANIZATION/TECHNICAL DISCIPLINE CONCURRENCE SHEET}

\begin{tabular}{|c|c|c|c|}
\hline Organization & Manager & Signature & Date \\
\hline Environmental Impact & E. W. McCann & & $11 / 13 / 47$ \\
\hline Performance Assessment & R. W. Andrews & & $11 / 3 / 9+$ \\
\hline Project Engineering & Paluferoulock & & ||$-|\rangle-7\rangle$ \\
\hline Licensing & K. L. Ashe & & $11-12-97$ \\
\hline Repository Design & K. Bhattacharyya & & $11 / 17 / 97$ \\
\hline Subsurface Design & D. G. McKenzie & & $11 / 13 / 21$ \\
\hline Surface Design & S. J. Meyers & & $11,17-97$ \\
\hline Scientific Program Operations & L. D. Rickertsen & & $11 / 17 / 97$ \\
\hline System Safety Assurance & P. S. Hastings & & 17010097 \\
\hline Systems Analysis and Modeling & S. F. Saterlie & & $\mathrm{k} / 13 / 97$ \\
\hline Waste Package Development & H. A. Benton & & $11 / 2 / 97$ \\
\hline Waste Package Materials & D. Stahl & & $1 / 10 / 9$ \\
\hline Office of Quality Assurance & R. G. Peck & & $11 / 17 / 97$ \\
\hline
\end{tabular}




\section{CONTENTS}

\section{Page}

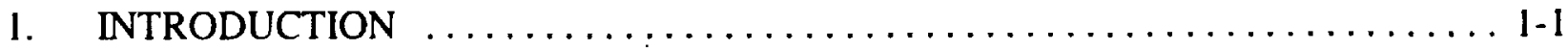

$1 . I$ OBJECTIVE $\ldots \ldots \ldots \ldots \ldots \ldots \ldots \ldots \ldots \ldots \ldots \ldots \ldots \ldots \ldots \ldots \ldots \ldots \ldots \ldots, 1$

1.2 SCOPE $\ldots \ldots \ldots \ldots \ldots \ldots \ldots \ldots \ldots \ldots \ldots \ldots \ldots \ldots \ldots \ldots \ldots \ldots \ldots \ldots \ldots, 1$

1.3 BACKGROUND $\ldots \ldots \ldots \ldots \ldots \ldots \ldots \ldots \ldots \ldots \ldots \ldots \ldots \ldots \ldots \ldots \ldots, 1$

1.4 ASSUMPTIONS $\ldots \ldots \ldots \ldots \ldots \ldots \ldots \ldots \ldots \ldots \ldots \ldots \ldots \ldots \ldots \ldots \ldots, 3$

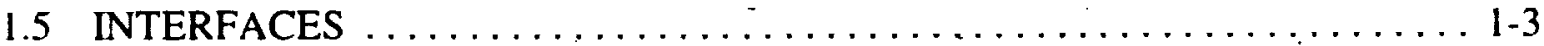

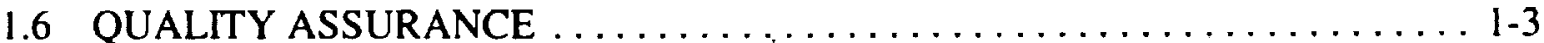

1.7 SOURCES, REFERENCES, AND RELATED DOCUMENTS $\ldots \ldots \ldots \ldots \ldots 1-4$

1.8 ORGANIZATION $\ldots \ldots \ldots \ldots \ldots \ldots \ldots \ldots \ldots \ldots \ldots \ldots \ldots, \ldots, \ldots$

2. CONTROLLED DESIGN ASSUMPTIONS TECHNICAL APPROACH $\ldots \ldots \ldots \ldots 2-1$

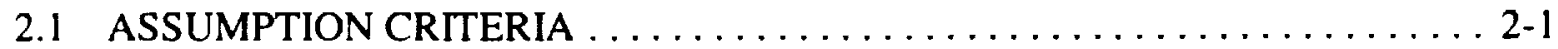

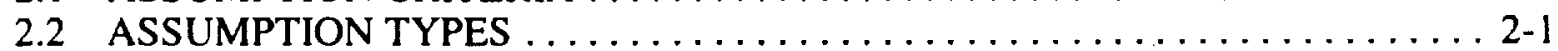

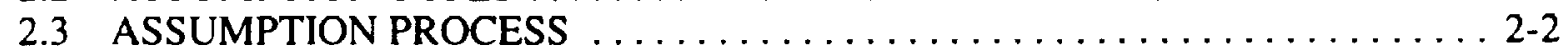

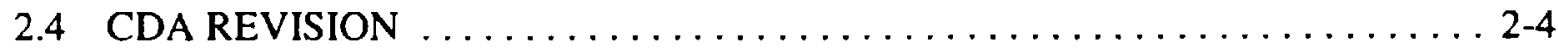

3. DESIGN REQUIREMENTS ASSUMPTIONS - KEY ASSUMPTIONS

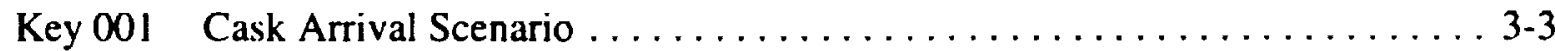

Key 002 Waste Form Arrival Scenario . . . . . . . . . . . . . . . . . . 3-9

Key 003 Waste Package Emplacement Scenario ................... 3-14

Key 004 Average Thermal SNF Characteristics .................. 3-16

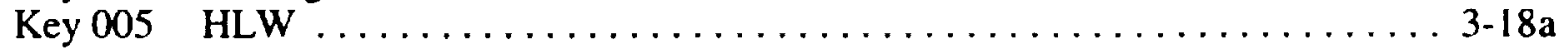

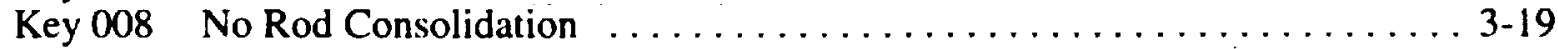

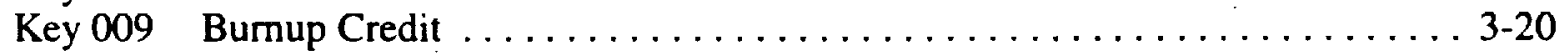

Key 010 Subsurface WP Transport $\ldots \ldots \ldots \ldots \ldots \ldots \ldots \ldots \ldots \ldots \ldots \ldots \ldots \ldots \ldots \ldots \ldots \ldots, 21$

Key 011 Horizontal In-Drift Emplacement ................... 3-22

Key 013 No Human Entry in Emplacement Drifts Containing Waste Packages . . . 3-23

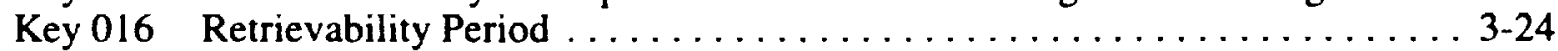

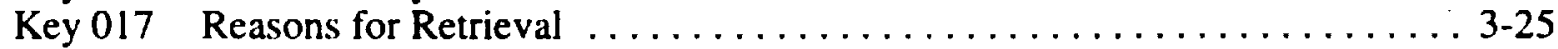

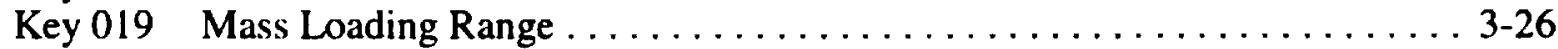

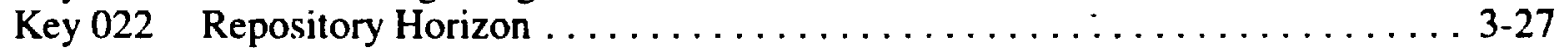

Key 023 Subsurface Fault Standoff $\ldots \ldots \ldots \ldots \ldots \ldots \ldots \ldots \ldots \ldots \ldots \ldots \ldots \ldots \ldots \ldots \ldots \ldots \ldots, 28$

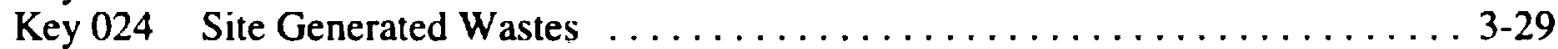

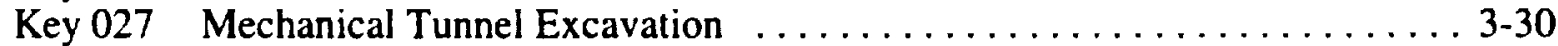

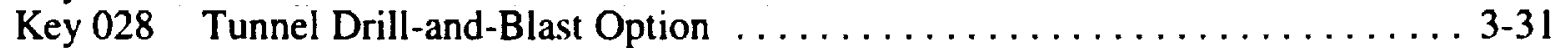

Key 030 Underground Rail Transport of Personnel and Supplies $\ldots \ldots \ldots \ldots \ldots$ 3-32

Key 031 Waste Package Shielding $\ldots \ldots \ldots \ldots \ldots \ldots \ldots \ldots \ldots \ldots \ldots \ldots \ldots \ldots \ldots \ldots, 33$

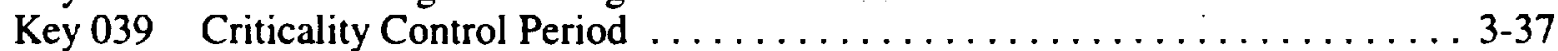

Key 046 Backfill in Emplacement Drifts $\ldots \ldots \ldots \ldots \ldots \ldots \ldots \ldots \ldots \ldots \ldots \ldots \ldots \ldots .38$

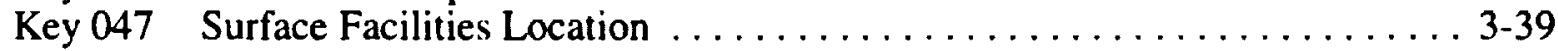

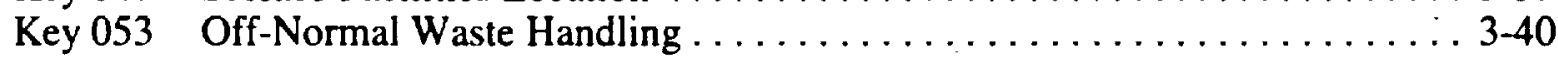

Key 055 Retrieval Demonstration ........................... 3-4

Key 057 Burnup or Thermal Measurements $\ldots \ldots \ldots \ldots \ldots \ldots \ldots \ldots \ldots \ldots \ldots \ldots \ldots \ldots \ldots, 42$

Key 058 Transportation Mode/Route Within Nevada . . . . . . . . . . . . 3-43

Key 059 MGDS Configuration Item Organization $\ldots \ldots \ldots \ldots \ldots \ldots \ldots \ldots \ldots \ldots \ldots \ldots, 44$

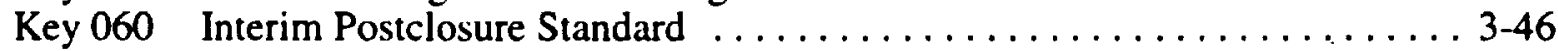




\section{CONTENTS (Continued)}

Page

Key 061 Performance Confirmation Requirements (1996) . . . . . . . . . . . 3-48

Key 063 Waste Package Destructive Testing ................... . 3-52

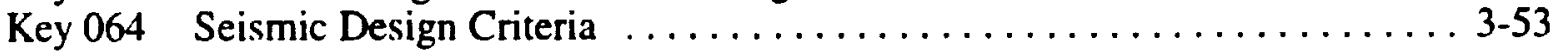

Key 065 Retrieval Design ........................... 3-54

Key 066 Gantry Emplacement and Pedestal Support . . . . . . . . . . . . . . 3-55

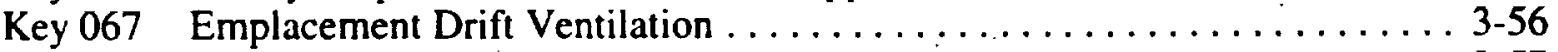

Key 068 Use of North Ramp for Waste Transport . . . . . . . . . . . . . . 3-57

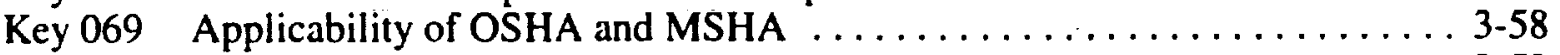

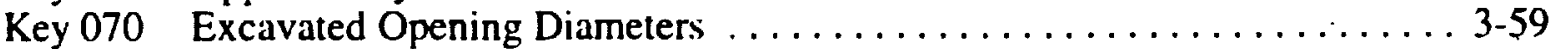

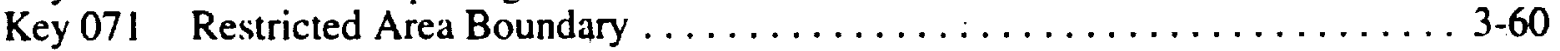

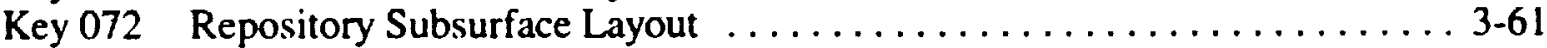

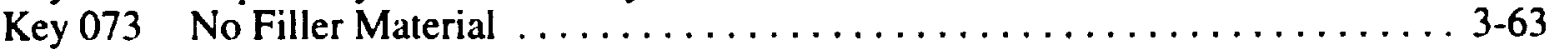

Key 074 Waste packages not breach for 3,000 years $\ldots \ldots \ldots \ldots \ldots \ldots \ldots$. . . . . . . . .

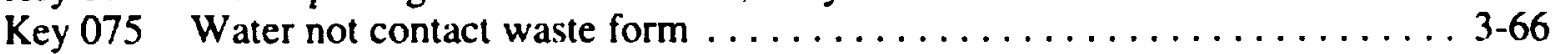

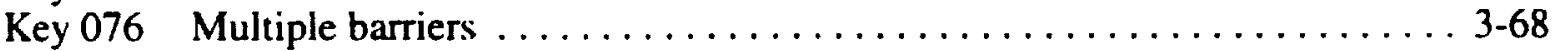

Key 077 Waste Package and Drift Spacing . . . . . . . . . . . . . . . 3-69

Key 078 Waste Package Loading \& Emplacement Order $\ldots \ldots \ldots \ldots \ldots \ldots \ldots$ 3-70

Key 079 Disposal Criticality Analysis Methodology $\ldots \ldots \ldots \ldots \ldots \ldots \ldots \ldots$ 3-72

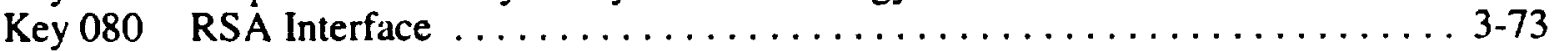

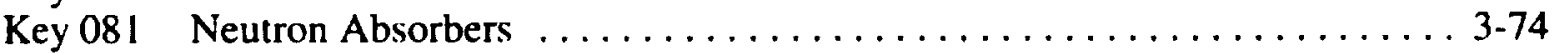

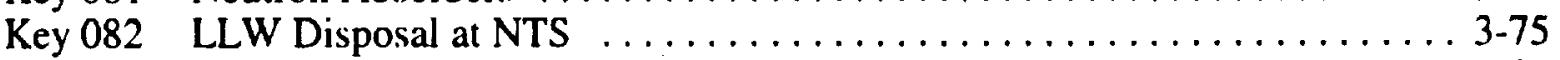

Key 083 Mapping of Repository Subsurface Openings $\ldots \ldots \ldots \ldots \ldots \ldots \ldots \ldots$ 3-76

Key 084 Hold Waste during Extended Off-normal Outage $\ldots \ldots \ldots \ldots \ldots \ldots \ldots$ 3-78

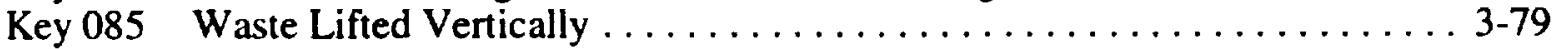

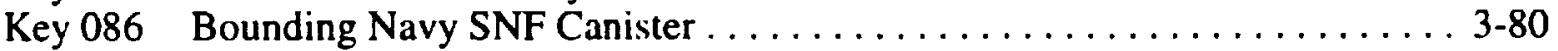

4. ENGINEERED BARRIER DESIGN REQUIREMENTS DOCUMENT ASSUMPTIONS (EBDRD)

EBDRD 3.2.3.3.A.13 Lining and Grouting Material Selection ... . . . . . 4-3

EBDRD 3.2.3.4.C.1.g SNF Weight $\ldots \ldots \ldots \ldots \ldots \ldots \ldots \ldots \ldots \ldots \ldots \ldots \ldots \ldots .4$

EBDRD 3.2.3.4.C.4 Commercial SNF Radionuclide Inventory/sotopic

Concentrations . . . . . . . . . . . . . . . . . 4-5

EBDRD 3.2.3.4.C.5 SNF Shipped Dose Rate Limits . . . . . . . . . . . . . . . 4-6

EBDRD 3.2.3.5 Engineered Barrier/Transportation Physical Interfaces . . . . . 4 47

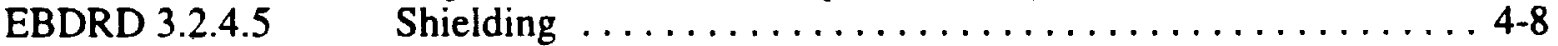

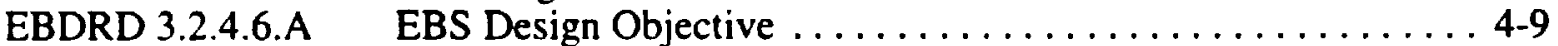

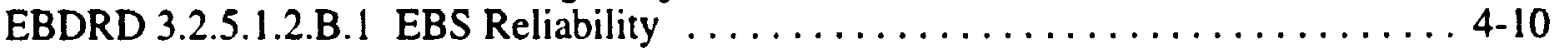

EBDRD 3.2.5.4 EBS Maintainable Preclosure Service Life . . . . . . . . . . 4-11

EBDRD 3.3.3.B Information on Label for Equipment and Parts . . . . . . . . 4-12

EBDRD 3.7.D EBS Minimum Performance $\ldots \ldots \ldots \ldots \ldots \ldots \ldots \ldots . . \ldots 4$

EBDRD 3.7.G.1 $\quad$ Borehole Wall Temperature ................. 4-14

EBDRD 3.7.G.2 Vertical Borehole Rock Mass and In-Drift Wall

Temperatures ........................... 4-15

EBDRD 3.7.G.3 TSw3 Temperature Limit ................ 4-16

EBDRD 3.7.G.4 Ground Surface Temperature Rise Limit . . . . . . . . . . . 4-17

EBDRD 3.7.G.5 Drift Temperature Limit for Borehole Emplacement ... . . 4-18 


\section{CONTENTS (Continued)}

EBDRD 3.7.G.6

EBDRD 3.7.1.I

EBDRD 3.7.1.J.1

EBDRD 3.7.1.J.2

EBDRD 3.7.1.J.3

EBDRD 3.7.1.1.F

EBDRD 3.7.1.2.A

EBDRD 3.7.1.2.B

EBDRD 3.7.1.2.C

EBDRD 3.7.1.2.D

EBDRD 3.7.1.2.E

EBDRD 3.7.1.2.H.2

EBDRD 3.7.1.2.H.3

EBDRD 3.7.1.3.A

EBDRD 3.7.1.3.D

EBDRD 3.7.2.B

EBDRD 3.7.3
Access Drift Temperature Limit $\ldots \ldots \ldots \ldots \ldots \ldots \ldots$. 4-19

Waste Package Substantially Complete Containment .... . . 4-20

Waste Package Extemal Dimensions $\ldots \ldots \ldots \ldots \ldots \ldots . .4$ 4-21

Waste Package Maximum Mass . . . . . . . . . . . . . . 4-22

Waste Package Surface Finish . . . . . . . . . . . . . . 4-23

Waste Package Drop Tolerance $\ldots \ldots \ldots \ldots \ldots \ldots \ldots .4$. 4 .24

Waste Package Handling and Transportation Loads . . . . . 4-25

Container Substantially Complete Containment . . . . . . . . 4-26

Controlled Release During Period of Isolation . . . . . . . . 4-27

Container to Limit Liquid Water Contact . . . . . . . . . . . 4-28

Container Information Label . . . . . . . . . . . . . . . . . . 4-29

Disposal Container Maximum Mass ................ 4-30

Disposal Container External Dimensions . . . . . . . . . . . . 4-31

Criticality Control Requirement $\ldots \ldots \ldots \ldots \ldots \ldots \ldots$ 4 4-32

Waste Package Internal Structure Loads $\ldots \ldots \ldots \ldots \ldots \ldots$. 4-33

Backfill Permeability ........................ 4-34

Emplacement Hardware Requirements ............ 4-35

\section{REPOSITORY DESIGN REQUIREMENTS DOCUMENT ASSUMPTIONS (RDRD)}

RDRD 3.2.1.2.B

RDRD 3.2.1.6.C

RDRD 3.2.1.6.D

RDRD 3.2.3.2.2.A.7

RDRD 3.2.3.2.2.A.11a

RDRD 3.2.3.4.B

RDRD 3.2.3.4.D

RDRD 3.7.1.C

RDRD 3.7.3.5.A.1

RDRD 3.7.3.5.A.2

RDRD 3.7.3.9.E

RDRD 3.7.4.1.A.2

RDRD 3.7.4.1.A.3

RDRD 3.7.5.A.5

RDRD 3.7.5.B.6

RDRD 3.7.5.N.1

RDRD 3.7.5.N.2

RDRD 3.7.5.N.5

RDRD 3.7.5.O.2
Waste Receiving Schedule . ................ 5-3

Disposal System Postclosure Performance (40 CFR 191) . . 5 5-4

Physical Barriers .......................... 5-5

Emplacement Concept $\ldots \ldots \ldots \ldots \ldots \ldots \ldots \ldots$ 5-6

Repository Design to Limit Waste Form - Water Contact . . 5-7

Non-Potable Water ........................ 5-8

Telephone Communications .................. 5-9

Special Sources of Groundwater . . . . . . . . . . . . . 5-10

General Underground Lighting ................ 5-11

Underground Service Facilities Lighting $\ldots \ldots \ldots \ldots \ldots$ 5-12

Site-Generated Hazardous Waste ................ 5-13

Storage Capacity for Waste Receipts $\ldots \ldots \ldots \ldots \ldots \ldots$ 5-14

Waste Handling Holding Areas $\ldots \ldots \ldots \ldots \ldots \ldots, 5-15$

Men-and-Materials Shaft Hoist Limits . . . . . . . . . . . 5-16

Underground Air Supply . . . . . . . . . . . . . . . . . 5-17

Waste Ramp Air Flow . . . . . . . . . . . . . . . . 5-18

Tuff Ramp Air Flow . ..................... 5-19

Shaft Size ............................ 5-20

Men-and-Materials Shaft Usage $\ldots \ldots \ldots \ldots \ldots \ldots \ldots .5-21$ 


\section{CONTENTS (Continued)}

\section{DESIGN CONCEPT SURFACE ASSUMPTIONS (DCS)}

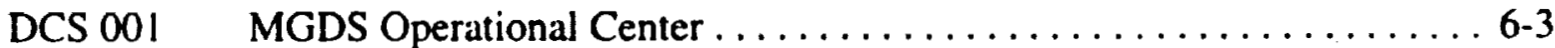

DCS 003 Occupational Exposure Limits ........................ 6-4

DCS $004 \quad$ ALARA Studies ............................... 6-5

DCS 008 Decontamination Equipment and Space $\ldots \ldots \ldots \ldots \ldots \ldots \ldots \ldots .6 .7$

DCS 011 Underground Waste Generation ......................6. 6-9

DCS $012 \quad$ No HLW in Waste Treatment Building ................. 6-10

DCS 013 Waste Generated by Performance Confirmation Activities ........ 6-11

DCS 019 Support Facilities Design $\ldots \ldots \ldots \ldots \ldots \ldots \ldots \ldots \ldots \ldots \ldots \ldots \ldots \ldots, 17$

DCS $020 \quad$ WHB Wet/Dry Handling $\ldots \ldots \ldots \ldots \ldots \ldots \ldots \ldots \ldots \ldots \ldots \ldots \ldots \ldots, 18$

DCS $021 \quad$ Special Tooling $\ldots \ldots \ldots \ldots \ldots \ldots \ldots \ldots \ldots \ldots \ldots \ldots \ldots \ldots \ldots \ldots \ldots .19$

7. DESIGN CONCEPT SUBSURFACE ASSUMPTIONS (DCSS)

DCSS 001

DCSS 005

DCSS 006

DCSS 009

DCSS 010

DCSS 014

DCSS 015

DCSS 016

DCSS 017

DCSS 018

DCSS 019

DCSS 020

DCSS 022

DCSS 023

DCSS 025

DCSS 027

DCSS 028

DCSS 029

DCSS 030

DCSS 031

DCSS 032

DCSS 033

DCSS 034

DCSS 035

DCSS 036

DCSS 037

DCSS 038

DCSS 039
Drift Orientation .............................. 7-3

Drift Excavation Methods .............................. 7-4

Maximum Excavation Extraction Ratio . . . . . . . . . . . . . 7-5

Maximum Ramp Grade ...................... 7-6

Repository Material Haridling Equipment $\ldots \ldots \ldots \ldots \ldots \ldots, 7-7$

Shaft Excavation Method $. \ldots \ldots \ldots \ldots \ldots \ldots \ldots \ldots \ldots \ldots, 7-8$

Ventilated Air Properties ............................... 7-9

Maximum Underground Air Velocity . . . . . . . . . . . . 7-10

Minimum Underground Air Velocity $\ldots \ldots \ldots \ldots \ldots \ldots \ldots, 7-11$

Minimum Underground Air Volume $\ldots \ldots \ldots \ldots \ldots \ldots \ldots \ldots \ldots$ 7-12

Maximum Underground Air Temperatures - Emplacement Drifts . . 7-13

Maximum Underground Air Temperatures - Access Mains ....... 7-14

"K" Factor for Ventilation Air Flow ................... 7-15

Maximum Preclosure Rock Surface Temperature $\ldots \ldots \ldots \ldots \ldots$ 7-16

Maximum Zeolite Temperature $\quad \ldots \ldots \ldots \ldots \ldots \ldots \ldots \ldots, 7-17$

Rock Support Material Restrictions $\ldots \ldots \ldots \ldots \ldots \ldots \ldots \ldots$ 7 18

Emplacement Drift, Shafts, Ramps Maintenance Plans ........ 7-19

Maximum Underground Air Temperatures - Exhaust Mains . . . . . 7-20

Limit Ground Surface Uplift ...................... 7-21

Limit Temperatures in PTn ..................... 7-22

Temporary Surface Facilities for Underground Construction $\ldots \ldots$ 7-23

Emplacement Drift Standoff ....................... 7-24

Emplacement Drift Ground Support ................. 7-25

Emplacement and DevelopmentArea Ventilation ........... 7-26

Emplacement Drift Entrance Doors . . . . . . . . . . . . . . . . 7-27

Invert Material . . . . . . . . . . . . . . . . . . . . . . . . . . . . . . .

Air Monitoring Underground $\ldots \ldots \ldots \ldots \ldots \ldots \ldots \ldots \ldots \ldots \ldots \ldots, 29$

Ventilation System Pressure Differential $\ldots \ldots \ldots \ldots \ldots \ldots \ldots$. 7-30 


\section{CONTENTS (Continued)}

8. DESIGN CONCEPT WASTE PACKAGE ASSUMPTIONS (DCWP)

DCWP 00I Limit Fuel Cladding Temperature $\ldots \ldots \ldots \ldots \ldots \ldots \ldots \ldots \ldots, 8-3$

DCWP 002 Limit HLW Glass Temperature $\ldots \ldots \ldots \ldots \ldots \ldots \ldots \ldots \ldots \ldots .4$

DCWP 004 Waste Package Materials ........................ 8-5

9. TECHNICAL DATA SURFACE ASSUMPTIONS (TDS)

TDS $002 \quad$ Topography/Morphology $\ldots \ldots \ldots \ldots \ldots \ldots \ldots \ldots \ldots \ldots \ldots \ldots \ldots .4$

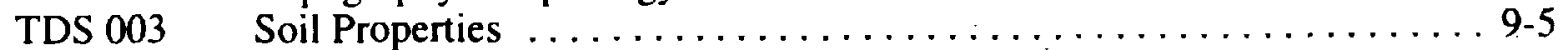

TDS $004 \quad$ Meteorology .................................

TDS 006 Design Basis Tomadoes .......................... 9-7

TDS $007 \quad$ Winds (Operating Basis and Standard) $\ldots \ldots \ldots \ldots \ldots \ldots \ldots \ldots .9 .8$

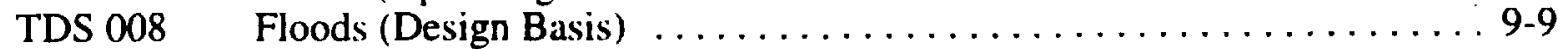

10. TECHNICAL DATA SUBSURFACE ASSUMPTIONS (TDSS)

TDSS $001 \quad$ In Situ Stress . . . . . . . . . . . . . . . . . . . . 10-3

TDSS 002 Ground Surface Temperature, Rock Thermal Gradient .......... 10-4

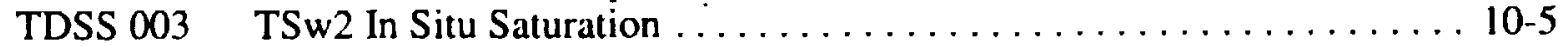

TDSS $004 \quad$ TSw2 Rock Densities ........................... 10-6

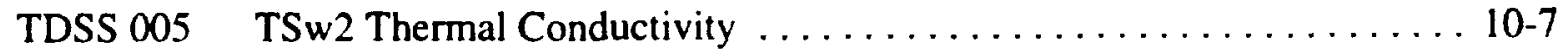

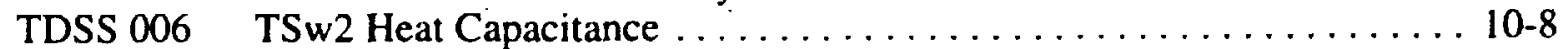

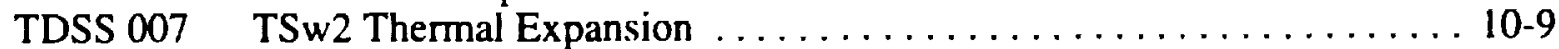

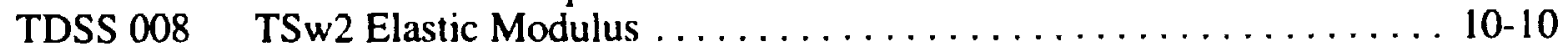

TDSS 009 TSw2 Poisson's Ratio ........................ 10-11

TDSS $010 \quad$ TSw2 Uniaxial Compressive Strength ................ 10-12

TDSS 011 TSw2 Mohr-Coulomb Strength Parameters ............... 10-13

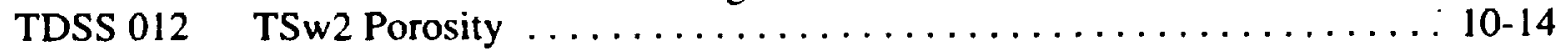

TDSS 017 Rock Joint Orientation and Frequency $\ldots \ldots \ldots \ldots \ldots \ldots \ldots \ldots \ldots \ldots \ldots$

TDSS 021 Surface Air Temperature/Humidity .................. 10-16

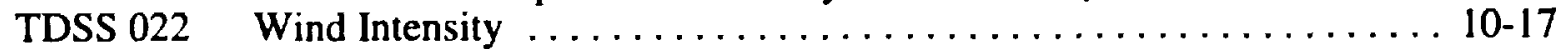

TDSS 025 Unsaturated Zone Groundwater Chemistry . . . . . . . . . . 10-20

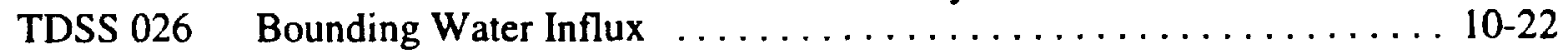

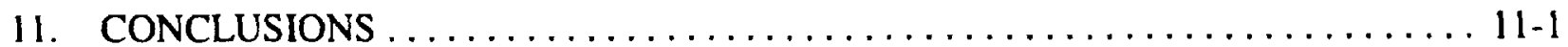

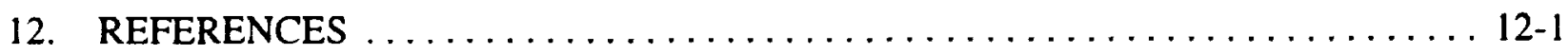

APPENDIX A. ASSUMPTION STATUS LOG $\ldots \ldots \ldots \ldots \ldots \ldots \ldots \ldots \ldots \ldots \ldots \ldots$

APPENDIX B. WITHDRAWN ASSUMPTIONS $\ldots \ldots \ldots \ldots \ldots \ldots \ldots \ldots \ldots \ldots \ldots$, B-I

Key $006(W) \quad$ MGDS Waste Receipt Period .....................

Key $007(W) \quad$ No MPC Repackaging for Heat Load Tailoring ............. B-4

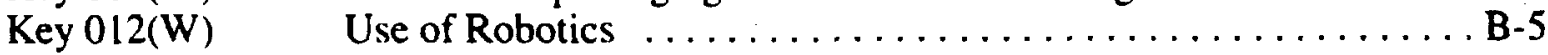


DCS 010 (W)

DCS 014 (W)

DCS 015 (W)

DCS 016 (W)

DCS 017 (W)

DCS 018 (W)

DCSS $002(W)$

DCSS 003(W)

DCSS 004(W)

DCSS 013(W)

DCSS $021(\mathrm{~W})$

DCSS 026(W)

DCWP 003 (W)

DCWP 005(W)

DCWP. 006 (W)

TDS 005(W)

TDS $001(\mathrm{~W})$

TDS 009 (W)

TDS $010(\mathrm{~W})$

TDS $011(\mathrm{~W})$

TDS 012(W)

TDS 013(W)

TDS 014(W)

TDS 015(W)

TDSS 013(W)

TDSS 014(W)

TDSS 015(W)

TDSS 018(W)

TDSS 019(W)

TDSS 020(W)

TDSS 023(W)

TDSS 024(W)

REQSE 001(W)

REQSE 002(W)

REQSE 003(W)
Hazardous Waste Disposal $\ldots \ldots \ldots \ldots \ldots \ldots \ldots . . .6$. 51 .

Cask Maintenance Operations ................ B-5lb

Transportation Cask Fleet Inventory ............. B-5lc

Trans. Cask Fleet Maintenance Frequency . . . . . . . . B-51d

WHB Dry Handling $\ldots \ldots \ldots \ldots \ldots \ldots \ldots \ldots \ldots$, B-5le

CMF Wet Handling . . . . . . . . . . . . . . .

Repository Horizon ....................... B-52

Underground Excavation Crown . . . . . . . . . . . B-53

Stand-Off Distance $\ldots \ldots \ldots \ldots \ldots \ldots \ldots \ldots \ldots \ldots$. B-54

In-Drift Emplacement . . . . . . . . . . . . . . . . . . B-55

Underground Air Quality ......................... B-56

Emplacement Drift Backfill .................... B-57

Alternate Waste Package Disposal Container Materials ... . . . B-58

Tentative Co-Disposed DOE SNF WP Dimensions ....... B59-a I

Tentative WP External Dimensions for Canistered SNF ... B B5-b

Seismic Environment .......................... B-60

Fault Displacement, Locations, Attitudes . .......... B-61

Surface Facilities/ALARA - Reclassified as DCS $002 \ldots .$. B-62

ALARA Studies - Reclassified as DCS 004 ............. B-63

Waste Handling Building -Reclassified as DCS 005 ..... B-64

Transportation Cask Maintenance Facility -

Reclassified as DCS $006 \ldots \ldots \ldots \ldots \ldots \ldots \ldots$. . . . . 65

Waste Treatment Building - Reclassified as DCS 007 . . . . B B-66

Decontamination .......................... B-67

Rod Consolidation ....................... B-68

Deformation Modulus ...................... B-69

Rock Compressive Strength $\ldots \ldots \ldots \ldots \ldots \ldots \ldots \ldots$ B-70

Rock Tensile Strength ..................... B-71

TSw2 Rock Joint Strength . . . . . . . . . . . . B-72

Rock Joint Stiffness . . . . . . . . . . . . . . . . B-73

Rock Mass Quality Indices $\ldots \ldots \ldots \ldots \ldots \ldots \ldots \ldots$ B-74

Unsaturated Zone Groundwater Flux $\ldots \ldots \ldots \ldots \ldots \ldots$ B-74a

Unsaturated Zone Groundwater $\mathrm{pH} \ldots \ldots \ldots \ldots \ldots \ldots$ B-74b

B-75

B-76

B-77

APPENDIX C Controlled Design Assumptions for Viability Assessment Issues . . . . . C C-I

APPENDIX D Alternate Assumptions $\ldots \ldots \ldots \ldots \ldots \ldots \ldots \ldots \ldots \ldots \ldots \ldots \ldots \ldots$ 


\section{FIGURES}

\section{Page}

2-1 Process for Generating, Revising, or Withdrawing Assumptions $\ldots \ldots \ldots \ldots \ldots \ldots 2-3$

3-1 Mined Geologic Disposal System Configuration Item Organization . . . . . . . . . 3-45

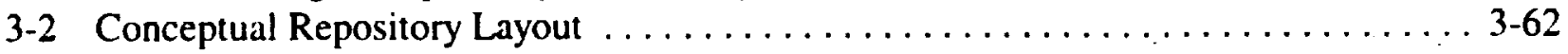


3-1. Baseline Commercial SNF Waste Stream - Truck Casks . . . . . . . . . . . . . . 3-5 I

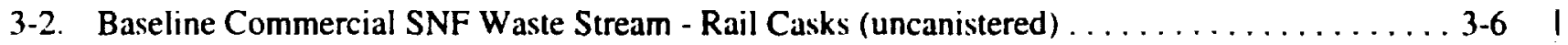

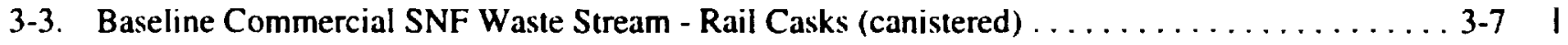

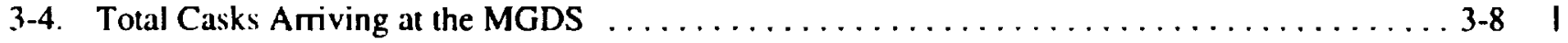

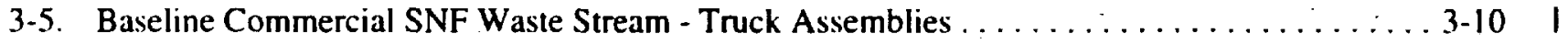

3-6. Baseline Commercial SNF Waste Stream - Rail Assemblies (uncanistered) $\ldots \ldots \ldots \ldots \ldots \ldots$. $\ldots \ldots$ I

3-7. Baseline Commercial SNF Waste Stream - Rail Assemblies (canistered) . . . . . . . . 3-12

3-8. Total Fuel Assemblies and HLW/DOE-SNF Canisters Arriving at the MGDS $\ldots \ldots \ldots \ldots \ldots .3-13 \quad$ I

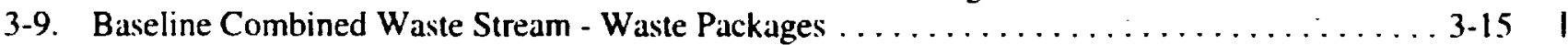

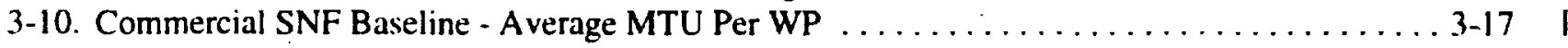

3-11. Commercial SNF Baseline - Average Initial Heat Per WP (kW/WP) $\ldots \ldots \ldots \ldots \ldots \ldots .18$ ।

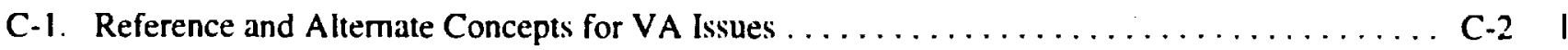

C-2. CDA Assumptions Related to Reference Concepts for VA Issues . . . . . . . . . . C-II I

C-3. CDA Assumptions Related to Alternate Concepts for VA Issues $\ldots \ldots \ldots \ldots \ldots \ldots \ldots$ C-15 I 


\section{ACRONYMS AND ABBREVIATIONS -}

\begin{tabular}{ll} 
ACD & Advanced Conceptual Design \\
ALARA & As Low As Reasonably Achievable \\
AML & Areal Mass Loading \\
ISTM & American Society of Testing and Materials \\
BCP & Baseline Change Proposal \\
BMP & Best Management Practices \\
BP & Big Rock Point (power plant) \\
BWR & Boiling Water Reactor \\
CCB & Change Control Board \\
CDA & Controlled Design Assumptions \\
CDB & Characteristics Data Base \\
CDR & Conceptual Design Report \\
CFR & Code of Federal Regulations \\
CMF & Cask Maintenance Facility \\
CRD & CRWMS Requirements Document \\
CRWMS & Civilian Radioactive Waste Management System \\
CSNF & Commercial Spent Nuclear Fuel \\
DC & Design Concept \\
DBE & Design Basis Event \\
DHLW & Defense High Level Waste \\
DI & Document Identifier \\
DIE & Determination of Importance Evaluation \\
DOE & Department of Energy \\
DOE/EM & DOE/Office of Environmental Management \\
DOE/RW & DOE/Office of Civilian Radioactive Waste Management \\
DPC & Dual Purpose Canister \\
DRD & Design Requirements Document \\
DSNF & DOE Spent Nuclear Fuel \\
EB & Engineered Barrier \\
EBDRD & Engineered Barrier Design Requirements Document \\
EBS & Engineered Barrier Segment \\
IOC & Emplacement Entry Area \\
EEA & Equivalent Energy Density \\
EED & Environmental Impact Statement \\
EIS & Emplacement Locomotive \\
EL & Exploratory Studies Facility \\
ESF & Geologic Repository Operations Area \\
GROA & High-Efficiency Particulate Air \\
HEPA & High Heat \\
HH & High-Level Waste \\
\hline
\end{tabular}




\section{ACRONYMS AND ABBREVIATIONS (Continued)}

$\begin{array}{ll}\text { LA } & \text { License Application } \\ \text { LG } & \text { Large } \\ \text { LLW } & \text { Low-Level Waste } \\ \text { M\&O } & \text { Management and Operating } \\ \text { MED } & \text { Medium } \\ \text { MGDS } & \text { Mined Geologic Disposal System } \\ \text { MGDS-RD } & \text { MGDS Requirements Document } \\ \text { MRS } & \text { Monitored Retrievable Storage } \\ \text { MPC } & \text { Multi-purpose Canister } \\ \text { MSHA } & \text { Federal Mine Safety and Health Administration } \\ \text { MTHM } & \text { Metric Tons Heavy Metal } \\ \text { MTU } & \text { Metric Tons of Uranium } \\ \text { NEPA } & \text { National Environmental Policy Act } \\ \text { NRC } & \text { Nuclear Regulatory Commission } \\ \text { NTS } & \text { Nevada Test Site } \\ \text { NWPAA } & \text { Nuclear Waste Policy Act, As Amended } \\ \text { OFF } & \text { Oldest Fuel First } \\ \text { OSHA } & \text { Federal Occupational Safety and Health Administration } \\ \text { PRA } & \text { Probabilistic Risk Assessment } \\ \text { PWR } & \text { Pressurized Water Reactor } \\ \text { QA } & \text { Quality Assurance } \\ \text { RCA } & \text { Radiologically Controlled Area } \\ \text { RCRA } & \text { Resource Conservation and Recovery Act of 1976, as amended } \\ \text { RDRD } & \text { Repository Design Requirements Document } \\ \text { RFP } & \text { Request for Proposals } \\ \text { RIB } & \text { Reference Information Base } \\ \text { RSA } & \text { Regional Service Agent } \\ \text { RW } & \text { Radioactive Waste } \\ \text { S } & \text { Surface } \\ \text { SAR } & \text { Safety Analysis Report } \\ \text { SCP } & \text { Site Characterization Plan } \\ \text { SE } & \text { Systems Engineering } \\ \text { SM } & \text { Small } \\ \text { SNF } & \text { Spent Nuclear Fuel } \\ \text { SPO } & \text { Scientific Program Operations } \\ \text { SRD } & \text { Site Requirements Document } \\ \text { SS } & \text { Subsurface } \\ \text { SSC } & \text { Structures, Systems, and Components } \\ \text { ST } & \text { South Texas Project (power plant) } \\ \text { TBD } & \text { To Be Determined } \\ \text { TBM } & \text { Tunnel Boring Machine } \\ \text { TBR } & \text { To Be Resolved } \\ \text { TBV } & \text { To Be Verified } \\ \text { TC } & \text { Transportation Cask } \\ & \end{array}$

Pressurized Water Reactor

Quality Assurance

Radiologically Conted

Resource Conservation and Recovery Act of 1976, as amended

Request for Proposals

Reference Information Base

Radioactive Waste

Surface

Safety Analysis Report

Site Characterization Plan

Systems Engineering

Small

Fue

Site Requirements Document

Subsurface

South Texas Project (power plant)

To Be Determined

Tunnel Boring Machine

To Be Resolved

Transportation Cask 


\section{ACRONYMS AND ABBREVIATIONS (Contimued)}

TD

Technical Data

TSLCC

Total System Life Cycle Cost

TSPA

Total-System Performance Assessment

UCF

Uncanistered Fuel

VA

Viability Assessment

WA

Waste Acceptance

WHB

Waste Handling Building

WP

Waste Package

WVDP

YFF

West Valley Demonstration Project

YMP

Youngest Fuel First

YMSCO

Yucca Mountain Site Characterization Project

Yucca Mountain Site Characterization Office 


\section{INTRODUCTION}

\subsection{OBJECTIVE}

The objective of the Controlled Design Assumptions Document (CDA) is to provide documentation and control of Mined Geologic Disposal System (MGDS) design assumptions in support of design and performance assessment in preparing for the Viability Assessment (VA), Suitability Report (SR),

I Environmental Impact Statement (EIS), and License Application (LA) milestones.

\subsection{SCOPE}

CDA document assumptions include conceptual and technical data assumptions, as well as tentative design requirements that are typically of interest or affect to the program (Civilian Radioactive Waste Management System [CRWMS]), project (MGDS), or to more than one element of the MGDS. The CDA supplements the current technical baseline documents of the MGDS until all assumptions and requirements are incorporated in the technical baseline. The document lists each assumption, identifies its rationale and design responsibility, and tracks its development status.

Several of the assumptions in this document have been intentionally specified to levels beyond those specified in sections of 10 CFR 60 to assure that the overall system performance objective for the geologic repository (10 CFR 60.112) will be met, with reasonable assurance.

\subsection{BACKGROUND}

The approach originally used in developing the Advanced Conceptual Design (ACD) was to develop multiple design concepts in parallel until sufficient scientific basis was available to support the selection of a single concept. The selection of a single concept was planned to occur at the completion of the ACD activities. Due to considerations such as limited resources, the changes in the program baseline, and the availability of increased scientific knowledge since publication of the Site Characterization Plan Conceptual Design Report, dated September 1987 (SCP-CDR) SNL 1987, Nevada Nuclear Waste Storage Investigations Project, a different process was necessary to help expedite repository/waste package design progress.

The process developed was referred to as the "focused" ACD approach. The essence of the process was based on the selection, in each design area, of a single primary design concept which was expected to meet the repository/waste package requirements. The selection of the primary concept was based on management decisions/assumptions which utilize the available technical data to support the decision. Each decision/assumption made that was not supported by sufficient technical data, generated a substantiation activity to validate the decision. Alternatives to major design features that are important to waste isolation were also considered as required by $10 \mathrm{CFR} 60$. The Focused ACD approach was based on the premise that meeting the requirements is adequate.

Following the conceptual design phase the purpose of the CDA has (beginning in Rev. 04) shifted to focus on facilitating the completion of the Phase I design for VA. In Revision 4, ICN 1, TDSS 023 was modified, Key Assumptions 074, 075, 076, and Technical Data Assumption 026 were added to the CDA, along with the corresponding adjustments to existing assumptions created by these 
additions. Key Assumption 074 identifies the approach for dealing with the redistribution of moisture during the high thermal phase, Key Assumption 075 requires that seeping water that will enter the emplacement drift is not to contact the waste form for 10,000 years, and Key Assumption 076 requires multiple barriers to not have common modes of failure. Bounding water flux rates are specified in TDSS 026 while more details on the chemistry of the water were added to TDSS 023. In the original document issue, the U.S. Department of Energy (DOE) had the responsibility for identifying the key assumptions and determining the values or judgments to be used for the key assumptions. This responsibility has since been delegated to the CRWMS Management and Operating Contractor (M\&O).

I In Revision 4, ICN 2, the controlled design assumptions were updated for applicability to design concepts associated with a series of issues important to the VA milestone. Briefing and documentation of these "VA issues", including status summaries, were provided in May 1997 (CRWMS 1997g). In Revision 4, ICN 2, a new Appendix C was added to the CDA Document to describe the reference and alternate design concepts associated with the individual VA issues. The assumptions in Sections 3 through 10 of this CDA Document were updated to reflect the reference concepts for the various VA issues. Appendix $C$ identifies the assumptions within Sections 3 through 10 that are related to each VA issue and whether they were changed or added in Revision 4 , ICN 2.

The reference concepts for the VA issues reflect the current design analysis and concepts for the MGDS. These design concepts are summarized in the Reference Design Description for a Geologic Repository (CRWMS M\&O 1997i). The assumptions in Sections 3 through 10 of the CDA Document provide basis for this reference system design.

Appendix $\mathrm{C}$ also identifies assumptions related to the alternate concept(s) for each VA issue. If the assumptions only apply to alternate concepts, they are not included in Sections 3 through 10 . Appendix D was added in Revision 4, ICN 2 to contain these assumptions (designated by the prefix ALT) for alternate concepts.

Some alternate concepts may be carried only until scheduled analyses provide an appropriate decision basis. Others may be carried because of some uncertainty associated with the performance of the reference concept or because they are dependent on strategy that is yet to be resolved for another issue. In many cases, the evaluation of altemate concepts will be documented as alternatives for License Application purposes even if the reference concept is retained.

1 The decisions between reference and alternate concepts are generally subject to resolution through 1 design analyses or systems analyses. The existence of an alternate concept does not imply that the 1 design for the applicable alternate concept is being developed. The ALT assumptions associated I with the alternate concepts are included in Appendix D to better understand the alternate concepts 1 and the potential impacts that they would have on the reference system design assumptions. The I ALT assumptions are not intended for any other use. 
INTENTIONALLY LEFT BLANK TO ACCOMMODATE ICN PAGES 


\subsection{ASSUMPTIONS}

Assumptions used in the preparation of each controlled design assumption are given in Sections II (Background) and III (Rationale) of each controlled design assumption Rationale Sheet. Assumptions listed in the documents referenced in Section 12 are considered in the assumptions themselves.

\subsection{INTERFACES}

The CDA document interfaces with the Preliminary Mined Geologic Disposal System Concept of Operations (CRWMS M\&O 1996h) document (see Section 1.7). The assumptions in the CDA document interface with the documents identified in Section 12 and in the controlled design assumptions.

\subsection{QUALITY ASSURANCE}

The Quality Assurance (QA) program is applicable to the CDA. The work associated with the CDA is identified in the QAP-2-0 activity evaluation entitled QAP 2-0 Work Control Evaluation for Development of the Controlled Design Assumptions Document (CRWMS M\&O 1996j). The QAP2-0 activity evaluation determined the activities to be subject to the requirements of the Quality Assurance Requirements and Description (QARD) (DOE 1995c) controls. Applicable procedural controls are listed in the QAP-2-0 evaluation. A QAP-2-3 classification analysis for the CDA is not applicable at this stage of the MGDS design. However, QAP-2-3 classification analyses to support the classification of the individual Systems, Structure, or Components (i.e., permanent items) will be performed for all permanent items identified in the CDA as the design and/or evaluation of these permanent items evolves. These QAP-2-3 classification analyses will either: 1) justify the item's inclusion on the MGDS Q-List (YMP 1992) or, 2) justify the item not being included on the MGDS $Q$-List (YMP 1992). In addition, these classification analyses will also address those permanent items which have already been added to the MGDS Q-List (YMP 1992) through direct inclusion by the DOE. Determination of Importance Evaluation (DIE) in accordance with NLP-2-0, Determination of Importance Evaluations, are not applicable because this activity is not a field activity. No scientific or engineering software was used in the development of the CDA.

Due to the nature of this document, all data contained herein are of indeterminate quality. Requirements or other technical, quality affecting data using these assumptions as a basis prior to substantiation must clearly identify the data as unqualified/unconfirmed and reference this document as the source.

NLP-3-15, To Be Verified (TBV) and To Be Determined (TBD) Monitoring System, is not used to identify data of indeterminant quality in this document because the CDA is a conceptual document that does not support construction, fabrication, or procurement, and will not be used as part of a verified design package to be released to another organization for use in other design work. 


\subsection{SOURCES, REFERENCES, AND RELATED DOCUMENTS ${ }^{-}$}

The assumptions contained in this document are developed based on, and are reflective of, the MGDS design process. The Preliminary Mined Geologic Disposal System Concept of Operations (CRWMS M\&O 1996h) is related to this document in the sense that some of the concepts of operations may have their bases in the assumptions of the CDA document.

Two special categories of controlled design assumptions (RDRD and EBDRD assumptions) assume modification or non-applicability of requirements contained in Revision 0, ICN-1 of the Repository Design Requirements Document (RDRD) (YMP 1994a) and Engineered Barrier Design Requirements Document (EBDRD) (YMP 1994b).

References that are used in developing the assumption rationales are contained in Section 12

\subsection{ORGANIZATION}

Section 2 describes the technical approach used to develop the controlled design assumptions. Section 3 lists all current assumptions to facilitate access and reference. Sections 3 through 10 contain the Assumption Rationale Sheets. Section 11 contains the conclusions, and Section 12 contains a list of references. Appendix A contains a log used to list all assumptions, including withdrawn assumptions, and document their status and responsible organizations. Appendix B contains the records of all withdrawn assumptions. 
INTENTIONALLY LEFT BLANK 


\section{CONTROLLED DESIGN ASSUMPTIONS TECHNICAL APPROACH}

This section describes the criteria for including design assumptions in this document and the process for developing and incorporating new assumptions, and updating or withdrawing existing assumptions.

\subsection{ASSUMPTION CRITERIA}

Each group within the Management and Operating Contractor (M\&O) Mined Geologic Disposal System (MGDS) Development Organization provides assumptions for this document to facilitate the Viability Assessment (VA).

Assumptions are controlled and tracked if they meet any of the following criteria:

- The assumption is important to the overall program in terms of policy and decision making.

- The assumption affects and requires coordination of more than one project, organizational group, or external agency.

- The assumption affects a major design element of the project and is important to the project, the interfaces between segments, or affects waste isolation and containment.

- The assumption affects the project technical baseline documents.

\section{$2.2 \quad$ ASSUMPTION TYPES}

The assumptions are categorized as follows:

\section{Key Assumptions}

An important type of assumptions are identified as "Key" assumptions. The criteria for identifying an assumption as a key assumption are the first or second criteria in Section 2.1. A key assumption may also address a highly controversial issue, or an issue lacking a clear consensus among U.S. Department of Energy (DOE) officials and participants. The first set of key assumptions was identified in the original issue of the CDA document by the Yucca Mountain Site Characterization Office (YMSCO) Repository, Waste Package Project Engineering and Systems Engineering staff. In the first revision of the document, control of key assumptions was transferred to the Management and Operating Contractor (M\&O).

\section{Design Requirement Document (DRD) Assumptions}

Assumptions of this type, labeled EBDRD and RDRD, refer to requirements in the Engineered Barrier Design Requirements Document (EBDRD) (YMP 1994b) and the Repository Design Requirements Document (RDRD) (YMP 1994a), respectively. Typically the DRD assumption in Section I of the Assumption Rationale Sheet will do one or more of the following: 
- Remove a TBD or TBV contained in the original requirement -

- State that the requirement is not applicable

- Replace the original DRD requirements with a new statement.

\section{Technical Data (TD) Assumptions}

Assumptions of this type include data selected from ranges of values specified in the Reference Information Base (RIB) (YMP 1995a) and elsewhere, as necessary, to support waste package and repository design.

\section{Design Concept (DC) Assumptions}

Assumptions of this type include identification of design concepts judgments and/or decisions made to move forward with the design. The design concept assumptions included in the document typically are those that have insufficient technical data to support a final decision on the design.

\section{Identification}

To identify the various assumptions, the abbreviation of their type is used in combination with a group of letters symbolizing their design responsibility. The groups of letters used are: $\mathbf{S}$, for Surface; SS, for Subsurface; and WP, for Waste Package. The letters R and EB represent Repository and Engineered Barrier, respectively, and are used to identify Design Requirement Document assumptions. Using this identification system, the types of assumptions included in this document, as listed, are:

- KEY

- EBDRD

- RDRD

- DCS
- DCSS

- DCWP

- TDS

- TDSS

\subsection{ASSUMPTION PROCESS}

Values or judgments for the original set of key assumptions (contained in Rev. 00 of this CDA, approved in 1994) were developed by an Administrative Panel consisting of personnel from Yucca Mountain Site Characterization Project (YMP), Repository/Waste Package, Project Engineering, and Systems Engineering. The assumptions were based on opinions voiced at a key assumptions workshop held at the YMP. Participants in this workshop included technical specialists and programmatic representatives from YMSCO; Sandia National Laboratories; Lawrence Livermore National Laboratory; U.S. Geological Survey; Los Alamos National Laboratory; the Civilian Radioactive Waste Management System (CRWMS) Management and Operating Contractor (M\&O) Contractor; University of Nevada, Reno; and University of Nevada, Las Vegas. Values and/or judgments for the non-key assumptions were developed and concurred with by the M\&O organizations participating in the waste package and/or repository $\mathrm{ACD}$.

Figure 2-1 illustrates the process followed for generating, revising, and withdrawing controlled design assumptions in this revision. After establishing the need for an assumption, an Assumption 


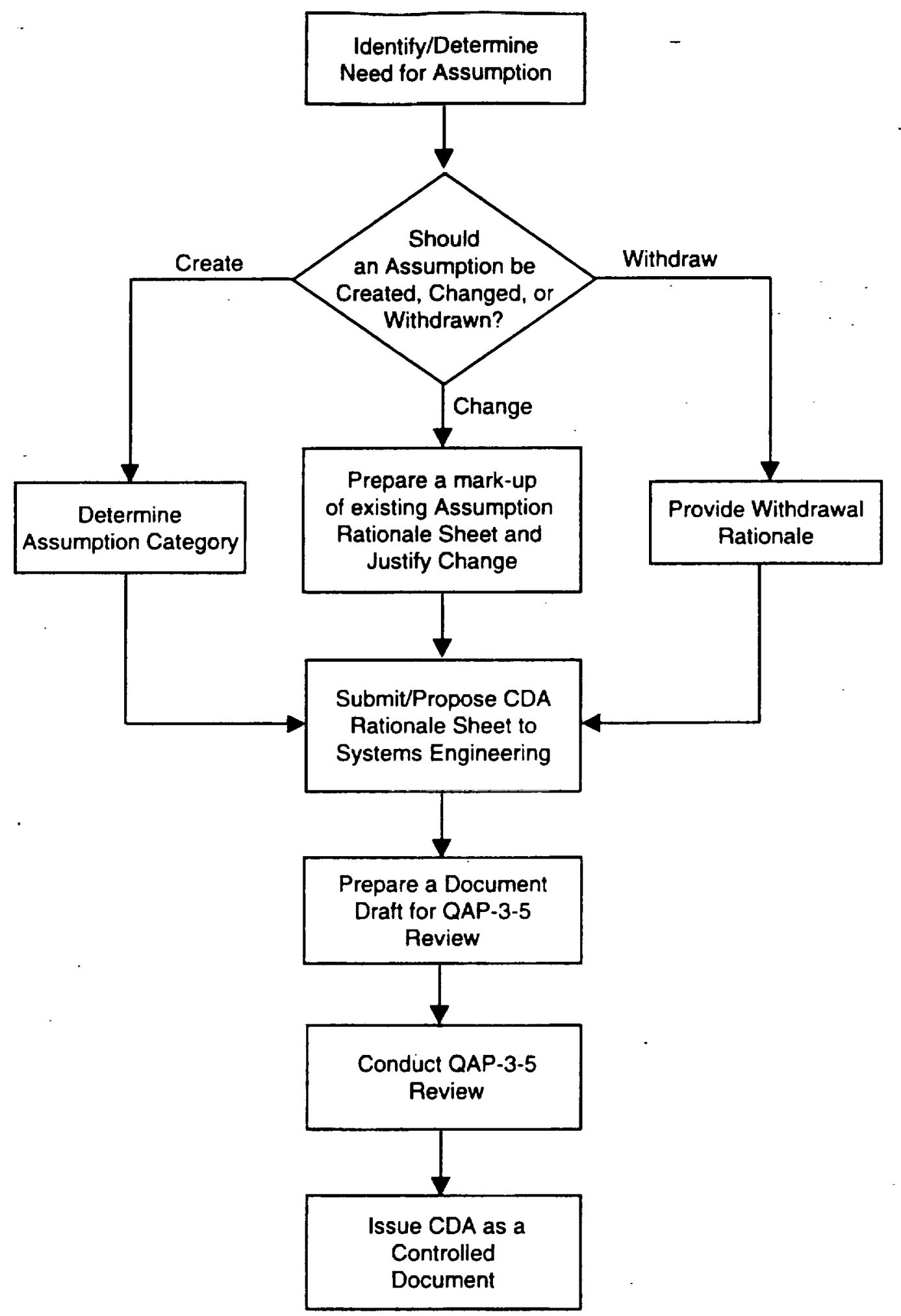

Figure 2-1. Process for Generating, Revising, or Withdrawing Assumptions 
Rationale Sheet is used for documenting it. In addition, the Assumption Status Log (Appendix A) is updated and is used to support documentation.

\section{Assumption Rationale Sheets}

Each new assumption made is documented on an Assumption Rationale. Sheet. The rationale sheet contains a unique assumption identifier (refer to Section 2.2), a statement of the assumption, background relative to the assumption (in a DRD assumption this would include the original statement of the requirement), identification of the requesting organization, a statement of the intended use or need for the assumption, rationale for the assumption, and identification of the responsible $\mathrm{M} \& \mathrm{O}$ organization.

\section{Assumption Withdrawal}

The reason for withdrawing an assumption must be stated on the Assumption Rationale Sheet. Unless the assumption is no longer applicable, the withdrawal will be justified if the assumption is incorporated in a MGDS technical baseline document; and that fact must also be documented on the Assumption Rationale Sheet.

Assumptions that are withdrawn have $\mathrm{a} W$ in parentheses just after the assumption identifier and are placed in Appendix B. The date of the document revision is then recorded as the Withdrawal Date on the Assumption Rationale Sheet.

\section{Assumption Status Log}

The Assumption Status Log (Appendix A) lists all controlled assumptions (current and withdrawn), documents their revision status, and identifies the responsible organization.

\subsection{CDA REVISION}

The Controlled Design Assumption (CDA) document is updated periodically as deemed necessary by its users. Review and distribution are conducted as required by $\mathrm{QA}$ procedures. 
Controlled Design Assumption

Assumption Rationale Sheet

\section{SECTION 3}

\section{KEY ASSUMPTIONS (KEY)}




\section{Controlled Design Assumption}

Assumption Rationale Sheet

INTENTIONALLY LEFT BLANK 


\section{Controlled Design Assumption \\ Assumption Rationale Sheet}

Assumption Identifier: Key 001

Subject: Cask Arrival Scenario

\section{STATEMENT OF ASSUMPTION}

The transportation cask arrival schedule at the Mined Geologic Disposal System (MGDS) is as indicated in the following tables. Table 3-1 provides the nominal number of transportation casks, by year, arriving at the repository by legal weight trucks. These casks do not contain canisters. Table 3-2 provides the nominal number of transportation casks, by year, arriving at the repository by train. These casks also do not contain canisters. Table 3-3 provides the nominal number of casks arriving, by year, at the repository by train. These casks contain non-disposable canisters. Table 3-4 provides the nominal number of casks arriving, by year, at the repository. The high level waste (HLW) and DOE Spent Nuclear Fuel (SNF) will have been loaded in disposable canisters before shipment to the repository, as is indicated in Key Assumptions 002 and 005 . As discussed in Key Assumption 005, a very small amount of the DOE SNF may be received uncanistered in casks if it can be handled and processed in the same facilities as the commercial SNF. This small quantity is not distinguished in the waste stream.

Exceptions to these tables must also be accommodated in order to create a design with sufficient flexibility to respond to present waste stream unknowns.

Exception 1: The total number of transportation casks received in any single year could reach 820.

Exception 2: The number of large disposable canisters containing commercial SNF received in any single year could reach 300 .

Exception 3: Surges in commercial SNF shipments could reach $20 \%$ per month higher than the monthly average in the peak year for 4 consecutive months.

\section{BACKGROUND}

Requesting Management and Operating Contractor (M\&O) organization:

(X) Surface, ( ) Subsurface, (X) Waste Package Development, or (X) Other (specify):

Requirements, Systems Analysis and Modeling

Need for assumption (statement of intended use):

The cask arrival scenario is necessary for sizing many elements of the MGDS system and for establishing average expected throughput rates.

\section{RATIONALE}

Rationale is based on Waste Quantity, Mix and Throughput Study Report (CRWMS M\&O 1997c). Table 3-1 is based on information contained in Table L-1 of that Throughput Study. Tables 3-2 and 3-3 were extracted from Table L-2 of the Throughput Study, and Table 3-4 was extracted from Table L-0 with HLW casks as corrected in CRWMS M\&O 1997f. 


\section{Controlled Design Assumption \\ Assumption Rationale Sheet}

The exceptions to the tables are included to reflect the other potential waste streams that dominated in other areas. The first exception is provided to reflect an alternative waste stream that had a larger number of maximum shipments received in a single year. It is extracted from I the recommended design levels in Table 5-13 of the Throughput Study The second exception

1 reflects the potential for the waste arriving at the repository in disposable canisters. Exception 3 1 is based on the approach proposed in Section 4.3.5 of the Throughput Study to conservatively I estimate surges.

\section{RESPONSIBILITY AND WITHDRAWAL}

Responsible Management and Operating Contractor (M\&O) organization: Systems Engineering Document(s) Supporting Withdrawal of Assumption:

Withdrawal Date: 


\section{Controlled Design Assumption}

Assumption Rationale Sheet

Key $001 \quad$ Table 3-1. Baseline Commercial SNF Waste Stream - Truck Casks

\begin{tabular}{|c|c|c|c|c|c|c|c|}
\hline $\begin{array}{l}\text { Cask Name } \\
\text { Capacity } \\
\text { Fuel Type }\end{array}$ & $\begin{array}{c}\text { Generic } \\
9 \\
\text { BWR }\end{array}$ & $\begin{array}{c}\text { Generic } \\
7 \\
\text { BWR }\end{array}$ & $\begin{array}{c}\text { Generic } \\
4 \\
\text { PWR }\end{array}$ & $\begin{array}{c}\text { Generic } \\
3 \\
\text { PWR }\end{array}$ & $\begin{array}{c}\text { High Heat } \\
7 \\
\text { BWR }\end{array}$ & $\begin{array}{c}\text { High Heat } \\
3 \\
\text { PWR }\end{array}$ & Total \\
\hline $\begin{array}{l}2010 \\
2011 \\
2012 \\
2013 \\
2014 \\
2015 \\
2016 \\
2017 \\
2018 \\
2019 \\
2020 \\
2021 \\
2022 \\
2023 \\
2024 \\
2025 \\
2026 \\
2027 \\
2028 \\
2029 \\
2030 \\
2031 \\
2032\end{array}$ & $\begin{array}{r}13 \\
14 \\
34 \\
13 \\
12 \\
22 \\
16 \\
4 \\
13 \\
4 \\
25 \\
12 \\
25 \\
32 \\
27 \\
15 \\
0 \\
0 \\
0 \\
0 \\
0 \\
0 \\
0\end{array}$ & $\begin{array}{r}0 \\
0 \\
0 \\
0 \\
0 \\
4 \\
0 \\
13 \\
35 \\
31 \\
0 \\
0 \\
0 \\
0 \\
0 \\
42 \\
0 \\
0 \\
0 \\
0 \\
0 \\
0 \\
0\end{array}$ & $\begin{array}{r}19 \\
18 \\
15 \\
61 \\
67 \\
59 \\
53 \\
63 \\
31 \\
18 \\
31 \\
46 \\
44 \\
27 \\
28 \\
49 \\
0 \\
0 \\
0 \\
0 \\
0 \\
0 \\
0\end{array}$ & $\begin{array}{r}0 \\
0 \\
0 \\
0 \\
14 \\
0 \\
0 \\
7 \\
11 \\
21 \\
36 \\
13 \\
36 \\
28 \\
15 \\
11 \\
0 \\
0 \\
0 \\
0 \\
0 \\
0 \\
0\end{array}$ & $\begin{array}{l}0 \\
0 \\
0 \\
0 \\
0 \\
0 \\
0 \\
6 \\
1 \\
1 \\
3 \\
3 \\
2 \\
4 \\
2 \\
4 \\
0 \\
0 \\
0 \\
0 \\
0 \\
0 \\
0\end{array}$ & $\begin{array}{r}0 \\
0 \\
0 \\
0 \\
2 \\
1 \\
48 \\
7 \\
23 \\
40 \\
14 \\
15 \\
3 \\
17 \\
21 \\
3 \\
0 \\
0 \\
0 \\
0 \\
0 \\
0 \\
0\end{array}$ & $\begin{array}{r}32 \\
32 \\
49 \\
74 \\
95 \\
86 \\
117 \\
100 \\
114 \\
115 \\
109 \\
89 \\
110 \\
108 \\
93 \\
124 \\
0 \\
0 \\
0 \\
0 \\
0 \\
0 \\
0\end{array}$ \\
\hline Total & 281 & 125 & 629 & 192 & 26 & 194 & 1447 \\
\hline
\end{tabular}




\section{Controlled Design Assumption \\ Assumption Rationale Sheet}

Key 001 Table 3-2. Baseline Commercial SNF Waste Stream - Rail Casks (uncanistered)

\begin{tabular}{|c|c|c|c|c|c|c|c|c|}
\hline $\begin{array}{l}\text { Cask Name } \\
\text { Capacity } \\
\text { Fuel Type }\end{array}$ & $\begin{array}{c}\text { LG Gen } \\
61 \\
\text { BWR }\end{array}$ & $\begin{array}{c}\text { LG Gen } \\
26 \\
\text { PWR }\end{array}$ & $\begin{array}{c}\text { SMGen } \\
24 \\
\text { BWR }\end{array}$ & $\begin{array}{c}\text { SM Gen } \\
12 \\
\text { PWA }\end{array}$ & $\begin{array}{c}\text { HH UCF } \\
17 \\
\text { BWR }\end{array}$ & $\begin{array}{c}\text { HH UCF } \\
7 \\
\text { PWR }\end{array}$ & $\begin{array}{l}\text { LG-ST } \\
12 \\
\text { PWR }\end{array}$ & $\begin{array}{c}\text { Total } \\
\text { UCF Rail }\end{array}$ \\
\hline 2010 & 0 & 0 & 0 & 0 & 0 & 0 & 0 & 0 \\
\hline 2011 & 10 & 16 & 35 & 10 & 0 & 0 & 0 & 71 \\
\hline 2012 & 15 & 36 & 53 & 51 & 0 & 0 & 7 & 162 \\
\hline 2013 & 17 & 58 & 81 & 77 & 0 & 0 & 14 & 247 \\
\hline 2014 & 38 & 85 & 137 & 140 & 0 & 35 & 0 & 435 \\
\hline 2015 & 36 & 90 & 109 & 142 & 1 & 24 & 17 & 419 \\
\hline 2016 & 42 & 77 & 123 & 133 & 4 & 26 & 7 & 412 \\
\hline 2017 & 29 & 86 & 100 & 115 & 3 & 43 & 14 & 390 \\
\hline 2018 & 36 & 86 & 96 & 123 & 6 & 20 & 12 & 379 \\
\hline 2019 & 30 & 78 & 74 & 93 & 1 & 32 & 13 & 321 \\
\hline 2020 & 30 & 77 & 50 & 66 & 5 & 32 & 7 & 267 \\
\hline 2021 & 24 & 64 & 33 & 74 & 7 & 11 & 8 & 221 \\
\hline 2022 & 29 & 67 & 22 & 51 & 9 & 20 & 11 & 209 \\
\hline $\begin{array}{l}2023 \\
2024\end{array}$ & $\begin{array}{l}22 \\
24\end{array}$ & $\begin{array}{l}67 \\
54\end{array}$ & $\begin{array}{l}29 \\
23\end{array}$ & $\begin{array}{l}32 \\
41\end{array}$ & $\begin{array}{l}7 \\
6\end{array}$ & $\begin{array}{r}31 \\
7\end{array}$ & $\begin{array}{r}8 \\
10\end{array}$ & $\begin{array}{l}196 \\
165\end{array}$ \\
\hline $\begin{array}{l}2024 \\
2025\end{array}$ & 16 & $\begin{array}{l}54 \\
52\end{array}$ & $\begin{array}{l}20 \\
14\end{array}$ & $\begin{array}{l}41 \\
39\end{array}$ & 5 & 10 & 9 & 145 \\
\hline 2026 & 10 & 8 & 0 & 0 & 0 & 0 & 0 & 18 \\
\hline 2027 & 3 & 34 & 0 & 0 & 0 & 0 & 0 & 37 \\
\hline 2028 & 5 & 24 & 0 & 0 & 0 & 0 & 0 & 29 \\
\hline 2029 & 3 & 14 & 0 & 0 & 0 & 0 & 0 & 17 \\
\hline 2030 & 7 & 26 & 0 & 0 & 0 & 0 & 0 & 33 \\
\hline 2031 & 3 & 40 & 0 & 0 & 0 & 0 & 0 & 43 \\
\hline 2032 & 82 & 182 & 0 & 0 & 0 & 0 & 14 & 278 \\
\hline 2033 & 58 & 109 & 0 & 0 & 0 & 0 & 3 & 170 \\
\hline Total & 569 & 1430 & 979 & 1187 & 54 & 291 & 154 & 4664 \\
\hline
\end{tabular}




\section{Controlled Design Assumption \\ Assumption Rationale Sheet}

Key 001 Table 3-3. Baseline Commercial SNF Waste Stream - Rail Casks (canistered)

\begin{tabular}{|l|r|r|r|r|r|r|r|r|}
\hline $\begin{array}{l}\text { Cask Name } \\
\text { Capacity } \\
\text { Fuel Type }\end{array}$ & $\begin{array}{c}\text { LG Can. } \\
61 \\
\text { BWR }\end{array}$ & $\begin{array}{c}\text { LG Can. } \\
\text { 24 } \\
\text { PWR }\end{array}$ & $\begin{array}{c}\text { MED } \\
\text { Can. 44 } \\
\text { BWR }\end{array}$ & $\begin{array}{c}\text { MED } \\
\text { Can. 21 } \\
\text { PWR }\end{array}$ & $\begin{array}{c}\text { SM Can. } \\
24 \\
\text { BWR }\end{array}$ & $\begin{array}{c}\text { SM Can. } \\
12 \\
\text { PWR }\end{array}$ & $\begin{array}{c}\text { LG Can. } \\
22 \\
\text { BP }\end{array}$ & $\begin{array}{c}\text { Total } \\
\text { Canistered } \\
\text { Rail }\end{array}$ \\
\hline 2010 & 5 & 9 & 4 & 7 & 0 & 0 & 0 & 25 \\
2011 & 0 & 6 & 0 & 0 & 0 & 0 & 0 & 6 \\
2012 & 0 & 2 & 0 & 0 & 0 & 0 & 0 & 2 \\
2013 & 0 & 16 & 0 & 0 & 8 & 0 & 0 & 24 \\
2014 & 0 & 5 & 0 & 0 & 4 & 0 & 1 & 10 \\
2015 & 1 & 4 & 0 & 0 & 8 & 0 & 1 & 14 \\
2016 & 0 & 7 & 0 & 0 & 10 & 4 & 1 & 22 \\
2017 & 0 & 8 & 12 & 3 & 16 & 3 & 1 & 43 \\
2018 & 2 & 5 & 3 & 4 & 24 & 4 & 6 & 48 \\
2019 & 0 & 15 & 10 & 22 & 41 & 6 & 2 & 96 \\
2020 & 6 & 22 & 23 & 26 & 38 & 8 & 0 & 123 \\
2021 & 7 & 27 & 38 & 34 & 47 & 8 & 0 & 161 \\
2022 & 2 & 25 & 23 & 47 & 68 & 12 & 0 & 177 \\
2023 & 9 & 30 & 30 & 52 & 43 & 15 & 0 & 179 \\
2024 & 9 & 39 & 43 & 56 & 40 & 12 & 0 & 199 \\
2025 & 13 & 36 & 46 & 39 & 95 & 21 & 0 & 250 \\
2026 & 33 & 81 & 52 & 70 & 143 & 31 & 1 & 411 \\
2027 & 20 & 39 & 55 & 103 & 136 & 24 & 4 & 381 \\
2028 & 26 & 54 & 59 & 100 & 88 & 19 & 1 & 347 \\
2029 & 30 & 76 & 49 & 96 & 77 & 18 & 1 & 347 \\
2030 & 51 & 76 & 21 & 94 & 64 & 11 & 2 & 319 \\
2031 & 42 & 86 & 22 & 71 & 56 & 24 & 1 & 302 \\
2032 & 0 & 3 & 0 & 0 & 0 & 0 & 3 & 6 \\
2033 & 0 & 0 & 0 & 0 & 0 & 0 & 1 & 1 \\
\hline Total & 256 & 671 & 490 & 824 & 1006 & 220 & 26 & 3493 \\
\hline
\end{tabular}




\section{Controlled Design Assumption \\ Assumption Rationale Sheet}

Table 3-4. Total Casks Arriving at the MGDS

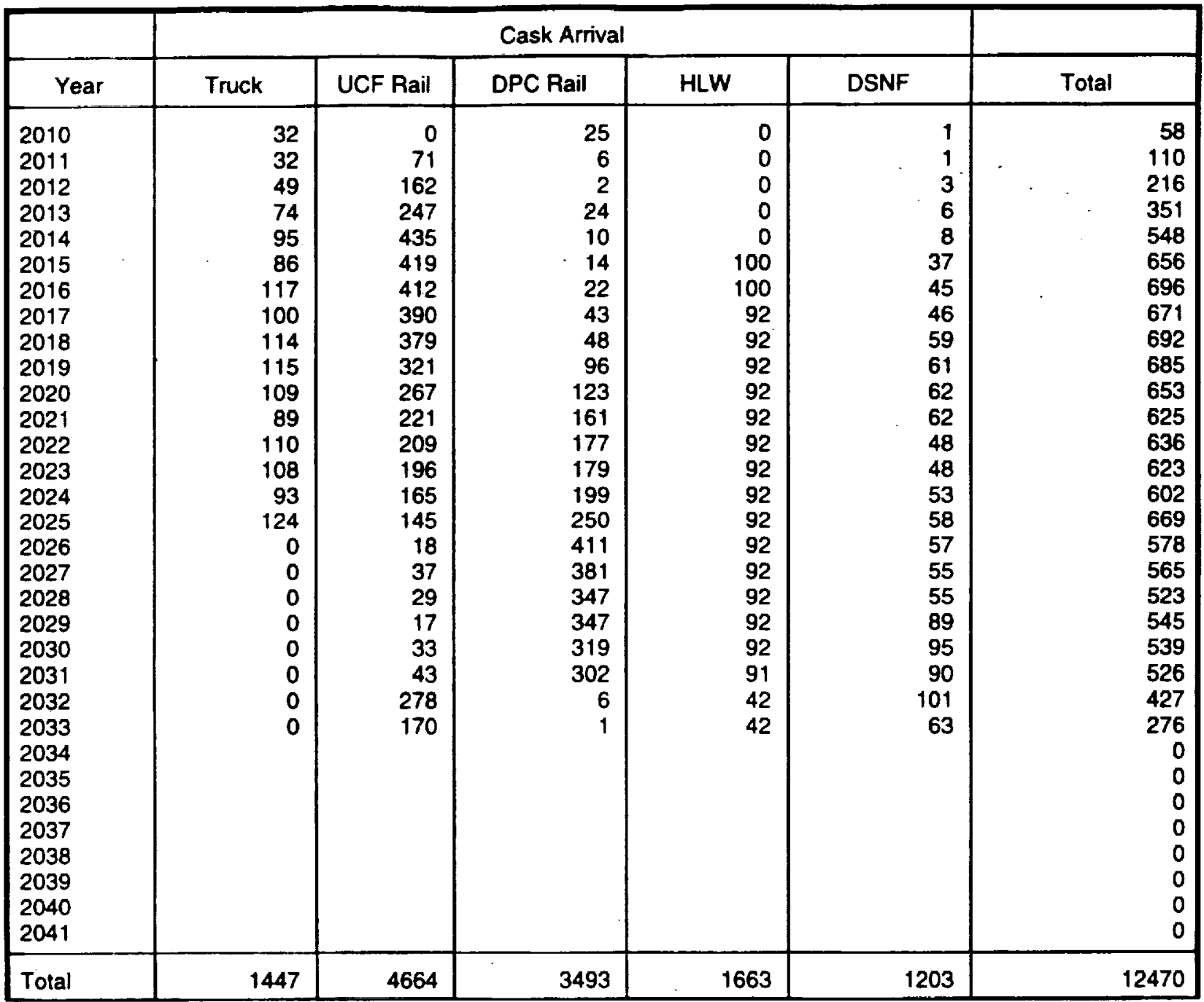




\section{Controlled Design Assumption \\ Assumption Rationale Sheet}

Assumption Identifier: Key 002

Subject: Waste Form Arrival Scenario

\section{STATEMENT OF ASSUMPTION}

The assembly arrival schedule at the Mined Geologic Disposal System (MGDS) is as indicated in the following tables. Table 3-5 provides the nominal number of assemblies, by year, arriving at the repository by legal weight trucks. These assemblies are not contained in canisters. Table 3-6 provides the nominal number of assemblies, by year, arriving at the repository by train. These assemblies also are not contained in canisters. Table 3-7 provides the nominal number of assemblies arriving, by year, at the repository by train. These assemblies are contained in nondisposable canisters. Table 3-8 provides the nominal number of commercial SNF assemblies (arriving in canisters or as bare assemblies) and high-level waste (HLW) and DOE SNF in disposable canisters arriving, by year, at the repository. As discussed in Key Assumption 005, a very small amount of the DOE SNF may be received uncanistered in casks if it can be handled and processed in the same facilities as the commercial SNF. This small quantity is not distinguished in the waste stream.

\section{BACKGROUND}

Requesting Management and Operating Contractor $(\mathrm{M} \& \mathrm{O})$ organization:

(X) Surface, ( ) Subsurface, (X) Waste Package Development, or (X) Other (specify): Requirements, Systems Analysis and Modeling

Need for assumption (statement of intended use):

The waste form arrival scenario is necessary for sizing many elements of the MGDS such as surface waste handling facility.

\section{RATIONALE}

Rationale for assumption (source author, date, and report title) or statement of reasoning behind engineering judgment:

Rationale is based on Waste Quantity, Mix and Throughput Study Report (CRWMS M\&O 1997c). Table 3-5 is based on information contained in Table L-3 of that Throughput Study. Tables 3-6 and 3-7 are extracted from Table L-4 of the Throughput Study, and Table 3-8 is extracted from Tables L- 0 and G-0.

\section{RESPONSIBILITY AND WITHDRAWAL}

Responsible Management and Operating Contractor $(\mathrm{M} \& \mathrm{O})$ organization: Systems Engineering

Document(s) Supporting Withdrawal of Assumption:

Withdrawal Date: 
Controlled Design Assumption

Assumption Rationale Sheet

Key 002 Table 3-5. Baseline Commercial SNF Waste Stream - Truck Ässemblies

\begin{tabular}{|c|r|r|r|r|r|r|r|}
\hline $\begin{array}{c}\text { Cask Name } \\
\text { Capacity } \\
\text { Fuel Type }\end{array}$ & $\begin{array}{c}\text { Generic 9 } \\
\text { BWR }\end{array}$ & $\begin{array}{c}\text { Generic 7 } \\
\text { BWR }\end{array}$ & $\begin{array}{c}\text { Generic 4 } \\
\text { PWR }\end{array}$ & $\begin{array}{c}\text { Generic 3 } \\
\text { PWR }\end{array}$ & $\begin{array}{c}\text { High Heat } \\
7 \\
\text { BWR }\end{array}$ & $\begin{array}{c}\text { High Heat } \\
3\end{array}$ & PWR \\
\hline 2010 & 117 & 0 & 76 & 0 & 0 & 0 & Total \\
2011 & 126 & 0 & 72 & 0 & 0 & 0 & 193 \\
2012 & 306 & 0 & 60 & 0 & 0 & 0 & 366 \\
2013 & 117 & 0 & 244 & 0 & 0 & 0 & 361 \\
2014 & 108 & 0 & 268 & 42 & 0 & 6 & 424 \\
2015 & 198 & 28 & 236 & 0 & 0 & 3 & 465 \\
2016 & 144 & 0 & 211 & 0 & 0 & 144 & 499 \\
2017 & 36 & 91 & 252 & 21 & 42 & 21 & 463 \\
2018 & 117 & 245 & 124 & 33 & 7 & 69 & 595 \\
2019 & 36 & 217 & 72 & 63 & 7 & 120 & 515 \\
2020 & 225 & 0 & 124 & 108 & 21 & 42 & 520 \\
2021 & 108 & 0 & 184 & 39 & 21 & 45 & 397 \\
2022 & 225 & 0 & 176 & 108 & 14 & 9 & 532 \\
2023 & 288 & 0 & 108 & 84 & 28 & 51 & 559 \\
2024 & 243 & 0 & 110 & 45 & 12 & 63 & 473 \\
2025 & 134 & 292 & 196 & 33 & 25 & 9 & 689 \\
2026 & 0 & 0 & 0 & 0 & 0 & 0 & 0 \\
2027 & 0 & 0 & 0 & 0 & 0 & 0 & 0 \\
2028 & 0 & 0 & 0 & 0 & 0 & 0 & 0 \\
2029 & 0 & 0 & 0 & 0 & 0 & 0 & 0 \\
2030 & 0 & 0 & 0 & 0 & 0 & 0 & 0 \\
2031 & 0 & 0 & 0 & 0 & 0 & 0 & 0 \\
2032 & 0 & 0 & 0 & 0 & 0 & 0 & 0 \\
2033 & 0 & 0 & 0 & 0 & 0 & 0 & 0 \\
\hline Total & 2528 & 873 & 2513 & 576 & 177 & 582 & 7249 \\
\hline
\end{tabular}




\section{Controlled Design Assumption Assumption Rationale Sheet}

Key 002 Table 3-6. Baseline Commercial SNF Waste Stream - Rail Assemblies (uncanistered)

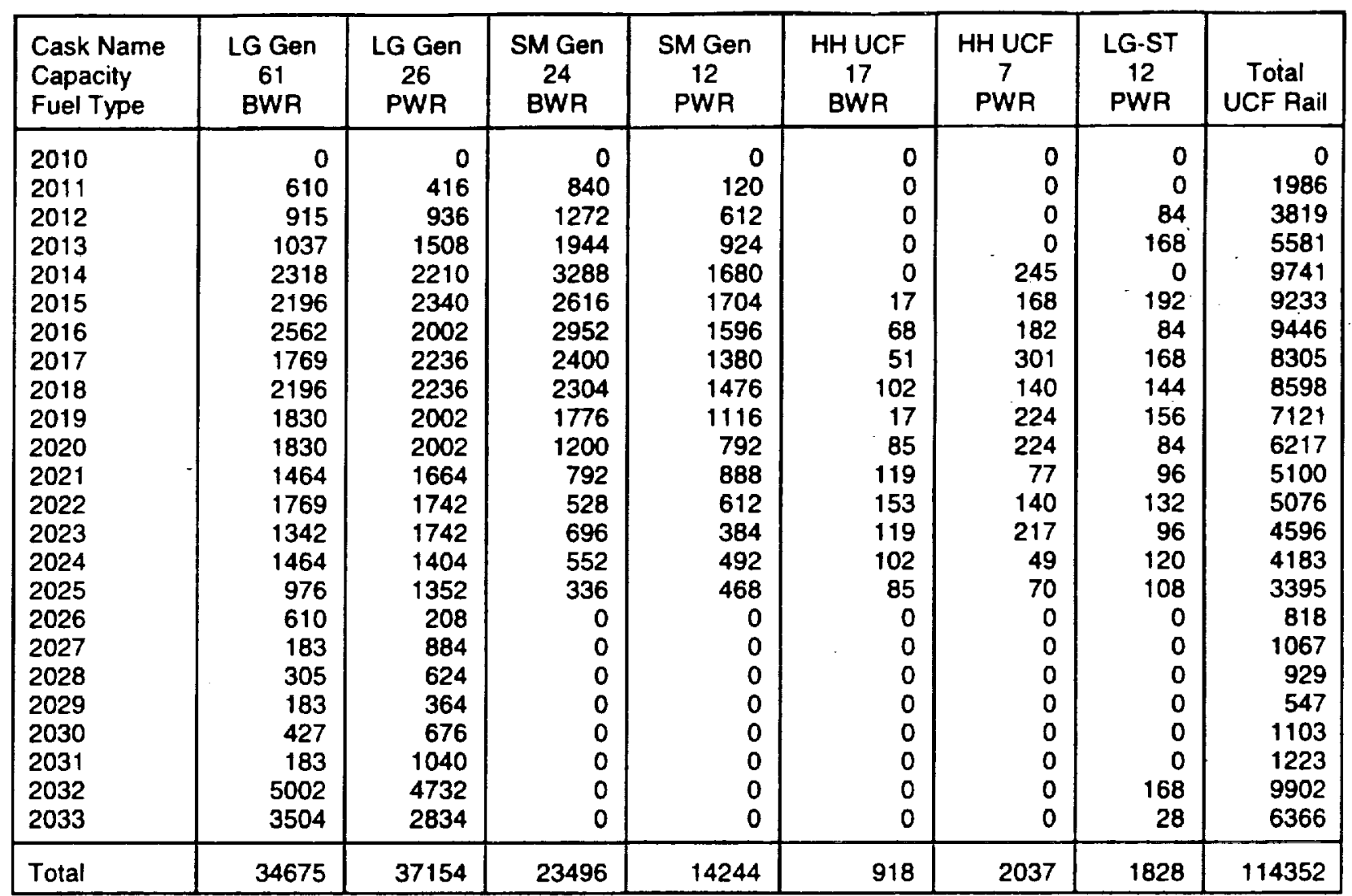




\section{Controlled Design Assumption \\ Assumption Rationale Sheet}

1 Key 002 Table 3-7. Baseline Commercial SNF Waste Stream - Rail Assemblies (canistered).

\begin{tabular}{|c|c|c|c|c|c|c|c|c|}
\hline $\begin{array}{l}\text { Cask Name } \\
\text { Capacity Fuel } \\
\text { Type }\end{array}$ & $\begin{array}{c}\text { LG Can. } \\
61 \\
\text { BWR }\end{array}$ & $\begin{array}{c}\text { LG Can. } \\
24 \\
\text { PWR }\end{array}$ & $\begin{array}{c}\text { MED Can. } \\
44 \\
\text { BWR }\end{array}$ & $\begin{array}{c}\text { MED Can. } \\
21 \\
\text { PWR }\end{array}$ & $\begin{array}{c}\text { SM Can. } \\
24 \\
\text { BWR }\end{array}$ & $\begin{array}{c}\text { SM Can. } \\
12 \\
\text { PWR }\end{array}$ & $\begin{array}{c}\text { LG Can. } \\
22 \\
B P\end{array}$ & $\begin{array}{c}\text { Total } \\
\text { Canistered } \\
\text { Fuel }\end{array}$ \\
\hline $\begin{array}{l}2010 \\
2011 \\
2012 \\
2013 \\
2014 \\
2015 \\
2016 \\
2017 \\
2018 \\
2019 \\
2020 \\
2021 \\
2022 \\
2023 \\
2024 \\
2025 \\
2026 \\
2027 \\
2028 \\
2029 \\
2030 \\
2031 \\
2032 \\
2033\end{array}$ & $\begin{array}{r}305 \\
0 \\
0 \\
0 \\
0 \\
61 \\
0 \\
0 \\
122 \\
0 \\
366 \\
427 \\
122 \\
549 \\
549 \\
756 \\
1920 \\
1220 \\
1586 \\
1830 \\
3109 \\
2562 \\
0 \\
0\end{array}$ & $\begin{array}{r}216 \\
133 \\
48 \\
363 \\
120 \\
96 \\
168 \\
192 \\
112 \\
360 \\
528 \\
648 \\
600 \\
720 \\
913 \\
864 \\
1936 \\
928 \\
1294 \\
1822 \\
1824 \\
2064 \\
72 \\
0\end{array}$ & $\begin{array}{r}176 \\
0 \\
0 \\
0 \\
0 \\
0 \\
0 \\
528 \\
132 \\
440 \\
1012 \\
1672 \\
1012 \\
1320 \\
1863 \\
1988 \\
2288 \\
2420 \\
2596 \\
2156 \\
924 \\
968 \\
0 \\
0\end{array}$ & $\begin{array}{r}147 \\
0 \\
0 \\
0 \\
0 \\
0 \\
0 \\
63 \\
84 \\
462 \\
546 \\
714 \\
987 \\
1087 \\
1176 \\
819 \\
1470 \\
2163 \\
2100 \\
2016 \\
1974 \\
1491 \\
0 \\
0\end{array}$ & $\begin{array}{r}0 \\
0 \\
0 \\
192 \\
96 \\
192 \\
222 \\
368 \\
576 \\
984 \\
912 \\
1128 \\
1622 \\
1032 \\
960 \\
2255 \\
3432 \\
3251 \\
2112 \\
1848 \\
1536 \\
1344 \\
0 \\
0\end{array}$ & $\begin{array}{r}0 \\
0 \\
0 \\
0 \\
0 \\
0 \\
48 \\
36 \\
48 \\
72 \\
96 \\
96 \\
144 \\
180 \\
144 \\
241 \\
364 \\
288 \\
228 \\
216 \\
132 \\
288 \\
0 \\
0\end{array}$ & $\begin{array}{r}0 \\
0 \\
0 \\
0 \\
22 \\
22 \\
22 \\
22 \\
132 \\
33 \\
0 \\
0 \\
0 \\
0 \\
0 \\
0 \\
22 \\
88 \\
22 \\
22 \\
44 \\
22 \\
66 \\
22\end{array}$ & $\begin{array}{r}844 \\
133 \\
48 \\
555 \\
238 \\
371 \\
460 \\
1209 \\
1206 \\
2351 \\
3460 \\
4685 \\
4487 \\
4888 \\
5605 \\
6923 \\
11432 \\
10358 \\
9938 \\
9910 \\
9543 \\
8739 \\
138 \\
22\end{array}$ \\
\hline Total & 15484 & 16021 & 21495 & 17299 & 24062 & 2621 & 561 & 97543 \\
\hline
\end{tabular}




\section{Controlled Design Assumption Assumption Rationale Sheet}

Key 002 Table 3-8. Total Fuel Assemblies and HLW/DOE-SNF Canisters Arriving at the MGDS

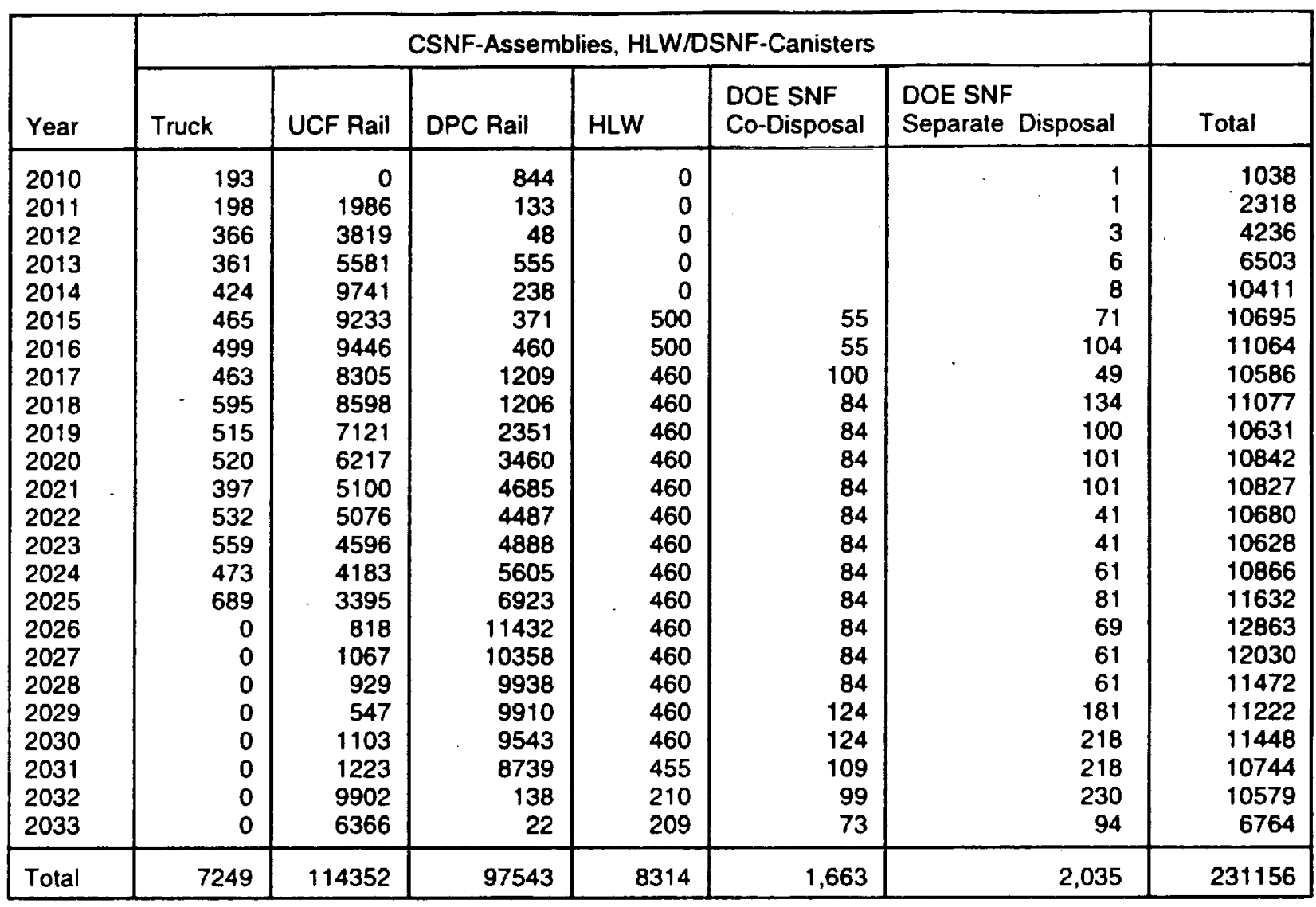




\section{Controlled Design Assumption \\ Assumption Rationale Sheet}

Assumption Identifier: Key 003

Subject: Waste Package Emplacement Scenario

\section{STATEMENT OF ASSUMPTION}

The waste package emplacement scenario at the Mined Geologic Disposal System (MGDS) is as indicated in Table 3-9. This emplacement scenario is consistent with MGDS-RD Table 3-3, which shows a steady state emplacement rate of commercial spent nuclear fuel (SNF) of 3,000 MTU/year. The commercial SNF disposed of in this scenario totals $63,000 \mathrm{MTU}$. The high-level I waste (HLW) and DOE SNF total approximately 7,000 MTU equivalents combined (see Key I Assumption 005).

\section{BACKGROUND}

Requesting Management and Operating Contractor (M\&O) organization:

(X) Surface, (X) Subsurface, (X) Waste Package Development, or (X) Other (specify):

Requirements, Systems Analysis and Modeling

Need for assumption (statement of intended use):

The waste package emplacement scenario is necessary for sizing many elements of the Mined Geologic Disposal System (MGDS) such as the underground facility.

\section{RATIONALE}

Rationale for assumption (source author, date, and report title) or statement of reasoning behind engineering judgment:

I Rationale is based on Waste Quantity, Mix and Throughput Study (CRWMS M\&O 1997c). Table

I 3-9 is based on information contained in Tables L-5 and G-0 Throughput Study with HLW/DSNF

I co-disposal waste packages as corrected in CRWMS M\&O 1997f.

\section{RESPONSIBILITY AND WITHDRAWAL}

Responsible Management and Operating Contractor (M\&O) organization: Systems Engineering

Document(s) Supporting Withdrawal of Assumption:

Withdrawal Date: 


\begin{tabular}{|c|c|c|c|c|c|c|c|c|c|c|c|}
\hline $\begin{array}{l}\text { Name } \\
\text { Capacity } \\
\text { Fuel Type } \\
\mathrm{K}_{\mathrm{m}} \text { Limit }\end{array}$ & $\begin{array}{c}\text { LG-WP } \\
44 \\
\text { BWR } \\
K<=1.0\end{array}$ & $\begin{array}{c}\text { LG-WP } \\
44 \\
\text { BWR } \\
K<=1.37\end{array}$ & $\begin{array}{c}\text { SM-WP } \\
24 \\
\text { BWP } \\
K<=1.54\end{array}$ & $\begin{array}{c}\text { ST-WP } \\
12 \\
\text { PWR-ST } \\
K<=1.13\end{array}$ & $\begin{array}{c}\text { LG-WP } \\
21 \\
\text { PWR } \\
K<=1.00\end{array}$ & $\begin{array}{c}\text { LG-WP } \\
21 \\
\text { PWR } \\
K<=1.13\end{array}$ & $\begin{array}{c}\text { LG-WP } \\
21 \\
\text { PWR } \\
K<=1.45\end{array}$ & $\begin{array}{c}\text { SM-WP } \\
12 \\
\text { PWR } \\
K<=1.02\end{array}$ & $\begin{array}{c}\text { HLW/ } \\
\text { DSNF Co- } \\
\text { Disposal }\end{array}$ & $\begin{array}{c}\text { DSNF } \\
\text { Separate } \\
\text { Disposal }\end{array}$ & Total \\
\hline $\begin{array}{l}2010 \\
2011 \\
2012 \\
2013 \\
2014 \\
2015 \\
2016 \\
2017 \\
2018 \\
2019 \\
2020 \\
2021 \\
2022 \\
2023 \\
2024 \\
2025 \\
2026 \\
2027 \\
2028 \\
2029 \\
2030 \\
2031 \\
2032 \\
2033\end{array}$ & $\begin{array}{r}3 \\
13 \\
20 \\
22 \\
37 \\
34 \\
41 \\
33 \\
49 \\
32 \\
35 \\
33 \\
38 \\
38 \\
43 \\
54 \\
12 \\
30 \\
17 \\
18 \\
28 \\
34 \\
31 \\
12\end{array}$ & $\begin{array}{r}11 \\
24 \\
38 \\
53 \\
96 \\
89 \\
96 \\
89 \\
86 \\
91 \\
95 \\
95 \\
79 \\
85 \\
84 \\
96 \\
176 \\
134 \\
135 \\
119 \\
111 \\
82 \\
85 \\
70\end{array}$ & $\begin{array}{r}0 \\
0 \\
0 \\
0 \\
0 \\
0 \\
0 \\
0 \\
0 \\
0 \\
0 \\
5 \\
15 \\
1 \\
8 \\
12 \\
2 \\
1 \\
1 \\
1 \\
2 \\
1 \\
0 \\
0\end{array}$ & $\begin{array}{r}0 \\
0 \\
7 \\
15 \\
0 \\
12 \\
8 \\
15 \\
12 \\
13 \\
8 \\
8 \\
11 \\
9 \\
10 \\
10 \\
0 \\
0 \\
0 \\
0 \\
0 \\
0 \\
14 \\
3\end{array}$ & $\begin{array}{r}3 \\
4 \\
19 \\
29 \\
45 \\
50 \\
57 \\
43 \\
52 \\
49 \\
51 \\
62 \\
61 \\
59 \\
63 \\
58 \\
77 \\
114 \\
92 \\
89 \\
88 \\
112 \\
105 \\
72\end{array}$ & $\begin{array}{r}17 \\
27 \\
56 \\
94 \\
150 \\
155 \\
131 \\
152 \\
133 \\
139 \\
138 \\
128 \\
131 \\
133 \\
118 \\
117 \\
94 \\
83 \\
109 \\
120 \\
129 \\
118 \\
118 \\
63\end{array}$ & $\begin{array}{r}1 \\
5 \\
0 \\
9 \\
7 \\
1 \\
3 \\
3 \\
4 \\
7 \\
5 \\
3 \\
3 \\
12 \\
15 \\
4 \\
20 \\
7 \\
2 \\
3 \\
5 \\
3 \\
7 \\
3\end{array}$ & $\begin{array}{r}2 \\
2 \\
9 \\
23 \\
30 \\
22 \\
32 \\
32 \\
31 \\
35 \\
36 \\
29 \\
38 \\
25 \\
26 \\
26 \\
0 \\
0 \\
0 \\
0 \\
0 \\
0 \\
0 \\
0\end{array}$ & $\begin{array}{r}100 \\
100 \\
92 \\
92 \\
92 \\
92 \\
92 \\
92 \\
92 \\
92 \\
92 \\
92 \\
92 \\
92 \\
92 \\
92 \\
91 \\
42 \\
42\end{array}$ & $\begin{array}{r}1 \\
1 \\
3 \\
6 \\
8 \\
40 \\
56 \\
33 \\
65 \\
49 \\
50 \\
50 \\
31 \\
31 \\
36 \\
41 \\
35 \\
31 \\
31 \\
51 \\
58 \\
58 \\
71 \\
47\end{array}$ & $\begin{array}{r}38 \\
76 \\
152 \\
251 \\
373 \\
503 \\
524 \\
492 \\
524 \\
507 \\
510 \\
505 \\
499 \\
485 \\
495 \\
510 \\
508 \\
492 \\
479 \\
493 \\
513 \\
499 \\
473 \\
312\end{array}$ \\
\hline Total & 707 & 2119 & 49 & 155 & 1454 & 2653 & 132 & 398 & 1663 & 883 & 10213 \\
\hline
\end{tabular}

Partially-filled waste packages are rounded up at the end of each year of operations.

$\mathrm{K}_{\mathrm{mt}}$ Limit is $\mathrm{K}_{\mathrm{um}}$ maximum, which is the upper limit of the acceptable criticality range. The ranges are defined in Table $2 \cdot 8$ of Waste Quantity, Mix and Throughput Study Report. The $K_{\text {minim }}$ min limit of the range is zero for each waste package type except where there is more than one column. In those cases, the minimum limit is the maximum limit in the preceding column for that waste package type. e.g., the acceptable range is trom 1.0 to 1.37 for the second LG-WP 44 BWR waste package.

Co-disposal waste packages with five HLW canisters and one DOE SNF canister.

Separate DOE SNF waste packages with varying numbers of canisters. 


\section{Controlled Design Assumption \\ Assumption Rationale Sheet}

Assumption Identifier: Key 004

Subject: Average Thermal SNF Characteristics

\section{STATEMENT OF ASSUMPTION}

The average commercial spent fuel characteristics upon receipt at the repository are:

25.9 years old with $39.56 \mathrm{Gwd} / \mathrm{MTU}$ burnup and $3.69 \mathrm{wt} . \%$ enrichment (PWR).

27.2 years old with $32.24 \mathrm{Gwd} / \mathrm{MTU}$ burnup and $3.00 \mathrm{wt} . \%$ enrichment (BWR).

Table 3-10 provides the average MTU/WP on a yearly basis. Table 3-11 provides the average heat output $(\mathrm{kW}) / \mathrm{WP}$.

\section{BACKGROUND}

Requesting Management and Operating Contractor (M\&O) organization:

( ) Surface, ( ) Subsurface, ( ) Waste Package Development, or (X) Other (specify):

Requirements, Systems Analysis and Modeling

Need for assumption (statement of intended use):

\section{RATIONALE}

Rationale for assumption (source author, date, and report title) or statement of reasoning behind engineering judgment:

1 Rationale is based on Waste Quantity, Mix and Throughput Study Report (CRWMS M\&O 1997c).

1 Tables 3-10 and 3-11 are based on information contained in Tables C-7 and C-8, respectively, of that Throughput Study. The average commercial spent fuel characteristics given above for PWR and BWR spent fuel for this baseline case are obtained from information in Table A-2 of that Throughput Study and reflect a youngest fuel first (YFF) scenario as follows: allocation rights to spent fuel pools and how much fuel to accept were calculated based on the order fuel was discharged (as per the Acceptance Priority Ranking and Annual Capacity Report) (DOE 1995e); SNF was selected from the pool in an order that first takes fuel that is 10 years old or older in YFF sequence, then fuel younger than 10 years old (down to 5 years old), then fuel from dry storage. This is not inconsistent with CFR 961.11 Appendix E.B.3 which indicates that fuel with a minimum age of 5 years will be accepted. Shipping casks designed for 10 year old fuel would be derated for fuel less than 10 years old, thus requiring more cask loadings by the utility if the YFF criteria were not first applied to the fuel at least 10 years old in the respective pool.

\section{RESPONSIBILITY AND WITHDRAWAL}

Responsible Management and Operating Contractor (M\&O) organization: Systems Engineering Document(s) Supporting Withdrawal of Assumption:

Withdrawal Date: 


\section{Controlled Design Assumption}

\section{Assumption Rationale Sheet}

Key 004 Table 3-10. Commercial SNF Baseline - Average MTU Per WP

\begin{tabular}{|c|c|c|c|c|c|c|c|c|c|}
\hline $\begin{array}{l}\text { Name } \\
\text { Capacity } \\
\text { Fuel Type } \\
\text { Kont Limit } \text { Lim }\end{array}$ & $\begin{array}{c}\text { LG-WP } \\
44 \\
8 W R \\
K<=1.00\end{array}$ & $\begin{array}{c}\text { LG-WP } \\
44 \\
\text { BWR } \\
K<=1.37\end{array}$ & $\begin{array}{c}\text { SM-WP } \\
24 \\
\text { BWR } \\
K<=1.54\end{array}$ & $\begin{array}{c}\text { ST-WP } \\
12 \\
\text { PWR-ST } \\
K<=1.13\end{array}$ & $\begin{array}{c}\text { LG-WP } \\
21 \\
\text { PWR } \\
K<=1.00\end{array}$ & $\begin{array}{c}\text { LG-WP } \\
21 \\
\text { PWR } \\
K<=1.13\end{array}$ & $\begin{array}{c}\text { LG-WP } \\
21 \\
\text { PWR } \\
K<=1.45\end{array}$ & $\begin{array}{c}\text { SM-WP } \\
12 \\
\text { PWR } \\
K<=1.02\end{array}$ & Average \\
\hline $\begin{array}{l}2010 \\
2011 \\
2012 \\
2013 \\
2014 \\
2015 \\
2016 \\
2017 \\
2018 \\
2019 \\
2020 \\
2021 \\
2022 \\
2023 \\
2024 \\
2025 \\
2026 \\
2027 \\
2028 \\
2029 \\
2030 \\
2031 \\
2032 \\
2033\end{array}$ & $\begin{array}{r}5.71 \\
7.18 \\
7.21 \\
7.38 \\
7.58 \\
7.57 \\
7.48 \\
7.6 \\
7.56 \\
7.43 \\
7.53 \\
7.71 \\
7.64 \\
7.73 \\
7.73 \\
7.54 \\
7.69 \\
7.76 \\
7.52 \\
7.68 \\
7.39 \\
7.53 \\
7.47 \\
7.15\end{array}$ & $\begin{array}{r}7.73 \\
7.69 \\
7.82 \\
7.75 \\
7.68 \\
7.79 \\
7.82 \\
7.9 \\
7.87 \\
8.07 \\
8.15 \\
8.11 \\
7.82 \\
7.94 \\
7.78 \\
7.73 \\
7.5 \\
7.53 \\
7.89 \\
7.96 \\
7.75 \\
7.78 \\
7.69 \\
7.81\end{array}$ & $\begin{array}{r}0 \\
0 \\
0 \\
0 \\
0 \\
0 \\
0 \\
0 \\
0 \\
0 \\
0 \\
3.5 \\
3.93 \\
0.52 \\
3.74 \\
3.84 \\
2.6 \\
0.12 \\
0.12 \\
1.03 \\
1.77 \\
0.6 \\
0 \\
0\end{array}$ & $\begin{array}{r}0 \\
0 \\
6.23 \\
6.13 \\
0 \\
6.46 \\
5.85 \\
6.35 \\
6.46 \\
6.33 \\
6.05 \\
6.46 \\
6.03 \\
6.46 \\
6.13 \\
6.26 \\
0 \\
0 \\
0 \\
0 \\
0 \\
0 \\
6.46 \\
5.02\end{array}$ & $\begin{array}{l}8.99 \\
9.02 \\
9.01 \\
9.15 \\
8.71 \\
8.96 \\
9.03 \\
9.06 \\
9.01 \\
9.04 \\
9 \\
8.99 \\
9.04 \\
9.03 \\
9.14 \\
8.83 \\
8.28 \\
8.68 \\
8.94 \\
9.02 \\
8.83 \\
9.04 \\
8.89 \\
8.92\end{array}$ & $\begin{array}{r}8.89 \\
8.78 \\
9.06 \\
9.02 \\
9.12 \\
9.02 \\
9.08 \\
9.08 \\
9.02 \\
9.1 \\
8.99 \\
9.06 \\
9.08 \\
9.01 \\
9.06 \\
9.08 \\
8.77 \\
8.78 \\
8.92 \\
9.01 \\
8.92 \\
8.94 \\
8.97 \\
8.91\end{array}$ & $\begin{array}{r}0.9 \\
8.89 \\
0 \\
8.65 \\
7.27 \\
2.54 \\
5.34 \\
8 \\
8.01 \\
7.72 \\
8.31 \\
7.01 \\
8.75 \\
8.85 \\
8.51 \\
8.84 \\
6.14 \\
7.2 \\
4.81 \\
5.96 \\
5.79 \\
7.52 \\
6.27 \\
6.63\end{array}$ & $\begin{array}{r}4.41 \\
4.03 \\
5.34 \\
5.32 \\
5.63 \\
5.24 \\
5.31 \\
5.45 \\
5.47 \\
5.44 \\
5.26 \\
5.35 \\
5.34 \\
5.2 \\
5.14 \\
5.08 \\
0 \\
0 \\
0 \\
0 \\
0 \\
0 \\
0 \\
0\end{array}$ & $\begin{array}{l}7.84 \\
8.05 \\
8.13 \\
8.08 \\
8.22 \\
8.24 \\
8.14 \\
8.22 \\
8.16 \\
8.21 \\
8.2 \\
8.23 \\
7.99 \\
8.27 \\
8.13 \\
7.96 \\
7.88 \\
8.16 \\
8.42 \\
8.54 \\
8.34 \\
8.53 \\
8.37 \\
8.39\end{array}$ \\
\hline Average & 7.54 & 7.81 & 3.34 & 6.25 & 8.91 & 9.01 & 7.4 & 5.32 & 8.21 \\
\hline
\end{tabular}

See footnote on $K_{\text {mimity }}$ in Table 3-9. 


\section{Controlled Design Assumption \\ Assumption Rationale Sheet}

Key 004 Table 3-11. Commercial SNF Baseline - Average Initial Heat Per WP (kWWP)

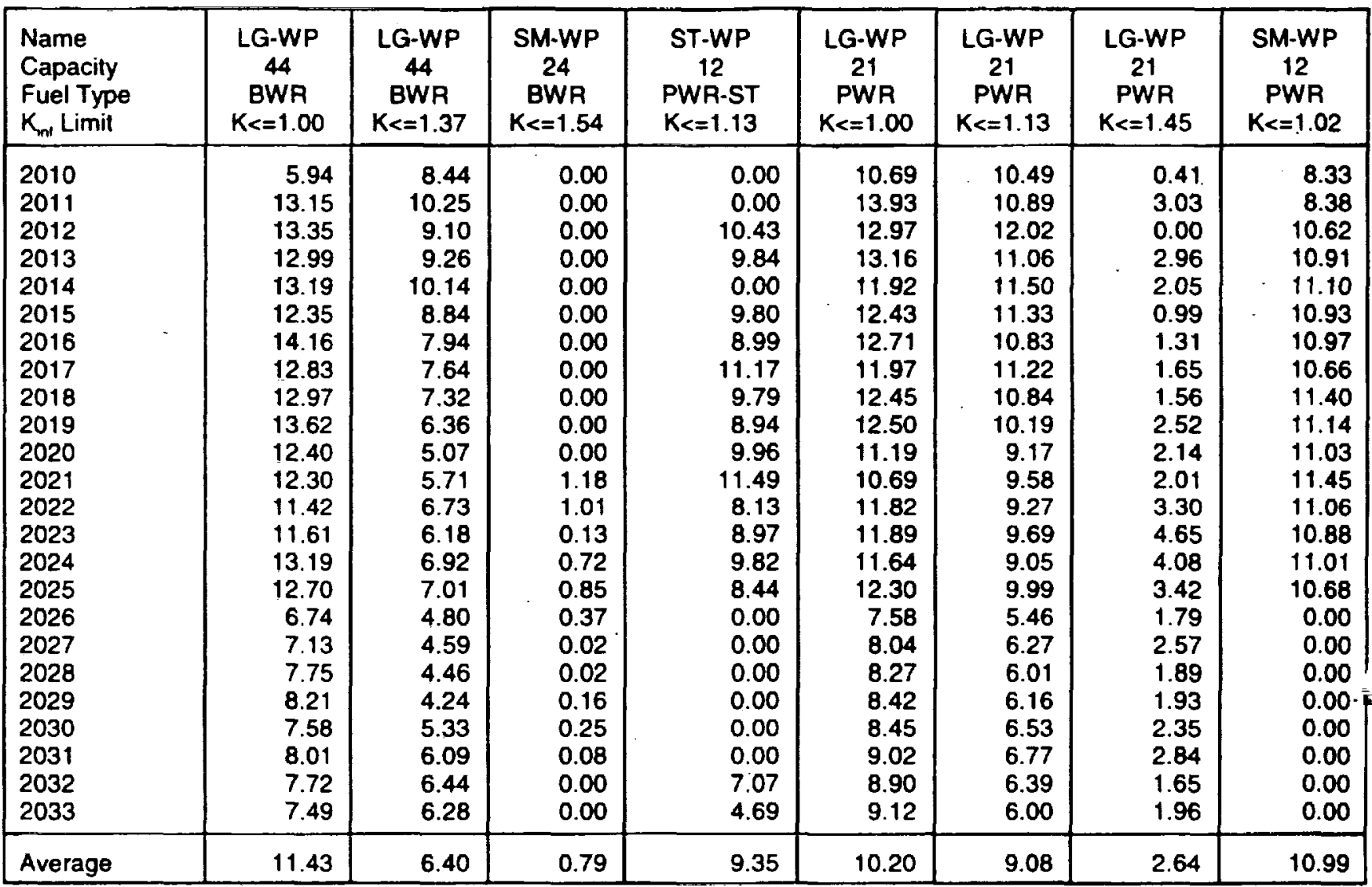

See footnote on $K_{\text {mimty }}$ in Table 3-9.

Average values, which were not shown in the Waste Quantity, Mix, and Throughput Study Report, were calculated as weighted averages of the values in the respective column using the waste package quantities from Table 3-9. 


\section{Controlled Design Assumption \\ Assumption Rationale Sheet}

I Assumption Identifier: Key 005

Sübject: HLW \& DOE SNF

\section{STATEMENT OF ASSUMPTION}

I The quantities of high-level waste (HLW) and U.S. Department of Energy (DOE) spent nuclear fuel (SNF) within the combined 7000 MTU equivalent to be disposed of in the repository are based on the direction and assumptions given in BCP-00-96-0005, Implementation of the Program Approach (DOE 1994b). The baseline change proposal (BCP) calls for the disposal at MGDS of 2333 MTHM of mostly canistered DOE SNF, replacing a similar amount out of the 7000 MTHM of high-level waste (HLW) previously planned for the repository. This leaves $4667 \mathrm{MTHM}$ of canistered HLW to be disposed of in the repository.

All HLW and most DOE SNF will be received in disposable canisters. At the repository, these canisters will be packaged for disposal, and the waste packages emplaced in the subsurface facility. Many of the DOE SNF canisters will be co-disposed in waste packages with the HLW canisters, and the remaining DOE SNF canisters will be disposed in separate waste packages. A small amount (approximately $50 \mathrm{MT}$ ) of DOE SNF may be received uncanistered if it meets the repository waste acceptance criteria and has acceptable characteristics so that it can be handled and processed in the same facilities as the commercial SNF.

Tables in Key Assumptions 001, 002, and 003 summarize the HLW and DOE SNF waste streams on a yearly basis. See Table 3-4 for the yearly streams of transportation cask arrivals. See Table 3-8 for the numbers of canisters of HLW and DOE SNF to be received each year. The DOE SNF canisters to be disposed of in separate waste packages are shown separately from those to be codisposed in HLW waste packages. Table 3-9 shows the number of co-disposal waste packages with five HLW canisters and one DOE SNF canister and the number of separate-disposal waste packages containing varying numbers of DOE SNF canisters.

\section{BACKGROUND}

Requesting Management and Operating Contractor (M\&O) organization:

(X) Surface, (X) Subsurface, (X) Waste Package Development, or (X) Other (specify): Requirements, Systems Analysis and Modeling

Need for assumption (statement of intended use):

I Design requirements specific to the DOE SNF needed for repository waste package design do not I yet exist in the Mined Geologic Disposal System (MGDS) Design Requirements Documents 1 (DRDs). 


\section{Controlled Design Assumption \\ Assumption Rationale Sheet}

\section{RATIONALE}

Rationale for assumption (source author, date, and report title) or statement of reasoning behind engineering judgment:

BCP-00-96-0005 specifies that the total HLW and DOE SNF to be disposed at the repository will be two-thirds and one-third of $7000 \mathrm{MTU}$ equivalent, respectively. (The HLW total is to include I 640 MTU equivalent of West Valley Commercial HLW.)

1 The rationale for the HLW and DOE SNF waste stream is based on Waste Quantity, Mix and

I Throughput Study Report (CRWMS M\&O 1997c). The supporting information for HLW and

1 DOE SNF are contained in Appendix G of that Throughput Study.

\section{RESPONSIBILITY AND WITHDRAWAL}

Responsible Management and Operating Contractor (M\&O) organization: Systems Engineering

Document(s) Supporting Withdrawal of Assumption:

Withdrawal Date: 


\section{Controlled Design Assumption \\ Assumption Rationale Sheet}

Assumption Identifier: Key 008

Subjēt: No Rod Consolidation

\section{STATEMENT OF ASSUMPTION}

Rod consolidation will not be performed at the Mined Geologic Disposal System (MGDS).

\section{BACKGROUND}

Requesting Management and Operating Contractor (M\&O) organization:

(X) Surface, ( ) Subsurface, (X) Waste Package Development, or (X) Other (specify):

Requirements, Systems Analysis and Modeling

Need for assumption (statement of intended use):

Retracts a Conceptual Design Report (CDR) baseline performance objective and permits the design of waste package and Mined Geologic Disposal System (MGDS) design criteria to proceed.

\section{RATIONALE}

Rationale for assumption (source author, date, and report title) or statement of reasoning behind engineering judgment:

- The concept of rod consolidation was based on the premise that it would cost less to develop, build, and operate the facilities and equipment necessary for consolidation than it would to buy, load, and emplace the larger number of waste packages required for intact fuel assemblies.

- Many studies have been conducted to evaluate the economic, operations, and schedule impacts related to rod consolidation.

- Study findings show that fuel disposal without rod consolidation reduces life cycle costs, shortens facility construction schedules, and offers additional operational advantages.

\section{RESPONSIBILITY AND WITHDRAWAL}

Responsible Management and Operating Contractor (M\&O) organization: Waste Package

Document(s) Supporting Withdrawal of Assumption:

Withdrawal Date: 


\section{Controlled Design Assumption \\ Assumption Rationale Sheet}

Assumption Identifier: Key 009

Subject: Burnup Credit

\section{STATEMENT OF ASSUMPTION}

1 Will be able to take credit for Principal Isotope burnup credit in disposal criticality evaluations of commercial light water reactor spent nuclear fuel (SNF).

\section{BACKGROUND}

Requesting Management and Operating Contractor (M\&O) organization:

( ) Surface, ( ) Subsurface, (X) Waste Package Development, or (X) Other (specify):

Requirements, Systems Analysis and Modeling

Need for assumption (statement of intended use):

Establishes probable performance parameter, allowing focused design criteria options for waste package and Mined Geologic Disposal System (MGDS) design.

\section{RATIONALE}

Rationale for assumption (source author, date, and report title) or statement of reasoning behind engineering judgment:

I Ongoing Technical Exchanges and Appendix 7 meetings with the NRC staff; results encouraging.

\section{RESPONSIBILITY AND WITHDRA WAL}

Responsible Management and Operating Contractor (M\&O) organization: Waste Package

I Development

Document(s) Supporting Withdrawal of Assumption:

Withdrawal Date: 


\section{Controlled Design Assumption \\ Assumption Rationale Sheet}

Assumption Identifier: Key 010

Subject:- Subsurface WP Transport

\section{STATEMENT OF ASSUMPTION}

Rail transport will be used for subsurface transport of waste packages.

\section{BACKGROUND}

Requesting Management and Operating Contractor (M\&O) organization:

( ) Surface, (X) Subsurface, ( ) Waste Package Development, (X) Other (specify): Requirements, Systems Analysis and Modeling

Need for assumption (statement of intended use):

Establishes likely subsurface transportation mode to permit focused subsurface design to proceed without rubber tire transport options.

\section{RATIONALE}

Rationale for assumption (source author, date, and report title) or statement of reasoning behind engineering judgment:

Rail system is:

- Compatible with handling of the current 21 and 12 PWR waste package.

- Well suited to in-drift emplacement mode.

- Ideal for supplying tunnel boring machine (TBM) operation and transportation of personnel.

- Repository subsurface gradient will allow use of rail system.

- Highly suitable for remote handled or automated operations.

\section{RESPONSIBILITY AND WITHDRA WAL}

Responsible Management and Operating Contractor (M\&O) organization: Subsurface

Document(s) Supporting Withdrawal of Assumption:

Withdrawal Date: 


\section{Controlled Design Assumption}

Assumption Rationale Sheet

Assumption Identifier: Key 011

Subject: Horizontal In-Drift Emplacement

\section{STATEMENT OF ASSUMPTION}

Waste packages will be emplaced in-drift in a horizontal mode.

\section{BACKGROUND}

Requesting Management and Operating Contractor (M\&O) organization:

( ) Surface, (X) Subsurface, (X) Waste Package Development, (X) Other (specify): Requirements, Systems Analysis and Modeling

Need for assumption (statement of intended use):

Establishes restrictive condition, which is essential for the development of focused Mined Geologic Disposal System (MGDS) design.

\section{RATIONALE}

Rationale for assumption (source author, date, and report title) or statement of reasoning behind engineering judgment:

- Based on the current 21 and 12 PWR waste packages, the borehole emplacement option is impractical.

- Facilitates subsurface waste handling including emplacement operations, heat transfer of large waste packages, and leads to smaller emplacement drift sizes.

- Advantageous for long-term criticality control.

\section{IV, RESPONSIBILITY AND WITHDRAWAL}

Responsible Management and Operating Contractor $(\mathrm{M} \& O)$ organization: Subsurface

Document(s) Supporting Withdrawal of Assumption:

Withdrawal Date: 


\section{Controlled Design Assumption \\ Assumption Rationale Sheet}

Assumption Identifier: Key 013

Subject: No Human Entry in Emplacement Drifts

Containing Waste Packages

\section{STATEMENT OF ASSUMPTION}

No human entry is planned in emplacement drifts while waste packages are present. The waste emplacement/retrieval equipment may use robotics and/or remote control features to perform operations and monitoring within the emplacement drifts. Under off-normal conditions, human entry will be considered if protection to the workers can be provided.

\section{BACKGROUND}

Requesting Management and Operating Contractor $(\mathrm{M} \& \mathrm{O})$ organization:

( ) Surface, (X) Subsurface, ( ) Waste Package Development, (X) Other (specify): Requirements, Systems Analysis and Modeling

Need for assumption (statement of intended use):

Establishes the need to investigate practical uses of robotics and remote control for subsurface activities and preclosure drift operations.

\section{RATIONALE}

Rationale for assumption (source author, date, and report title) or statement of reasoning behind engineering judgment:

Repository Design Requirements Document (RDRD) (YMP 1994a): Geologic Repository Operations Area (GROA) shall to the extent practicable achieve occupational doses that are as low as reasonably achievable (ALARA). Under off-normal conditions, radiation exposures to workers should be within allowable limits.

\section{RESPONSIBILITY AND WITHDRAWAL}

Responsible Management and Operating Contractor $(\mathrm{M} \& \mathrm{O})$ organization: Subsurface

Document(s) Supporting Withdrawal of Assumption:

Withdrawal Date: 


\section{Controlled Design Assumption \\ Assumption Rationale Sheet}

Assumption Identifier: Key 016

Subject: Retrievability Period

\section{STATEMENT OF ASSUMPTION}

The repository will be designed for a retrievability period of up to 100 years after initiation of emplacement.

\section{BACKGROUND}

Requesting Management and Operating Contractor (M\&O) organization:

( ) Surface, ( ) Subsurface, ( ) Waste Package Development, (X) Other (specify): Requirements, Systems Analysis and Modeling

Need for assumption (statement of intended use):

Establishes the performance objective for life cycle and durability criteria to support the design of surface and subsurface facilities as well as to support concepts of retrieval of waste packages.

\section{RATIONALE}

Rationale for assumption (source author, date, and report title) or statement of reasoning behind engineering judgment:

Required by Implementation of the Program Approach (DOE 1994b).

\section{RESPONSIBILITY AND WITHDRAWAL}

Responsible Management and Operating Contractor (M\&O) organization: Systems Engineering

Document(s) Supporting Withdrawal of Assumption:

Withdrawal Date: 


\section{Controlled Design Assumption}

Assumption Rationale Sheet

Assumption Identifier: Key 017

Subject: Reasons for Retrieval

\section{STATEMENT OF ASSUMPTION}

Retrieval of emplaced waste may be performed for the following reasons:

- Failure in site, waste package, or some other system causing an unreasonable risk to public health and safety.

- The determination that recovery of valuable resources from the spent nuclear fuel is necessary.

\section{BACKGROUND}

Requesting Management and Operating Contractor (M\&O) organization:

(X) Surface, (X) Subsurface, (X) Waste Package Development, (X) Other (specify): Requirements, Systems Analysis and Modeling

Need for assumption (statement of intended use):

Required by the Nuclear Waste Policy Act, as Amended (NWPAA) (DOE 1995b).

\section{RATIONALE}

Rationale for assumption (source author, date, and report title) or statement of reasoning behind engineering judgment:

- Consistent with Program Approach assumptions.

- Nuclear Waste Policy Act, as Amended (NWPAA) (DOE 1995b).

- Retrievability System Study September 1994.

\section{RESPONSIBILITY AND WITHDRAWAL}

Responsible Management and Operating Contractor (M\&O) organization: Systems Engineering Document(s) Supporting Withdrawal of Assumption:

Withdrawal Date: 


\section{Controlled Design Assumption \\ Assumption Rationale Sheet}

Assumption Identifier: Key 019

Subject: Mass Loading Range

\section{STATEMENT OF ASSUMPTION}

Surface, subsurface and waste package designs will be based on a reference mass loading range of I 19.8-24.7 kgU/m² (80-100 metric tons of uranium (MTU) per acre) or an Equivalent Energy Density (EED) producing similar thermal conditions. The areal mass loading (AML) value includes the metric tons of uranium from commercial and Naval spent nuclear fuel, but does not include the I "equivalent metric tons of uranium" from low burnup DOE spent nuclear fuel or from (reprocessed) defense or commercial high level waste. The excluded equivalent MTU (which is nominally about $10 \%$ of the repository capacity) will be disposed of within the same footprint as the heat-producing waste accounted for in the AML value.

Other aspects of thermal management are addressed in Key Assumptions 067, 077, and 078.

\section{BACKGROUND}

Requesting Management and Operating Contractor (M\&O) organization:

( ) Surface, (X) Subsurface, (X) Waste Package Development, (X) Other (specify): Requirements, Systems Analysis and Modeling

Need for assumption (statement of intended use):

Establishes a design range permitting Mined Geologic Disposal System (MGDS) and waste package design options to proceed with criteria to achieve these objectives.

\section{RATIONALE}

Rationale for assumption (source author, date, and report title) or statement of reasoning behind engineering judgment:

- No final decision on design mass loading has been made because drift scale in situ test data are not yet available; the flexibility to accommodate higher or lower thermal loads is part of the thermal strategy.

- The reference mass loading range is consistent with current thermal strategy (CRWMS M\&O 1995).

- The design mass loading will tend to the upper end of the reference range, unless constrained by other limits in this document or in requirements documents. 


\section{Controlled Design Assumption Assumption Rationale Sheet}

- The Thermal Loading Study of FY96 (CRWMS M\&O 1996g) récommended limiting the mass loading to no more than $22.2 \mathrm{kgU} / \mathrm{m}^{2}$ (90 MTU/acre). This limit was based on limiting the temperature of the average top of the zeolite layer $(170 \mathrm{~m}$ below the repository horizon) to $90^{\circ} \mathrm{C}$. The numerical relationship between $A M L$ and temperature at a particular depth has some degree of uncertainty. Since the zeolite protection requirement is specifically included in assumption DCSS 025 (independent of any uncertainty in the relationship between AML and temperature at depth), the reference AML is not changed in this section. However, the design must meet both requirements.

\section{RESPONSIBILITY AND WITHDRAWAL}

Responsible Management and Operating Contractor (M\&O) organization: Systems Engineering

Document(s) Supporting Withdrawal of Assumption:

Withdrawal Date: 
Controlled Design Assumption

Assumption Rationale Sheet 


\section{Controlled Design Assumption \\ Assumption Rationale Sheet}

Assumption Identifier: Key 022

Sū̄ject: Repository Horizon

\section{STATEMENT OF ASSUMPTION}

For the reference mass loading given in Key Assumption 019 the repository horizon will be located mainly in the TSw2 geologic unit within the primary area.

\section{BACKGROUND}

Requesting Management and Operating Contractor (M\&O) organization:

( ) Surface, (X) Subsurface, ( ) Waste Package Development, (X) Other (specify): Requirements, Systems Analysis and Modeling

Need for assumption (statement of intended use):

Clarifies incompatibility of low thermal loading and assumes a scenario permitting subsurface design criteria to proceed compatibly with Key Assumption 003.

\section{RATIONALE}

Rationale for assumption (source author, date, and report title) or statement of reasoning behind engineering judgment:

- Recent evaluations indicate the TSw $1 / T S w 2$ contact is not well defined and some rock within the presently defined TSw I unit is suitable for the emplacement of SNF and HLW. Revised assumption provides more flexibility.

- Primary area is consistent with site characterization activities.

- Primary area is as defined in Mansure, A. J. and Ortiz, T. S., Preliminary Evaluation of the Subsurface Area Available for a Potential Nuclear Waste Repository at Yucca Mountain (SNL 1984). The primary area is not rigidly defined. Therefore, rigidly restricting the repository to an arbitrarily defined unit is not warranted. Modest crossing of the boundary between units should be allowed.

Assumption is consistent with the thermal strategy reference loading.

\section{RESPONSIBILITY AND WITHDRAWAL}

Responsible Management and Operating Contractor (M\&O) organization: Subsurface

Document(s) Supporting Withdrawal of Assumption:

Withdrawal Date: 


\section{Controlled Design Assumption}

Assumption Rationale Sheet

Assumption Identifier: Key 023

Subject: Subsurface Fault Standoff

\section{STATEMENT OF ASSUMPTION}

To the extent practical, repository openings will be located to avoid Type 1 faults. For unavoidable Type 1 faults that intersect emplacement drifts, allow a $15 \mathrm{~m}$ standoff from the edge of the fault zone to the nearest waste package.

Avoidance is assumed to be adequate by using a $60 \mathrm{~m}$ offset from the main trace of a fault at the repository level. Exception: 120-m stand off should be used on the west side of the Ghost Dance Fault because the Exploratory Studies Facility (ESF) Topopah Spring Main drift will be excavated before the Ghost Dance Fault characteristics are fully investigated.

\section{BACKGROUND}

Requesting Management and Operating Contractor (M\&O) organization:

( ) Surface, (X) Subsurface, ( ) Waste Package Development, (X) Other (specify): Requirements, Systems Analysis and Modeling

Need for assumption (statement of intended use):

Establishes design criteria permitting Repository layout to proceed consistent with these objectives.

\section{RATIONALE}

Rationale for assumption (source author, date, and report title) or statement of reasoning behind engineering judgment:

NUREG 1494, Staff Technical Position on Consideration of Fault Displacement Hazards in Geologic Repository Design (NRC 1994). Key Assumption 023 Rev. 01 is a combined version of Key Assumption 023 Rev. 00, Key Assumption 034 Rev. 00, and Key Assumption 035 Rev. 00.

\section{RESPONSIBILITY AND WITHDRAWAL}

Responsible Management and Operating Contractor (M\&O) organization: Subsurface

Document(s) Supporting Withdrawal of Assumption:

Withdrawal Date: 


\section{Controlled Design Assumption \\ Assumption Rationale Sheet}

Assumption Identifier: Key 024

Subject: Site Generated Wastes

\section{STATEMENT OF ASSUMPTION}

Secondary site generated waste (low-level, hazardous, mixed, and municipal) will be transported to government-approved offsite facilities for disposal. Radioactive low-level waste (LLW) will be processed and packaged for shipment to off-Yucca Mountain-Site disposal, as designated in Key Assumption 082, and used dual-purpose canisters (DPCs) will be prepared for off-site recycling or disposal. Hazardous and mixed wastes will be collected and packaged for transport to RCRAapproved off-site treatment, storage and disposal facility. Temporary accumulations would be accommodated onsite to facilitate treatment of low-level waste and packaging of all waste types prior to transport to designated facilities. Offsite disposal and recycling options are to be assessed.

\section{BACKGROUND}

Requesting Management and Operating Contractor (M\&O) organization:

(X) Surface, ( ) Subsurface, ( ) Waste Package Development, (X) Other (specify): Requirements, Systems Analysis and Modeling

- $\quad$ 10 CFR 60.132 states "Radioactive Waste Treatment Facilities shall be designed to process any radioactive wastes generated at the geologic repository operations area into a form suitable to permit safe disposal at the geologic repository operations area or to permit safe transportation and conversion to a form suitable for disposal at an alternative site in accordance with any regulations that are applicable."

Need for assumption (statement of intended use):

Clarifies the functional requirements and waste flows for the Waste Treatment facilities and Mined Geologic Disposal System (MGDS) site to be included in the License Application (LA) and Environmental Impact Statement (EIS).

\section{RATIONALE}

Rationale for assumption (source author, date, and report title) or statement of reasoning behind engineering judgment:

Site-generated Waste Quantities and Disposal Options are being studied, with results due to be reported September 1997 as B00000000-01717-5705-00078. Options for LLW disposal on-site and off-site will be evaluated in that study and the rationale documented. The availability of the LLW facility at the NTS, as addressed in Key Assumption 082, would provide a relatively low-cost alternative that is particularly convenient for transportation. Options for DPC disposal will also be investigated in the study. Hazardous waste quantities are too small to warrant permitting for treatment, storage and disposal. Mixed waste quantities comprise a small fraction of the hazardous wastes. Radioactive Waste (RW) policy excludes mixed waste from disposal at Mined Geologic Disposal System (MGDS) (June 22, 1995, Dreyfus' memorandum bounding NEPA analysis to nonRCRA spent nuclear fuel (SNF) and vitrified high-level waste [HLW]). Collection of municipal 


\section{Controlled Design Assumption \\ Assumption Rationale Sheet}

and construction wastes (nonradioactive, nonhazardous) in dumpsters for transport to State-

permitted landfills is expected to provide environmentally-acceptable disposal at a reasonable cost.

IV. RESPONSIBILITY AND WITHDRA WAL

Responsible Management and Operating Contractor (M\&O) organization: Systems Engineering

Document(s) Supporting Withdrawal of Assumption:

Withdrawal Date: 


\section{Controlled Design Assumption \\ Assumption Rationale Sheet}




\section{Controlled Design Assumption \\ Assumption Rationale Sheet}

Assumption Identifier: Key 027

Subject: Mec̄hanical Tunnel Excavation

\section{STATEMENT OF ASSUMPTION}

The primary method of tunnel excavation will be mechanical.

\section{BACKGROUND}

Requesting Management and Operating Contractor (M\&O) organization:

( ) Surface, (X) Subsurface, ( ) Waste Package Development, (X) Other (specify): Requirements, Systems Analysis and Modeling

Need for assumption (statement of intended use):

Limits consideration of other primary excavation methods to permit focused underground design.

\section{RATIONALE}

Rationale for assumption (source author, date, and report title) or statement of reasoning behind engineering judgment:

- 10 CFR 60.133(e)(2): Openings shall be designed to reduce deleterious rock movement.

- 10 CFR 60.133(f): Use excavation methods that limit potential for creating preferential pathways for groundwater.

- NUREG 1347, Staff Site Characterization Analysis of the Department of Energy's Site Characterization Plan, Yucca Mountain (NRC 1989) Comment 132: Compare the alternatives of drilling, blasting, and mechanical excavation methods.

- NWTRBs First Report to Congress: Maximize use of the most modern mechanical excavation techniques in studies of tunnel excavation methods.

- Results of the Exploratory Studies Facility (ESF) Altematives Study recommended mechanical excavation.

\section{RESPONSIBILITY AND WITHDRAWAL}

Responsible Management and Operating Contractor (M\&O) organization: Subsurface

Document(s) Supporting Withdrawal of Assumption:

Withdrawal Date: 


\section{Controlled Design Assumption}

Assumption Rationale Sheet

Assumption Identifier: Key 028

Subject: Tuñnel Drill-and-Blast Option

\section{STATEMENT OF ASSUMPTION}

Where it is impractical to use mechanical methods, drill-and-blast may be used to a limited degree primarily in non-emplacement areas of the repository.

\section{BACKGROUND}

Requesting Management and Operating Contractor $(\mathrm{M} \& \mathrm{O})$ organization:

( ) Surface, (X) Subsurface, ( ) Waste Package Development, (X) Other (specify): Requirements, Systems Analysis and Modeling

Need for assumption (statement of intended use):

Establishes limited secondary excavation alternative limitations to permit focused underground design.

\section{RATIONALE}

Rationale for assumption (source author, date, and report title) or statement of reasoning behind engineering judgment:

- 10 CFR 60.133(e)(2): Openings shall be designed to reduce deleterious rock movement.

- 10 CFR 30.133(f): Use excavation methods that limit potential for creating preferential pathways for groundwater.

- NUREG 1347, Staff Site Characterization Analysis of the Department of Energy's Site Characterization Plan, Yucca Mountain (NRC 1989), Comment 132: Compare the alternatives of drilling and blasting and mechanical excavation methods.

- NWTRBs First Report to Congress: Maximize use of the most modern mechanical excavation techniques in studies of tunnel excavation methods.

\section{RESPONSIBILITY AND WITHDRAWAL}

Responsible Management and Operating Contractor $(\mathrm{M} \& \mathrm{O})$ organization: Subsurface

Document(s) Supporting Withdrawal of Assumption:

Withdrawal Date: 


\section{Controlled Design Assumption}

Assumption Rationale Sheet

Assumption Identifier: Key 030

Subject: Underground $\bar{R}$ ail Transport of Personnel

I. STATEMENT OF ASSUMPTION

and Supplies

Rail will be used for transporting underground supplies and personnel to the extent practical.

\section{BACKGROUND}

Requesting Management and Operating Contractor $(\mathrm{M} \& \mathrm{O})$ organization:

( ) Surface, (X) Subsurface, ( ) Waste Package_Development, (X) Other (specify): Requirements, Systems Analysis and Modeling

Need for assumption (statement of intended use):

Limits consideration of alternate subsurface transport method to permit focused underground design.

\section{RATIONALE}

Rationale for assumption (source author, date, and report title) or statement of reasoning behind engineering judgment:

Rail system is:

- Takes advantage of the rail system required to transport heavy waste packages.

- Well suited to in-drift emplacement mode.

- Ideal for supplying tunnel boring machine.(TBM) operation and transportation of personnel.

- Repository subsurface gradient will allow use of rail system.

- Highly suitable for remote handled or automated operations.

\section{RESPONSIBILITY AND WITHDRAWAL}

Responsible Management and Operating Contractor $(\mathrm{M} \& \mathrm{O})$ organization: Subsurface

Document(s) Supporting Withdrawal of Assumption:

Withdrawal Date: 


\section{Controlled Design Assumption \\ Assumption Rationale Sheet}

Assumption Identifier: Key 031

Subject: Waste Package Shielding

I. STATEMENT OF ASSUMPTION

A. Waste package containment barriers will provide sufficient shielding for protection of waste package materials from radiation enhanced corrosion.

B. Individual waste packages will not provide any additional shielding for personnel protection.

C. Additional shielding for personnel protection will be provided on the subsurface transporter and in surface and subsurface facilities.

\section{BACKGROUND}

Requesting Management and Operating Contractor (M\&O) organization:

(X) Surface, ( X ) Subsurface, (X) Waste Package Development, (X) Other (specify):

Requirements, Systems Analysis and Modeling

Need for assumption (statement of intended use):

Establishes coordinated criteria to permit waste package and Repository facilities design to proceed.

\section{RATIONALE}

Rationale for assumption (source author, date, and report title) or statement of reasoning behind engineering judgment:

- Cost, size, and weight of individually shielded waste packages may be excessive.

- Mined Geologic Disposal System (MGDS) will meet as low as reasonably achievable (ALARA) requirement, with more cost effective shielding options.

- Personnel radiation protection from individual waste packages will be provided through the use of:

(1) remote handling equipment in the assembly and emplacement areas,

(2) a shielded waste package transporter during emplacement operations, and

(3) shielding and seals at the entrances to the emplacement drifts.

\section{RESPONSIBILITY AND WITHDRAWAL}

Responsible Management and Operating Contractor $(\mathrm{M} \& O)$ organization: Systems Engineering

Document(\$) Supporting Withdrawal of Assumption:

Withdrawal Date: 


\section{Controlled Design Assumption Assumption Rationale Sheet}




\section{Controlled Design Assumption}

Assumption Rationale Sheet

Assumption Key 037 has been withdrawn 


\section{Controlled Design Assumption Assumption Rationale Sheet}




\section{Controlled Design Assumption}

Assumption Rationale Sheet

Assumption Identifier: Key 039

Subject: Criticality Control Period

\section{STATEMENT OF ASSUMPTION}

The Criticality Control Period lasts to the end of the period of regulatory concern, which is currently undefined. It is presently assumed that the time of concern is greater than 10,000 years after closure.

\section{BACKGROUND}

Requesting Management and Operating Contractor $(\mathrm{M \& O})$ organization:

( ) Surface, (. ) Subsurface, (X) Waste Package Development, (X) Other (specify): Requirements, Systems Analysis and Modeling

Need for assumption (statement of intended use):

Identifies the required period for criticality analysis.

\section{RATIONALE}

Rationale for assumption (source author, date, and report title) or statement of reasoning behind engineering judgment:

The criticality control period is chosen to last to the end of the period of regulatory concern. This has generally been considered to be 10,000 years after closure of the repository.

Assumption in accordance with 10 CFR 60.131(h). Note: On December 4, 1996 there was a 1 change to 10 CFR 60; paragraph 10 CFR 60.131(b)(7) was renumbered 10 CFR 60.131(h).

The interim postclosure standard (see Key 060) contains a 10,000 year time frame for controlling peak dose, but also states that time periods beyond 10,000 years must be considered.

\section{RESPONSIBILITY AND WITHDRAWAL}

Responsible Management and Operating Contractor (M\&O) organization: Systems Engineering Document(s) Supporting Withdrawal of Assumption:

Withdrawal Date: 


\section{Controlled Design Assumption \\ Assumption Rationale Sheet}

Assumption Identifier: Key 046

Subject: Back̄ill in Emplacement Drifts

\section{STATEMENT OF ASSUMPTION}

I The repository design should not preclude the use of emplacement drift backfill at the end of the preclosure period. The specifications for the emplacement drift envelope to accommodate are: 1) level single layer backfill (quartz sand, crushed tuff, or other material of similar favorable thermohydrologic properties), and 2) waste packages should initially be covered with at least 0.6 meters of material.

\section{BACKGROUND}

Requesting Management and Operating Contractor (M\&O) organization:

( ) Surface, (X) Subsurface, (X) Waste Package Development, (X) Other (specify): Requirements, Systems Analysis and Modeling

Need for assumption (statement of intended use):

Establishes a scenario which permits performance objectives and design criteria to be developed for the waste package and the Mined Geologic Disposal System (MGDS).

\section{RATIONALE}

Rationale for assumption (source author, date, and report title) or statement of reasoning behind engineering judgment:

I A Waste Isolation Study (B00000000-01717-5705-00062, REV 00) is currently being completed which evaluates the effects of backfill on temperature and relative humidity of the waste package.

This study concludes that backfill provided little or no performance benefit for flux of $6.2 \mathrm{~mm} /$ year. It did recommend that the ability to backfill be preserved, as it may be needed to support other barrier concepts, such as the survivability of a drip shield.

I In light of the current repository performance margins and uncertainties, the underground repository layout should provide a sufficient envelope such that a reasonable backfill emplacement system could be designed and backfit at a later date. It is assumed that the emplaced backfill will not have to be compacted after placement. Further discussion of this conclusion can be found in the Engineered Barrier System Performance Requirements Systems Study Report (CRWMS M\&O 1996d).

\section{RESPONSIBILITY AND WITHDRAWAL}

Responsible Management and Operating Contractor $(\mathrm{M} \& O)$ organization: Systems Engineering

Document(s) Supporting Withdrawal of Assumption:

Withdrawal Date: 


\section{Controlled Design Assumption \\ Assumption Rationale Sheet}

Assumption Identifier: Key 047

Subject: Surface Facilities Location

\section{STATEMENT OF ASSUMPTION}

The proposed repository waste handling and administrative surface facilities will be located adjacent to the north portal. Flood considerations for locating surface facilities are included in Assumption TDS 008.

Administrative facilities will be located east of the nuclear facilities.

\section{BACKGROUND}

Requesting Management and Operating Contractor (M\&O) organization:

(X) Surface, ( ) Subsurface, ( ) Waste Package Development, ( ) Other (specify):

Need for assumption (statement of intended use):

Establishes probable general siting of facilities based on performance objectives to permit specific facility siting criteria to proceed.

\section{RATIONALE}

Rationale for assumption (source author, date, and report title) or statement of reasoning behind engineering judgment:

- Site Characterization Plan/Conceptual Design Report proposed the location of the central surface facilities at the entrance to the waste ramp portal.

- Northem Midway Valley is more likely to contain an area demonstrably free of late Quatemary surface faults.

- The Exploratory Studies Facility (ESF) alternatives study recommended relocation of the waste and tuff ramps portals based on Option 30 findings.

- The current technical baseline identifies a north and south poral location in accordance with the ESF enhanced configuration.

- The ESF is presentiy located at the entrance to the north portal.

- The south portal will have a steeper ramp grade ( 2.62 percent) compared to the north portal ramp (2.15 percent).

- Planned site improvements for the ESF can be used for the proposed repository surface facilities.

- Prevailing winds were analyzed during Advanced Conceptual Design (ACD).

- Relative location of Administrative and Nuclear facilities considers prevailing winds in the event of an accidental hazardous release.

\section{RESPONSIBILITY AND WITHDRA WAL}

Responsible Management and Operating Contractor (M\&O) organization: Surface

Document(s) Supporting Withdrawal of Assumption:

Withdrawal Date: 


\section{Controlled Design Assumption \\ Assumption Rationale Sheet}

Assumption Identifier: Key 053

Subject:- Off-Normal Waste Handling

\section{STATEMENT OF ASSUMPTION}

The Mined Geologic Disposal System (MGDS) shall have the capability to handle canistered waste forms that require remedial processing. This includes remediation due to inability to load waste into a disposal container in the canistered configuration. Such off-normal handling includes opening the canister, removing the waste form, discarding the canister, and repacking the waste form in a disposal container.

\section{BACKGROUND}

\section{Original Version}

MGDSRD 3.2.3.2.3.1.1.L.

The Repository Segment shall have the capability to handle any abnormal multi-purpose canisters (MPCs) and other canistered waste forms that require remedial processing. Such processing may include opening the canister, transferring the waste form, adding filler material and resealing. [10CFR60.135(a)(1)] [CRD 3.7.4.2.D]

Requesting Management and Operating Contractor (M\&O) organization:

(X) Surface, ( ) Subsurface, ( ) Waste Package Development, ( ) Other (specify):

Need for assumption (statement of intended use):

Defines a probable functional requirement to permit continued development of the repository Waste Handling Building (WHB).

\section{RATIONALE}

Rationale for assumption (source author, date, and report title) or statement of reasoning behind engineering judgment:

This assumption complies with the Mined Geologic Disposal System Requirements Document (MGDS-RD) (DOE 1996c) requirements cited in the Background Section. The assumption pertains to disposable waste canisters that are otherwise intended not to be opened. The Referenced 10 CFR 60 and CRD sections are under "off-normal" headings. Therefore, this requirement applies to an off-normal occurrence.

A separate, single operation cell will provide for the required remedial operations on an off-normal basis. This cell is proposed to prevent special operations from interfering with normal waste handling operations. The cell will need to be adaptable to multiple functional roles for one-time or low-volume events. Probable events and best remedial methodology will need to be investigated before operations and equipment can be defined for this area. Programmatic guidance defines an approach where the addition of filler material to canistered waste, as a criticality remediation measure, may be unnecessary (IOC \#VA.SE.GUR.8/95.016).

\section{RESPONSIBILITY AND WITHDRAWAL}

Responsible Management and Operating Contractor (M\&O) organization: Surface

Document(s) Supporting Withdrawal of Assumption:

Withdrawal Date: 


\section{Controlled Design Assumption \\ Assumption Rationale Sheet}

Assumption Identifier: Key 055

Subject: Retrieval Demonstration

\section{STATEMENT OF ASSUMPTION}

Proof of principle demonstrations of waste package retrieval will be conducted following license application.

\section{BACKGROUND}

Requesting Management and Operating Contractor (M\&O) organization:

( ) Surface, (X) Subsurface, ( ) Waste Package Development, (X) Other (specify): Requirements, Systems Analysis and Modeling

Need for assumption (statement of intended use):

Provides input to test planning and scheduling.

\section{RATIONALE}

Rationale for assumption (source author, date, and report title) or statement of reasoning behind engineering judgment:

Proof of principle required as a result of uncertainties associated with the performance of retrieval equipment in the underground environment.

Consistent with Program Approach assumptions.

Meets 10 CFR 60 and U.S. Department of Energy (DOE) requirements.

Proof of principle demonstration consistent with DOE position as stated in Appendix D of Position of Retrievahility for a Geologic Repository (DOE 1985).

This assumption will be reexamined if a requirement to conduct retrieval demonstration prior to license application is established by DOE.

\section{RESPONSIBILITY AND WITHDRA WAL}

Responsible Management and Operating Contractor (M\&O) organization: Subsurface

Document(s) Supporting Withdrawal of Assumption:

Withdrawal Date: 


\section{Controlled Design Assumption \\ Assumption Rationale Sheet}

I Assumption Identifier: Key 057

Subject: Bumup or Thermal Measurements

\section{STATEMENT OF ASSUMPTION}

Repository waste handling baseline design will not have canistered spent nuclear fuel burnup or thermal measurement capability.

I The burnup of every uncanistered commercial fuel assembly will need to be measured prior to 1 emplacement in a waste package. The repository surface facility will have the capacity to perform a I measurement verifying the burnup record for each fuel assembly. Fuel assemblies shipped in I burmup credit transportation casks will have the necessary measurements prior to shipment to the I repository, and no additional measurement will be required.

1

\section{BACKGROUND}

Requesting Management and Operating Contractor (M\&O) organization:

1 (X) Surface, ( ) Subsurface, (X) Waste Package Development, (X) Other (specify): Systems Engineering (Vienna)

Need for assumption (statement of intended use):

Waste Handling Building (WHB) Design

\section{RATIONALE}

Rationale for assumption (source author, date, and report title) or statement of reasoning behind engineering judgment:

Burnup measurements of spent nuclear fuel (SNF) in disposable waste canisters will be performed, 1 at purchaser sites, if required for transportation. For assemblies received at the repository in I disposable canisters any needed measurements would have to be made prior to loading the canister $I$ and the data provided with the canistered SNF.

Ongoing discussions with the Nuclear Regulatory Commission Staff indicate they will require a burnup measurement of some sort before burnup credit is allowed. Bumup measurement systems are addressed in Appendix B of Topical Report on Actinide Only Burnup Credit for PWR Spent Nuclear Fuel Packages (DOE 1997).

\section{RESPONSIBILITY AND WITHDRAWAL}

Responsible Management and Operating Contractor (M\&O) organization: Systems Engineering Document(s) Supporting Withdrawal of Assumption:

Withdrawal Date: 


\section{Controlled Design Assumption \\ Assumption Rationale Sheet}

Assumption Identifier: Key 058

Subject: Transportation Mode/Route Within Nevada

\section{STATEMENT OF ASSUMPTION}

Spent nuclear fuel (SNF) and high-level waste (HLW) arriving in Nevada on mainline commercial rail lines, will be transported to the repository via rail. The rail routes being considered are described in the Nevada Potential Repository Preliminary Transportation Strategy - Study 2 (CRWMS M\&O 1995c). For costing purposes, a straight cost average of the four routes will be used: 1) Caliente - base route; 2) Carlin - Monitor Valley via Ralston; 3) Valley Modified- via Indian Hills; and 4) Jean - Wilson Pass Option via Stewart Valley.

The Caliente Route is the baseline route for the Life Cycle Cost Estimate.

\section{BACKGROUND}

Requesting Management and Operating Contractor (M\&O) organization:

(X) Surface, ( ) Subsurface, ( ) Waste Package Development, (X) Other (specify): Systems Engineering (Vienna)

Need for assumption (statement of intended use):

\section{RATIONALE}

Rationale for assumption (source author, date, and report title) or statement of reasoning behind engineering judgment:

These were the least expensive options from the four rail corridors being considered according to the findings of the Nevada Potential Repository Preliminary Transportation Strategy - Study 2 (CRWMS M\&O 1995c). Using the average of four routes is consistent with the position that the route will be selected once the National Environmental Protection Act (NEPA) process is concluded.

The Caliente route is selected as an Advanced Conceptual Design (ACD) baseline since it appears to be feasible and provides an apparent upper bound on the cost of a rail line to the repository. The route has overall favorable characteristics relative to land use and public acceptance.

It is noted that no decision has been made relative to the transportation mode. The heavy haul transportation mode remains an option. The final decision can only be made in accordance with the NEPA process.

\section{RESPONSIBILITY AND WITHDRAWAL}

Responsible Management and Operating Contractor (M\&O) organization: Systems Engineering

Document(s) Supporting Withdrawal of Assumption:

Withdrawal Date: 


\section{Controlled Design Assumption \\ Assumption Rationale Sheet}

Assumption Identifier: Key 059

Subject: MGDS Configuration Item Organization

\section{STATEMENT OF ASSUMPTION}

The configuration items of the Engineered Barrier Segment (EBS) and the configuration items groups of the repository (Surface and Subsurface) are organized as shown in Figure 3-1.

\section{BACKGROUND}

Requesting Management and Operating Contractor $(\mathrm{M} \& \mathrm{O})$ organization:

(X) Surface, (X) Subsurface, (X) Waste Package Development, (X) Other (specify): Systems Engineering

Need for assumption (statement of intended use):

Configuration Management and Requirements Allocation.

\section{RATIONALE}

Rationale for assumption (source author, date, and report title) or statement of reasoning behind engineering judgment:

The figure is based on Advanced Conceptual Design (ACD) development.

\section{RESPONSIBILITY AND WITHDRAWAL}

Responsible Management and Operating Contractor (M\&O) organization: Systems Engineering (Requirements)

Document(s) Supporting Withdrawal of Assumption:

Withdrawal Date: 


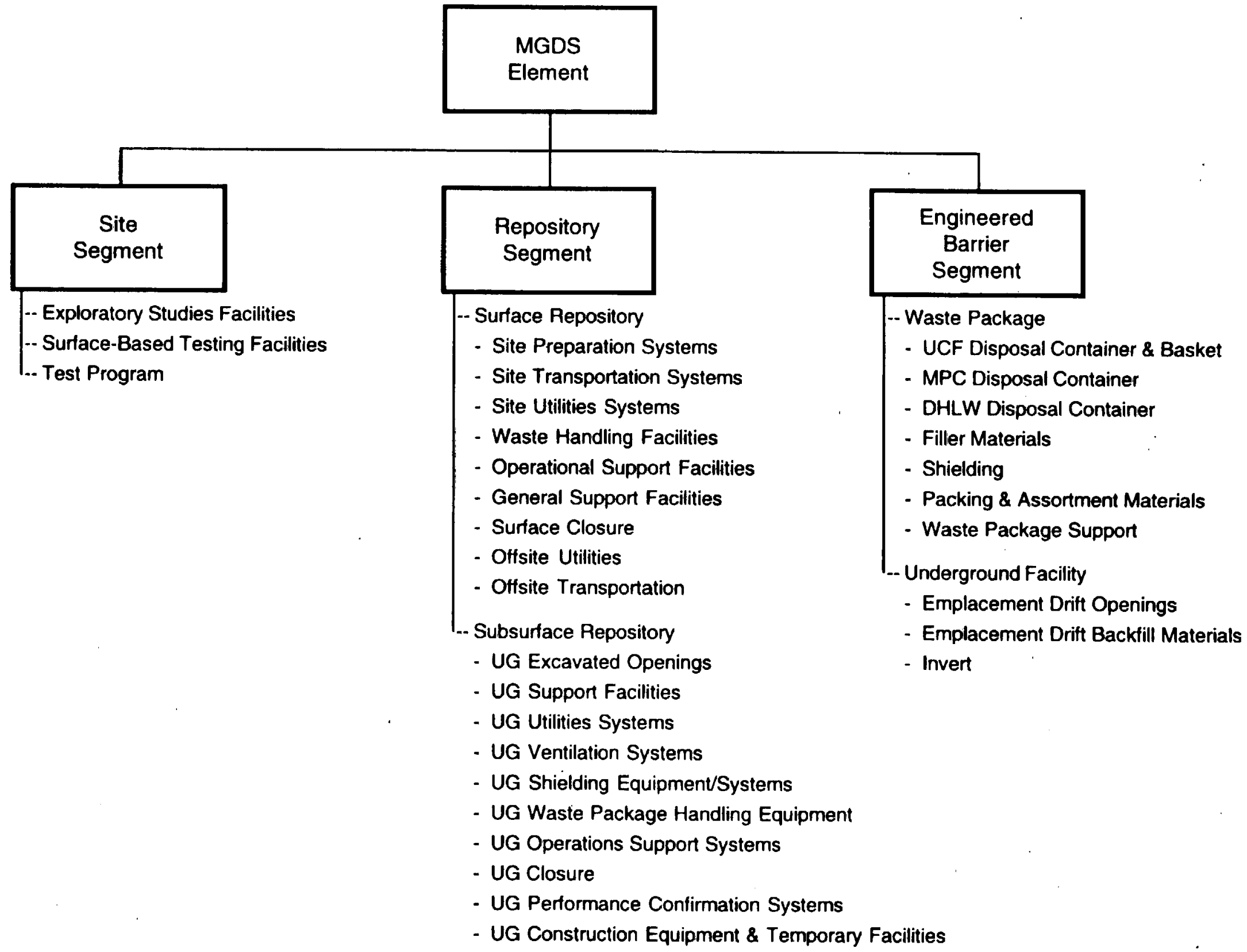

Figure 3-1. Mined Geologic Disposal System Configuration Item Organization 


\section{Controlled Design Assumption \\ Assumption Rationale Sheet}

Assumption Identifier: Key 060

Súbject:- Interim Postclosure Standard

\section{STATEMENT OF ASSUMPTION}

Until a new Environmental Protection Agency (EPA) standard is promulgated, the Yucca Mountain Site

I Characterization Office (YMSCO) will use the following interim requirement and goal as a planning basis for evaluating the postclosure performance of the repository:

I The interim system-level requirement is a quantitative statement of necessary performance for the

I first 10,000 years after closure. It is followed by a system-level performance goal that recognizes there needs to be sufficient defense-in-depth in the repository's multiple barriers system to ensure that public safety is protected beyond 10,000 years. This is a serious system performance goal. It is qualitative because of increasing uncertainties beyond the first 10,000 years.

\section{Requirement}

The expected annual dose to an average individual in a critical group living $20 \mathrm{~km}$ from the repository shall not exceed 25 mrem from all pathways and all radionuclides during the first 10,000 years after closure.

Goal

Conduct analyses past 10,000 years to gain insight into longer-term system performance. For this period, the expected annual dose to an average individual in a critical group living $20 \mathrm{~km}$ from the repository should be below the 10,000 year requirement.

\section{BACKGROUND}

Requesting Management and Operating Contractor (M\&O) organization:

( ) Surface, ( ) Subsurface, (X) Waste Package Development, (X) Other (specify): Systems Engineering

Need for assumption (statement of intended use):

I Guidance is needed for a postclosure standard since 40 CFR 191 is no longer applicable to a repository at I Yucca Mountain (per the Waste Isolation Plant Land and Withdrawal Act of 1992) and a new standard I specific to Yucca Mountain (as required by the Energy Policy Act of 1992) has not yet been promulgated.

\section{RATIONALE}

Rationale for assumption (source author, date, and report title) or statement of reasoning behind engineering judgment:

I The interim postclosure requirement and goal was established by YMSCO (YMP 1997) with the following rationale:

Consistent with the U.S. Nuclear Regulatory Commission (NRC) [Chairman Jackson's testimony to the Subcommittee on Energy and Power, U.S. House of Representatives, April 29, 1997 (Jackson 1997)], the DOE considers that 10,000 years is sufficient time to demonstrate waste isolation. The DOE supports the NRC in its position that an annual effective dose of 100 mrem to the average member of the population within the vicinity of Yucca Mountain protects public health and safety. To provide reasonable assurance and to be consistent with the NRC's regulations on decommissioning nuclear power reactors (61 FR 39278; 10 CFR Parts 2, 50, and 51), the DOE has invoked an interim requirement so that it may move forward and demonstrate the safety case for a repository at Yucca Mountain. 


\section{Controlled Design Assumption \\ Assumption Rationale Sheet}

Assumption Identifier: Key 060 (continued)

Subject: Interim Postclosure Standard

\section{RESPONSIBILITY AND WITHDRA WAL}

Responsible Management and Operating Contractor (M\&O) organization: Systems Engineering

Document(s) Supporting Withdrawal of Assumption:

Withdrawal Date: 


\title{
Controlled Design Assumption \\ Assumption Rationale Sheet
}

\section{Assumption Identifier: Key 06 I}

\author{
Subject: Performance Confirmation \\ Requirements (1996)
}

\section{STATEMENT OF ASSUMPTION}

The following set of requirements is hased on the FY 96 Performance Comfirmation Concept Study Report (CRWMS M\&O 1996e) and will be used as a basis for Mined Geologic Disposal Syslem (MGDS) Performanic Confirmation planning and design.

1. Repository design and operation shall provide facilities, access, instrumentation, recording, maintenance. and support for measuring/monitoring the performance confirmation parameters identified in Appendix D of the FY 96 Performance Confirmation Concept Study. Report_(CRWMS M\&O 1996c).

2. The performance confirmation monitoring and measuring system shall have a maintainable service life of $\mathbf{2 5}$ years ( 100 years plus the duration of initial construction plus the duration of final closure plus any lime period during site characterization for which the system must be operable). Specific equipment and components shall have maintainahle service lives dependent upon their identified function. These service lives are to be determined (TBD).

3. Planning of repository design and operations for performance confirmation test facilitice and support shall consider the performance confirmation concepts identified in Section 5 of the Performance Confirmution Concept Sticdy Report (CRWMS M\&O 1996e) as a point of departure.

4. The performanec confirmalion system shall be planned to permit availability of TBD percent.

5. Test locations/environments, samples, and specimens, onsite and offsite, shall be representative of the Repository environments and design elements.

6. Performance confirmation staff, measurement and monitoring hardware and software, shall he availabic to support the variable demand for analysis, assessment, and periodic reporting throughout the Performance Confirmation Program.

7. Surface-based borcholes shall he provided for monitoring unsalurated zone hydrology and shall avoid underground excavations.

8. At leasi one alcove shall he provided for testing and monitoring the Ghost Dance Fault prior to and following waste emplacement.

9. Monitoring of at least two percent of the thermal rock mass behavior (to be related to the number of emplacement drifts) shall be performed; a portion of the rock mass to be monitored should be near the first emplacement drifts to contain waste.

10. The Repository Subsurface Facilities shall provide underground openings (drifts, alcoves, boreholes, and ancillary excavations), access. data acquisition, and test support to implement performance confirmation monitoring and test recommendations including interface and coordination with Site Investigation Testing. Repository Testing, Waste Package Testing, and Surface Support. These operations are to include, hut are not to be limited to, capabilities for:

a. Any ground support system (i.c., shotcrete or concrete) that covers the repository subsurface opening rock wall surface shall not he installed until after necessary rock mapping is complete.

b. TBD samples of rock core shall be acquired following emplacement drift excavalion.

c. Placement and recovery of material coupons or specimens in the emplacement drift or other underground locations shall be performed at least once every 10 years.

d. Recovery of selected or malfunctioning waste packages shall be performed on a non-routine basis, as required.

e. The design. excavation. and ground support of emplacement drifts shall permit installation of and access to tes /monitoring instrumentation, and observation drift instrumentation, and provide access for remotely operated vehicles or mobile inspection platforms to obtain measurements. 


\section{Controlled Design Assumption \\ Assumption Rationale Sheet}

Assumption Identifier: EBDRD 3.7.1.2.C

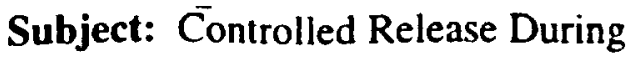

Period of Isolation

\section{STATEMENT OF ASSUMPTION}

The container shall contribute to controlling the release rate of radionuclides during the period of isolation.

\section{BACKGROUND}

Original Version

EBDRD 3.7.1.2

C. The container shall contribute (To Be Determined [TBD]) to controlling the release of radionuclides during the period of isolation.

[Derived][10 CFR 60.135(a)(1)]

Requesting Management and Operating Contractor (M\&O) organization:

( ) Surface, ( ) Subsurface, (X) Waste Package Development, ( ) Other (specify):

Need for assumption (statement of intended use):

\section{RATIONALE}

Rationale for assumption (source author, date, and report title) or statement of reasoning behind engineering judgment:

The amount of contribution to the overall performance requirement will be quantitatively defined as Viability Assessment Design (VA) progresses.

\section{RESPONSIBILITY AND WITHDRAWAL}

Responsible Management and Operating Contractor (M\&O) organization: Waste Package

Document(s) Supporting Withdrawal of Assumption:

Withdrawal Date: 


\section{STATEMENT OF ASSUMPTION}

D. The intent of this requirement is now addressed in Key Assumption 075.

\section{BACKGROUND}

Requesting Management and Operating Contractor $(\mathrm{M} \& \mathrm{O})$ organization:

( ) Surface, ( ) Subsurface, ( ) Waste Package Development, (X) Other (specify):

Systems Analysis and Modeling

\section{Qriginal Version}

EBDRD 3.7.1.2

D. The container shall be designed to limit the amount of liquid water (To Be Determined [TBD]) allowed to contact the enclosed waste form.

[Derived]

Need for assumption (statement of intended use):

Waste Package Design; Performance Assessment.

\section{RATIONALE}

Rationale for assumption (source author, date, and report title) or statement of reasoning behind engineering judgment:

Water is being required to be kept off of the waste form, as per Key Assumption 075.

\section{RESPONSIBILITY AND WITHDRAWAL}

Responsible Management and Operating Contractor (M\&O) organization: Systems Analysis and Modeling

Document(s) Supporting Withdrawal of Assumption:

Withdrawal Date: 


\section{Controlled Design Assumption \\ Assumption Rationale Sheet}

Assumption Identifier: EBDRD 3.7.1.2.E

Subject: Coñainer Information Label

\section{STATEMENT OF ASSUMPTION}

Resolution of To Be Determined (TBD) in the corresponding Engineered Barrier Design Requirements Document (EBDRD) requirement not required for Viability Assessment.

\section{BACKGROUND}

\section{Original Version}

\section{EBDRD 3.7.1.2.E INFORMATION ON LABEL}

The container shall provide a means of unique identification, which shall be a label documenting the process history of the container's contents and shall be attached to the body and lid of the container. The information on the label shall be To Be Determined (TBD).

[MGDS-RD 3.7.3.3.F][ 10 CFR 60.135(b)(4)]

Requesting Management and Operating Contractor (M\&O) organization:

( ) Surface, ( ) Subsurface, ( ) Waste Package Development, ( ) Other (specify):

Need for assumption (statement of intended use):

\section{RATIONALE}

Rationale for assumption (source author, date, and report title) or statement of reasoning behind engineering judgment:

This requirement is at a level of detail below that to be addressed during Viability Assessment.

\section{RESPONSIBILITY AND WITHDRAWAL}

Responsible Management and Operating Contractor (M\&O) organization: Waste Package

Document(s) Supporting Withdrawal of Assumption:

Withdrawal Date: 


\section{STATEMENT OF ASSUMPTION}

The waste package disposal container shall meet the following criteria:

I Mass of empty disposal container (including top lids) shall not exceed $38,000 \mathrm{~kg}$.

\section{BACKGROUND}

Original Version

EBDRD 3.7.1.2.H THE CONTAINER SHALL MEET THE FOLLOWING CRITERIA:

The maximum weight shall be To Be Determined (TBD).

Requesting Management and Operating Contractor (M\&O) organization:

(X) Surface, (X) Subsurface, (X) Waste Package Development, ( ) Other (specify):

Need for assumption (statement of intended use):

Surface and subsurface facility designs are partially based on the mass of the waste package.

\section{RATIONALE}

Rationale for assumption (source author, date, and report title) or statement of reasoning behind engineering judgment:

1 The mass represents the tare mass (container mass: barriers and lids only) of the disposal I container to dispose of the large Naval SNF canister for which bounding dimensions and mass 1 are given in Key Assumption 086. The above mass value bounds the preliminary estimation of

I the mass of the large Naval SNF canister disposal container.

\section{RESPONSIBILITY AND WITHDRAWAL}

Responsible Management and Operating Contractor (M\&O) organization: Waste Package Document(s) Supporting Withdrawal of Assumption:

Withdrawal Date: 


\section{Controlled Design Assumption \\ Assumption Rationale Sheet}

Assumption Identifier: EBDRD 3.7.1.2.H.3 Subject: Disposal Container Extemal

\section{STATEMENT OF ASSUMPTION}

I The dimensions of the disposal containers for commercial SNF, HLW, and DOE SNF are

I assumed identical to those of the waste packages and will be within the dimension ranges given in Assumption EBDRD 3.7.1.J.1.

\section{BACKGROUND}

Original Version

EBDRD 3.7.1.2.H THE CONTAINER SHALL BE DESIGNED TO MEET THE FOLLOWING CRITERIA:

3. The envelope shall be To Be Determined (TBD).

Requesting Management and Operating Contractor (M\&O) organization:

( ) Surface, ( ) Subsurface, (X) Waste Package Development, ( ) Other (specify):

Need for assumption (statement of intended use):

Surface and Subsurface facility designs are partially based on the size of the waste package. The waste package and any container used must be compatible.

\section{RATIONALE}

Rationale for assumption (source author, date, and report title) or statement of reasoning behind engineering judgment:

At this time no packing material is assumed external to the container; therefore, the container and I waste package external dimensions are the same by definition. There will, however, be minor I variations in dimensions due to temperature change and weld distortion.

\section{RESPONSIBILITY AND WITHDRAWAL}

Responsible Management and Operating Contractor $(M \& O)$ organization: Waste Package Document(s) Supporting Withdrawal of Assumption:

Withdrawal Date: 


\section{Controlled Design Assumption}

Assumption Rationale Sheet

Assumption Identifier: EBDRD 3.7.1.3.A

Subject: Criticälity Control Requirement

\section{STATEMENT OF ASSUMPTION}

Preclosure:

The internal structure shall provide separation of the waste forms such that nuclear criticality shall not be possible unless at least two unlikely, independent, and concurrent or sequential changes have occurred in the conditions essential to nuclear criticality safety.

The calculated effective multiplication factor $\left(k_{\text {eif }}\right)$ must be sufficiently below unity to show at least a five percent margin after the allowance for the bias in the method of calculation and the uncertainty in the experiments used to validate the method of calculation.

Postclosure:

The Engineered Barrier System shall be designed such that the probability and consequences of nuclear criticality provide reasonable assurances that the performance objective of 10 CFR 60.112 is met.

\section{BACKGROUND}

\section{Original Version}

EBDRD 3.7.1.3.A

The calculated effective multiplication factor $\left(k_{\text {cff }}\right)$ must be sufficiently below unity to show at least a five percent margin after allowance for the bias in the method of calculation and the calculation uncertainty in the experiments used to validate the method of calculation (To Be Determined [TBD]).

[MGDS-RD 3.2.2.6.A][10 CFR 60.131(b)(7)]]

Requesting Management and Operating Contractor (M\&O) organization:

( ) Surface, ( ) Subsurface, (X) Waste Package Development, ( ) Other (specify):

Need for assumption (statement of intended use):

\section{RATIONALE}

Rationale for assumption (source author, date, and report title) or statement of reasoning behind engineering judgment:

(NOTE: It is suggested that the EBDRD Section 3.7.1.3.A be rephrased to follow 10 CFR 60.131(h). On December 4, 1996 there was a change to 10 CFR 60; paragraph 10 CFR 60.131(b)(7) was renumbered 10 CFR 60.131(h). 


\section{Controlled Design Assumption \\ Assumption Rationale Sheet}

I The preclosure assumption is based directly on 10CFR 60.131(h). The postclosure assumption is based on wording for a new postclosure criticality regulation proposed by U.S. Department of Energy (DOE) to Nuclear Regulatory Commission (NRC). The NRC has indicated recognition that a new postclosure rule is needed.

\section{RESPONSIBILITY AND WITHDRAWAL}

Responsible Management and Operating Contractor Organization: Waste Package

Document(s) Supporting Withdrawal of Assumption:

Withdrawal Date: 

Assumption Identifier: EBDRD 3.7.1.3.D

Subject: Waste Package Internal Structure Loads

\section{STATEMENT OF ASSUMPTION}

For Viability Assessment (VA), the loads imposed on the internal structure are similar to the waste package loads.

- Static load on the waste package due to its own weight during handling and transportation.

- Withstand a drop of $2 \mathrm{~m}$.

\section{BACKGROUND}

Original Version

EBDRD 3.7.1.3.D The internal structure shall be capable of withstanding handling, emplacement, and retrieval loads.

Requesting Management and Operating Contractor (M\&O) organization:

( ) Surface, ( ) Subsurface, (X) Waste Package Development, ( ) Other (specify):

Need for assumption (statement of intended use):

\section{RATIONALE}

Rationale for assumption (source author, date, and report title) or statement of reasoning behind engineering judgment:

For Viability Assessment (VA), the internal container structure will be evaluated using the same loads as the container barriers. If different loading scenarios are generated, additional loading conditions will be developed.

\section{RESPONSIBILITY AND WITHDRAWAL}

Responsible Management and Operating Contractor (M\&O) organization: Waste Package Document(s) Supporting Withdrawal of Assumption:

Withdrawal Date: 


\section{Controlled Design Assumption}

Assumption Rationale Sheet

Assumption Identifier: EBDRD 3.7.2.B

Subjēt: Backfill Permeability

\section{STATEMENT OF ASSUMPTION}

BACKFILL PERMEABILITY (if emplacement drift backfill is used).

The requirements for backfill placed in emplacement drifts are:.

B. The backfill permeability shall not have an adverse effect on the long-term performance of the waste package.

\section{BACKGROUND}

Original Version

EBDRD 3.7.2.B BACKFILL PERMEABILITY

The requirements for backfill placed in other underground openings in the repository are addressed in the Repository Design Requirements Document.

B. The backfill shall have a permeability of To Be Determined (TBD).

Requesting Management and Operating Contractor $(\mathrm{M} \& \mathrm{O})$ organization:

( ) Surface; ( ) Subsurface, (X) Waste Package Development, ( ) Other (specify):

Need for assumption (statement of intended use):

\section{RATIONALE}

Rationale for assumption (source author, date, and report title) or statement of reasoning behind engineering judgment:

Wording consistent with wording of Section 3.7.2.A and 3.7.2.C.

\section{RESPONSIBILITY AND WITHDRA WAL}

Responsible Management and Operating Contractor (M\&O) organization: Waste Package

Document(s) Supporting Withdrawal of Assumption:

Withdrawal Date: 


\title{
Controlled Design Assumption \\ Assumption Rationale Sheet
}

\author{
Assumption Identifier: EBDRD 3.7.3 \\ Subject: Emplacement̄ Hardware Requirements
}

\section{STATEMENT OF ASSUMPTION}

The emplacement hardware is used to support and protect the emplaced waste packages. Examples of emplacement hardware are a pedestal under the waste package for the in-drift emplacement concept and a carriage and rail system for the horizontal opening concept. Emplacement hardware does not include ground support hardware, which is part of the Repository Segment. Emplacement hardware requirements will be added during Advanced Conceptual Design (ACD) and Viability Assessment (VA).

\section{BACKGROUND}

\section{Original Version}

EBDRD 3.7.3 EMPLACEMENT HARDWARE REQUIREMENTS

The emplacement hardware requirements (To Be Determined [TBD]) are for hardware used to support and protect the emplaced waste packages. Examples of emplacement hardware are a pedestal under the waste package for the in-drift emplacement concept and a carriage and rail system for the horizontal opening concept. Emplacement hardware does not include ground support hardware, which is part of the Repository Segment. Emplacement hardware requirements will be added during and after ACD.

Requesting Management and Operating Contractor (M\&O) organization:

( ) Surface, ( ) Subsurface, ( ) Waste Package Development, (X) Other (specify):

Systems Analysis and Modeling/Requirements

Need for assumption (statement of intended use):

Removal of the "TBD" from the statement does not impact waste package or subsurface design at this time. Performance requirements will have to be developed for the emplacement hardware architecture identified during ACD and VA and added to Section 3.7.3 of the Engineered Barrier Design Requirements Document (EBDRD).

\section{RATIONALE}

Rationale for assumption (source author, date, and report title) or statement of reasoning behind engineering judgment:

Performance requirements cannot be allocated to emplacement hardware until that hardware is identified during ACD and VA.

\section{RESPONSIBILITY AND WITHDRAWAL}

Responsible Management and Operating Contractor (M\&O) organization: Waste Package

Document(s) Supporting Withdrawal of Assumption:

Withdrawal Date: 
Controlled Design Assumption

Assumption Rationale Sheet

INTENTIONALLY LEFT BLANK 


\section{Controlled Design Assumption}

Assumption Rationale Sheet

\section{SECTION 5}

\section{REPOSITORY DESIGN REQUIREMENTS DOCUMENT ASSUMPTIONS (RDRD)}




\section{Controlled Design Assumption}

Assumption Rationale Sheet

INTENTIONALLY LEFT BLANK 


\section{Controlled Design Assumption \\ Assumption Rationale Sheet}

Assumption Identifier: RDRD 3.2.1.2.B

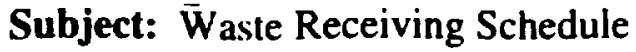

\section{STATEMENT OF ASSUMPTION}

Design of Waste Handling Operations are presently based on tables in Key Assumptions 001, 002,003 , and 053.

\section{BACKGROUND}

\section{Original Version}

RDRD 3.2.1.2

B. The repository shall be capable of receiving waste according to the schedule shown in Table 3.3 of this document.

[MGDS RD 3.2.1.3.J][CRD 3.7.4.2.G]

Requesting Management and Operating Contractor (M\&O) organization:

( ) Surface, ( ) Subsurface, ( ) Waste Package Development, (X) Other (specify):

Systems Analysis and Modeling

Need for assumption (statement of intended use):

The waste receiving schedule is necessary for sizing all elements of the Mined Geologic Disposal System (MGDS) and for establishing the average expected throughput rates.

\section{RATIONALE}

Rationale for assumption (source author, date, and report title) or statement of reasoning behind engineering judgment:

Key Assumptions 001,002 , and 003 contain the latest and most accurate data available; they are being used by Surface Design to proceed with waste handling design. Further updates are expected.

\section{RESPONSIBILITY AND WITHDRAWAL}

Responsible Management and Operating Contractor (M\&O) organization: Systems Analysis

Document(s) Supporting Withdrawal of Assumption:

Withdrawal Date: 


\section{Controlled Design Assumption \\ Assumption Rationale Sheet}

Assumption Identiffer: RDRD 3.2.1.6.C

Subject: Disposal System Postclosure

Performance (40 CFR 191)

\section{STATEMENT OF ASSUMPTION}

The corresponding Repository Design Requirements Document (RDRD) requirement is considered to be not applicable.

\section{BACKGROUND}

Qriginal Version

RDRD 3.2.1.6

C. The disposal system shall be designed to provide a reasonable expectation, based on performance assessments, that the cumulative releases of radionuclides to the accessible environment for 10,000 years after disposal from all significant processes and events that may affect the disposal system shall have a likelihood of less than one chance in 10 of exceeding the quantities calculated according to Table A-1 of Appendix A of 40 CFR 191; and have a likelihood of less than one chance in 1,000 of exceeding 10 times the quantities calculated according to Table A-1 of Appendix A of 40 CFR 191 (TBR).

[MGDS-RD 3.2.1.7.C][40 CFR 191.13(a)(TBR)]

Requesting Management and Operating Contractor $(\mathrm{M \& O})$ organization:

( ) Surface, ( ) Subsurface, ( ) Waste Package Development, (X) Other (specify): Systems Analysis and Modeling

Need for assumption (statement of intended use):

This is a basic requirement for the design of the Mined Geologic Disposal System (MGDS).

\section{RATIONALE}

Rationale for assumption (source author, date, and report title) or statement of reasoning behind engineering judgment:

Groundwater protection will adhere to interim standard stated in Key Assumption 060. 40 CFR 191 has been remanded.

\section{RESPONSIBILITY AND WITHDRAWAL}

Responsible Management and Operating Contractor (M\&O) organization: Systems Engineering Document(s) Supporting Withdrawal of Assumption:

Withdrawal Date: 
Assumption Identifier: RDRD 3.2.1.6.D

Sübject: Physical Barriers

\section{STATEMENT OF ASSUMPTION}

D. Facilities shall be provided to support active institutional controls at the repository site, including physical barriers to human intrusion. Facilities to maintain the institutional controls and physical barriers shall also be provided.

1. Little or no material tracking internal to Radiologically Controlled Area (RCA)/Protected Area.

2. A single fence perimeter is adequate for Radiologically Controlled Area (RCA)/Protected Area.

3. No International Atomic Energy Agency (IAEA) Inspection Design impact.

\section{BACKGROUND}

\section{Original Version}

\section{RDRD 3.2.1.6. PHYSICAL BARRIERS}

D. Facilities shall be provided to support active institutional controls at the repository site, including physical barriers to human intrusion and maintenance facilities (To Be Verified [TBV]).

Requesting Management and Operating Contractor (M\&O) organization:

( ) Surface, (X) Subsurface, ( ) Waste Package Development, ( ) Other (specify):

Need for assumption (statement of intended use):

The original statement is unclear; it appears to require physical barriers to maintenance facilities. Security measure levels have not been defined by a security analysis to date.

\section{RATIONALE}

Rationale for assumption (source author, date, and report title) or statement of reasoning behind engineering judgment:

The assumption sets a modest security level for waste material until a security analysis determines that a stricter system is required.

\section{RESPONSIBILITY AND WITHDRA WAL}

Responsible Management and Operating Contractor (M\&O) organization: Surface

Document(s) Supporting Withdrawal of Assumption:

Withdrawal Date: 
Assumption Identifier: RDRD 3.2.3.2.2.A.7

Subject: Emplacement Concept

\section{STATEMENT OF ASSUMPTION}

The Repository Segment shall accommodate horizontal, in-drift emplacement of waste packages.

\section{BACKGROUND}

\section{Original Version}

RDRD 3.2.3.2.2.A.7

7. The Repository Segment shall accommodate the emplacement concept (To Be Determined [TBD]) selected during Advanced Conceptual Design (ACD).

Requesting Management and Operating Contractor (M\&O) organization:

( ) Surface, (X) Subsurface, ( ) Waste Package Development, ( ) Other (specify):

Need for assumption (statement of intended use):

\section{RATIONALE}

Rationale for assumption (source author, date, and report title) or statement of reasoning behind engineering judgment:

The selection of this emplacement method is based on the Advanced Conceptual Design (ACD) efforts.

\section{RESPONSIBILITY AND WITHDRAWAL}

Responsible Management and Operating Contractor $(\mathrm{M} \& \mathrm{O})$ organization: Subsurface

Document(s) Supporting Withdrawal of Assumption:

Withdrawal Date: 


\section{Controlled Design Assumption}

Assumption Rationale Sheet Assumption Identifier: RDRD 3.2.3.2.2.A.11a Subject: Repository Design to Limit Waste
Form - Water Contact

\section{STATEMENT OF ASSUMPTION}

a) The repository shall be designed so that a combination of characteristics will support the engineered barrier system to prevent the seeping water from coming into contact with the waste form in all but 10 waste form locations for a period of at least 10,000 years.

\section{BACKGROUND}

\section{Original Version}

RDRD 3.2.3.2.2.A.11

a) The repository layout shall be designed so that a combination of characteristics will assist in keeping liquid water from contacting the waste packages for the first 300 to 1000 (to be verified) years after closure.

[Derived]

Requesting Management and Operating Contractor (M\&O) organization:

( ) Surface, ( ) Subsurface, ( ) Waste Package Development, (X) Other (specify):

Systems Analysis and Modeling

Need for assumption (statement of intended use):

The requirement is needed for general repository design and to set initial standards for postclosure performance.

\section{RATIONALE}

Rationale for assumption (source author, date, and report title) or statement of reasoning behind engineering judgment:

This interpretation is in support of Key Assumption 075.

\section{RESPONSIBILITY AND WITHDRA WAL}

Responsible Management and Operating Contractor (M\&O) organization: Systems Engineering Document(s) Supporting Withdrawal of Assumption:

Withdrawal Date: 


\section{Controlled Design Assumption \\ Assumption Rationale Sheet}

Assumption Identifier: RDRD 3.2.3.4.B

Subject: Non-Potable Water

\section{STATEMENT OF ASSUMPTION}

B. Non-potable water. The Repository Segment will connect with the exiting Nevada Test Site (NTS) water supply system.

\section{BACKGROUND}

Original Version

RDRD 3.2.3.4.B

\section{NON-POTABLE WATER (3 PARTS)}

B. Non-potable water. The Repository Segment interfaces with the To Be Determined (TBD) water supply system. The Mined Geologic Disposal System (MGDS) requires To Be Determined (TBD) gallon(s) per day at To Be Determined (TBD) psi.

Requesting Management and Operating Contractor (M\&O) organization:

(X) Surface, (X) Subsurface, ( ) Waste Package Development, ( ) Other (specify):

Need for assumption (statement of intended use):

Need to identify water system source.

\section{RATIONALE}

Rationale for assumption (source author, date, and report title) or statement of reasoning behind engineering judgment:

Use existing water supply system.

\section{RESPONSIBILITY AND WITHDRAWAL}

Responsible Management and Operating Contractor (M\&O) organization: Surface

Document(s) Supporting Withdrawal of Assumption:

Withdrawal Date: 


\section{Controlled Design Assumption \\ Assumption Rationale Sheet}

Assumption Identifier: RDRD 3.2.3.4.D

Subject: Tēephone Communications

I. STATEMENT OF ASSUMPTION

D. Telephone communications. The Repository Segment shall connect to the existing Nevada Test Site (NTS) telephone system.

\section{BACKGROUND}

Original Version

RDRD 3.2.3.4.D

D. Telephone communications. The Repository Segment interfaces with the NTS switched telephone system at To Be Determined (TBD). The Mined Geologic Disposal System (MGDS) requires:

1. TBD Federal Telecommunication System (FTS) lines with TBD quality.

2. TBD commercial long distance lines with TBD quality.

3. TBD lines to the local NTS exchange with TBD quality.

4. TBD private lines.

Requesting Management and Operating Contractor (M\&O) organization:

( ) Surface, ( ) Subsurface, ( ) Waste Package Development, (X) Other (specify):

Systems Analysis and Modeling

Need for assumption (statement of intended use):

The requirement as stated in the Repository Design Requirements Document (RDRD) assumes a level of detail that far exceeds what is needed for Viability Assessment (VA). It also ignores existing agreements between Yucca Mountain Site Characterization Office (YMSCO) and NTS with regards to communications.

\section{RATIONALE}

Rationale for assumption (source author, date, and report title) or statement of reasoning behind engineering judgment:

U.S. Department of Energy (DOE) NTS Standard Operating Procedure Chapter 5301, Telecommunications, defines the responsibilities and interfaces for all aspects of telecommunications at the NTS. Repository Design Requirements Document (RDRD) Requirement 3.2.3.4.D is consistent with current policy. See the following:

YMP-FOI-5301, Field Telecommunications

NTS-SOP-5301, Telecommunications

NTS-SOP-5302, Telecommunications--Radio Utilization Program

\section{RESPONSIBILITY AND WITHDRAWAL}

Responsible Management and Operating Contractor (M\&O) organization: Surface

Document(s) Supporting Withdrawal of Assumption:

Withdrawal Date: 


\section{Controlled Design Assumption \\ Assumption Rationale Sheet}

Assumption Identifier: RDRD 3.7.1.C

Subject: Speciā Sources of Groundwater

\section{STATEMENT OF ASSUMPTION}

The corresponding Repository Design Requirements Document (RDRD) requirement is considered to be not applicable.

\section{BACKGROUND}

Original Version

\section{RDRD 3.7.1 GROUNDWATER}

C. Groundwater. If any of the average annual radionuclide concentrations existing in a special source of groundwater (if one exists) before construction of the disposal system already exceed the limits in 40 CFR 191.16(a), the disposal system shall be designed to provide a reasonable expectation that, for 1,000 years after disposal, undisturbed performance of the disposal system shall not increase the existing average annual radionuclide concentrations in water withdrawn from the special source of groundwater by more than the limits established in 40 CFR 191.16(a) (TBR).

[MGDS-RD 3.7.2.2.C][40 CFR 191.16(b) (TBR)]

Requesting Management and Operating Contractor (M\&O) organization:

(X) Surface, ( ) Subsurface, ( ) Waste Package Development, ( ) Other (specify):

Need for assumption (statement of intended use):

\section{RATIONALE}

Rationale for assumption (source author, date, and report title) or statement of reasoning behind engineering judgment:

Groundwater protection will adhere to interim standards stated in Key Assumption 060.

There are no special sources of groundwater at Yucca Mountain, as defined in 40 CFR 191.12(0); therefore, the requirements of 40 CFR 191.16 do not impact Yucca Mountain. In addition, 40 CFR 191 has been remanded.

\section{RESPONSIBILITY AND WITHDRAWAL}

Responsible Management and Operating Contractor $(\mathrm{M} \& \mathrm{O})$ organization:

Systems Engineering /Site Investigation

Document(s) Supporting Withdrawal of Assumption:

Withdrawal Date: 


\section{Controlled Design Assumption \\ Assumption Rationale Sheet}

Assumption Identifier: RDRD 3.7.3.5.A.1

Subject: Genēral Underground Lighting

\section{STATEMENT OF ASSUMPTION}

General lighting for underground shall meet OSHA and MSHA codes.

\section{BACKGROUND}

RDRD 3.7.3.5.A

\section{UNDERGROUND GENERAL LIGHTING}

1. General lighting for underground shall be at least To Be Determined ft-candles in the mains.

Requesting Management and Operating Contractor (M\&O) organization:

( ) Surface, ( ) Subsurface, ( ) Waste Package Development, (X) Other (specify):

Systems Analysis and Modeling

Need for assumption (statement of intended use):

Viability Assessment (VA) design to address adequate lighting for underground workings.

\section{RATIONALE}

Rationale for assumption (source author, date, and report title) or statement of reasoning behind engineering judgment:

Setting numerical limits for underground lighting should not be in the Repository Design Requirements Document (RDRD). Those limits are established in the building codes that govem underground construction, as well as MSHA and OSHA requirements.

\section{RESPONSIBILITY AND WITHDRA WAL}

Responsible Management and Operating Contractor (M\&O) organization: Subsurface

Document(s) Supporting Withdrawal of Assumption:

Withdrawal Date: 


\section{Controlled Design Assumption \\ Assumption Rationale Sheet}

Assumption Identifier: RDRD 3.7.3.5.A.2 Subject: Underground Service Facilities Lighting

\section{STATEMENT OF ASSUMPTION}

General lighting for underground service facilities not related to waste handling or security shall meet OSHA and MSHA codes.

\section{BACKGROUND}

\section{Original Version}

\section{RDRD 3.7.3.5.A UNDERGROUND GENERAL LIGHTING}

2. In the service facilities not related to waste handling or security, lighting shall be at least To Be Determined ft-candles.

[Derived]

Requesting Management and Operating Contractor (M\&O) organization:

( ) Surface, ( ) Subsurface, ( ) Waste Package Development, (X) Other (specify):

Systems Analysis and Modeling

Need for assumption (statement of intended use):

Advanced Conceptual Design (ACD) to design adequate lighting for underground workings.

\section{RATIONALE}

Rationale for assumption (source author, date, and report title) or statement of reasoning behind engineering judgment:

Setting numerical limits for underground lighting should not be in the Repository Design Requirements Document (RDRD). Those limits are established in the building codes that govern underground construction, as well as MSHA and OSHA requirements.

\section{RESPONSIBILITY AND WITHDRAWAL}

Responsible Management and Operating Contractor (M\&O) organization: Subsurface

Document(s) Supporting Withdrawal of Assumption:

Withdrawal Date: 


\title{
Controlled Design Assumption \\ Assumption Rationale Sheet
}

\author{
Assumption Identifier: RDRD 3.7.3.9.E \\ Subject: Site-Gēnerated Hazardous Waste
}

\section{STATEMENT OF ASSUMPTION}

E. Hazardous waste will be collected and packaged onsite for transport to an offsite Resource Conservation and Recovery Act of 1976 (RCRA) approved treatment, storage. and disposal facility.

\section{BACKGROUND}

Requesting Management and Operating Contractor (M\&O) organization:

(X) Surface. ( ) Subsurface, ( ) Waste Package Development, ( ) Other (specify):

Original Version:

RDRD 3.7.3.9 SITE-GENERATED WASTE TREATMENT

E. Nonradioactive hazardous waste disposal facilities shall have sufficient capacity to process the quantities of hazardous waste anticipated throughout the operation of the repository (To Be Determined [TBD]). Nonradioactive hazardous waste disposal facilities shall comply with U.S. Department of Energy (DOE) Orders 5480.3 and 5480.4 .

[Derived][DOE Order 5480.3; 5480.4]

Need for assumption (statement of intended use):

\section{RATIONALE}

Rationale for assumption (source author, date, and report title) or statement of reasoning behind engineering judgment:

This assumption is needed to document the requirement to provide compliance with appropriate U.S. Department of Energy (DOE) requirements involving the handling of nonradioactive hazardous wastes. The quantities of this waste will be determined during the course of the Viability Assessment (VA). See related Key Assumption 024.

\section{RESPONSIBILITY AND WITHDRAWAL}

Responsible Management and Operating Contractor (M\&O) organization: Surface

Document(s) Supporting Withdrawal of Assumption:

Withdrawal Date: 


\section{Controlled Design Assumption \\ Assumption Rationale Sheet}

Assumption Identifier: RDRD 3.7.4.1.A.2 Subject: Storage Capacity for Waste Receipts

\section{STATEMENT OF ASSUMPTION}

The corresponding Repository Design Requirements Document (RDRD) requirement is considered to be not applicable.

\section{BACKGROUND}

\section{Original Version}

\section{RDRD 3.7.4.I.A STORAGE CAPACITY FOR WASTE RECEIPTS}

2. Waste handling facilities shall provide a temporary storage capacity equivalent to To $\mathrm{Be}$ Determined (TBD) waste receipts.

Requesting Management and Operating Contractor (M\&O) organization:

(X) Surface, (X) Subsurface, ( ) Waste Package Development, ( ) Other (specify):

Need for assumption (statement of intended use):

\section{RATIONALE}

Rationale for assumption (source author, date, and report title) or statement of reasoning behind engineering judgment:

Requirement for surface facility holding or buffer areas will determine the capacity of waste handling facility or other facility storage requirements. No need for requirement.

See Rationale for Assumption RDRD 3.7.4.1.A.3

\section{RESPONSIBILITY AND WITHDRAWAL}

Responsible Management and Operating Contractor (M\&O) organization: Surface

Document(s) Supporting Withdrawal of Assumption:

Withdrawal Date: 


\title{
Controlled Design Assumption \\ Assumption Rationale Sheet
}

\author{
Assumption Identifier: RDRD 3.7.4.1.A.3 \\ Subject: Waste Handling Holding Areas
}

\section{STATEMENT OF ASSUMPTION}

3. Waste handling facilities shall have buffer or holding areas at certain steps spread out within these operations. These areas will have sufficient capacity that in the event of an unplanned stoppage, operations may be completed to a reasonable safety shut down condition. This includes the receipt of in-transit casks, emptying casks, filling and sealing disposal containers, and decontaminating and emptying cask dispatch.

[10CFR60.132(a)] [Derived.]

\section{BACKGROUND}

\section{Original Version}

RDRD 3.7.4.I WASTE HANDLING REQUIREMENTS

A. Waste Handling

3. Storage facilities shall have the capability to store the waste as received from offsite, as well as the prepared waste packages onsite (To Be Determined [TBD]).

[Derived]

Requesting Management and Operating Contractor $(\mathrm{M} \& \mathrm{O})$ organization:

(X) Surface, (X) Subsurface, ( ) Waste Package Development, ( ) Other (specify):

Need for assumption (statement of intended use):

The need is to ensure safe completion of operations.

\section{RATIONALE}

Rationale for assumption (source author, date, and report title) or statement of reasoning behind engineering judgment:

The term "storage" has many connotations on this project. Capacity to receive unlimited offsite waste has significant design impact, which cannot be necessarily met at this time. Until other criteria is established to limit this capacity, this assumption defines the limit as that waste which is in processing or in transit to reduce the need to reverse an operation as a result of a stoppage anywhere in the Mined Geologic Disposal System (MGDS):

- "Buffer" capacity is needed to provide "surge" in the process activities and to maintain steady process flow in the overall system. Because the Nuclear Waste Policy Act (NWPA) does not permit extensive, longterm interim storage at the repository, this assumption interprets any reference to storage in surface facilities as a short-term holding area for steady process flow and for safe, unplanned stoppages. These holding areas are not to be used for waste form or waste package aging, or for storage of retrieved waste packages. Holding area capacities will be determined by design process flow simulations.

\section{RESPONSIBILITY AND WITHDRAWAL}

Responsible Management and Operating Contractor (M\&O) organization: Surface

Document(s) Supporting Withdrawal of Assumption:

Withdrawal Date: 


\section{Controlled Design Assumption \\ Assumption Rationale Sheet}

Assumption Identifier: RDRD 3.7.5.A.5 Subject: Men-and-Materials Shaft Hoist Limits

I. STATEMENT OF ASSUMPTION

The corresponding Repository Design Requirements Document (RDRD) requirement is considered to be not applicable.

\section{BACKGROUND}

\section{Original Version}

\section{RDRD 3.7.5.A SIZE AND WEIGHT OF HOISTING SYSTEM}

5. The size and weight limits of the hoisting system in the men-and-materials (To Be Verified [TBV]) shaft for materials handling shall be To Be Determined (TBD).

Requesting Management and Operating Contractor (M\&O) organization:

( ) Surface, (X) Subsurface, ( ) Waste Package Development, ( ) Other (specify):

Need for assumption (statement of intended use):

\section{RATIONALE}

Rationale for assumption (source author, date, and report title) or statement of reasoning behind engineering judgment:

At the very least, the requirement is mislocated. 3.7.5.A deals with requirements for shaft conveyances handling radioactive waste. No radioactive waste will, or should, be handled in a men-and-materials shaft. Even if the requirement were in a more suitable location, the limits referred to are design and function dependent. Such detail does not belong as a requirement at the Repository Design Requirements Document (RDRD) level.

\section{RESPONSIBILITY AND WITHDRA WAL}

Responsible Management and Operating Contractor (M\&O) organization: Subsurface

Document(s) Supporting Withdrawal of Assumption:

Withdrawal Date: 


\section{Controlled Design Assumption Assumption Rationale Sheet}

Assumption Identifier: RDRD 3.7.5.B.6

Subject:- Underground Air Supply

\section{STATEMENT OF ASSUMPTION}

Supply and exhaust adequate quantities of air to and from underground working areas such that operator safety, health, and productivity requirements are maintained.

\section{BACKGROUND}

\section{Original Version}

RDRD 3.7.5.B

6. Supply and exhaust adequate quantities of air (To Be Determined [TBD]) to and from underground working areas such that operator safety, health and productivity requirements are maintained. [Derived]

Requesting Management and Operating Contractor (M\&O) organization:

( ) Surface, (X) Subsurface, ( ) Waste Package Development, ( ) Other (specify):

Need for assumption (statement of intended use):

Affects ventilation design.

\section{RATIONALE}

Rationale for assumption (source author, date, and report title) or statement of reasoning behind engineering judgment:

The requirement as stated is valid without the To Be Determined (TBD). The air quantity is architecture and operations dependent and does not belong in the Repository Design Requirements Document (RDRD).

\section{RESPONSIBILITY AND WITHDRA WAL}

Responsible Management and Operating Contractor (M\&O) organization: Subsurface

Document(s) Supporting Withdrawal of Assumption:

Withdrawal Date: 


\section{Controlled Design Assumption \\ Assumption Rationale Sheet}

Assumption Identifier: RDRD 3.7.5.N.1

Subject: Waste Ramp Air Flow

\section{STATEMENT OF ASSUMPTION}

The corresponding Repository Design Requirements Document (RDRD) requirement is considered to be not applicable.

\section{BACKGROUND}

\section{Original Version}

RDRD 3.7.5.N SHAFT AIRFLOW

1. The waste ramp shall permit flow of intake ventilation air for the emplacement area, which, when combined with the airflow in the shafts, is adequate for emplacement operations (To Be Verified [TBV]).

Requesting Management and Operating Contractor (M\&O) organization:

( ) Surface, (X) Subsurface, ( )Waste Package Development, ( ) Other (specify):

Need for assumption (statement of intended use):

Sets requirements for shaft, ramp, and ventilation design.

\section{RATIONALE}

Rationale for assumption (source author, date, and report title) or statement of reasoning behind engineering judgment:

Remove Design Specific requirement that presupposes the routes for providing ventilation air. Assumes there will be shafts and they will be used for air intake. Assumes the waste ramp will be used to supply air to the emplacement areas. This is inappropriate.

\section{RESPONSIBILITY AND WITHDRAWAL}

Responsible Management and Operating Contractor $(\mathrm{M} \& \mathrm{O})$ organization: Subsurface

Document(s) Supporting Withdrawal of Assumption:

Withdrawal Date: 


\section{Controlled Design Assumption}

Assumption Rationale Sheet

Assumption Identifier: RDRD 3.7.5.N.2

Subject: Tuff Ramp Air Flow

\section{STATEMENT OF ASSUMPTION}

The corresponding Repository Design Requirements Document (RDRD) requirement is considered to be not applicable.

\section{BACKGROUND}

\section{Original Version}

\section{RDRD 3.7.5.N TUFF RAMP AIRFLOW}

2. The tuff ramp shall permit flow of ventilation airflow capacity adequate to meet the return air requirements of the development area during the construction and operation periods (To Be Verified [TBV]).

Requesting Management and Operating Contractor (M\&O) organization:

( ) Surface, (X) Subsurface, ( ) Waste Package Development, ( ) Other (specify):

Need for assumption (statement of intended use):

Affects architecture.

\section{RATIONALE}

Rationale for assumption (source author, date, and report title) or statement of reasoning behind engineering judgment:

It is architecture and function dependent.

\section{RESPONSIBILITY AND WITHDRAWAL}

Responsible Management and Operating Contractor (M\&O) organization: Subsurface

Document(s) Supporting Withdrawal of Assumption:

Withdrawal Date: 


\section{STATEMENT OF ASSUMPTION}

If shafts are used, the shaft size shall be determined by the size of the conveyances needed to move materials, personnel, and equipment underground; the volume of ventilation flow needed; and the space required for utility lines.

\section{BACKGROUND}

\section{Original Version}

\section{RDRD 3.7.5.N SHAFTS (SIZE REQUIREMENTS)}

5. If shafts are used, the shaft size shall be determined by the size of the conveyances needed to move materials, personnel, and equipment underground; the volume of ventilation flow needed; and the space required for utility lines (To Be Determined [TBD]).

Requesting Management and Operating Contractor (M\&O) organization:

( ) Surface, (X) Subsurface, ( ) Waste Package Development, ( ) Other (specify):

Need for assumption (statement of intended use):

Affects shaft design.

\section{RATIONALE}

Rationale for assumption (source author, date, and report title) or statement of reasoning behind engineering judgment:

The requirement as stated is valid without the To Be Determined (TBD). The requirement gives the criteria for determining the shaft size; it need not also give the shaft size or the areas required for the items used to determine the shaft size. These will be determined during design and are architecture and operations dependent.

\section{RESPONSIBILITY AND WITHDRAWAL}

Responsible Management and Operating Contractor (M\&O) organization: Subsurface Document(s) Supporting Withdrawal of Assumption:

Withdrawal Date: 


\title{
Controlled Design Assumption \\ Assumption Rationale Sheet
}

\author{
Assumption Identifier: RDRD 3.7.5.0.2 \\ Subject: Men-añd-Materials Shaft Usage
}

\section{STATEMENT OF ASSUMPTION}

The corresponding Repository Design Requirements Document (RDRD) requirement is considered to be not applicable.

\section{BACKGROUND}

\section{Original Version}

\section{RDRD 3.7.5.O MEN-AND-MATERIALS SHAFT}

2. The service main shall be adequate to handle the transport of development personnel, supplies, utility lines, and machinery to the men-and-materials shaft (To Be Verified [TBV]), to the service facilities for the development area, and to the development area.

Requesting Management and Operating Contractor $(\mathrm{M} \& \mathrm{O})$ organization:

( ) Surface, (X) Subsurface, ( ) Waste Package Development, ( ) Other (specify):

Need for assumption (statement of intended use):

Affects repository architecture.

\section{RATIONALE}

Rationale for assumption (source author, date, and report title) or statement of reasoning behind engineering judgment:

Requirement assumes there will be a men-and-materials shaft and a service main. Both of these are architecture-dependent and should not be specified in the Repository Design Requirements Document (RDRD).

\section{RESPONSIBILITY AND WITHDRA WAL}

Responsible Management and Operating Contractor (M\&O) organization: Subsurface

Document(s) Supporting Withdrawal of Assumption:

Withdrawal Date: 

Controlled Design Assumption

Assumption Rationale Sheet

\section{SECTION 6}

DESIGN CONCEPT SURFACE ASSUMPTIONS (DCS) 


\section{Controlled Design Assumption Assumption Rationale Sheet}

INTENTIONALLY LEFT BLANK 


\section{Controlled Design Assumption \\ Assumption Rationale Sheet}

Assumption Identifier: DCS 00I

Subject: M̄GDS Operational Center

\section{STATEMENT OF ASSUMPTION}

A future Mined Geologic Disposal System (MGDS) operational center will be required to maintain communications with the transportation network, maintain inventories, and support security and safeguards requirements. This center will be located at the repository.

\section{BACKGROUND}

Requesting Management and Operating Contractor (M\&O) organization:

(X) Surface, ( ) Subsurface, ( ) Waste Package Development, ( ) Other (specify):

Need for assumption (statement of intended use):

General functions and location are assumed to assign budgeting criteria.

\section{RATIONALE}

Rationale for assumption (source author, date, and report title) or statement of reasoning behind engineering judgment:

Probable functional requirements to be established by Trans-RD:

This center could maintain communications with all casks in transit and will maintain constant records of the spent nuclear fuel (SNF) being transported to the MGDS. All spent nuclear fuel (SNF) in lag storage or being handled will be tracked throughout the MGDS. Records that identify the emplacement location of each and every fuel assembly will be maintained in this facility. Incoming and outgoing casks will be tracked and their status monitored. This facility could act as the Geologic Repository Operations Area (GROA) center for emergency control.

This facility could maintain the necessary records to maintain conformance to all safeguards and security requirements.

\section{RESPONSIBILITY AND WITHDRA WAL}

Responsible Management and Operating Contractor (M\&O) organization: Systems Engineering Document(s) Supporting Withdrawal of Assumption:

Withdrawal Date: 


\section{Controlled Design Assumption \\ Assumption Rationale Sheet}

Assumption Identifier: DCS 003

Subject: Occupational Exposure Limits

\section{STATEMENT OF ASSUMPTION}

The Surface Facilities that house radioactive materials or in which work is performed on radioactive materials will be designed to control occupational exposures to as low as reasonably achievable (ALARA) and less than 500 millirem per year.

\section{BACKGROUND}

Requesting Management and Operating Contractor $(\mathrm{M} \& \mathrm{O})$ organization:

(X) Surface, ( ) Subsurface, ( ) Waste Package Development, ( ) Other (specify):

Need for assumption (statement of intended use):

This assumption provides the allowable exposure allowed for occupational dose and is the basis for calculations involving radiological safety.

\section{RATIONALE}

Rationale for assumption (source author, date, and report title) or statement of reasoning behind engineering judgment:

The assumptions in conformance to the U.S. Department of Energy (DOE) Radiological Control Manual, the Nevada (NV)/Yucca Mountain Site Characterization Project (YMP) Radiological Control Manual, and 10 CFR 20.

\section{RESPONSIBILITY AND WITHDRAWAL}

Responsible Management and Operating Contractor (M\&O) organization: Surface

Document(s) Supporting Withdrawal of Assumption:

Withdrawal Date: 


\section{Controlled Design Assumption \\ Assumption Rationale Sheet}

Assumption Identifier: DCS 004

Subject: ALARA Studies

\section{STATEMENT OF ASSUMPTION}

As low as reasonably achievable (ALARA) studies will be conducted as needed to establish the allowable dose rates upon which various radiological safety calculations will be based.

\section{BACKGROUND}

Requesting Management and Operating Contractor $(\mathrm{M} \& \mathrm{O})$ organization:

(X) Surface, ( ) Subsurface, ( ) Waste Package Development, ( ) Other (specify):

Need for assumption (statement of intended use):

ALARA is a requirement that is established to ensure that radiological safety is adhered to in the design and operation of nuclear facilities.

\section{RATIONALE}

Rationale for assumption (source author, date, and report title) or statement of reasoning behind engineering judgment:

ALARA is required in the U.S. Department of Energy (DOE) Radiological Control Manual, the Nevada (NV)/Yucca Mountain Site Characterization Project (YMP) Radiological Control Manual, and 10 CFR 20.

\section{RESPONSIBILITY AND WITHDRA WAL}

Responsible Management and Operating Contractor (M\&O) organization: Surface

Document(s) Supporting Withdrawal of Assumption:

Withdrawal Date: 
Controlled Design Assumption

Assumption Rationale Sheet 


\section{Controlled Design Assumption \\ Assumption Rationale Sheet}

Assumption Identifier: DCS 008

Subject: Decontamination Equipment and Space

\section{STATEMENT OF ASSUMPTION}

Necessary equipment and space required for decontamination will be provided in each building where contamination will be present.

\section{BACKGROUND}

Requesting Management and Operating Contractor (M\&O) organization:

(X) Surface, ( ) Subsurface, ( ) Waste Package Development, ( ) Other (specify):

Need for assumption (statement of intended use):

\section{RATIONALE}

Rationale for assumption (source author, date, and report title) or statement of reasoning behind engineering judgment:

To prevent the spread of contamination that would occur by having to transport all contaminated items to a central decontamination facility, provisions will be provided to perform these activities as near to the source of contamination as possible and to "promote waste minimization." The Decontamination Facility cited in the Site Characterization Plan (SCP)/Conceptual Design Report (CDR) will not be used. This assumption substitutes the necessary equipment and space needed for decontamination.

\section{RESPONSIBILITY AND WITHDRAWAL}

Responsible Management and Operating Contractor (M\&O) organization: Surface

Document(s) Supporting Withdrawal of Assumption:

Withdrawal Date: 


\section{Controlled Design Assumption}

Assumption Rationale Sheet 


\section{Controlled Design Assumption \\ Assumption Rationale Sheet}

Assumption Identifier: DCS 011

Subject: Underground Waste Generation

\section{STATEMENT OF ASSUMPTION}

Significant quantities of secondary mixed or low-level radioactive wastes will not be generated by underground emplacement operations.

\section{BACKGROUND}

Requesting Management and Operating Contractor (M\&O) organization:

(X) Surface, ( ) Subsurface, ( ) Waste Package Development, ( ) Other (specify):

DCS 007 indicates that the Waste Treatment Building (WTB) will be located at the Geologic Repository Operations Area (GROA) to handle onsite generated low-level waste. DCS 010 assumes nonradioactive waste will not be sent to the WTB.

Need for assumption (statement of intended use):

An underground radiologically controlled area (RCA) waste assumption is needed to design the WTB and waste treatment processes.

\section{RATIONALE}

Rationale for assumption (source author, date, and report title) or statement of reasoning behind engineering judgment:

The emplacement area of the underground is assumed to be within the radiologically controlled area (RCA) but is not expected to be manned. Significant secondary mixed or low-level waste materials should not be generated. Underground hazardous wastes will not be sent to the WTB, as defined in DCS 010.

\section{RESPONSIBILITY AND WITHDRA WAL}

Responsible Management and Operating Contractor (M\&O) organization: Subsurface

Document(s) Supporting Withdrawal of Assumption:

Withdrawal Date: 


\section{Controlled Design Assumption \\ Assumption Rationale Sheet}

Assumption Identifier: DCS 012

Subject: No HLW in $\overline{\text { Waste }}$ Treatment Building

\section{STATEMENT OF ASSUMPTION}

The Waste Treatment Building (WTB) will not process secondary transuranic or high-level waste (HLW). If such waste materials are generated, they will be packaged at the point of generation and disposed in the underground emplacement area via the Waste Handling Building (WHB).

\section{BACKGROUND}

Requesting Management and Operating Contractor $(\mathrm{M} \& \mathrm{O})$ organization:

(X) Surface, ( ) Subsurface, ( ) Waste Package Development, ( ) Other (specify):

Need for assumption (statement of intended use):

Current controlled assumptions do not address secondary transuranic or HLW disposition. This assumption is needed to design the WTB, any other surface facilities that could generate these materials, and the underground facilities. Impact on the underground design is expected to be negligible.

\section{RATIONALE}

Rationale for assumption (source author, date, and report title) or statement of reasoning behind engineering judgment:

The facilities that could generate HLW, such as the Cask Maintenance Facility (CMF) or Waste Handling Building (WHB), are designed for HLW operations (e.g., underwater or in hot cells) and could better accommodate handling secondary HLW packaging. The WTB will be designed primarily for contact operations involving low-level radioactive waste (LLRW) materials.

\section{RESPONSIBILITY AND WITHDRAWAL}

Responsible Management and Operating Contractor (M\&O) organization: Surface

Document(s) Supporting Withdrawal of Assumption:

Withdrawal Date: 


\section{Controlled Design Assumption \\ Assumption Rationale Sheet}

Assumption Identifier: DCS 013

Subject: Waste Generated by Performance Confirmation Activities

\section{STATEMENT OF ASSUMPTION}

Waste quantities generated by the performance confirmation operations will be negligible.

As a result, wastes generated by the performance confirmation operations will not impact the design of the Waste Treatment Building (WTB).

\section{BACKGROUND}

Requesting Management and Operating Contractor $(\mathrm{M \& O})$ organization:

(X) Surface, ( ) Subsurface, ( ) Waste Package Development, ( ) Other (specify):

Need for assumption (statement of intended use):

It is necessary to assume the impact of the unspecified mission of the performance confirmation operations on the design of the Waste Treatment Building (WTB) and the waste treatment processes.

\section{RATIONALE}

Rationale for assumption (source author, date, and report title) or statement of reasoning behind engineering judgment:

Assumption is based on the 1996 Management and Operating Contractor (M\&O) Performance Confirmation Concept Study (B00000000-01717-5705-00035). Destructive testing on waste packages will be conducted only if these are recovered on a contingency basis.

\section{RESPONSIBILITY AND WITHDRAWAL}

Responsible Management and Operating Contractor $(M \& O)$ organization: Surface

Document(s) Supporting Withdrawal of Assumption:

Withdrawal Date: 


\section{Controlled Design Assumption \\ Assumption Rationale Sheet}




\section{Controlled Design Assumption}

Assumption Rationale Sheet

Assumption DCS 015 has been withdrawn - 
Controlled Design Assumption

Assumption Rationale Sheet 


\section{Controlled Design Assumption}

Assumption Rationale Sheet

\section{Assumption DCS 017 has been withdrawn}


Controlled Design Assumption

Assumption Rationale Sheet

Assumption DCS 018 has been withdrawn

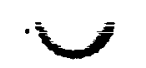




\section{Controlled Design Assumption}

Assumption Rationale Sheet

Assumption Identifier: DCS 019

Subject: ${ }^{-}$Support Facilities Design

\section{STATEMENT OF ASSUMPTION}

Support Facilities comprise those described in the Site Characterization Project Conceptual Design Report (SCP-CDR) and will not be addressed within Viability Assessment (VA) design efforts.

\section{BACKGROUND}

Requesting Management and Operating Contractor (M\&O) organization:

(X) Surface, ( ) Subsurface, ( ) Waste Package Development, or ( ) Other (specify):

Need for assumption (statement of intended use):

Focus of VA design effort.

\section{RATIONALE}

Rationale for assumption (source author, date, and report title) or statement of reasoning behind engineering judgment:

Support facilities design is assumed to follow standard practice.

IV. RESPONSIBILITY AND WITHDRAWAL

Responsible Management and Operating Contractor $(M \& O)$ organization: Surface

Document(s) Supporting Withdrawal of Assumption:

Withdrawal Date: 


\section{Controlled Design Assumption \\ Assumption Rationale Sheet}

Assumption Identifier: DCS 020

Subject:- WHB Wet/Dry Handling

\section{STATEMENT OF ASSUMPTION}

The Waste Handling Building (WHB) will use a wet waste handling concept using fuel pools for opening casks and dual-purpose canisters (DPCs) and removing and staging the SNF assemblies. Other operations, including the loading of SNF assemblies into disposal containers and all handling of disposal canisters for HLW, DOE SNF and commercial SNF, will be performed in dry hot cells.

\section{BACKGROUND}

Requesting Management and Operating Contractor (M\&O) organization:

(X) Surface, ( ) Subsurface, ( ) Waste Package Development, ( ) Other (specify):

Need for assumption (statement of intended use):

Clarification that the WHB will use fuel pools for selected applications and dry hot cells for other applications. This concept, as summarized above in the Statement of Assumption, is described as the "Wet Waste Handling System" and presented as the recommended concept in the Waste Handling Systems Configuration Analysis (CRWMS M\&O 1997b). The assumption is included to establish a program position for the concept as recommended in this approved analysis.

\section{RATIONALE}

Rationale for assumption (source author, date, and report title) or statement of reasoning behind engineering judgement:

The current Waste Form Scenario includes predominantly uncanistered waste and waste packaged in non-reusable DPCs, distinctly different from the Multi-Purpose Canister (disposable canister) that was a basis for the Advanced Conceptual Design. The Waste Handling Systems Configuration Analysis included a material handling simulation and decisions analysis to compare wet and dry design alternatives for the uncanistered waste form scenarios, and recommended a wet waste handling system concept based on optimum performance effectiveness.

The wet waste handling system concept is selected based on the throughput required to handle a significant increase in spent fuel assemblies at the Repository, and it utilizes proven methods and equipment for handling spent fuel assemblies in a pool environment for similar applications. In addition, there are advantages of reduced occupational exposure during maintenance and recovery operations, and reduced life cycle cost.

\section{RESPONSIBILITY/SUBSTANTIATION/WITHDRAWAL}

Responsible Management and Operating Contractor (M\&O) organization: Surface Design

Document(s) Supporting Withdrawal of Assumption:

Withdrawal Date: 


\section{STATEMENT OF ASSUMPTION}

The Waste Handling Building will include the flexibility to receive, handle, and unload a variety of shipping casks and canisters. Special tooling (yokes, grapples, fixtures, etc.) will be required to handle these waste form configurations as defined in Key Assumptions 001, 002, and 003.

The maximum number of types that will be received at the repository are as follows:

* Shipping Casks (15 types)

* Spent Fuel Assemblies (12 types)

* Disposal Containers (6 types)

* Disposable Canisters ( 3 types)

\section{BACKGROUND}

Requeșting Management and Operating Contractor (M\&O) organization:

(X) Surface, ( ) Subsurface, ( ) Waste Package Development, or ( ) Other (specify):

Need for assumption (statement of intended use):

Scoping of the waste handling design and sizing of storage spaces.

\section{RATIONALE}

Rationale for assumption (source author, date, and report title) or statement of reasoning behind engineering judgment:

The number of types were estimated by the Surface Design based on the variety of waste form configurations that are expected.

\section{RESPONSIBILITY AND WITHDRAWAL}

Responsible Management and Operating Contractor $(M \& O)$ organization: Surface

Document(s) Supporting Withdrawal of Assumption:

Withdrawal Date: 
Controlled Design Assumption

Assumption Rationale Sheet

INTENTIONALLY LEFT BLANK 
Controlled Design Assumption

Assumption Rationale Sheet

SECTION 7

DESIGN CONCEPT SUBSURFACE ASSUMPTIONS (DCSS) 
Controlled Design Assumption

Assumption Rationale Sheet

INTENTIONALLY LEFT BLANK

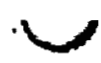




\section{Controlled Design Assumption \\ Assumption Rationale Sheet}

Assumption Identifier: DCSS 001

Subject: Drift Orientation

\section{STATEMENT OF ASSUMPTION}

Preferred drift orientation:

- Orientation of emplacement drifts will be at least 30 degrees from dominant joint orientations. Using the latest information on joint orientations, the emplacement drift orientation will generally fall between N70W and S75W.

- Orientation of maintainable access drifts, mains, ramps, etc. will be as needed to complement emplacement drift orientation, generally forming intersections of 70-90 degrees where practicable.

Contingency drift orientation:

Contingency layouts not meeting the preferred orientations are required in case substantiation of TDSS-017 indicates the joint orientations assumed are incorrect.

\section{BACKGROUND}

Requesting Management and Operating Contractor (M\&O) organization:

( ) Surface, (X) Subsurface, ( ) Waste Package Development, ( ) Other (specify):

Need for assumption (statement of intended use):

Geometric guidance for repository layouts.

\section{RATIONALE}

Rationale for assumption (source author, date, and report title) or statement of reasoning behind engineering judgment:

Engineering judgment in order to maximize stability of emplacement drifts and accept less than maximum stability in other excavations. This is based on a philosophy or desire to eliminate having to enter emplacement drifts, where heat and radiation pose formidable problems, to perform maintenance on a regular basis. Lesser stability is acceptable in other excavations because maintenance on a regular basis does not have to overcome formidable problems. The 30 degrees needs no substantiation. The actual emplacement drift orientations will depend on the dominant joint orientations as confirmed during site characterization. There is a need (10CFR60.21(c)(ii)(D)) to study alternatives and to be prepared with contingency layouts if the joint orientation changes from that assumed.

\section{RESPONSIBILITY AND WITHDRAWAL}

Responsible Management and Operating Contractor (M\&O) organization: Subsurface Document(s) Supporting Withdrawal of Assumption:

Withdrawal Date: 


\section{Controlled Design Assumption \\ Assumption Rationale Sheet}

Assumption Identifier: DCSS 005

Subject: Drift Excavation Methods

\section{STATEMENT OF ASSUMPTION}

Drift excavation methods:

- Primary: tunnel boring machine (TBM)

- Secondary: other mechanical methods, and drill-and-blast where mechanical methods are impractical.

\section{BACKGROUND}

Requesting Management and Operating Contractor (M\&O) organization:

( ) Surface, (X) Subsurface, ( ) Waste Package Development, ( ) Other (specify):

Need for assumption (statement of intended use):

Affects the layout of drifts in plan.

\section{RATIONALE}

Rationale for assumption (source author, date, and report title) or statement of reasoning behind engineering judgment:

"Mined Geologic Disposal System Advanced Conceptual Design Report," March 1996, B00000000-01717-5705-00027, Rev. 00.

Key Assumption 027 mandates mechanical excavation as the primary method of tunnel excavation. Drill-and-blast excavation must be allowed as a fallback option, and to agree with Key Assumption 028.

Approximately $6000 \mathrm{~m}$ of Exploratory Studies Facility (ESF) excavation by TBM demonstrates the viability of using a TBM for repository excavation.

IV. RESPONSIBILITY AND WITHDRAWAL

Responsible Management and Operating Contractor (M\&O) organization: Subsurface

Document(s) Supporting Withdrawal of Assumption:

Withdrawal Date: 


\section{Controlled Design Assumption \\ Assumption Rationale Sheet}

Assumption Identifier: DCSS 006

Subject: Maximum Excavation Extraction Ratio

\section{STATEMENT OF ASSUMPTION}

Maximum excavation extraction ratio for emplacement drifts: 30 percent.

\section{BACKGROUND}

Requesting Management and Operating Contractor $(\mathrm{M} \& \mathrm{O})$ organization:

( ) Surface, (X) Subsurface, ( ) Waste Package Development, ( ) Other (specify):

Need for assumption (statement of intended use):

Affects layout of excavations.

\section{RATIONALE}

Rationale for assumption (source author, date, and report title) or statement of reasoning behind engineering judgment:

Excavation extraction ratio is defined as the area (in plan view) excavated divided by the total area considered. The 30 percent is a conservative value to promote long-term opening stability. It has its basis in two-dimensional elastic stress analysis. For two circular openings in a hydrostatic stress field, there is essentially no stress increase felt at one tunnel due to the presence of the other tunnel for center-to-center tunnel spacings of three diameters or greater. (Three diameter center-to-center spacing equals 33 percent excavation extraction ratio.) Rev. 01 of the Controlled Design Assumptions (CDA) is to limit this to emplacement areas and exclude it from the areas where no emplacement occurs.

\section{RESPONSIBILITY AND WITHDRAWAL}

Responsible Management and Operating Contractor (M\&O) organization: Subsurface

Document(s) Supporting Withdrawal of Assumption:

Withdrawal Date: 


\section{Controlled Design Assumption \\ Assumption Rationale Sheet}

Assumption Identifier: DCSS 009

Subject: Maximum Ramp Grade

\section{STATEMENT OF ASSUMPTION}

Maximum grade in ramps: $\leq 3$ percent to accommodate rail transport.

Maximum grade in mains: minimize, but $\leq 2$ percent in mains used for emplacement drift access.

Maximum grade in emplacement drifts: minimize within 0.25 to 0.75 percent range for drainage.

\section{BACKGROUND}

Requesting Management and Operating Contractor (M\&O) organization:

( ) Surface, (X) Subsurface, ( ) Waste Package Development, ( ) Other (specify):

Need for assumption (statement of intended use):

Affects layout of repository.

\section{RATIONALE}

Rationale for assumption (source author, date, and report title) or statement of reasoning behind engineering judgment:

Earlier layouts of the repository and Exploratory Studies Facility (ESF) had much steeper drift and ramp grades, which make for less safe operations and preclude use of conventional rail equipment for haulage and transportation. These grades provide for safer operation, regardless of the transport method, and allow use of conventional rail transport. Three percent is commonly accepted as the steepest slope on which trains can operate efficiently.

\section{RESPONSIBILITY AND WITHDRAWAL}

Responsible Management and Operating Contractor (M\&O) organization: Subsurface

Document(s) Supporting Withdrawal of Assumption:

Withdrawal Date: 


\section{Controlled Design Assumption \\ Assumption Rationale Sheet}

Assumption Identifier: DCSS 010

Subject: Repository Material Handling Equipment

\section{STATEMENT OF ASSUMPTION}

Repository material handling equipment:

- Supplies: rail transport.

- Excavated Rock: conveyor belt, or conveyor belt variation preferred when practical.

\section{BACKGROUND}

Requesting Management and Operating Contractor $(\mathrm{M \& O})$ organization:

( ) Surface, (X) Subsurface, ( ) Waste Package Development; ( ) Other (specify):

Need for assumption (statement of intended use):

Affects repository layout and operations.

\section{RATIONALE}

Rationale for assumption (source author, date, and report title) or statement of reasoning behind engineering judgment:

Current plans are for underground rail transport of waste packages. Also using rail transport for supplies simplifies underground operations. Use of a conveyor belt for transporting excavated materials reduces the underground transportation fleet required and reduces operating costs where excavated opening size and configuration makes use of a conveyor system practical.

This assumption is part of the Mined Geologic Disposal System Advanced Conceptual Design Report (B00000000-01717-5705-00027 Rev. 00).

\section{RESPONSIBILITY AND WITHDRAWAL}

Responsible Management and Operating Contractor $(\mathrm{M \& O})$ organization: Subsurface

Document(s) Supporting Withdrawal of Assumption:

Withdrawal Date: 


\section{Controlled Design Assumption \\ Assumption Rationale Sheet}

Assumption Identifier: DCSS 014

Subject: S̄haft Excavation Method

\section{STATEMENT OF ASSUMPTION}

Shaft excavation method: Mechanical where practical.

\section{BACKGROUND}

Requesting Management and Operating Contractor $(\mathrm{M \& O})$ organization:

( ) Surface, (X) Subsurface, ( ) Waste Package Development, ( ) Other (specify):

Need for assumption (statement of intended use):

Affects shaft size and support methods and also scheduling and sequencing of construction.

\section{RATIONALE}

Rationale for assumption (source author, date, and report title) or statement of reasoning behind engineering judgment:

Mechanical excavation methods cause the least disturbance to the rock and are analogous to using mechanical excavation methods in drifts and ramps.

\section{RESPONSIBILITY AND WITHDRAWAL}

Responsible Management and Operating Contractor $(M \& O)$ organization: Subsurface

Document(s) Supporting Withdrawal of Assumption:

Withdrawal Date: 


\section{Controlled Design Assumption \\ Assumption Rationale Sheet}

Assumption Identifier: DCSS 015

Subject: Ventilated Air Properties

\section{STATEMENT OF ASSUMPTION}

Properties of ventilation air:

$\begin{array}{ll}\text { Standard Density: } & 1.2 \mathrm{~kg} / \mathrm{m}^{3} \\ \text { Thermal Conductivity: } & 0.02564 \mathrm{~W} / \mathrm{mK} \\ \text { Heat Capacity: } & 1.2082 \mathrm{~kJ} / \mathrm{m}^{3} \mathrm{~K}\end{array}$

\section{BACKGROUND}

Requesting Management and Operating Contractor (M\&O) organization:

( ) Surface, (X) Subsurface, ( ) Waste Package Development, ( ) Other (specify):

Need for assumption (statement of intended use):

Used in ventilation system design.

\section{RATIONALE}

Rationale for assumption (source author, date, and report title) or statement of reasoning behind engineering judgment:

Density from Industrial Ventilation, A Manual of Recommended Practice, 18th Edition, American Conference of Governmental Industrial Hygienists, 1984, Cincinnati, Ohio, Figure MS 10 in the Metric Supplement in the back of the volume.

Other values from Fundamentals of Heat and Mass Transfer, Second Edition, Incroprera and DeWitt, John Wiley and Sons, 1985, page 767 (Table A.4).

All values are for standard temperature and pressure. Values for other temperatures and pressures should be adjusted by consulting Table A.4.

\section{RESPONSIBILITY AND WITHDRAWAL}

Responsible Management and Operating Contractor $(\mathrm{M} \& \mathrm{O})$ organization: Subsurface Document(s) Supporting Withdrawal of Assumption:

Withdrawal Date: 


\section{Controlled Design Assumption}

Assumption Rationale Sheet

Assumption Identifier: DCSS 016

Subject: Maximum Ūnderground Air Velocity

\section{STATEMENT OF ASSUMPTION}

Maximum allowable air velocity in:

$\begin{array}{lrl}\text { Ramps: } & 7.6 & \mathrm{~m} / \mathrm{s} \\ \text { Ventilation Shaft: } & 20.3 & \mathrm{~m} / \mathrm{s} \\ \text { Personnel Shaft: } & 11.7 & \mathrm{~m} / \mathrm{s} \\ \text { Emplacement Drifts } & & \\ \text { during Construction: } & 3.0 & \mathrm{~m} / \mathrm{s} \\ \text { Exhaust Mains: } & 10.2 & \mathrm{~m} / \mathrm{s} \\ \text { Service Mains: } & 7.6 & \mathrm{~m} / \mathrm{s} \\ \text { Waste Handling Main: } & 7.6 & \mathrm{~m} / \mathrm{s} \\ \text { Ductwork: } & 30.5 & \mathrm{~m} / \mathrm{s}\end{array}$

\section{BACKGROUND}

Requesting Management and Operating Contractor $(\mathrm{M} \& O)$ organization:

( ) Surface, (X) Subsurface, ( ) Waste Package Development, ( ) Other (specify):

Need for assumption (statement of intended use):

Used in ventilation system design. May affect excavated dimensions.

\section{RATIONALE}

Rationale for assumption (source author, date, and report title) or statement of reasọning behind engineering judgment:

Emplacement drift values are from Mine Ventilation and Air Conditioning, Second Edition, Hartman, Mutmansky, and Wang, John Wiley and Sons, 1982, page 394.

Ductwork values are from Tunnel Engineering Handbook, Bickel and Kuesel, Van Nostrand Reinhold Company, 1982, page 529.

All other values are from the Site Characterization Plan Conceptual Design Report, Section 3.4.4, Table 3-23.

\section{RESPONSIBILITY AND WITHDRAWAL}

Responsible Management and Operating Contractor (M\&O) organization: Subsurface

Document(s) Supporting Withdrawal of Assumption:

Withdrawal Date: 


\section{Controlled Design Assumption}

Assumption Rationale Sheet

Assumption Identifier: DCSS 017

Subject: Minimum Ūnderground Air Velocity

\section{STATEMENT OF ASSUMPTION}

Minimum required air velocity in:

Ramps:

(For Active Excavation)

Shafts:

$0.51 \mathrm{~m} / \mathrm{s}$

(For Development Maintenance)

Emplacement Drifts:

$0.51 \mathrm{~m} / \mathrm{s}$

$0.31 \mathrm{~m} / \mathrm{s}$

Exhaust Mains:

$0.51 \mathrm{~m} / \mathrm{s}$

$0.31 \mathrm{~m} / \mathrm{s}$

Service Mains: $\quad 0.51 \mathrm{~m} / \mathrm{s}$

$0.51 \mathrm{~m} / \mathrm{s}$

$0.31 \mathrm{~m} / \mathrm{s}$

$0.31 \mathrm{~m} / \mathrm{s}$

Waste Handling Main: $0.51 \mathrm{~m} / \mathrm{s}$

Ductwork:

$12.7 \mathrm{~m} / \mathrm{s}$

$0.31 \mathrm{~m} / \mathrm{s}$

$0.31 \mathrm{~m} / \mathrm{s}$

$10.2 \mathrm{~m} / \mathrm{s}$

\section{BACKGROUND}

Requesting Management and Operating Contractor (M\&O) organization:

( ) Surface, (X) Subsurface, ( ) Waste Package Development, ( ) Other (specify):

Need for assumption (statement of intended use):

Used in ventilation system design.

\section{RATIONALE}

Rationale for assumption (source author, date, and report title) or statement of reasoning behind engineering judgment:

Ductwork value from Industrial Ventilation, A Manual of Recommended Practice, 18th Edition, American Conference of Governmental Industrial Hygienists, 1984, Cincinnati, Ohio, Table 4-2.

All other values are from engineering judgment.

\section{RESPONSIBILITY AND WITHDRAWAL}

Responsible Management and Operating Contractor (M\&O) organization: Subsurface

Document(s) Supporting Withdrawal of Assumption:

Withdrawal Date: 


\section{Controlled Design Assumption \\ Assumption Rationale Sheet}

Assumption Identifier: DCSS 018

Subject: Minimum Ūnderground Air Volume

\section{STATEMENT OF ASSUMPTION}

Minimum required air volume per:

$\begin{array}{ll}\text { Diesel } \mathrm{kW}: & 0.0791\left(\mathrm{~m}^{3} / \mathrm{s}\right) / \mathrm{kW} \\ \text { Underground Worker: } & 0.0944\left(\mathrm{~m}^{3} / \mathrm{s}\right) / \text { person }\end{array}$

\section{BACKGROUND}

Requesting Management and Operating Contractor (M\&O) organization:

( ) Surface, (X) Subsurface, ( ) Waste Package Development, ( ) Other (specify):

Need for assumption (statement of intended use):

Affects ventilation system design.

\section{RATIONALE}

Rationale for assumption (source author, date, and report title) or statement of reasoning behind engineering judgment:

Both values from Repository Underground Ventilation System Concepts, September 1993, Sections 5.2.1 and 5.2.2, DI B00000000-01717-5705-00003, Rev. 00. See it for additional sources such as 29 CFR 1926 and 30 CFR.

These are universally accepted values.

\section{RESPONSIBILITY AND WITHDRA WAL}

Responsible Management and Operating Contractor (M\&O) organization: Subsurface

Document(s) Supporting Withdrawal of Assumption:

Withdrawal Date: 


\section{Controlled Design Assumption \\ Assumption Rationale Sheet}

Assumption Identifier: DCSS 019

Subject: Maximum Underground Air Temperatures -

Emplacement Drifts

\section{STATEMENT OF ASSUMPTION}

Maximum allowable air temperature in emplacement drifts during:

$\begin{array}{ll}\text { Construction: } & 27^{\circ} \mathrm{C} \text { effective } \\ \text { Emplacement: } & 50^{\circ} \mathrm{C} \text { dry-bulb, only in portion requiring access } \\ \text { Caretaker: } & \text { no limit, determined by rock temperature } \\ \text { Retrieval: } & 50^{\circ} \mathrm{C} \text { dry-bulb, only in portion requiring access } \\ \text { Backfilling: } & 50^{\circ} \mathrm{C} \text { dry-bulb }\end{array}$

\section{BACKGROUND}

Requesting Management and Operating Contractor (M\&O) organization:

( ) Surface, (X) Subsurface, ( ) Waste Package Development, ( ) Other (specify):

Need for assumption (statement of intended use):

Affects ventilation system design.

\section{RATIONALE}

Rationale for assumption (source author, date, and report title) or statement of reasoning behind engineering judgment:

Construction effective temperature from Mine Ventilation and Air Conditioning, Section 20-5, Second Edition, by H. L. Hartman, J. M. Mutmansky and Y. J. Wang, published by John Wiley and Sons, Inc., 1982. Effective temperature is the most popular empirical heat-stress index that refers the combined effect of temperature, humidity, and velocity of the air to a single empirical temperature scale reflecting equal sensations of warmth or cold. Effective temperature in working spaces can be determined using standard effective temperature charts.

Emplacement and retrieval from Site Characterization Plan Conceptual Design Report (SCP CDR), page 2-65. The low temperature is needed only in portions where equipment must operate. It is not necessary to cool the entire drift for access to a small portion.

There may be no ventilation in the emplacement drifts during the caretaker period. If there is no ventilation, the air temperature will be the same as the rock surface temperature.

Temperatures for retrieval and backfilling apply only to drifts being prepared for retrieval or backfilling, or to drifts in which these activities are actively occurring. After emplacement has been completed in a drift and through repository closure, the drift is considered to be in the caretaker period, except for when it is undergoing retrieval or backfilling.

\section{RESPONSIBILITY AND WITHDRAWAL}

Responsible Management and Operating Contractor $(\mathrm{M} \& \mathrm{O})$ organization: Subsurface

Document(s) Supporting Withdrawal of Assumption:

Withdrawal Date: 


\section{Controlled Design Assumption \\ Assumption Rationale Sheet}

\section{Assumption Identifier: DCSS 020}

Subject: Maximum Underground Air Temperatures -

Access Mains

\section{STATEMENT OF ASSUMPTION}

Maximum allowable air temperature in access (ventilation intake) mains during:

$\begin{array}{ll}\text { Construction: } & 27^{\circ} \mathrm{C} \text { effective } \\ \text { Operations: } & 27^{\circ} \mathrm{C} \text { effective } \\ \text { Caretaker: } & 27^{\circ} \mathrm{C} \text { effective } \\ \text { Retrieval: } & 27^{\circ} \mathrm{C} \text { effective } \\ \text { Backfilling: } & 50^{\circ} \mathrm{C} \text { dry-bulb }\end{array}$

\section{BACKGROUND}

Requesting Management and Operating Contractor (M\&O) organization:

( ) Surface, (X) Subsurface, (X) Waste Package Development, ( ) Other (specify):

Need for assumption (statement of intended use):

Affects ventilation system design and operation of other equipment.

\section{RATIONALE}

Rationale for assumption (source author, date, and report title) or statement of reasoning behind engineering judgment:

Construction, operation, caretaker and retrieval temperatures from Mine Ventilation and Air Conditioning, Section 20-5, Second Edition, by H. L. Hartman, J. M. Mutmansky and Y. J. Wang, published by John Wiley and Sons, Inc., 1982. Effective temperature is the most popular empirical heat-stress index that refers the combined effect of temperature, humidity, and velocity of the air to a single empirical temperature scale reflecting equal sensations of warmth or cold. Effective temperature in working spaces can be determined using standard effective temperature charts.

\section{RESPONSIBILITY AND WITHDRA WAL}

Responsible Management and Operating Contractor (M\&O) organization: Subsurface

Document(s) Supporting Withdrawal of Assumption:

Withdrawal Date: 


\section{Controlled Design Assumption \\ Assumption Rationale Sheet}

Assumption Identifier: DCSS 022

Subject: "K" Factor for Ventilation Air Flow

\section{STATEMENT OF ASSUMPTION}

"K" factor for ventilation air flow in:

Shafts: $\quad \begin{gathered}\text { Ventilation Shaft } \\ \text { Man-and-Material Shaft } \\ \text { Waste Ramp }\end{gathered}$
Ramps: $\quad$ Tuff Ramp
Exhaust Mains:
Service Mains:
TBM Launch Mains:
Waste Main:
Emplacement Drifts
$\quad$ Without Waste Packages:
With Waste Packages:
Metal Ventilation Duct

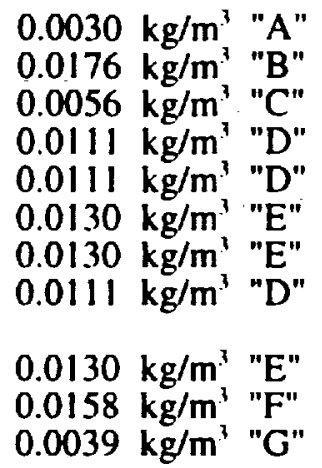

\section{BACKGROUND}

Requesting Management and Operating Contractor (M\&O) organization:

( ) Surface, (X) Subsurface, ( ) Waste Package Development, (X) Other (specify):

Need for assumption (statement of intended use):

Affects ventilation system design.

\section{RATIONALE}

Rationale for assumption (source author, date, and report title) or statement of reasoning behind engineering judgment:

"A" SCP/CDR, page C-16, for smooth lined unobstructed shaft.

"B" SCP/CDR, page C-159, for lined shaft with two sets of buntons.

"C" SCP/CDR, page C-158, for straight unobstructed tunnel in sedimentary rock.

"D" SCP/CDR, page C-158, for straight slightly obstructed tunnel in sedimentary rock.

"E" SCP/CDR, page C-158, for straight moderately obstructed tunnel in sedimentary rock.

"F" Engineering judgment assuming heavily obstructed tunnel.

"G" Preliminary measurement of $1.67 \mathrm{~m}$ diameter metal duct in Exploratory Studies Facility (ESF) operation.

Shaft descriptions for "A" and "B" are per Site Characterization Plan (SCP)/Conceptual Design Report (CDR), page $C-16$. Tunnel descriptions for " $C$ " - " $F$ " match those for maximum values in Table 6-1 in Mine Ventilation and Air Conditioning, Second Edition, Hartman, Mutmansky, and Wang, John Wiley and Sons, 1982.

Rev. 01 corrects a decimal point error.

\section{RESPONSIBILITY AND WITHDRA WAL}

Responsible Management and Operating Contractor (M\&O) organization: Subsurface

Document(s) Supporting Withdrawal of Assumption:

Withdrawal Date: 


\section{Controlled Design Assumption \\ Assumption Rationale Sheet}

Assumption Identifier: DCSS 023

Subject: Maximum Preclosure Rock

\section{STATEMENT OF ASSUMPTION}

Surface Temperature

Maximum allowable preclosure rock surface temperature in:

$\begin{array}{lrl}\text { Shafts: } & 35^{\circ} \mathrm{C} & \text { - unventilated } \\ \text { Ramps: } & 35^{\circ} \mathrm{C} & \text { - unventilated } \\ \text { Mains: } & 50^{\circ} \mathrm{C} & \\ \text { Emplacement Drifts: } & 200^{\circ} \mathrm{C} & \end{array}$

Temporary increases in these temperatures are allowed during initial cooling of emplacement drifts for maintenance, performance confirmation, retrieval and backfillings.

\section{BACKGROUND}

Requesting Management and Operating Contractor (M\&O) organization:

( ) Surface, (X) Subsurface, ( ) Waste Package Development, ( ) Other (specify):

Need for assumption (statement of intended use):

Affects ventilation system design and operation of other equipment. Affects emplacement drift size and drift, shaft, and ramp stand-off distances from the emplacement areas.

\section{RATIONALE}

Rationale for assumption (source author, date, and report title) or statement of reasoning behind engineering judgment:

Emplacement drifts based on project position on thermal goals, a thermomechanical limit to maintain drift wall stability, and a need to allow monitoring prior to closure.

Other values from Site Characterization Plan (SCP) Table 8.3.2.4-5. Value for "mains" taken as the same as the value for "access drifts" in the SCP. Our mains are comparable to the SCPs access drifts. The temperatures are limited to the unventilated condition because the intent is to limit the temperatures, caused solely by thermal load from the waste package, outside of the emplacement drifts. Subsequent ventilation of the emplacement drifts may temporarily cause the rock surface temperatures in the exhaust mains to rise, which is acceptable.

\section{RESPONSIBILITY AND WITHDRAWAL}

Responsible Management and Operating Contractor $(\mathrm{M} \& O)$ organization: Surface

Document(s) Supporting Withdrawal of Assumption:

Withdrawal Date: 


\section{Controlled Design Assumption}

Assumption Rationale Sheet

Assumption Identifier: DCSS 025

Subject: Maximum Zeolite Temperature

\section{STATEMENT OF ASSUMPTION.}

The temperature at the average top of the zeolite layer beneath the potential emplacement area I shall not exceed $90^{\circ}$. The vertical distance from the emplacement area horizon to the average top of the zeolite layer in the Primary Area is estimated at $170 \mathrm{~m}$.

\section{BACKGROUND}

Requesting Management and Operating Contractor $(\mathrm{M} \& \mathrm{O})$ organization:

( ) Surface, (X) Subsurface, (X) Waste Package Development, ( ) Other (specify):

Need for assumption (statement of intended use):

Affects location and extent of repository and also waste package spacing.

\section{RATIONALE}

Rationale for assumption (source author, date, and report title) or statement of reasoning behind engineering judgment:

This goal is provided to limit mineralogic conversion of clinoptilolite, with significant sorptive properties for some radionuclides, to analcime, which has poor sorptive properties. Natural analog studies have found that this conversion may take place above $90^{\circ}$ to $100^{\circ} \mathrm{C}$ in $\mathrm{J}-13$ water chemistry. The zeolitized layer within the $\mathrm{CHn}$, as discussed in the Thermal Loading Study for

I FY 1996 and as defined by the LANL site scale geologic model, is at least $125 \mathrm{~m}$ and on average

1 about $170 \mathrm{~m}$ below the primary area portion of the potential repository. If alternative emplacement areas are considered, the average depth to the top of the zeolitized layer beneath those areas will need to be estimated. The temperature at this average top depth shall not exceed

I $90^{\circ} \mathrm{C}$. Reference: Thermal Loading Study for FY96, DI: B00000000-01717-5705-00044

I Rev. 01.

\section{RESPONSIBILITY/SUBSTANTIATION/WITHDRAWAL}

Responsible Management and Operating Contractor (M\&O) organization: Systems Engineering Requirements

Document(s) Supporting Withdrawal of Assumption:

Withdrawal Date: 


\section{Controlled Design Assumption \\ Assumption Rationale Sheet}

Assumption Identifier: DCSS 027

Subject: Rock Support Material Restrictions

\section{STATEMENT OF ASSUMPTION}

Organic materials (e.g., epoxy resin, timber) are restricted for use as rock support and other postclosure permanent materials in all openings.

Concrete (subject to restrictions on chemical composition of cementitious materials) and steel are allowable preclosure construction material in all openings.

\section{BACKGROUND}

Requesting Management and Operating Contractor $(\mathrm{M} \& \mathrm{O})$ organization:

( ) Surface, (X) Subsurface, (X) Waste Package Development, ( ) Other (specify):

Need for assumption (statement of intended use):

Affects rock support design and possibly other underground work.

\section{RATIONALE}

Rationale for assumption (source author, date, and report title) or statement of reasoning behind engineering judgment:

These restrictions are necessary to minimize the impact of subsurface construction on waste isolation. The use of organics and specific cementitious materials should be approved by the Determination of Importance (DI) group. As indicated in Assumption EBDRD 3.2.3.3.A.13, I performance evaluations are needed to determine any adverse impacts to waste isolation.

The restriction on the use of concrete include construction of systems, structures, and components that will be removed prior to closure.

\section{RESPONSIBILITY AND WITHDRA WAL}

Responsible Management and Operating Contractor (M\&O) organization: Subsurface

Document(s) Supporting Withdrawal of Assumption:

Withdrawal Date: 


\section{Controlled Design Assumption \\ Assumption Rationale Sheet}

Assumption Identifier: DCSS 028

Subject: Ë̄mplacement Drift, Shafts, Ramps Maintenance Plans

\section{STATEMENT OF ASSUMPTION}

Emplacement drifts will be designed to be stable through the caretaker period, with the goal to minimize or eliminate planned maintenance to sustain the ability to retrieve, sample, or relocate waste packages. Shafts, ramps, and all other drifts will be designed to be stable, but may rely on periodic planned maintenance.

\section{BACKGROUND}

Requesting Management and Operating Contractor (M\&O) organization:

( ) Surface, (X) Subsurface, (X) Waste Package Development, ( ) Other (specify):

Need for assumption (statement of intended use):

Affects design and cost of openings as well as operations and maintenance.

\section{RATIONALE}

Rationale for assumption (source author, date, and report title) or statement of reasoning behind engineering judgment:

Based on engineering judgment that long term, periodic maintenance in emplacement drifts is unfeasible. Long term maintenance elsewhere is feasible, and therefore this should allow a more economical design. See Key Assumption 013 for human entry under off-normal conditions.

\section{RESPONSIBILITY AND WITHDRA WAL}

Responsible Management and Operating Contractor (M\&O) organization: Subsurface

Document(s) Supporting Withdrawal of Assumption:

Withdrawal Date: 


\section{Controlled Design Assumption \\ Assumption Rationale Sheet}

Assumption Identifier: DCSS 029

Subject: Maximum Underground Air Temperatures -

Exhaust Mains

\section{STATEMENT OF ASSUMPTION}

Maximum allowable air temperature in exhaust mains during:

$\begin{array}{ll}\text { Construction: } & 27^{\circ} \mathrm{C} \text { effective } \\ \text { Operations: } & 50^{\circ} \mathrm{C} \text { dry-bulb } \\ \text { Caretaker: } & 50^{\circ} \mathrm{C} \text { dry-bulb } \\ \text { Retrieval: } & \\ \text { Backfilling: } & 50^{\circ} \mathrm{C} \text { dry-bulb }\end{array}$

\section{BACKGROUND}

Requesting Management and Operating Contractor $(\mathrm{M} \& O)$ organization:

( ) Surface, (X) Subsurface, (X) Waste Package Development, ( ) Other (specify):

Need for assumption (statement of intended use):

Affects ventilation system design.

\section{RATIONALE}

Rationale for assumption (source author, date, and report title) or statement of reasoning behind engineering judgment:

Construction effective temperature from Mine Ventilation and Air Conditioning, Section 20-5, Second Edition, by H. L. Hartman, J. M. Mutmansky and Y. J. Wang. published by John Wiley and Sons, Inc., 1982. Effective temperature is the most popular empirical beat-stress index that refers the combined effect of temperature, humidity, and velocity of the air to a single empirical temperature scale reflecting equal sensations of warmth or cold. Effective temperature in working spaces can be determined using standard effective temperature chans.

Operations and Caretaker - assumed same as "Maximum Allowable Rock Surface Temperature in Mains" (DCSS 023).

Retrieval - air temperature would normally be no greater than the rock surface temperature ( 50 degrees $C$ per DCSS 023), but could be as high as the emplacement drift rock surface temperature if the emplacement drifts are ventilated through the exhaust mains.

Backfilling - this temperature is for backfilling within the exhaust mains, during which there is no flowthrough ventilation. This is the same as the rock surface temperature (DCSS 023).

\section{RESPONSIBILITY AND WITHDRAWAL}

Responsible Management and Operating Contractor (M\&O) organization: Subsurface

Document(s) Supporting Withdrawal of Assumption:

Withdrawal Date: 


\section{Controlled Design Assumption}

Assumption Rationale Sheet

Assumption Identifier: DCSS 030

Subject: Limit Ground Surface Uplift

\section{STATEMENT OF ASSUMPTION}

Limit surface uplift to less than $0.5 \mathrm{~cm} / \mathrm{yr}$ and relative motion of the top of TSw I to less than $1 \mathrm{~m}$ with no intact rock failure and no continuous joint slip.

\section{BACKGROUND}

Requesting Management and Operating Contractor (M\&O) organization:

( ) Surface, (X) Subsurface, ( ) Waste Package Development, ( ) Other (specify):

Need for assumption (statement of intended use):

\section{RATIONALE}

Rationale for assumption (source author, date, and report title) or statement of reasoning behind engineering judgment:

These limits appear as goals 3 and 4 in the 1993 Site Characterization Plan Thermal Goals Reevaluation report, DI B00000000-01717-5705-00005, Rev. 00.

\section{RESPONSIBILITY AND WITHDRAWAL}

Responsible Management and Operating Contractor (M\&O) organization: Systems Engineering

Document(s) Supporting Withdrawal of Assumption:

Withdrawal Date: 


\section{Controlled Design Assumption \\ Assumption Rationale Sheet}

Assumption Identifier: DCSS 031

Subject: Limit Temperatures in PTn

\section{STATEMENT OF ASSUMPTION}

Limit temperatures in PTn (Upper Paint Brush non-welded) to less than $115^{\circ} \mathrm{C}$.

\section{BACKGROUND}

Requesting Management and Operating Contractor (M\&O) organization:

( ) Surface, (X) Subsurface, ( ) Waste Package Development, ( ) Other (specify):

Need for assumption (statement of intended use):

\section{RATIONALE}

Rationale for assumption (source author, date, and report title) or statement of reasoning behind engineering judgment:

The general goal to establish a thermal limit in the PTn units was recommended in 1993 (Site Characterization Plan Thermal Goals Reevaluation, DI B00000000-01717-5705-00005 Rev. 00 ). No actual values were recommended at that time so a working value equal to that established for the TSw 3 (vitrophyre tuff) is established here. The TSw3 temperature limit has since been eliminated, therefore the 115 degrees $C$ value needs to be evaluated during the substantiation process.

Note: This thermal goal has been written in the format of requirement EBDRD 3.7.G so that upon substantiation, it may be captured by the Management and Operating Contractor (M\&O) Requirements and incorporated into EBDRD 3.7.G or in the appropriate section of the Repository Design Requirements Document (RDRD).

\section{RESPONSIBILITY AND WITHDRA WAL}

Responsible Management and Operating Contractor (M\&O) organization: Systems Engineering Document(s) Supporting Withdrawal of Assumption:

Withdrawal Date: 


\section{Controlled Design Assumption \\ Assumption Rationale Sheet}

Assumption Identifier: DCSS 032

Subject: Temporary Surface Facilities for

Underground Construction

\section{STATEMENT OF ASSUMPTION}

Underground construction will not use the north portal for access once emplacement operations begin.

\section{BACKGROUND}

Requesting Management and Operating Contractor (M\&O) organization:

(X) Surface, ( ) Subsurface, ( ) Waste Package Development, ( ) Other (specify):

Need for assumption (statement of intended use):

Affects logistics of underground construction and location of construction accesses.

\section{RATIONALE}

Rationale for assumption (source author, date, and report title) or statement of reasoning behind engineering judgment:

Key Assumption 047 states that the permanent repository surface facilities will be located next to the north portal. The concept of operations has emplacement and development (construction) operations to use separate accesses. Therefore, the north portal cannot be used for construction once emplacement begins. However, this does allow initial development to be carried out using the north portal. Temporary surface facilities for underground construction will be located accordingly.

\section{RESPONSIBILITY AND WITHDRAWAL}

Responsible Management and Operating Contractor (M\&O) organization: Surface, Subsurface Document(s) Supporting Withdrawal of Assumption:

Withdrawal Date: 


\section{Controlled Design Assumption \\ Assumption Rationale Sheet}

Assumption Identifier: DCSS 033

Subject: Emplacement Drift Standoff

\section{STATEMENT OF ASSUMPTION}

The greater of iwo standoff distances in the cmplacement drifts for thermal and radiological concerns will he utilized for calculating the usable emplacement area as follows:

- A $35 \mathrm{~m}$ thermal standoff distance is used to limit the surface rock temperalure of the adjacent main drift. This thermal standoff is defined as the perpendicular distance from the ecnter of the closest cmplaced waste package to the nearest edge of the main drift.

- A $13 \mathrm{~m}$ radiological standoff distance is used for limiting the radiological dose in the adjacent main drift. This radiological standoff is defined as the distance from the center of the closest emplaced waste package (o) the door of the emplacement drift. This distance is equal to the sum of the distances from the door to the edge of the wasle package $(10 \mathrm{~m})$ plus half the length of the waste package (approximately $3 \mathrm{~m}$ ).

\section{BACKGROUND}

Requesting Management and Operating Contractor (M\&O) organization:

( ) Surface, (X) Subsurface, ( ) Wasle Package Development, ( ) Other (specify):

Need for assumption (statement of intended use):

Affects total uscable emplacement area.

\section{RATIONALE}

Rationale for assumption (source author, date, and report title) or statement of reasoning behind engineering judgment:

Thermal Standoff

Past Repository layouts, especially the Site Characterization Plan, Yucca Mountain Sire, have allowed adequate standoff to limit the main drift wall temperature to less than $50^{\prime \prime} \mathrm{C}$ for the first 50 years after emplacement. Based on previous studies compiled within the Initial Summan'Report for Repository/Waste Package Advanced Conceptual Design, thermal standoff distances were given for a narrow range of thermal loadings and specific emplacement conditions The thermal loading range in the studies is consistent with the current program thermal loading of 83 MTU/acres. However, the emplacement conditions do not quite match the current repository design. Among the differences are the emplacement mode is now in-drift, the length of time to sustain main drift wall temperature is now 150 years, and continuous ventilation is now considered in the main drifts throughout the period of operations.

\section{Radiological Standoff}

A radiological standoff is needed to limit the radiological dose in the adjacent main drift. For current work, the position of the closest emplaced waste package from the door is based on engineering judgement. Preliminary assessment suggests that the selected value is satisfactory provided there is sufficient shielding just inside the door to the emplacement drift as well as outside the door in the turnout for worker protection in the main drift once the emplacement drift is full and closed for caretaker operations. the door to the emplacement drift is at the end of a 25 $40 \mathrm{~m}$ long turnout (curved section plus straight section) that provides a transition for rail transport from the main drift to the emplacement drift entrance.

\section{RESPONSIBILITY AND WITHDRA WAL}

Responsible Management and Operating Contractor (M\&O) organization: Subsurface

Document(s) Supporting Withdrawal of Assumption:

Withdrawal Date: 


\section{Controlled Design Assumption \\ Assumption Rationale Sheet}

Assumption Identifier: DCSS $034 \quad$ Subject: Emplacement Drift Ground Support

\section{STATEMENT OF ASSUMPTION}

A single ground support type will be used in emplacement drifts.

Candidate ground support types under consideration:

- Precast concrete

- Cast In Place concrete

- Steel sets

\section{BACKGROUND}

Requesting Management and Operating Contractor (M\&O) organization:

( ) Surface, (X) Subsurface, ( ) Waste Package Development, or ( ) Other (specify):

Need for assumption (statement of intended use):

Needed to focus ground support design.

\section{RATIONALE}

Rationale for assumption (source author, date, and report title) or statement of reasoning behind engineering judgment:

Using a single ground support type greatly simplifies design and construction by eliminating field decisions regarding ground classification and support type to be installed.

A single ground support type allows for efficient application of materials, emphasis on longevity, and minimization of maintenance.

\section{RESPONSIBILITY AND WITHDRAWAL}

Responsible Management and Operating Contractor $(\mathrm{M} \& \mathrm{O})$ organization: Subsurface

Document(s) Supporting Withdrawal of Assumption:

Withdrawal Date: 


\section{Controlled Design Assumption \\ Assumption Rationale Sheet}

Assumption Identifier: DCSS 035

Subject: Empläcement and Development

Area Ventilation

\section{STATEMENT OF ASSUMPTION}

The ventilation systems for the development and emplacement areas will be provided by two separate and independent systems that are physically separated in the underground.

\section{BACKGROUND}

Requesting Management and Operating Contractor (M\&O) organization:

( ) Surface, (X) Subsurface, ( ) Waste Package Development, or ( ) Other (specify):

Need for assumption (statement of intended use):

10 CFR $60.133(\mathrm{~g})(3)$ states "The ventilation system shall be designed to separate the ventilation of excavation and waste emplacement areas."

\section{RATIONALE}

Rationale for assumption (source author, date, and report title) or statement of reasoning behind engineering judgment:

Reduces risk of radioactive release into development area.

Allows each fan system to be optimized for emplacement and development activities.

\section{RESPONSIBILITY AND WITHDRAWAL}

Responsible Management and Operating Contractor (M\&O) organization: Subsurface

Document(s) Supporting Withdrawal of Assumption:

Withdrawal Date: 


\section{Controlled Design Assumption \\ Assumption Rationale Sheet}

Assumption Identifier: DCSS 036

Subject: Emplacement Drift Entrance Doors

\section{STATEMENT OF ASSUMPTION}

Doors are required at entrances to emplacement drifts.

\section{BACKGROUND}

Requesting Management and Operating Contractor (M\&O) organization:

( ) Surface, (X) Subsurface, ( ) Waste Package Development, or ( ) Other (specify):

Need for assumption (statement of intended use):

Needed to focus design.

\section{RATIONALE}

Rationale for assumption (source author, date, and report title) or statement of reasoning behind engineering judgment:

Doors at entrances to emplacement drifts serve two purposes: they control access to the emplacement drifts and they provide control of ventilation through the drifts. They will also inherently provide some amount of radiological shielding.

\section{RESPONSIBILITY AND WITHDRA WAL}

Responsible Management and Operating Contractor (M\&O) organization: Subsurface

Document(s) Supporting Withdrawal of Assumption:

Withdrawal Date: 


\section{Controlled Design Assumption \\ Assumption Rationale Sheet}

Assumption Identifier: DCSS 037

Subject: Invert Material

\section{STATEMENT OF ASSUMPTION}

Invert material will consist of concrete/crushed tuff material combination. Other material additives may be used as necessary (refer to Assumption EBDRD 3.2.3.3.A.13).

\section{BACKGROUND}

Requesting Management and Operating Contractor (M\&O) organization:

( ) Surface, (X) Subsurface, ( ) Waste Package Development, or ( ) Other (specify):

Need for assumption (statement of intended use):

Needed to focus design efforts.

\section{RATIONALE}

Rationale for assumption (source author, date, and report title) or statement of reasoning behind engineering judgment:

Supports an invert system that is constructable and meets requirements for waste package support and engineered barrier performance.

\section{RESPONSIBILITY AND WITHDRA WAL}

Responsible Management and Operating Contractor (M\&O) organization: Subsurface

Document(s) Supporting Withdrawal of Assumption:

Withdrawal Date: 


\section{Controlled Design Assumption \\ Assumption Rationale Sheet}

Assumption Identifier: DCSS 038

Subject: Air Monitoring Underground

\section{STATEMENT OF ASSUMPTION}

Air in underground excavations, including shafts and ramps, will be monitored as required for health, safety, and performance confirmation.

\section{BACKGROUND}

Requesting Management and Operating Contractor (M\&O) organization:

( ) Surface, (X) Subsurface, ( ) Waste Package Development, or ( ) Other (specify):

Need for assumption (statement of intended use):

Needed to focus design.

\section{RATIONALE}

Rationale for assumption (source author, date, and report title) or statement of reasoning behind engineering judgment:

Performance Confirmation monitoring will be required in specified locations throughout the repository. Since the shafts currently are to be used for exhaust air, it is logical to monitor them.

\section{RESPONSIBILITY AND WITHDRAWAL}

Responsible. Management and Operating Contractor (M\&O) organization: Subsurface

Document(s) Supporting Withdrawal of Assumption:

Withdrawal Date: 


\section{Controlled Design Assumption \\ Assumption Rationale Sheet}

Assumption Identifier: DCSS 039

Subject: Ventilation Sys̄em Pressure Differential

\section{STATEMENT OF ASSUMPTION}

The ventilation systems for the emplacement and development areas shall be designed such that there is a pressure differential from the development to emplacement sides. The pressure in the development area shall be higher than the pressure in the emplacement area by approximately 189-531 $\mathrm{Pa}(0.76-2.14$ inches water gage).

\section{BACKGROUND}

Requesting Management and Operating Contractor (M\&O) organization:

( ) Surface, (X) Subsurface, ( ) Waste Package Development, or ( ) Other (specify):

Need for assumption (statement of intended use):

Affects ventilation and repository layout designs.

\section{RATIONALE}

Rationale for assumption (source author, date, and report title) or statement of reasoning behind engineering judgment:

The pressure differential assures that any air leakage will be from the development area to the emplacement area. This reduces the risk of an airborne radioactive particle release into the development area. The pressure differential value is based on practical limitations on the bulkheads to be installed between the development and emplacement areas.

\section{RESPONSIBILITY AND WITHDRAWAL}

Responsible Management and Operating Contractor (M\&O) organization: Subsurface

Document(s) Supporting Withdrawal of Assumption:

Withdrawal Date: 


\section{Controlled Design Assumption}

Assumption Rationale Sheet

SECTION 8

DESIGN CONCEPT WASTE PACKAGE ASSUMPTIONS (DCWP) 
Controlled Design Assumption Assumption Rationale Sheet 


\section{Controlled Design Assumption \\ Assumption Rationale Sheet}

Assumption Identifier: DCWP 001

Subject: Limit Füel Cladding Temperature

\section{STATEMENT OF ASSUMPTION}

Limit the fuel cladding temperature to less than 350 degrees $\mathrm{C}$.

\section{BACKGROUND}

Requesting Management and Operating Contractor (M\&O) organization:

( ) Surface, ( ) Subsurface, (X) Waste Package Development, (X) Other (specify):

Systems Analysis and Modeling

Need for assumption (statement of intended use):

Performancé measure.

\section{RATIONALE}

Rationale for assumption (source author, date, and report title) or statement of reasoning behind engineering judgment:

The SCP established this thermal goal. It was reevaluated in 1993 and found to be still valid (Site Characterization Plan Thermal Goals Reevaluation, DI B00000000-01717-5705-00005, Rev. 00). Note: EBDRD 3.2.3.4.C.2 places a "derived" $350^{\circ} \mathrm{C}$ maximum temperature requirement on Waste Acceptance so that the: "Temperature will not have exceeded $350^{\circ} \mathrm{C}$ (TBV) during storage under inert gas." EBDRD 3.2.3.4.C.2 should not be confused with the intent of DCWP-001. DCWP-001 is a long term goal to enhance the Zircaloy cladding performance.

The $350^{\circ} \mathrm{C}$ value may change as more information is gathered on temperature sensitivity of Zircaloy cladding. Assurance is needed to maintain cladding temperatures to values low enough to enhance the Zircaloy cladding performance as a barrier.

Thermal Loading Study for FY96, DI: B00000000-01717-5705-00044 Rev. 00, recommended retention of the $350^{\circ} \mathrm{C}$ limit on the cladding temperature.

\section{RESPONSIBILITY AND WITHDRAWAL}

Responsible Management and Operating Contractor (M\&O) organization:

Systems Engineering (Vienna)

Document(s) Supporting Withdrawal of Assumption:

Withdrawal Date: 


\section{Controlled Design Assumption \\ Assumption Rationale Sheet}

Assumption Identifier: DCWP 002

Subject: Limit HLW Glass Temperature

\section{STATEMENT OF ASSUMPTION}

Limit the temperature of the high-level waste (HLW) glass to less than $400^{\circ} \mathrm{C}$ during storage at the producer sites and during transport to the repository.

\section{BACKGROUND}

Requesting Management and Operating Contractor (M\&O) organization:

( ) Surface, ( ) Subsurface, (X) Waste Package Development, (X) Other (specify):

Systems Analysis and Modeling

Need for assumption (statement of intended use):

Performance measure.

\section{RATIONALE}

Rationale for assumption (source author, date, and report title) or statement of reasoning behind engineering judgment:

The Site Characterization Plan (SCP) established this thermal goal to assure that the glass transition temperature is not exceeded. It was reevaluated in 1993 and found to be still valid based on conversations with Savannah River personnel (Site Characterization Plan Thermal Goals Reevaluation, DI B00000000-01717-5705-00005 Rev. 00). The goal should be retained for the present with the goal reevaluated when new information is supplied by Savannah River.

\section{RESPONSIBILITY AND WITHDRAWAL}

Responsible Management and Operating Contractor (M\&O) organization: Systems Analysis and Modeling

Document(s) Supporting Withdrawal of Assumption:

Withdrawal Date: 
Controlled Design Assumption

Assumption Rationale Sheet

Assumption Identifier: DCWP 004

Subject: Waste Package Materials

\section{STATEMENT OF ASSUMPTION}

The following materials will be used in future waste package (WP) design work:

\begin{tabular}{|l|l|}
\hline \multicolumn{1}{|c|}{ Component } & \multicolumn{1}{c|}{ Material } \\
\hline Corrosion allowance barrier for SNF waste forms & ASTM A 516 Grade 55 or 70 \\
\hline Corrosion resistant barrier for SNF waste forms & ASTM B 443 \\
\hline Fuel basket tubes for SNF waste forms & ASTM A 516 Grade 55 or 70 \\
\hline Fuel basket plates for SNF waste forms & Neutronit A 978 or equivalent \\
\hline Waste container fill gas for SNF waste forms & Helium \\
\hline Basket guides for SNF waste forms & ASTM A 516 Grade 55 or 70 \\
\hline Corrosion allowance barrier for HLW glass & ASTM A 516 Grade 55 or 70 \\
\hline Corrosion resistant barrier for HLW glass & ASTM B 443 \\
\hline Canister guide for HLW glass & ASTM A 516 Grade 55 or 70 \\
\hline
\end{tabular}

HLW - High-Level Waste, SNF - Spent Nuclear Fuel

Where a choice is indicated (ASTM A 516 Grade 55 or 70 ), either of these materials could be used; a choice between them will require additional engineering analysis.

\section{BACKGROUND}

Requesting Management and Operating Contractor (M\&O) organization:

( ) Surface, ( ) Subsurface, (X) Waste Package Development, or ( ) Other (specify):

Need for assumption (statement of intended use):

\section{RATIONALE}

Rationale for assumption (source author, date, and report title) or statement of reasoning behind engineering judgment:

Materials selected in Waste Package Material Selection Analysis (BBA000000-01717-020000020 REV 00).

\section{RESPONSIBILITY AND WITHDRAWAL}

Responsible Management and Operating Contractor (M\&O) organization: Waste Package

Document(s) Supporting Withdrawal of Assumption:

Withdrawal Date: 


\section{Controlled Design Assumption}

Assumption Rationale Sheet

Assumption DCWP 005 has been withdrawn

\section{Assumption DCWP O0S has been withdrawn}


Controlled Design Assumption

Assumption Rationale Sheet

Assumption DCWP 006 has been withdrawn 
Controlled Design Assumption

Assumption Rationale Sheet

INTENTIONALLY LEFT BLANK

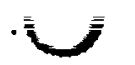




\section{Controlled Design Assumption}

Assumption Rationale Sheet

\section{SECTION 9}

\section{TECHNICAL DATA SURFACE ASSUMPTIONS (TDS)}


Controlled Design Assumption

Assumption Rationale Sheet

INTENTIONALLY LEFT BLANK 
Controlled Design Assumption

Assumption Rationale Sheet 


\section{Controlled Design Assumption}

Assumption Rationale Sheet

Assumption Identifier: TDS 002

Subject: Topography/Morphology

\section{STATEMENT OF ASSUMPTION}

The Topographical Survey Data and Surface Morphology shall be as described in Section 1.11 of the Reference Information Base (RIB).

\section{BACKGROUND}

Requesting Management and Operating Contractor $(\mathrm{M} \& \mathrm{O})$ organization:

(X) Surface, ( ) Subsurface, ( ) Waste Package Development, ( ) Other (specify):

Need for assumption (statement of intended use):

This information is needed as input for site layouts

\section{RATIONALE}

Rationale for assumption (source author, date, and report title) or statement of reasoning behind engineering judgment:

This information is taken directly from the Reference Information Base (RIB).

\section{RESPONSIBILITY AND WITHDRAWAL}

Responsible Management and Operating Contractor (M\&O) organization: Scientific Program Operations

Document(s) Supporting Withdrawal of Assumption:

Withdrawal Date: 


\section{Controlled Design Assumption \\ Assumption Rationale Sheet}

Assumption Identifier: TDS 003

Subject: Soil Properties

\section{STATEMENT OF ASSUMPTION}

The Soil Properties are described in Sections 1.1311,1.1312, 1.1313, and 1.1314 of the RIB.

The soil hydrologic properties, soil mechanical properties, soil geochemical properties, and soil physical properties are given.

\section{BACKGROUND}

Requesting Management and Operating Contractor (M\&O) organization:

(X) Surface, ( ) Subsurface, ( ) Waste Package Development, ( ) Other (specify):

Need for assumption (statement of intended use):

This information is needed as input into surface facilities layouts, surface facilities structural design, and certain environmental considerations that will be incorporated into the overall design.

\section{RATIONALE}

Rationale for assumption (source author, date, and report title) or statement of reasoning behind engineering judgment:

This information is taken directly from the Reference Information Base (RIB).

\section{RESPONSIBILITY AND WITHDRAWAL}

Responsible Management and Operating Contractor (M\&O) organization: Scientific Program Operations

Document(s) Supporting Withdrawal of Assumption:

Withdrawal Date: 


\section{Controlled Design Assumption \\ Assumption Rationale Sheet}

Assumption Identifier: TDS 004

\section{STATEMENT OF ASSUMPTION}

The Site Meteorology includes data on normal atmospheric and climatic conditions at the site based on historical data. These conditions are delineated in Section 1.3 of the Reference Information Base (RIB).

\section{BACKGROUND}

Requesting Management and Operating Contractor (M\&O) organization:

(X) Surface, ( ) Subsurface, ( ) Waste Package Development, ( ) Other (specify):

Need for assumption (statement of intended use):

This information will be used as input into various features of the facilities designs and will impact the operational concepts.

\section{RATIONALE}

Rationale for assumption (source author, date, and report title) or statement of reasoning behind engineering judgment:

This information is taken directly from the Reference Information Base (RIB).

\section{RESPONSIBILITY AND WITHDRAWAL}

Responsible Management and Operating Contractor (M\&O) organization: Scientific Program Operations

Document(s) Supporting Withdrawal of Assumption:

Withdrawal Date: 


\section{Controlled Design Assumption \\ Assumption Rationale Sheet}

Assumption Identifier: TDS 006

Subject: Design Basis Tomadoes

\section{STATEMENT OF ASSUMPTION}

The Design Basis Tomado (DBT) will be based on the "Parameters of Design-Basis Tomadoes (DBTs) for NTS," which are given in the Reference Information Base (RIB), Section I.3b, Table 2. Even though tomadoes have never been observed on the Nevada Test Site (NTS) or within 150 miles of the NTS, the surface facilities design will be consistent with that used at the NTS.

\section{BACKGROUND}

Requesting Management and Operating Contractor (M\&O) organization:

(X) Surface, ( ) Subsurface, ( ) Waste Package Development, ( ) Other (specify):

Need for assumption (statement of intended use):

The design of nuclear facilities must assure that the designs considers severe natural phenomena.

\section{RATIONALE}

Rationale for assumption (source author, date, and report title) or statement of reasoning behind engineering judgment:

- This material came directly from the Reference Information Base (RIB).

- Differences between the RIB and NRC Regulatory guide 1.76, "Design Basis for Nuclear Power Plants" are to be evaluated for compliance with the NRC regulatory requirements.

- Sandstorm loading is assumed to be bounded by tomado and tomado missile loading and hence are not addressed in a separate CDA assumption.

\section{RESPONSIBILITY AND WITHDRAWAL}

Responsible Management and Operating Contractor (M\&O) organization: Scientific Program Operations

Document(s) Supporting Withdrawal of Assumption:

Withdrawal Date: 


\section{Controlled Design Assumption \\ Assumption Rationale Sheet}

Assumption Identifier: TDS 007

Subject: Winds (Operating Basis and Standard)

\section{STATEMENT OF ASSUMPTION}

The prevailing wind summary given in the Meterological Monitoring Program Summary Report January 1994 through December 1994 (BA0000000-01717-5700-00001) will be used as the Operating Basis Wind and Standard Wind for surface facilities design considerations.

\section{BACKGROUND}

Requesting Management and Operating Contractor (M\&O) organization:

(X) Surface, ( ) Subsurface, ( ) Waste Package Development, ( ) Other (specify):

Need for assumption (statement of intended use):

The Concept of Operations uses this information for such considerations as dust suppression, effluent release calculations, etc.

\section{RATIONALE}

Rationale for assumption (source author, date, and report title) or statement of reasoning behind engineering judgment:

- This report provides the best source of local wind data.

- Sandstorm loading is assumed to be bounded by tomado and tornado missile loading and hence are not addressed in a separate CDA assumption.

\section{RESPONSIBILITY AND WITHDRAWAL}

Responsible Management and Operating Contractor (M\&O) organization: Scientific Program Operations

Document(s) Supporting Withdrawal of Assumption:

Withdrawal Date: 


\section{Controlled Design Assumption \\ Assumption Rationale Sheet}

Assumption Identifier: TDS 008

Subject: Floods (Design Basis)

\section{STATEMENT OF ASSUMPTION}

The Design Basis Flood shall be based on the Probable Maximum Flood Boundaries identified in Tables 2.6.2-1 and 2.6.2-2 of the Technical Basis Report for Surface Characteristics, Preclosure Hydrology and Erosion. Document No.: YMP/TBR-001, Rev. 0.

\section{BACKGROUND}

Requesting Management and Operating Contractor (M\&O) organization:

(X) Surface, ( ) Subsurface, ( ) Waste Package Development, ( ) Other (specify):

Need for assumption (statement of intended use):

Drainage areas and peak flood discharges will be factors that will impact the location and layout of the various surface facilities.

\section{RATIONALE}

Rationale for assumption (source author, date, and report title) or statement of reasoning behind engineering judgment:

This information governs that which previously was cited in the Reference Information Base (RIB). This report was developed to provide surface characteristics, preclosure hydrology, and erosion at the Yucca Mountain Site, to support evaluation of siting guidelines of $10 \mathrm{CFR}$ Part 960, General Guidelines for the Recommendation of Sites for the Nuclear Waste Repositories.

Differences between YMP/TBR-001 and NRC Regulatory guide 1.59, "Design Basis Floods for Nuclear Power Plants" are to be evaluated for compliance with NRC regulatory requirements.

\section{RESPONSIBILITY AND WITHDRAWAL}

Responsible Management and Operating Contractor (M\&O) organization: Scientific Program Operations

Document(s) Supporting Withdrawal of Assumption:

Withdrawal Date: 
Controlled Design Assumption

Assumption Rationale Sheet

INTENTIONALLY LEFT BLANK 
Controlled Design Assumption

Assumption Rationale Sheet

SECTION 10

TECHNICAL DATA SUBSURFACE ASSUMPTIONS (TDSS) 
Controlled Design Assumption

Assumption Rationale Sheet

INTENTIONALLY LEFT BLANK 


\section{STATEMENT OF ASSUMPTION}

Rock in situ stress at proposed repository horizon:

\begin{tabular}{lll} 
Parameter & Average Value & Range \\
\cline { 2 - 3 } Vertical Stress & $7.0 \mathrm{MPa}$ & $5.0-10.0 \mathrm{MPa}$ \\
Min Horiz/Vert Stress & $0.5 \mathrm{MPa}$ & $0.3-0.8 \mathrm{MPa}$ \\
Max Horiz/Vert Stress & $0.6 \mathrm{MPa}$ & $0.3-1.0 \mathrm{MPa}$ \\
Bearing - Min Horiz Stress & N57W & N50W $-\mathrm{N} 65 \mathrm{~W}$ \\
Bearing - Max Horiz Stress & N32E & N25E - N40E
\end{tabular}

\section{BACKGROUND}

Requesting Management and Operating Contractor (M\&O) organization:

( ) Surface, (X) Subsurface, ( ) Waste Package Development, or ( ) Other (specify):

Need for assumption (statement of intended use):

Affects repository layout and induced stresses.

\section{RATIONALE}

Rationale for assumption (source author, date, and report title) or statement of reasoning behind engineering judgment:

From Site Characterization Plan Conceptual Design Report (SCP CDR)

\section{RESPONSIBILITY AND WITHDRAWAL}

Responsible Management and Operating Contractor (M\&O) organization: Scientific Program Operations

Document(s) Supporting Withdrawal of Assumption:

Withdrawal Date: 


\section{Controlled Design Assumption \\ Assumption Rationale Sheet}

Assumption Identifier: TDSS 002

Subject: Groünd Surface Temperature, Rock Thermal Gradient

\section{STATEMENT OF ASSUMPTION}

Average rock temperature at ground surface: $18.7^{\circ} \mathrm{C}$.

Thermal gradient in rock: $\quad 0.020^{\circ} \mathrm{C} / \mathrm{m}$ for depth 0 to $150 \mathrm{~m}$

$0.018^{\circ} \mathrm{C} / \mathrm{m}$ for depth 150 to $400 \mathrm{~m}$

$0.030^{\circ} \mathrm{C} / \mathrm{m}$ for depth 400 to $541 \mathrm{~m}$

\section{BACKGROUND}

Requesting Management and Operating Contractor (M\&O) organization:

( ) Surface, (X) Subsurface, ( ) Waste Package Development, ( ) Other (specify):

Need for assumption (statement of intended use):

Affects repository rock temperature from thermal loading and ventilation system design.

\section{RATIONALE}

Rationale for assumption (source author, date, and report title) or statement of reasoning behind engineering judgment:

From Reference Information Base (RIB), Rev. 03 ICN 1, Section 1.1326a, text on page 4 and Figure 4 on page 20 , which is based on temperature profile in USW G-4.

\section{RESPONSIBILITY AND WITHDRAWAL}

Responsible Management and Operating Contractor (M\&O) organization: Scientific Program Operations

Document(s) Supporting Withdrawal of Assumption:

Withdrawal Date: 


\section{Controlled Design Assumption}

Assumption Rationale Sheet

Assumption Identifier: TDSS 003

Subject: ${ }^{-}$TSw2 In Situ Saturation

\section{STATEMENT OF ASSUMPTION}

In situ degree of saturation (percent) - TSw2: 65 .

\section{BACKGROUND}

Requesting Management and Operating Contractor (M\&O) organization:

( ) Surface, (X) Subsurface, ( ) Waste Package Development, ( ) Other (specify):

Need for assumption (statement of intended use):

Affects repository rock temperature from thermal loading and ventilation system design.

\section{RATIONALE}

Rationale for assumption (source author, date, and report title) or statement of reasoning behind engineering judgment:

Mean value from Reference Information Base (RIB), Rev. 03, Section 1.1321d, Table 1. See Reference Information Base (RIB) for variability.

\section{RESPONSIBILITY AND WITHDRAWAL}

Responsible Management and Operating Contractor (M\&O) organization: Scientific Program Operations

Document(s) Supporting Withdrawal of Assumption:

Withdrawal Date: 


\section{STATEMENT OF ASSUMPTION}

Average TSw2 density is $2274 \mathrm{~kg} / \mathrm{m}^{3}$.

\section{BACKGROUND}

Requesting Management and Operating Contractor $(\mathrm{M} \& \mathrm{O})$ organization:

( ) Surface, (X) Subsurface, ( )Waste Package Development, ( ) Other (specify):

Need for assumption (statement of intended use):

Basic parameter for rock mechanics design.

\section{RATIONALE}

Rationale for assumption (source author, date, and report title) or statement of reasoning behind engineering judgment:

Value from Exploratory Studies Facility (ESF) Ground Support Analysis, BABEE0000-017170200-00002, REV 00, Table V-1. Value is mean of dry density at in situ degree of saturation.

\section{RESPONSIBILITY AND WITHDRAWAL}

Responsible Management and Operating Contractor $(M \& O)$ organization: Scientific Program Operations

Document(s) Supporting Withdrawal of Assumption:

Withdrawal Date: 


\section{Controlled Design Assumption \\ Assumption Rationale Sheet}

Assumption Identifier: TDSS 005

Subject: TSw̄2 Thermal Conductivity

\section{STATEMENT OF ASSUMPTION}

Thermal conductivity of rock mass (dry and in situ saturation) - TSw2: $2.1 \mathrm{~W} / \mathrm{mK}$.

\section{BACKGROUND}

Requesting Management and Operating Contractor (M\&O) organization:

( ) Surface, (X) Subsurface, ( ) Waste Package Development, ( ) Other (specify):

Need for assumption (statement of intended use):

Affects repository rock temperature from thermal loading and ventilation system design.

\section{RATIONALE}

Rationale for assumption (source author, date, and report title) or statement of reasoning behind engineering judgment:

Mean value from Reference Information Base (RIB), Rev. 03, Section 1.1326a, Table 2. See Reference Information Base (RIB) for variability.

\section{RESPONSIBILITY AND WITHDRAWAL}

Responsible Management and Operating Contractor (M\&O) organization: Scientific Program Operations

Document(s) Supporting Withdrawal of Assumption:

Withdrawal Date: 


\section{Controlled Design Assumption}

Assumption Rationale Sheet

Assumption Identifier: TDSS 006

Subject: TSw2 Heat Capacitance

\section{STATEMENT OF ASSUMPTION}

Heat capacitance of in situ rock - TSw2:

$\begin{array}{rl}2.0324 \times 10^{6} \mathrm{~J} / \mathrm{m}^{3} \mathrm{~K} @ 25^{\circ} \mathrm{C} & 2.0065 \times 10^{6} \mathrm{~J} / \mathrm{m}^{3} \mathrm{~K} @ 115^{\circ} \mathrm{C} \\ 2.1280 \times 10^{6} \mathrm{~J} / \mathrm{m}^{3} \mathrm{~K} @ 50^{\circ} \mathrm{C} & 2.1114 \times 10^{6} \mathrm{~J} / \mathrm{m}^{3} \mathrm{~K} @ 155^{\circ} \mathrm{C} \\ 2.2638 \times 10^{6} \mathrm{~J} / \mathrm{m}^{3} \mathrm{~K} @ 94^{\circ} \mathrm{C} & 2.1912 \times 10^{6} \mathrm{~J} / \mathrm{m}^{3} \mathrm{~K} @ 195^{\circ} \mathrm{C} \\ 10.7683 \times 10^{6} \mathrm{~J} / \mathrm{m}^{3} \mathrm{~K} @ 95^{\circ} \mathrm{C} & 2.2692 \times 10^{6} \mathrm{~J} / \mathrm{m}^{3} \mathrm{~K} @ 235^{\circ} \mathrm{C} \\ 10.4690 \times 10^{6} \mathrm{~J} / \mathrm{m}^{3} \mathrm{~K} @ 105^{\circ} \mathrm{C} & 2.3410 \times 10^{6} \mathrm{~J} / \mathrm{m}^{3} \mathrm{~K} @ 275^{\circ} \mathrm{C} \\ 10.1984 \times 10^{6} \mathrm{~J} / \mathrm{m}^{3} \mathrm{~K} @ 114^{\circ} \mathrm{C} & \end{array}$

\section{BACKGROUND}

Requesting Management and Operating Contractor $(\mathrm{M} \& \mathrm{O})$ organization:

( ) Surface, (X) Subsurface, ( ) Waste Package Development, ( ) Other (specify):

Need for assumption (statement of intended use):

Affects repository rock temperature from thermal loading and ventilation system design.

\section{RATIONALE}

Rationale for assumption (source author, date, and report title) or statement of reasoning behind engineering judgment:

From Reference Information Base (RIB), Rev. 03, Section 1.1326a, Table 6. Rev. 00 of this document added values for a wider temperature range.

\section{RESPONSIBILITY AND WITHDRAWAL}

Responsible Management and Operating Contractor (M\&O) organization: Scientific Program Operations

Document(s) Supporting Withdrawal of Assumption:

Withdrawal Date: 


\section{Controlled Design Assumption}

Assumption Rationale Sheet

Assumption Identifier: TDSS 007

Subject: $\bar{T} S w 2$ Thermal Expansion

\section{STATEMENT OF ASSUMPTION}

Thermal expansion coefficient of in situ rock during heating - TSw2:

$\begin{array}{lrr}5.07 \times 10^{-6} / \mathrm{C} @ & 25- & 50^{\circ} \mathrm{C} \\ 7.03 \times 10^{-6} / \mathrm{C} @ & 50- & 100^{\circ} \mathrm{C} \\ 8.19 \times 10^{-6} / \mathrm{C} @ & 100-150^{\circ} \mathrm{C} \\ 8.97 \times 10^{-6} / \mathrm{C} @ & 150- & 200^{\circ} \mathrm{C}\end{array}$

\section{BACKGROUND}

Requesting Management and Operating Contractor (M\&O) organization:

( ) Surface, (X) Subsurface, ( ) Waste Package Development, ( ) Other (specify):

Need for assumption (statement of intended use):

Affects repository rock temperature and stress from thermal loading and ventilation system design.

\section{RATIONALE}

Rationale for assumption (source author, date, and report title) or statement of reasoning behind engineering judgment:

Values from Geotechnical Characterization of the North Ramp of the Exploratory Studies Facility (SAND95-0488).

\section{RESPONSIBILITY AND WITHDRAWAL}

Responsible Management and Operating Contractor (M\&O) organization: Scientific Program Operations

Document(s) Supporting Withdrawal of Assumption:

Withdrawal Date: 


\section{Controlled Design Assumption \\ Assumption Rationale Sheet}

Assumption Identifier: TDSS 008

Subject: TSw2 Elastic Modulus

\section{STATEMENT OF ASSUMPTION}

Elastic modulus of intact rock - TSw2 (at ambient temperature).

Rock Mass Quality Category

1

Elastic Modulus (GPa)

6.37

8.96

3

12.55

4

17.11

5

23.51

\section{BACKGROUND}

Requesting Management and Operating Contractor (M\&O) organization:

( ) Surface, (X) Subsurface, ( ) Waste Package Development, ( ) Other (specify):

Need for assumption (statement of intended use):

Needed for stress and deformation calculations of rock mass.

\section{RATIONALE}

Rationale for assumption (source author, date, and report title) or statement of reasoning behind engineering judgment:

Values from Sandia National Laboratories Data Transmittal for Rock Mass Mechanical Properties Estimates from NRG Drilling Program, TDIF 304414, DTN: SNF29041993002.062, June 1995.

\section{RESPONSIBILITY AND WITHDRA WAL}

Responsible Management and Operating Contractor (M\&O) organization: Scientific Program Operations

Document(s) Supporting Withdrawal of Assumption:

Withdrawal Date: 
Assumption Identifier: TDSS 009

Subject: TSw2 Poisson's Ratio

\section{STATEMENT OF ASSUMPTION}

Poisson's ratio (at ambient temperature):

Intact Rock - TSw2: 0.21

Rock Mass - TSw2: 0.21

\section{BACKGROUND}

Requesting Management and Operating Contractor (M\&O) organization:

( ) Surface, (X) Subsurface, ( ) Waste Package Development, ( ) Other (specify):

Need for assumption (statement of intended use):

Needed for stress and deformation calculations of rock mass.

\section{RATIONALE}

Rationale for assumption (source author, date, and report title) or statement of reasoning behind engineering judgment:

Values from Sandia National Laboratories Data Transmittal for Rock Mass Mechanical Properties Estimates from NRG Drilling Program, TDIF 304414, DTN: SNF29041993002.062, June 1995.

\section{RESPONSIBILITY AND WITHDRAWAL}

Responsible Management and Operating Contractor (M\&O) organization: Scientific Program Operations

Document(s) Supporting Withdrawal of Assumption:

Withdrawal Date: 


\section{Controlled Design Assumption \\ Assumption Rationale Sheet}

Assumption Identifier: TDSS 010

Subject: TSw2 Uniaxial Compressive Strength

\section{STATEMENT OF ASSUMPTION}

Uniaxial compressive strength of intact rock - Tsw2: $155 \mathrm{MPa}$ (at ambient temperature).

\section{BACKGROUND}

Requesting Management and Operating Contractor (M\&O) organization:

( ) Surface, (X) Subsurface, ( ) Waste Package Development, ( ) Other (specify):

Need for assumption (statement of intended use):

Needed for stress and deformation calculations of rock mass.

Basic parameter for rock mechanics design.

\section{RATIONALE}

Rationale for assumption (source author, date, and report title) or statement of reasoning behind engineering judgment:

Mean value from Reference Information Base (RIB), Rev. 03, Section 1.1322a, Table 1. See Reference Informatin Base (RIB) for variability.

\section{RESPONSIBILITY AND WITHDRAWAL}

Responsible Management and Operating Contractor (M\&O) organization: Scientific Program Operations

Document(s) Supporting Withdrawal of Assumption:

Withdrawal Date: 


\section{Controlled Design Assumption \\ Assumption Rationale Sheet}

Assumption Identifier: TDSS 011

Subject: TSw2 Mohr-Coūomb Strength Parameters

\section{STATEMENT OF ASSUMPTION}

Mohr-Coulomb strength parameters of intact rock - TSw2 (at ambient temperature):

\begin{tabular}{ccc} 
Rock Mass Quality Category & Cohesion $(\mathrm{MPa})$ & Eriction Angle (Degrees) \\
\cline { 2 - 2 } 1 & 1.3 & 49 \\
2 & 1.6 & 49 \\
3 & 2.2 & 50 \\
4 & 2.8 & 50 \\
5 & 3.8 & 50
\end{tabular}

\section{BACKGROUND}

Requesting Management and Operating Contractor $(\mathrm{M} \& \mathrm{O})$ organization:

( ) Surface, (X) Subsurface, ( ) Waste Package Development, ( ) Other (specify):

Need for assumption (statement of intended use):

Needed for evaluation of stability of rock structure.

\section{RATIONALE}

Rationale for assumption (source author, date, and report title) or statement of reasoning behind engineering judgment:

Values from Sandia National Laboratories Data Transmittal for Rock Mass Mechanical Properties Estimates from NRG Drilling Program, TDIF 304414, DTN: SNF29041993002.062, June 1995.

\section{RESPONSIBILITY AND WITHDRAWAL}

Responsible Management and Operating Contractor (M\&O) organization: Scientific Program Operations

Document(s) Supporting Withdrawal of Assumption:

Withdrawal Date: 
Assumption Identifier: TDSS 012

Subject: TSw2 Porosity

\section{STATEMENT OF ASSUMPTION}

Porosity of intact rock - TSw2: 0.121 .

\section{BACKGROUND}

Requesting Management and Operating Contractor (M\&O) organization:

( ) Surface, (X) Subsurface, ( ) Waste Package Development, ( ) Other (specify):_)

Need for assumption (statement of intended use):

Needed to calculate rate at which water is absorbed or removed from rock. Affects thermal calculations and ventilation system design.

\section{RATIONALE}

Rationale for assumption (source author, date, and report title) or statement of reasoning behind engineering judgment:

Mean value from Reference Information Base (RIB), Rev. 03, Section 1.1321a, Table 1. See Reference Information Base (RIB) for variability.

\section{RESPONSIBILITY AND WITHDRAWAL}

Responsible Management and Operating Contractor (M\&O) organization: Scientific Program Operations

Document(s) Supporting Withdrawal of Assumption:

Withdrawal Date: 


\section{Controlled Design Assumption}

Assumption Rationale Sheet

Assumption Identifier: TDSS 017

Subject: Rock Joint Örientation and Frequency

\section{STATEMENT OF ASSUMPTION}

Rock joint orientation:

$\begin{array}{lll} & \text { Strike } & \text { Dip } \\ \text { Major Joint Set } & \text { N10-12W } & 75-90 \text { NE/SW } \\ \text { Minor Joint Sets } & \text { N25E } & 10 S E \\ & \text { N }- \text { N45E } & 80-90 \text { SE/NW }\end{array}$

Rock joint frequency: TSw2: $2.51 / \mathrm{m}$ for $70-80$ degree joints, $11.28 / \mathrm{m}$ for $80-90$ degree joints (mean value)

\section{BACKGROUND}

Requesting Management and Operating Contractor (M\&O) organization:

( ) Surface, (X) Subsurface, ( ) Waste Package Development, ( ) Other (specify):

Need for assumption (statement of intended use):

Needed for rock mass stability and deformation calculations.

\section{RATIONALE}

Rationale for assumption (source author, date, and report title) or statement of reasoning behind engineering judgment:

From Lin et al., SNL SAND92-0449, Table 3-9.

\section{RESPONSIBILITY AND WITHDRA WAL}

Responsible Management and Operating Contractor (M\&O) organization: Scientific Program Operations

Document(s) Supporting Withdrawal of Assumption:

Withdrawal Date: 


\section{Controlled Design Assumption \\ Assumption Rationale Sheet}

Assumption Identifier: TDSS 021

Subject: Surface Āir Temperature/Humidity

\section{STATEMENT OF ASSUMPTION}

Surface air temperature:

Maximum:

Minimum:

$42.2^{\circ} \mathrm{C}$

Annual Average:

$12.7^{\circ} \mathrm{C}$

Surface air humidity:

$\begin{array}{ll}\text { Maximum: } & 71 \text { percent } \\ \text { Minimum: } & 13 \text { percent } \\ \text { Annual Average: } & 54 \text { percent }\end{array}$

\section{BACKGROUND}

Requesting Management and Operating Contractor (M\&O) organization:

( ) Surface, (X) Subsurface, ( ) Waste Package Development, ( ) Other (specify):

Need for assumption (statement of intended use):

Affects underground ventilation and cooling system design.

\section{RATIONALE}

Rationale for assumption (source author, date, and report title) or statement of reasoning behind engineering judgment:

Temperature data from Reference Information Base (RIB), Rev. 03, Section 1.3a, Table 1.

Humidity data from Reference Information Base (RIB), Rev. 03, Section 1.3a, Table 3. Annual average taken as the 4 am value (the highest value) for conservatism at this time.

Source is Nevada Test Site (NTS) data obtained from Yucca Flat, which is located about 25 miles northeast of Yucca Mountain.

\section{RESPONSIBILITY AND WITHDRAWAL}

Responsible Management and Operating Contractor (M\&O) organization: Scientific Program Operations

Document(s) Supporting Withdrawal of Assumption:

Withdrawal Date: 
Assumption Identifier: TDSS 022

Subject: Wind Intensity

\section{STATEMENT OF ASSUMPTION}

Wind intensity:

$$
\begin{aligned}
& \text { Annual Average: } \quad 3.2 \mathrm{~m} / \mathrm{s} \\
& \text { Peak: } \quad>27 \mathrm{~m} / \mathrm{s}
\end{aligned}
$$

\section{BACKGROUND}

Requesting Management and Operating Contractor (M\&O) organization:

( ) Surface, (X) Subsurface, ( ) Waste Package Development, ( ) Other (specify):

Need for assumption (statement of intended use):

Affects design of ventilation exhaust system.

\section{RATIONALE}

Rationale for assumption (source author, date, and report title) or statement of reasoning behind engineering judgment:

From Reference Information Base (RIB), Rev. 03, ICN 1, Section 1.3a, Table 4, which is based on Nevada Test Site (NTS) data obtained from Yucca Flat located about 25 miles northeast of Yucca Mountain.

\section{RESPONSIBILITY AND WITHDRA WAL}

Responsible Management and Operating Contractor (M\&O) organization: Scientific Program Operations

Document(s) Supporting Withdrawal of Assumption:

Withdrawal Date: 


\section{Controlled Design Assumption}

Assumption Rationale Sheet 


\section{Controlled Design Assumption \\ Assumption Rationale Sheet}

Assumption TDSS 024 has been withdrawn 


\section{Controlled Design Assumption \\ Assumption Rationale Sheet}

Assumption Identifier: TDSS 025

Subject: Unsaturated Zonē Groundwater Chemistry

\section{STATEMENT OF ASSUMPTION}

The composition of seeping water (per Assumption TDSS 026) that enters the excavated volume of the repository is:

Typical: $\quad \mathrm{pH} 7.4(\mathrm{~J}-13)$

Variability: $\mathrm{pH} 4.5$ to 10.5

Concentration factor of 0.1 to 10 times the nominal J-13

These variabilities of the water chemistry are applicable to the water influx at the edge of the excavated volume.

\section{BACKGROUND}

Requesting Management and Operating Contractor (M\&O) organization:

() Surface, () Subsurface, ( ) Waste Package Development, or (X) Other (specify): Program Chief Scientist

Needed to determine waste package corrosion rates.

\section{RATIONALE}

The following rationale describes the basis for the assumed values of the water chemistry presented in this assumption. A formal request to the Site Evaluation Program Operations is being prepared to obtain qualified data from which to refine these values.

Since the repository horizon is well above the saturated zone, the source of seeping water is presumably precipitation (rainwater). As the water (i.e., aqueous solution) percolates through the soil and rock, its composition gradually changes from that of rainwater to that of J-13.

$\mathrm{J}-13$ well water has been extracted from TSw2 in the saturated zone, east of Yucca Mountain, so its composition should be indicative of the composition of groundwater at the TSw2 repository horizon. The composition of J-13 has been published in Reference 1 (pg. 38, Table 3-2). Compositions of typical rainwater have also been published in Reference 2 (pg. 165, Table 38). Comparison of the compositions cited above shows that, for each reported constituent, rainwater is more dilute than J-13 well water. Since dissolved constituents generally increase the corrosion capabilities of water, and since the composition of the percolating groundwater is progressing from the dilute composition of rainwater to the more concentrated composition of J-13 groundwater in the saturated zone, it is conservative to assume that the seeping water that enters the excavated volume has the composition of $\mathrm{J}-13$ well water. It is noted that the excavated volume, rather than the emplacement drift, is specified because a concrete drift lining, if used, may significantly affect the composition of the groundwater.

Because of local effects, the composition of water in some very localized environments (e.g., in a corrosion pit, under a microbial colony, after interactions with the engineered barrier system, with the waste package, or with any cementitious materials in the drift) may be more concentrated in some species.

The water involved in steady state ambient flow and especially the thermally induced mobilized flow will have more opportunities to be chemically altered than the episodic ambient flow. This is a very complex process to understand and predict. Estimates are being provided in this 


\section{Controlled Design Assumption Assumption Rationale Sheet}

assumption to cover the expected range of variability for those chemical properties that may have the largest potential to impact the engineered barrier design. These parameters are the water $\mathrm{pH}$ and the ionic concentration. Effects from major microbial activity and/or acidic divergence could lower the $\mathrm{pH}$ (Reference 3 ). A conservative estimate is a $\mathrm{pH}$ of 4.5 . The results from the calculations in Reference 4, indicate that $\mathrm{pH}$ values can change in the alkaline regions from 7 to 10.5. The dynamic nature of the heating and cooling of the rock surrounding the emplacement drifts could also contribute to increased concentration of ions in the water by boiling off part of the water as it travels through the rock. This increase in concentration is conservatively being assumed as a factor of 10 . Under conditions such as the episodic flow, the travel path of the water to the excavated openings is relatively direct and quick and therefore the ionic concentration of condensate may be more dilute than J-13. This is being assumed to be one tenth of the concentration of the measured J-13 ionic concentration (References 5 and 6 ).

\section{References:}

1) D. Wilder, "Preliminary Near-Field Environment Report, Volume II: Scientific Overview of Near-Field Environment and Phenomena", UCRL-LR-107476 Vol. 2, April 1993

2) Georg Mathess and John C. Harvey, "The Properties of Groundwater", John Wiley \& Sons, New York, 1982

3) William Murphy, "Geochemical Models for Gas-Water-Rock Interactions in a Proposed Nuclear Waste Repository at Yucca Mountain, Nevada", Center of Nuclear Waste Regulatory Analyses, San Antonio, Texas

4) Peter Lichtner, "Multiphase Multicomponent Nonisothermal Reactive Transport in Partially Saturated Porous Media", Presented at the International Conference on Deep Geologic Disposal of Radioactive Waste, 1996,

5) CRWMS M\&O 1997. Single Heater Test Interim Report. BABEAF000-01717-690000001, REV 0.

6) Glassley, W. and DeLoach, L. 1997. Second Quarter Results of Chemical Measurements in the Single Heater Test, REV 0. Livermore, California: Lawrence Livermore National Laboratory.

\section{RESPONSIBILITIES AND WITHDRAWAL}

Responsible Management and Operating Contractor (M\&O) organization: Site Evaluation Operations

Document(s) Supporting Withdrawal of Assumption:

Withdrawal Date: 


\section{Controlled Design Assumption \\ Assumption Rationale Sheet}

\section{Assumption Identifier: TDSS 026}

Subject: Boūnding Water Percolation

\section{STATEMENT OF ASSUMPTION}

The amount of liquid water that percolates downward, and is potentially available to seep into the emplacement drift in the vicinity of one waste package can be estimated in several ways. The following assumptions provide design-basis flow conditions. The ambient (naturally existing) flow rates are developed for the present day conditions (up to 100 years after initial emplacement of waste), near-term conditions (up to 300 years after initial emplacement) and long term conditions (up to 20,000 years after initial emplacement). A separate estimate of flow for drainage design is provided. In addition, the assumption provides the anticipated flow for thermally mobilized water. Design calculations should include the sum of the mobilized and ambient water flow (either the fully mediated, the steady focused or the episodic focused). The assumptions are as follows:

Ambient Fully Mediated (steady in time and uniform in space) Flow: (in the vicinity of one waste package)

Present-day: $0.05 \mathrm{~m}^{3} / \mathrm{year}$

Near-term: $\quad 0.1 \mathrm{~m}^{3} /$ year

Long-term: $\quad 0.5 \mathrm{~m}^{3} / \mathrm{year}$

Ambient Steady Focused (steady in time and focused in space) Flow: (on average, the engineered barrier system in the vicinity of a waste package will be exposed to such a flow once every 40 years)

Present-day: $2 \mathrm{~m}^{3}$ of water, occurring over one year

Near-term: $\quad 4 \mathrm{~m}^{3}$ of water, occurring over one year

Long-term: $20 \mathrm{~m}^{3}$ of water, occurring over one year

Ambient Episodic Focused (episodic in time and focused in space) Flow; (on average, the engineered barrier system in the vicinity of a waste package will be exposed to such a flow once every 40 years)

Present-day: $2 \mathrm{~m}^{3}$ of water, occurring over one week, one time in the year

Near-term: $\quad 4 \mathrm{~m}^{3}$ of water, occurring over one week, one time in the year

Long-term: $20 \mathrm{~m}^{3}$ of water, occurring over one week, one time in the year

\section{Drainage flow:}

Present-day: $0.2 \mathrm{~m}^{3} / \mathrm{m}$ of drift occurring over one week, one time per year Near-term: $\quad 0.4 \mathrm{~m}^{3} / \mathrm{m}$ of drift occurring over one week, one time per year Long-term: $\quad 2 \mathrm{~m}^{3} / \mathrm{m}$ of drift occurring over one week, one time per year 


\section{Controlled Design Assumption}

Assumption Rationale Sheet

\section{Mobilized flow (for present-day, near-term and long-term):}

$60 \mathrm{~m}^{3} / y e a r$ from emplacement to 30 years for a line load design or to 300 years for a point load design.

\section{BACKGROUND}

Requesting Management and Operating Contractor (M\&O) organization:

( )Surface, ( ) Subsurface, ( ) Waste Package Development, or (X ) Other (specify): Program Chief Scientist

Need for assumption (statement of intended use):

Needed for repository and waste package design to respond to percolating water potentially available to seep into the emplacement drifts.

\section{RATIONALE}

The following rationale describes the basis for the assumed flows presented in this assumption. A formal request to the Site Evaluations Program Operations is being prepared to obtain qualified data from which to refine these flow values.

The unsaturated zone at Yucca Mountain is composed of a sequence of variably-welded and variably-fractured tuff units, distinguishable in terms of their average flow properties: in descending order from the surface, these include the Tiva Canyon welded (TCW) and the Paintbrush nonwelded (PTn) units, and proposed repository host rock, the Topopah Spring welded (TSw) unit. Water reaching the TSw unit percolates downward to it from the surface through the overlying units. The percolation flux in the TSw unit itself is difficult to determine. It cannot be measured directly and only inferred from indirect lines of evidence. The rock is highly heterogeneous and the nature of flow in the unsaturated zone is chaotic and nonlinear, making such inference extremely difficult. Nevertheless, studies to date provide information that can be used to estimate a reasonable bound to the flow conditions that might affect the engineered barrier system.

Net infiltration into the TCw unit of water precipitating onto the surface of Yucca Mountain provides an upper boundary condition for the percolation flux. Current evidence suggests that present-day net infiltration averages about $5 \mathrm{~mm} /$ year across the site (Reference 1). This evidence also suggests that the infiltration varies significantly across the site. Precipitation at the site is episodic so that net infiltration at any specific location is intermittent, with episodes of higher infiltration occurring in short-duration events over only a few days to a week in any given year. Some estimates suggest that infiltration flux, averaged over the site, could be as much as $30 \mathrm{~mm}$ in some years and negligible in other years, under present conditions (Reference 1).

Because precipitation at the surface could increase in the future, net infiltration at the site could also increase. Modeling that accounts for global warming over the next three hundred years (near-term) due to the greenhouse effect suggests net infiltration could be twice present-day averages (Reference 2). In the longer term even greater fluxes might occur. Projections of possible climates in the next 20,000 years (long-term) suggest infiltration could increase by about a factor of 10 over present-day values (Reference 2 ): 


\section{Controlled Design Assumption \\ Assumption Rationale Sheet}

Estimates from a number of different lines of evidence (References 3-7) suggest the percolation flux in the host rock presently averages between 2 and $15 \mathrm{~mm} / \mathrm{year}$ across the site. This range is consistent with the estimate of present-day net infiltration flux.

Like the net infiltration, the percolation at depth is likely to be variable in both space and time. The PTn unit may provide significant mediation of the flow; however, this has not yet been shown conclusively. Also the possibility of spatial focusing of the flow as it proceeds downward, increasing the percolation flux in different locations at different times, cannot presently be precluded. It is reasonably conservative to assume that the average present-day percolation flux is the same as the average present-day infiltration rate, and that this flow could focus in different locations in the host rock.

This information suggests that the engineered barrier system should be designed to withstand percolation fluxes averaging on the order of $5 \mathrm{~mm} /$ year and ranging from near zero to as much as $30 \mathrm{~mm}$ year in the wettest years, if present-day conditions were assumed to continue. Under warming trends over the next few hundred years, average flux could double, with a range of near zero to $60 \mathrm{~mm} /$ year. Under longer term changes (over the next 20,000 years), the average percolation flux could increase by a factor of ten $(50 \mathrm{~mm} / \mathrm{year})$, with a range between near zero and $300 \mathrm{~mm} /$ year

Present-day flux is likely to be variable in time with values in some years much different than in others. If the percolation flux reflects the characteristics of the infiltration at the surface, it could also be intermittent within the year, with episodes of duration totaling as much as a week. Increased flux over the next few hundred years and in the longer term may occur because of increased frequency of these episodes, because of the increased intensity in individual episodes, or because the nature of the episodes changes (e.g. episodes of precipitation dominated by rainfall changing to those dominated by snow fall). For the purpose of design (wo cases should considered: one in which the flow is steady in flowing years and one in which the flow is episodic within the flowing years, with durations lasting seven days in those years.

The above flux estimates can be used to derive conservative design basis flows for the engineered barrier system. For engineered barriers of $10 \mathrm{~m}^{2}$ cross-sectional area and for flow that is fully mediated such that the flux is uniform across the repository and constant in time, the average flow contacting the portion of the engineered barrier system associated with a single waste package would be $0.05 \mathrm{~m}^{3} /$ year $\left(5 \mathrm{~mm} /\right.$ year $\times 10 \mathrm{~m}^{2}=0.05 \mathrm{~m}^{3} /$ year $)$. However, if the flow focuses, a greater amount of water could intersect the engineered barrier system associated with a single waste package. At an areal mass loading of $85 \mathrm{MTHM} / \mathrm{acre}$, the average area of host rock allocated to each waste package is about $400 \mathrm{~m}^{2}$. If all of the flow occurring in that area were in fact concentrated, as much as $2 \mathrm{~m}^{3}\left(5 \mathrm{~mm} /\right.$ year $\mathrm{x} 400 \mathrm{~m}^{2}=2 \mathrm{~m}^{3} /$ year) could intersect the portion of the engineered barrier system associated with a single waste package if that water all focused to that location. This flow could be constant in time or could be episodic, for example, with a duration of one week out of the year. Since the waste package area is about 1/40 of the area collecting the flowing water, each engineered barrier system region associated with a waste package should be exposed to focused flow about once every 40 years.

A greater design-basis flow should be considered for an engineered barrier system designed for longer-term conditions. In the near-term case, the average annual exposure could be as much as $0.1 \mathrm{~m}^{3} /$ year $\left(10 \mathrm{~mm} /\right.$ year $\times 10 \mathrm{~m}^{2}=0.1 \mathrm{~m}^{3} /$ year $)$ and for focused flow $4 \mathrm{~m}^{3} /$ year $(10 \mathrm{~mm} /$ year $\mathrm{x}$ $400 \mathrm{~m}^{2}=4 \mathrm{~m}^{3} / \mathrm{year}$ ). For systems designed for long-term periods (on the order of 20,000 years), the design basis should consider an average flow of $0.5 \mathrm{~m}^{3} /$ year $\left(50 \mathrm{~mm} /\right.$ year $\times 10 \mathrm{~m}^{2}=0.5$ $\mathrm{m}^{3} /$ year) and a focused flow of $20 \mathrm{~m}^{3}$ of water per year $\left(50 \mathrm{~mm} /\right.$ year $\times 400 \mathrm{~m}^{2}=20 \mathrm{~m}^{3} /$ year $)$.

The ambient flow values presented in this assumption are based on the average flux for that time. period and a specific ambient condition. The year to year variation in annual flux can be from 


\section{Controlled Design Assumption Assumption Rationale Sheet}

near zero to as much as six times the average value utilized in this assumption. The following table presents the range of low and high flow values that correspond to the year to year variations in flux values.

The ambient flow calculations described above account for time- and space-averaged fluxes, the year to year variations of those fluxes (as shown in the "range" table), the long term variation of those fluxes ("present-day", "near-term" and "long-term" cases), steady spatial focusing of the flux into a few fractures, and episodic spacial focusing of the flux into a few fractures. The variation not included is the spatial variation of average flux across the footprint. This variation is between near zero to a factor of five times the average infiltration flux (Reference I). It is not known how the variation transfers to percolation flux at depth, because the PTn unit has properties which can mediate, divert, or focus the flow, depending on the behavior of the fractures.

The drainage system should also be designed to withstand flows of water from such episodes. For a 5.5-m wide drift, a drainage system designed for present-day conditions should be capable of handling wet year ephemeral flows amounting to as much as $0.2 \mathrm{~m}^{3}$ of water per meter of drift ( $30 \mathrm{~mm} /$ year $\times 5.5 \mathrm{~m}$ drift width $=0.165 \mathrm{~m}^{3} / \mathrm{m}$, rounded to $0.2 \mathrm{~m} 3 / \mathrm{m}$ ) occurring over periods totaling one week. This quantity should be increased by a factor of 2 for a system designed to last three hundred years and by a factor of 10 for one designed to be effective on the order of 20,000 years.

\section{Range of Ambient Flow Values}

\begin{tabular}{|c|c|c|}
\hline \multirow{2}{*}{ Flow Condition } & \multicolumn{2}{|c|}{ Flow Values (m³ year) } \\
\cline { 2 - 3 } & Minimum & Maximum \\
\hline Ambient Fully Mediated & & 0.3 \\
\hline Present-day & near zero & 0.6 \\
\hline Near-term & near zero & 3 \\
\hline Long-term & near zero & 12 \\
\hline Ambient Episodic Steady & & 24 \\
\hline Present-day & near zero & 120 \\
\hline Near-term & near zero & \\
\hline Long-term & near zero & 12 \\
\hline Ambient Episodic Focused & & 24 \\
\hline Present-day & near zero & 120 \\
\hline Near-term & near zero & \\
\hline Long-term & near zero & \\
\hline & & \\
\hline
\end{tabular}

The flow conditions could be modified by the heat generated by the waste. Model simulations for nominal percolation fluxes and areal loading of $85 \mathrm{MTHM} / \mathrm{acre}$ (Reference 8) estimate that as much as $500 \mathrm{~mm} /$ year of water may be mobilized at a location $3 \mathrm{~m}$ above the drift. This 


\section{Controlled Design Assumption Assumption Rationale Sheet}

mobilization is estimated to persist for a few decades for line loading and a few centuries for point loading. It is possible that little of this mobilized water would flow into emplacement drifts. Nevertheless, for conservative design purposes, it is prudent to assume that such mobilization generates flow into drifts of this magnitude. Assuming that the mobilized water over the area from twice the drift diameter in each dimension focuses on to each engineered barrier system region associated with a waste package, the design basis for thermally perturbed conditions would consider an additional increment of water during the mobilization period of 60 $\mathrm{m}^{3}$ each year $\left(500 \mathrm{~mm} /\right.$ year $\left.\times 11 \mathrm{~m} \times 11 \mathrm{~m}=60 \mathrm{~m}^{3}\right)$. The applicable period would be several decades for line loading of the waste packages and several centuries for point loading.

\section{References:}

1) A. Flint, J. Hevesi and L. Flint, "Conceptual and numerical Model of Infiltration for the YUCCA Mountain Area, Nevada, USGS Milestone Report 3GUT623M, September 20, 1996, Denver, Colorado.

2) A. Flint, USGS Level 3 Milestone Report, SPH22FM4, March 10, 1997.

3) Bodvarsson, G.S., and T.M. Bandurraga, 1996. "Development and Calibration of the Three-Dimensional Site-Scale Unsaturated Zone Model of Yucca Mountain, Nevada," Lawrence Berkeley National Laboratory report.

4) Fabryka-Martin, J.T., A.V. Wolfsberg, P.R. Dixon, S.S. Levy, J. Musgrave, and H.J. Turin, 1996. "Summary Report of Chlorine-36 Studies: Systematic Sampling for Chlorine-36 in the ESF." Los Alamos National Laboratory Level 3 Milestone Report 3783M.

5) Weeks, E.P., 1997. "Major Pathways for Flow Through Yucca Mountain--Preliminary Thoughts," Presentation to the Unsaturated Zone Flow Model Expert Elicitation Workshop, Feb 3-4, 1997, Amargosa Valley, Nevada.

6) Yang et al., 1997, in preparation.

7) Paces, J.B., L.A. Neymark, B.D. Marshall, J.F. Whelan, and Z.E. Peterman, 1996. “Ages and Origins of Subsurface Secondary Minerals in the ESF," USGS Milestone Report 3GQH450M3.

8) D. Wilder, "Near-Field and Altered-Zone Environmental Report", UCRL-LR-124998, August 23, 1996

\section{RESPONSIBILITIES AND WITHDRA WAL}

Responsible Management and Operating Contractor (M\&O) organization: Site Evaluation Operations

Document(s) Supporting Withdrawal of Assumption:

Withdrawal Date: 


\section{CONCLUSIONS}

The descriptions of the functional analysis and the concept of operations for the Mined Geologic Disposal System have been removed from the Controlled Design Assumptions, Revision 04 document. The functional analysis and concept of operations are now documented in the Mined Geologic Disposal System Functional Analysis Document (B00000000-01717-1708-00006 REV 01) and the Preliminary Mined Geologic Disposal System Concept of Operations (B00000000-017174200-00004 Rev. 00). Also, the appropriate prior assumptions were either withdrawn or updated, and new assumptions have been added to capture current design concepts. 


\section{REFERENCES}

10 CFR 2. Rules of Practice for Domestic Licensing Proceedings and Issuance of Orders. I Washington D.C.: U.S. Government Printing Office.

10 CFR 20. Standards for Protection Against Radiation. 1995. Washington, D.C.: U.S. Govemment Printing Office.

10 CFR 50. Domestic Licensing of Production and Utilization Facilities. Washington D.C.: U.S. I Government Printing Office.

10 CFR 51. Environmental Protection Regulations for Domestic Licensing and Related Regulatory Functions. Washington D.C.: U.S. Government Printing Office.

10 CFR 60. Disposal of High-Level Radioactive Waste in Geologic Repositories. 1995. Washington, D.C.: U.S. Government Printing Office.

10 CFR 71. Packaging and Transportation of Radioactive Material. 1995. Washington, D.C.: U.S. Government Printing Office.

10 CFR 960. General Guidelines for the Recommendation of Sites for Nuclear Waste Repositories. 1995. Washington, D.C.: U.S. Government Printing Office.

29 CFR 1926. Safety and Health Regulations for Construction. 1995. Washington, D.C.: U. S. Government Printing Office.

29 USC 651. Federal Occupational Safety and Health Act. 29 USC 651, et seq.

30 USC 801. Federal Mine Safety and Health Act of 1977. 30 USC 801, et seq.

30 CFR 57. Safety and Health Standards-- Underground Metal and Nonmetal Mines. July 1995.

40 CFR 191. Environmental Radiation Protection Standards for Management and Disposal of Spent Nuclear Fuel, High-Level and Transuranic Radioactive Wastes. July 1995.

40 USC 10101. Nuclear Waste Policy Act of 1982. 40 USC 10101, et. seq.

42 USCA 6900. Resource Conservation and Recovery Act (RCRA) of 1976. 42 USCA 6900, et. seq.

61 FR 39278 (Federal Register), 1996. Decommissioning of Nuclear Power Reactors, 10 CFR Parts 2, 50, and 51, U.S. Nuclear Regulatory Commission. Federal Register, Vol. 61, No. 146, pp 39278 39304, July 29, 1996. Washington D.C.: U.S. Government Printing Office. 
Bickel and Kuesel. Tunnel Engineering Handbook. 1982. Van Nostrand Reinhold Company.

BNL 1996. Bodvarsson, G. S., and Bandurraga, T.M. Development and Calibration of ThreeDimensional Site-Scale Unsaturated Zone Model of Yucca Mountain, Nevada. August 1996. Berkeley, California: Berkeley National Laboratories, Earth Sciences Division.

CRWMS M\&O 1988. Total System Performance Assessment - 1988: An Evaluation of the Potential Yucca Mountain Report. December 1, 1988. Las Vegas, Nevada: U.S. Department of Energy, Civilian Radioactive Waste Management System.

CRWMS M\&O 1992. Monitored Retrievable Storage Facility Conceptual Design Report. TSO.92.0323.0257. May 1, 1992. Vienna, Virginia: U.S. Department of Energy, Civilian Radioactive Waste Management System Management and Operating Contractor.

CRWMS M\&O 1993a. Site Characterization Plan Thermal Goals Reevaluation. B0000000001717-5705-00005 REV 00. September 8, 1993. Las Vegas, Nevada: U.S. Department of Energy, Civilian Radioactive Waste Management System Management and Operating Contractor.

CRWMS M\&O 1993b. Repository Underground Ventilation System Concepts. B00000000-017175705-00003 REV 00. September 1993. Las Vegas, Nevada: U.S. Department of Energy, Civilian Radioactive Waste Management System Management and Operating Contractor.

CRWMS M\&) 1993c. Monitored Retrievable Storage Facility Cask Maintenance Facility Design Study Report Final Draft (MRSR-0001) February 28, 1993. Vienna, Virginia: U.S. Department of Energy, Civilian Radioactive Waste Management System Management and Operating Contractor.

CRWMS M\&O 1994a. Seismic Design Inputs for the Exploratory Studies Facility at Yucca Mountain. BAB000000-01717-5705-00001 REV 02. October 10, 1994. Las Vegas, Nevada: U.S. Department of Energy, Civilian Radioactive Waste Management System Management and Operating Contractor.

CRWMS M\&O 1994b. Retrievability Period System Study Report. B0,0000000-01717-5705-00017 REV 00. September 1994. Las Vegas, Nevada: U.S. Department of Energy, Civilian Radioáctive Waste Management System Management and Operating Contractor.

CRWMS M\&O 1994c. Initial Summary Report for Repository/Waste Package Advanced Conceptual Design. B00000000-01717-5705-00015 REV 00. August 1994. Las Vegas, Nevada: U.S. Department of Energy, Civilian Radioactive Waste Management System Management and Operating Contractor.

CRWMS M\&O 1994d. Waste Package Performance Allocation/Emplacement Mode System Study. B00000000-01717-5705-00018 REV 00. September 1994. Las Vegas, Nevada: U.S. Department of Energy, Civilian Radioactive Waste Management System Management and Operating Contractor. 
CRWMS M\&O 1994e. Multi-Purpose Canister (MPC) Implementation Program, Conceptual Design Phase Report, MPC MRS Facility Conceptual Design Report. A20000000-00811-570500004. September 1994. Vienna, Virginia: U.S. Department of Energy, Civilian Radioactive Waste Management System Management and Operating Contractor.

CRWMS M\&O 1994f. Total System Performance Assessment - 1994: An Evaluation of the Potential Yucca Mountain Report B00000000-01717-2200-00099 REV 01. March 1, 1994. Las Vegas, Nevada: U.S. Department of Energy, Civilian Radioactive Waste Management System Management and Operating Contractor.

CRWMS M\&O 1995g. Total System Performance Assessment - 1995: An Evaluation of the Potential Yucca Mountain Report. B00000000-01717-2200-00136 REV 00. August 1995. Las Vegas, Nevada: U.S. Department of Energy, Civilian Radioactive Waste Management System Management and Operating Contractor.

CRWMS M\&O 1995h. Waste Package Sizing Spreadsheet PCD Sizing, Masses, and Costing. 1OC\# LV.WP.WEW.7/95-229. July 14, 1995. Las Vegas, Nevada: U.S. Department of Energy, Civilian Radioactive Waste Management System Management and Operating Contractor.

CRWMS M\&O 1995i. Nevada Potential Repository Preliminary Transportation Strategy - Study 2. B00000000-01717-4600-00050 REV 00. September 1995. Las Vegas, Nevada: U.S. Department of Energy, Civilian Radioactive Waste Management System Management and Operating Contractor.

CRWMS M\&O 1995j. Qualification of Spent Nuclear Fuel Assembly Characteristics for use a Design Basis. E00000000-01717-0200-00002 REV 02. November 29, 1995. Vienna, Virginia: U.S. Department of Energy, Civilian Radioactive Waste Management System Management and Operating Contractor.

CRWMS M\&O 1995k. Yucca Mountain Site Characterization Project Meteorological Monitoring Program Summary Report January 1994 Through December 1994. BA0000000-01717-570000001. December 29, 1995. Las Vegas, Nevada: U.S. Department of Energy, Civilian Radioactive Waste Management System Management and Operating Contractor.

CRWMS M\&O 19951. ESF Ground Support Analysis. BABEE0000-01717-0200-00002 REV 00. September 1995. Las Vegas, Nevada: U.S. Department of Energy, Civilian Radioactive Waste Management System Management and Operating Contractor.

CRWMS M\&O 1995m. Criticality Control Material in MPC Design. IOC\#VA.SE.GUR.8/95.016. August 1, 1995. Vienna, Virginia: U.S. Department of Energy, Civilian Radioactive Waste Management System Management and Operating Contractor.

CRWMS M\&O 1995n. System Logistics and Waste Stream Data for MGDS CDA Update. IOC\#VA.SA.JK.03/95.038. March 28, 1995. Vienna, Virginia: U.S. Department of Energy, Civilian Radioactive Waste Management System Management and Operating Contractor. 
CRWMS M\&O 19950. FY 95 CDA Update Waste Stream Follow On Data. IOC\#VA.SA.JD.04/95.046. April 7, 1995. Vienna, Virginia: U.S. Department of Energy, Civilian Radioactive Waste Management System Management and Operating Contractor.

CRWMS M\&O 1995p. Control of Activities. QAP-2-0, Rev. 2. February 27, 1995. Las Vegas, Nevada: U.S. Department of Energy, Civilian Radioactive Waste Management System Management and Operating Contractor.

CRWMS M\&O 1995q. Classification of Permanent Items. QAP-2-3, Rev. 7. January 31, 1995. Las Vegas, Nevada: U.S. Department of Energy, Civilian Radioactive Waste Management System Management and Operating Contractor.

I CRWMS M\&O 1995r. Proposed Thermal Loading Strategy. A00000000-1717-17201 00001(MOL:19951 107.0072). Vienna, Virginia: U.S. Department of Energy, Civilian Radioactive I Waste Management System Management and Operating Contractor.

CRWMS M\&O 1996a. Mined Geologic Disposal System Advanced Conceptual Design Report. B00000000-01717-5705-00027 REV 00. March 1996. Las Vegas, Nevada: U.S. Department of Energy, Civilian Radioactive Waste Management System Management and Operating Contractor.

CRWMS M\&O 1996b. Mined Geologic Disposal System Functional Analysis Document. B00000000-01717-1708-00006 REV 01. September 27, 1996. Las Vegas, Nevada: U.S. Department of Energy, Civilian Radioactive Waste Management System Management and Operating Contractor.

I CRWMS M\&O 1996c has been deleted.

CRWMS M\&O 1996d. Engineered Barrier System Performance Requirements Systems Study Report. BB0000000-01717-5705-00001 REV 00. August 30, 1996. Las Vegas, Nevada: U.S. Department of Energy, Civilian Radioactive Waste Management System Management and Operating 1 Contractor (see update of this report in CRWMS M\&O 1997d).

CRWMS M\&O 1996e. Performance Confirmation Concept Study Report. B00000000-017175705-00035 REV 00. August 30, 1996. Las Vegas, Nevada: U.S. Department of Energy, Civilian Radioactive Waste Management System Management and Operating Contractor.

CRWMS M\&O 1996f. Waste Package Materials Selection Analysis. BBA000000-01717-020000020 REV 00. August 1, 1996. Las Vegas, Nevada: U.S. Department of Energy, Civilian Radioactive Waste Management System Management and Operating Contractor.

CRWMS M\&O 1996g. Thermal Loading Study for FY96. B00000000-01717-5705-00044 REV

I 01. November 8, 1996. Las Vegas, Nevada: U.S. Department of Energy, Civilian Radioactive Waste Management System Management and Operating Contractor. 
CRWMS M\&O 1996h. Preliminary Mined Geologic Disposal System Concept of Operations. B00000000-01717-4200-00004 REV 00. September 12, 1996. Las Vegas, Nevada: U.S. Department of Energy, Civilian Radioactive Waste Management System Management and Operating Contractor.

CRWMS M\&O 1996i. Update of Waste Package Spreadsheet for Sizing and Masses. IOC\# LV.WP.WEW.9.96-227. September 30, 1996. Las Vegas, Nevada: U.S. Department of Energy, Civilian Radioactive Waste Management System Management and Operating Contractor.

CRWMS M\&O 1996j. QAP-2-O, Work Control Evaluation for Development of the Controlled Design Assumptions Document. B00000000-01717-2200-00118 REV 03. August 2, 1996. Las Vegas, Nevada: U.S. Department of Energy, Civilian Radioactive Waste Management System Management and Operating Contractor.

CRWMS M\&O 1996k. Technical Document Preparation Plan for the Controlled Design Assumptions Document. B00000000-01717-4600-00031 REV 06. August 14, 1996. Las Vegas, Nevada: U.S. Department of Energy, Civilian Radioactive Waste Management System Management and Operating Contractor.

CRWMS M\&O 19961. Determination of Importance Evaluations. NLP-2-0, Rev. 2. March 15 1996. Las Vegas, Nevada: U.S. Department of Energy, Civilian Radioactive Waste Management System Management and Operating Contractor.

CRWMS M\&O 1996m. To Be Verified (TBV) and To Be Determined (TBD) Monitoring System. NLP-3-15, Rev. 3. February 19, 1996. Las Vegas, Nevada: U.S. Department of Energy, Civilian Radioactive Waste Management System Management and Operating Contractor.

CRWMS M\&O 1996n. Disposal Criticality Analysis Methodology Technical Report. B0000000001717-5705-00020, Rev. 00. August 15, 1996. Las Vegas, Nevada: U.S. Department of Energy, Civilian Radioactive Waste Management System Management and Operating Contractor.

CRWMS M\&O 19960. Second Waste Package Probabilistic Criticality Analysis: Generation and Evaluation of Internal Criticality Configurations. BBA000000-01717-2200-00005 Rev. 00. 1996. Las Vegas, Nevada: U.S. Department of Energy, Civilian Radioactive Waste Management System Management and Operating Contractor.

CRWMS M\&O 1997. Single Heater Test Interim Report. BABEAF000-01717-6900-00001, REV 0.

CRWMS M\&O 1997b. Waste Handling System Configuration Analysis. BCBD00000-01717-020000001 REV 01. March 14, 1997. Las Vegas, Nevada: U.S. Department of Energy, Civilian Radioactive Waste Management System Management and Operating Contractor.

CRWMS M\&O 1997c. Waste Quantity, Mix and Throughput Study Report. B00000000-017175705-00059 REV 00. March 31, 1997. Las Vegas, Nevada: U.S. Department of Energy, Civilian Radioactive Waste Management System Management and Operating Contractor. 
CRWMS M\&O 1997d. Engineered Barrier System Performance Requirements Systems Study Report. BB0000000-01717-5705-00001 REV 02. January 14, 1997. Las Vegas, Nevada: U.S.

I Department of Energy, Civilian Radioactive Waste Management System Management and Operating I Contractor.

CRWMS M\&O 1997e. Determination of Waste Package Design Configurations. BBAA0000001717-0200-00017, Rev. 00. April 1997. Las Vegas, Nevada: U.S. Department of Energy, Civilian Radioactive Waste Management System Management and Operating Contractor.

CRWMS M\&O 1997f. Throughput Study Data/Input to CDA: Correction of Numerical Discrepancies. IOC\# LV.SES.OEL.7/97-047. July 17, 1997. O.E. Lev to Gary Teraoka. Las Vegas, Nevada: U.S. Department of Energy, Civilian Radioactive Waste Management System Management and Operating Contractor.

CRWMS M\&O 1997g. Mined Geologic Disposal System Design Issues -- Issue Resolution and Design Status. Letter \# LV.EIO.RDS.05/97-018. May 12, 1997. Richard D. Snell to Dr. Stephan J. Brocoum. Las Vegas, Nevada: U.S. Department of Energy, Civilian Radioactive Waste Management System Management and Operating Contractor.

CRWMS M\&O 1997h. Development of the Controlled Design Assumptions Document. Implementing Line Procedure NLP-3-32, Rev. 1. Las Vegas, Nevada: U.S. Department of Energy, Civilian Radioactive Waste Management System Management and Operating Contractor.

Czarnecki, J.B. and Waddell, R.K. 1984. Finite-Element Simulation of Ground-Water Flow in the Vicinity of Yucca Mountain, Nevada. USGS/WRI-84-4349. Denver, Colorado: U.S. Geological Survey.

DOE 1985. Position on Retrievability for a Geologic Repository. OGR/B-2, Appendix D. March 12, 1985. U.S. Department of Energy.

DOE 1988. Site Characterization Plan. Yucca Mountain Site, Nevada Research and Development Area, Nevada. DOE/RW-0199. December 1988. U.S. Department of Energy, Office of Civilian Radioactive Waste Management.

DOE 1992. U.S. Department of Energy Radiological Control Manual. DOE/EH-0256T. June 1992. U.S. Department of Energy.

DOE 1994a. NV/YMP Radiological Control Manual. DOE/NV-1063059. December 1994. Las Vegas, Nevada: U.S. Department of Energy, Yucca Mountain Site Characterization Project.

DOE 1994b. Implementation of the Program Approach. BCP-00-94-0005. October 11, 1994. U.S. Department of Energy, Office of Civilian Radioactive Waste Management.

DOE 1994c. Radio Utilization Program. NTS-SOP-5302. February 3, 1994. U.S. Department of Energy, Nevada Test Site Standard Operating Procedure. 
DOE 1995a. U.S. Department of Energy (DOE) NTS Standard Operating Procedure Chapter 5301, Telecommunications. NTS-SOP-5301. October 25, 1995. U.S. Department of Energy, Nevada Test Site Standard Operating Procedure.

DOE 1995b. Nuclear Waste Policy Act, as Amended, with Appropriations Acts Appended. DOE/RW-0438, Rev. I February 1995. Washington, DC: U.S. Department of Energy, Office of Civilian Radioactive Waste Management.

DOE 1995c. Quality Assurance Requirements and Description. DOE/RW-0333P, Rev. 5. October 31, 1995. Las Vegas, Nevada: U.S. Department of Energy, Yucca Mountain Site Characterization Project.

DOE 1995d. Dreyfus, D. Information Only: Initiation of National Environmental Policy Act Requirements for the Potential Repository at Yucca Mountain, Nevada. June 22, 1995. U. S. Department of Energy, Office of Civilian Radioactive Waste Management.

DOE 1996a. MPC Policy Change Baseline Change Proposal. BCP 00-96-0002, BCP Rev. 0. February 14, 1996. U.S. Department of Energy, Office of Civilian Radioactive Waste Management.

DOE 1996b. Civilian Radioactive Waste Management System Requirements Document. DOE/RW0406, Rev. 2, DCN-1 (A00000000-00811-1708-00003). June 1996. Washington, D.C.: U.S. Department of Energy, Office of Civilian Radioactive Waste Management.

DOE 1996. Mined Geologic Disposal System Requirements Document. DOE/RW-0404P, Rev. 2, DCN-1 (B0000000-00811-1708-00002). June 1996. Washington, D.C.: U.S. Department of Energy, Office of Civilian Radioactive Waste Management.

DOE 1996. Transportation System Requirements Document. DOE/RW-0425, Rev. 2, DCN-1 (D00000000-00811-1708-00002). June 1996. Washington, D.C.: U.S. Department of Energy, Office of Civilian Radioactive Waste Management.

DOE 1996. Waste Acceptance System Requirements Document. DOE/RW-035IP, Rev. 2, DCN-1 (E00000000-00811-1708-00001). June 1996. Washington, D.C.: U.S. Department of Energy, Office of Civilian Radioactive Waste Management.

DOE 1997. Topical Report on Actinide Only Burnup Credit for PWR Spent Nuclear Fuel Packages. DOE/RW-0472, Rev. 1, May 1997. U.S. Department of Energy, Office of Civilian Radioactive Waste Management.

DOE Order 5480.3. Safety Requirements for the Packaging and Transportation of Hazardous Materials, Hazardous Substances, and Hazardous Wastes. U.S. Department of Energy.

DOE Order 5480.4. Environmental Protection, Safety and Health Protection Standards. U.S. Department of Energy. 
DOE Order 5820.2A. Radioactive Waste Management. U.S. Department of Energy.

DOE Order 6430.1A. General Design Criteria. U.S. Department of Energy.

Flint, A.; Hevesi, J.; and Flint, L 1996. Conceptual and Numerical Model of Infiltration for the Yucca Mountain Area, Nevada (DRAFT). Water Resources Investigation Report (not yet assigned). Denver, Colorado: U. S. Geological Survey.

Glassley, W. and DeLoach, L. 1997. Second Quarter Results of Chemical Measurements in the Single Heater Test, REV 0. Livermore, Califomia: Lawrence Livermore National Laboratory.

I Guida, Richard A. 1997a. Department of the Navy letter to Russell Dyer, YMSCO, relating to bounding dimensions and weight of Naval SNF canisters, dated October 29, 1997.

Guida, Richard A. 1997b. Department of the Navy letter to Wesley Bames, YMSCO, relating to dimensions and weight of Naval SNF canisters, dated February 14, 1997.

Hartmann, H. L., Mutmansky, J.M. and Wang, Y.J. Mine Ventilation and Air Conditioning. Second Edition. 1982. New York: John Wiley and Sons, Inc.

Incropera and DeWitt. Fundamentals of Heat and Mass Transfer. Second Edition. 1985. New York: John Wiley and Sons, Inc.

Industrial Ventilation, A Manual of Recommended Practice. 18th Edition. 1984. Cincinnati, Ohio: American Conference of Governmental Industrial Hygienists.

Jackson, S.A 1997. Statement Presented by Chairman Shirley Ann Jackson United States Nuclear Regulatory Commission to the Subcommittee on Energy and Power, Committee on Commerce. United States House of Representatives Concerning High-Level Waste Legislation. Submitted on April 29, 1997, Washington, D.C.

LANL 1996. Fabryka-Martin, J., et. al. Summary Report of Chlorine-36 Studies: Sampling, Analysis and Simulation of Chlorine-36 in the Exploratory Studies Facility. LA-CST-TIP-96-002, DRAFT. August 29, 1996. Los Alamos, New Mexico: Los Alamos National Laboratory.

LANL 1996. Fabryka-Martin, J., et. al. Summary Report of Chlorine-36 Studies. LA-CST-TIP-96003, DRAFT. August 30, 1996. Los Alamos, New Mexico: Los Alamos National Laboratory.

LANL 1996. Robinson, Bruce A., et. al. Modeling of Flow, Radionuclide Migration, and Environmental Isotope Distributions at Yucca Mountain. Draft. Los Alamos, New Mexico: Los Alamos National Laboratory.

Lichtner, P. 1996. Multiphase Multicomponent Nonisothermal Reactive Transport in Partially Saturated Porous Media. Presented at the International Conference on Deep Geologic Disposal of Radioactive Waste. 
Luckey, R.R.; Tucci, P.; Faunt, C.C.; Erin, E.M.; Steinkampf, W.C.; D'Agnese, F.A.; and Patterson, G.L. 1996. Status of Understanding of the Saturated-zone Ground-water Flow System at Yucca Mountain, Nevada as of 1995. Denver, Colorado: U.S. Geological Survey Water Resources Investigations Report.

Mathess, G. and Harvey, J. C. 1982. The Properties of Groundwater. New York, New York: John Wiley \& Sons.

Murphy, W. Geochemical Models for Gas-Water-Rock Interactions in a Proposed Nuclear Waste Repository at Yucca Mountain, Nevada. San Antonio, Texas: Center of Nuclear Waste Regulatory Analyses.

NRC 1974. Design Basis Tomado for Nuclear Power Plants. NRC Reg. Guide 1.76. 1974. Nuclear Regulatory Commission. October 1, 1996.

NRC 1977. Design Basis Floods for Nuclear Power Plants. NRC Reg. Guide 1.59, Rev 2. 1977. Nuclear Regulatory Commission.

NRC 1989. Staff Site Characterization Analysis of the Department of Energy's Site Characterization Plan. Yucca Mountain. NUREG 1347. August 1989. Nuclear Regulatory Commission.

NRC 1990. Clarification of 300-1000 years for Substantially Complete Containment of High-Level Waste within the Waste Packages, under 10CFR60.113(a)(1)(ii)(A). Nuclear Regulatory Staff Position 60-001. Nuclear Regulatory Commission.

NRC 1994. Staff Technical Position on Consideration of Fault Displacement Hazards in Geologic Repository Design. NUREG 1494 September 1994. Nuclear Regulatory Commission.

NWTRB. First Report to U.S. Congress and the U.S. Secretary of Energy from the Nuclear Waste Technical Review Board. March 1, 1990. Nuclear Waste Technical Review Board.

Simecka, William B. 1994. Key Assumptions for Focused Mined Geologic Disposal System (MGDS) Development. Letter to L. Dale Foust from William B. Simecka. AMEFO:PDS-3545.

SNL 1984. Preliminary Evaluation of the Subsurface Area Available for a Potential Nuclear Waste Repository at Yucca Mountain. SAND84-0175. December 1984. Albuquerque, New Mexico: Sandia National Laboratories.

SNL 1987. Site Characterization Plan Conceptual Design Report (SCP-CDR), Nevada Nuclear Waste Storage Investigations Project. SAND84-2641. September 1987. Albuquerque, New Mexico: Sandia National Laboratories.

SNL 1991. Dennis, W. A. Exploratory Studies Facility Alternatives Study: Final Report. SAND910025. September 1991. Albuquerque, New Mexico: Sandia National Laboratories. 
SNL 1993. Lin, et al. Fracture Analysis and Rock Quality Designation Estimation for the Yucca Mountain Site Characterization Project. SAND92-0449. February 1993. Albuquerque, New Mexico: Sandia National Laboratories.

SNL 1995. Data Transmittal for Rock Mass Mechanical Properties Estimates for NRG Drilling Program. TDIF 304416, DTN: SNF29041993002.064. June 1995.

SNL 1995. Brechtel, C.E., et al. Geotechnical Characterization of the North Ramp of the Exploratory Studies Facility. SAND95-0488. May 1995. Albuquerque, New Mexico: Sandia National Laboratories.

Wilder, D. 1993. Preliminary Near-Field Environment Report, Volume II: Scientific Overview of Near-Field Environment and Phenomena. UCRL-LR-107476 Vol. 2. Livermore, California: Lawrence Livermore National Laboratory.

Wilson, M. L.; Gauthier, J. H.; Barnard, R. W.; Barr, G. E.; Dockery, H. A.; Dunn, E.; Eaton, R. R.; Guerin, D. C.; Lu, N.; Martinez, M. J.; Nilson, R.; Rautman, C. A.; Robey, T. H.; Ryder, E. E.; Schenker, A. R.; Shannon, S. A.; Skinner, L. H.; Halsey, W. G.; Gansemer, J. D.; Lewis, L. C.; Lamont, A. D.; Triay, I. R.; Maijer, A.; Morris, D. E. 1994. Total-System Performance Assessment for Yucca Mountain - SNL Second Iteration (TSPA-1993). SAND 93-2675. Albuquerque, New Mexico: Sandia National Laboratories.

YMP 1990. 530I Field Telecommunications. YMP-F0I-5301 Rev. O September 5, 1990. U.S. Department of Energy, Yucca Mountain Site Characterization Project.

YMP 1992. Q-List. YMP/90-55Q Rev. 3 December 1994. Las Vegas, Nevada: U.S. Department of Energy, Yucca Mountain Site Characterization Project.

YMP 1993. Yucca Mountain Site Characterization Project, Tracers, Fluids and Materials Management Plan. YMP/91-23 Rev. 2 December 1993. Las Vegas, Nevada: U.S. Departiment of Energy, Yucca Mountain Site Characterization Project.

YMP 1994. Repository Design Requirements Document. YMP/CM-0023 Rev. 0 ICN I September 2, 1994. Las Vegas, Nevada: U.S. Department of Energy, Yucca Mountain Site Characterization Project.

YMP 1994. Engineered Barrier Design Requirements Document. YMP/CM-0024 Rev. 0 ICN 1 September 21, 1994. Las Vegas, Nevada: U.S. Department of Energy, Yucca Mountain Site Characterization Project.

YMP 1995a. Reference Information Base. YMP/93-02 Rev. 3 ICN-1 October 1995. Las Vegas, Nevada: U.S. Department of Energy, Yucca Mountain Site Characterization Project.

YMP 1995b. Technical Basis for Surface Characteristics, Preclosure Hydrology, and Erosion. YMP/TBR-001 Rev. O April 1995. U.S. Department of Energy, Yucca Mountain Site Characterization Project. 
YMP 1996. Preclosure Seismic Design Methodology for a Geologic Repository at Yucca Mountain. YMP/TR-003-NP Rev. I DRAFT A. August 1996. U.S. Department of Energy, Yucca Mountain Site Characterization Project.

YMP 1997. Interim Postclosure Requirement and Goal. Letter AML:AVL-1872. July 14, 1997. Wesley E. Barnes to L.D. Foust. U.S. Department of Energy, Office of Civilian Radioactive Waste Management, Yucca Mountain Site Characterization Project. 
INTENTIONALLY LEFT BLANK

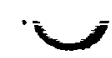


APPENDIX A

ASSUMPTION STATUS LOG 


\section{Controlled Design Assumption}

Assumption Status Log

As of Revision 04. ICN 3

Key Assumptions

\begin{tabular}{|c|c|c|c|}
\hline $\begin{array}{l}\text { Assumption } \\
\text { Identifier }\end{array}$ & Assumption Subject & $\begin{array}{l}\text { Responsible } \\
\text { Organization }\end{array}$ & $\begin{array}{c}\text { Status (New, } \\
\text { Revised, Unchanged, } \\
\text { Withdrawn) }\end{array}$ \\
\hline Key 002 & Waste Form Arrival Scenario & SE & $\mathrm{U}$ \\
\hline Key 003 & Waste Package Emplacement Scenario & SE & $\mathrm{U}$ \\
\hline Key 005 & HLW and DOE SNF & $\mathrm{SE}$ & $\mathrm{U}$ \\
\hline Key $006(W)$ & MGDS Waste Receipt Period & -- & $\mathrm{U}$ \\
\hline Key $007(W)$ & No MPC Repackaging for Heat Load Tailoring & $\ldots$ & $\mathbf{U}$ \\
\hline Key 008 & No Rod Consolidation & WP & $\mathrm{U}$ \\
\hline Key 009 & Burnup Credit & WP & $\mathbf{U}$ \\
\hline Key 013 & $\begin{array}{l}\text { No Human Entry in Emplacement Drifts Containing } \\
\text { Waste Packages }\end{array}$ & SS & $\mathbf{U}$ \\
\hline Key $014(W)$ & Preclosure Monitoring Activities - Robotics & - & $\mathbf{U}$ \\
\hline Key $015(W)$ & Remote Handling Systems & - & $\mathrm{U}$ \\
\hline Key 016 & Retrievability Period & SE & $\mathrm{U}$ \\
\hline
\end{tabular}


Controlled Design Assumption

Assumption Status Log

As of Revision 04, ICN 3

Key Assumptions

\begin{tabular}{|c|c|c|c|}
\hline $\begin{array}{l}\text { Assumption } \\
\text { Identiffer }\end{array}$ & Assumption Subject & $\begin{array}{l}\text { Responsible } \\
\text { Organization }\end{array}$ & $\begin{array}{c}\text { Status (New, } \\
\text { Revised, Unchanged, } \\
\text { Withdrawn) }\end{array}$ \\
\hline Key 017 & Reasons for Retrieval & SE & $\mathbf{U}$ \\
\hline Key $018(W)$ & Storage of Retrieved Packages & - & $\underline{\mathbf{U}}$ \\
\hline Key 019 & Mass Loading Range & SE & $\mathbf{U}$ \\
\hline Key $020(W)$ & Thermal Load Decision Date & - & $\mathbf{U}$ \\
\hline Key $021(W)$ & Performance Confirmation Areas for Thermal Loads & -- & $\mathrm{U}$ \\
\hline Key 022 & Repository Horizon & SS & $\mathrm{U}$ \\
\hline Key 023 & Subsurface Fault Standoff & SS & $\mathrm{U}$ \\
\hline Key 024 & Site-Generated Wastes & SE & $\mathrm{U}$ \\
\hline Key $025(W)$ & -- & -- & $\mathrm{U}$ \\
\hline Key $026(W)$ & -- & -- & $\mathbf{U}$ \\
\hline Key 027 & Mechanical Tunnel Excavation & SS & $\mathrm{U}$ \\
\hline Key 028 & Tunnel Drill-and-Blast Option & SS & $\underline{U}$ \\
\hline Key 029(W) & Technical Baseline Change (Remove Rod Consolidation) & -- & $\mathrm{U}$ \\
\hline Key 030 & Underground Transport of Personnel and Supplies & SS & $\mathrm{U}$ \\
\hline
\end{tabular}


Controlled Design Assumption

Assumption Status Log

As of Revision 04, ICN 3

Key Assumptions

\begin{tabular}{|c|c|c|c|}
\hline $\begin{array}{l}\text { Assumption } \\
\text { Identifier }\end{array}$ & Assumption Subject & $\begin{array}{l}\text { Responsible } \\
\text { Organization }\end{array}$ & $\begin{array}{c}\text { Status (New, } \\
\text { Revised, Unchanged, } \\
\text { Withdrawn) }\end{array}$ \\
\hline Key 031 & Waste Package Shielding & SE & $\mathbf{U}$ \\
\hline Key 032(W) & -- & -- & $\mathrm{U}$ \\
\hline Key $033(W)$ & Individual Waste Package Shielding & -- & $\mathrm{U}$ \\
\hline Key 034(W) & -- & -- & $\mathrm{U}$ \\
\hline Key $035(W)$ & - & -- & $\mathrm{U}$ \\
\hline Key $036(W)$ & $\begin{array}{l}\text { Substantially Complete Containment } \\
\text { (10 CFR 60.113) }\end{array}$ & -- & $\mathrm{U}$ \\
\hline Key $037(W)$ & Expected Waste Package Lifetime & - & $\mathbf{U}$ \\
\hline Key $038(W)$ & Waste Packages Breached at 1000 Years & -- & $\mathbf{U}$ \\
\hline Key 039 & Criticality Control Period & SE & $\mathbf{U}$ \\
\hline Key $040(W)$ & Period of Waste Isolation & -- & $\mathbf{U}$ \\
\hline Key $041(W)$ & Receipt and Emplacement Rates & - & $\mathrm{U}$ \\
\hline Key $042(W)$ & Waste Package Materials - High Thermal Load & -- & $\mathrm{U}$ \\
\hline Key $043(W)$ & Waste Package Materials - High Thermal Load & - & $\mathrm{U}$ \\
\hline Key 044(W) & -- & -- & $\mathbf{U}$ \\
\hline Key 045(W) & Alternative Waste Package Materials & -- & $\mathrm{U}$ \\
\hline Key 046 & Backfill in Emplacement Drifts & SE & $\mathrm{U}$ \\
\hline
\end{tabular}


Controlled Design Assumption

Assumption Status Log

As of Revision 04, ICN 3

Key Assumptions

\begin{tabular}{|l|l|c|c|}
\hline \multicolumn{1}{|c|}{$\begin{array}{c}\text { Assumption } \\
\text { Identifier }\end{array}$} & \multicolumn{1}{|c|}{ Assumption Subject } & \multicolumn{1}{|c|}{$\begin{array}{c}\text { Responsible } \\
\text { Organization }\end{array}$} & $\begin{array}{c}\text { Status (New, } \\
\text { Bevised, Unchanged, } \\
\text { Withdrawn) }\end{array}$ \\
\hline Key 047 & Surface Facilities Location & S & U \\
\hline Key 048(W) & Aluminum Boron in First MPC Procurement & U \\
\hline Key 049(W) & Aluminum Boron not Acceptable Long Term & - & U \\
\hline Key 050(W) & MPC Redesign in Second Procurement & -- & U \\
\hline Key 051(W) & First MPC Procurement Delivery Schedule & - & U \\
\hline Key 052(W) & Addition of Filler Material at the Repository & SE & U \\
\hline Key 053 & Off-Normal Waste Handling & S & U \\
\hline Key 054(W) & Normal Waste Handling Building Capability (No Filler & S & U \\
\hline Key 055 & Retrieval Demonstration & SS & U \\
\hline Key 056(W) & Interim Fuel Storage & SE & U \\
\hline Key 057 & Burnup or Thermal Measurement & SE & U \\
\hline Key 058 & Transportation Mode/Route Within Nevada & SE & U \\
\hline Key 059 & MGDS Configuration Item Organization & SE & U \\
\hline
\end{tabular}




\section{Controlled Design Assumption}

Assumption Status Log

As of Revision 04. ICN 3

Key Assumptions

\begin{tabular}{|c|c|c|c|}
\hline $\begin{array}{l}\text { Assumption } \\
\text { Identifier }\end{array}$ & Assumption Subject & $\begin{array}{l}\text { Responsible } \\
\text { Organization }\end{array}$ & $\begin{array}{c}\text { Status (New, } \\
\text { Revised, Unchanged, } \\
\text { Withdrawn) }\end{array}$ \\
\hline Key 060 & Interim Postclosure Standard & SE & $\mathbf{U}$ \\
\hline Key 061 & Performance Confirmation Requirements (1996) & SE & $\mathbf{U}$ \\
\hline Key $062(W)$ & DOE SNF & -- & $\mathbf{U}$ \\
\hline Key 063 & Waste Package Destructive Testing & SE & $\mathbf{U}$ \\
\hline Key 064 & Seismic Design Criteria & SE & $\mathrm{U}$ \\
\hline Key 065 & Retrieval Design & $\mathbf{S}$ & $\mathbf{U}$ \\
\hline Key 066 & Gantry Emplacement and Pedestal Support & SS & $\mathrm{U}$ \\
\hline Key 067 & Emplacement Drift Ventilation & SS & $\mathbf{U}$ \\
\hline Key 068 & Use of North Ramp for Waste Transport & SS & $\mathbf{U}$ \\
\hline Key 069 & Applicability of MSHA and OSHA & SS & $\mathrm{U}$ \\
\hline Key 070 & Excavated Opening Diameters & SS & $\mathbf{U}$ \\
\hline Key 071 & Restricted Area Boundary & $\mathbf{S}$ & $\mathbf{U}$ \\
\hline Key 072 & Repository Subsurface Layout & SS & $\mathbf{U}$ \\
\hline Key 073 & No Filler Material & WP & $\mathrm{U}$ \\
\hline Key 074 & Waste Package Not Breach for 3,000 years & SE & $\mathbf{U}$ \\
\hline Key 075 & Water Not Contact Waste Package for 10,000 years & SE & $\mathbf{U}$ \\
\hline Key 076 & Multiple Barriers & WP, SS & $\mathbf{U}$ \\
\hline Key $077^{\circ}$ & Waste Package and Drift Spacing & SS & $\mathrm{U}$ \\
\hline
\end{tabular}


Controlled Design Assumption

Assumption Status Log

As of Revision 04, ICN 3

Key Assumptions

\begin{tabular}{|l|l|c|c|}
\hline $\begin{array}{c}\text { Assumption } \\
\text { Identifier }\end{array}$ & \multicolumn{1}{|c|}{ Assumption Subject } & $\begin{array}{c}\text { Responsible } \\
\text { Organization }\end{array}$ & $\begin{array}{c}\text { Status (New, } \\
\text { Revised, Unchanged, } \\
\text { Withdrawn) }\end{array}$ \\
\hline Key 078 & Waste Package Loading and Emplacement Order & SS & U \\
\hline Key 079 & Disposal Criticality Analysis Methodology & WP & U \\
\hline Key 080 & RSA Interface & SE & U \\
\hline Key 081 & Neutron Absorbers & WP & U \\
\hline Key 082 & LLW Disposal at NTS & ESRP & U \\
\hline Key 083 & Mapping of Respoitory Subsurface Openings & SE & U \\
\hline Key 084 & Hold Waste during Extended Off-normal Outage & S & U \\
\hline Key 085 & Waste Lifted Vertically & S & U \\
\hline Key 086 & Bounding Navy SNF Canister & WP & N \\
\hline
\end{tabular}


Controlled Design Assumption

Assumption Status Log

As of Revision 04, ICN 3

EBDRD

\begin{tabular}{|c|c|c|c|}
\hline $\begin{array}{l}\text { Assumption } \\
\text { Identifier }\end{array}$ & Assumption Subject & $\begin{array}{l}\text { Responsible } \\
\text { Organization }\end{array}$ & $\begin{array}{c}\text { Status (New, Revised, } \\
\text { Unchanged, } \\
\text { Withdrawn) }\end{array}$ \\
\hline $\begin{array}{l}\text { EBDRD } \\
\text { 3.1.5.E(W) }\end{array}$ & Shielding Allocations & -- & $\mathbf{U}$ \\
\hline $\begin{array}{l}\text { EBDRD } \\
\text { 3.2.3.3.A. } 13\end{array}$ & Lining and Grouting Material Selection . & SS & $\mathbf{U}$ \\
\hline $\begin{array}{l}\text { EBDRD } \\
\text { 3.2.3.4.C.1.g }\end{array}$ & SNF Weight & SE & U \\
\hline $\begin{array}{l}\text { EBDRD } \\
\text { 3.2.3.4.C.4 }\end{array}$ & $\begin{array}{l}\text { Commercial SNF Radionuclide Inventory/Isotopic } \\
\text { Concentrations }\end{array}$ & SE & $\mathbf{U}$ \\
\hline $\begin{array}{l}\text { EBDRD } \\
\text { 3.2.3.4.C.5 }\end{array}$ & SNF Shipped Dose Rate Limits & SE & $\mathbf{U}$ \\
\hline $\begin{array}{l}\text { EBDRD } \\
3.2 .3 .5\end{array}$ & $\begin{array}{c}\text { Engineered Barrier/Transportation Physical Interfaces } \\
.\end{array}$ & $\begin{array}{c}\text { SE } \\
\text { (Requirements) }\end{array}$ & $\mathrm{U}$ \\
\hline $\begin{array}{l}\text { EBDRD } \\
3.2 .4 .5\end{array}$ & Shielding & SE & $\mathrm{U}$ \\
\hline $\begin{array}{l}\text { EBDRD } \\
3.2 .4 .6 . \mathrm{A}\end{array}$ & EBS Design Objective & SE & $\mathrm{U}$ \\
\hline
\end{tabular}


Controlled Design Assumption

Assumption Status Log

As of Revision 04, ICN 3 EBDRD

\begin{tabular}{|l|l|c|c|}
\hline \multicolumn{1}{|c|}{$\begin{array}{c}\text { Assumption } \\
\text { Identifier }\end{array}$} & \multicolumn{1}{|c|}{ Assumption Subject } & $\begin{array}{c}\text { Responsible } \\
\text { Organization }\end{array}$ & $\begin{array}{c}\text { Status (New, Revised, } \\
\text { Unchanged, } \\
\text { Withdrawn) }\end{array}$ \\
\hline $\begin{array}{l}\text { EBDRD } \\
\text { 3.2.5.1.2.B.1 }\end{array}$ & EBS Reliability & $\begin{array}{c}\text { SE } \\
\text { (Specialty) }\end{array}$ & $\mathrm{U}$ \\
\hline $\begin{array}{l}\text { EBDRD } \\
\text { 3.2.5.1.2.B.1.a(W) }\end{array}$ & Waste Form Reliability & -- & $\mathrm{U}$ \\
\hline $\begin{array}{l}\text { EBDRD } \\
\text { 3.2.5.1.2.B.1.b(W) }\end{array}$ & Waste Container Reliability & -- & $\mathrm{U}$ \\
\hline $\begin{array}{l}\text { EBDRD } \\
\text { 3.2.5.1.2.B.1.c(W) }\end{array}$ & Waste Package Internal Structure Reliability & -- & $\mathrm{U}$ \\
\hline $\begin{array}{l}\text { EBDRD } \\
\text { 3.2.5.1.2.B.1.d(W) }\end{array}$ & Waste Package Packing Reliability & -- & $\mathrm{U}$ \\
\hline EBDRD 3.2.5.4 & EBS Maintainable Preclosure Service Life & SE & $\mathrm{U}$ \\
\hline EBDRD 3.3.3.B & Information on Label for Equipment and Parts & WP & $\mathrm{U}$ \\
\hline EBDRD 3.3.9.A(W) & Government-Furnished Property & -- & $\mathrm{U}$ \\
\hline EBDRD 3.3.9.B(W) & Handling of Government-Furnished Property & -- & $\mathrm{U}$ \\
\hline
\end{tabular}




\section{Controlled Design Assumption}

Assumption Status Log

As of Revision 04, ICN 3

EBDRD

\begin{tabular}{|l|l|c|c|}
\hline \multicolumn{1}{|c|}{$\begin{array}{c}\text { Assumption } \\
\text { Identifier }\end{array}$} & \multicolumn{1}{|c|}{ Assumption Subject } & $\begin{array}{c}\text { Responsible } \\
\text { Organization }\end{array}$ & $\begin{array}{c}\text { Status (New, Revised, } \\
\text { Unchanged, } \\
\text { Withdrawn) }\end{array}$ \\
\hline EBDRD 3.4.2(W) & Drawings & $\begin{array}{c}\text { SE } \\
\text { (Requirements) }\end{array}$ & U \\
\hline EBDRD 3.7.C(W) & Substantially Complete Containment & -- & U \\
\hline EBDRD 3.7.D & Engineered Barrier Segment Minimum Performance & SE & U \\
\hline EBDRD 3.7.F(W) & Rock-Induced Waste Package Loading & WP & U \\
\hline EBDRD 3.7.G.1 & Borehole Wall Temperature & SE \\
\hline $\begin{array}{l}\text { EBDRD } \\
\text { 3.7.G.2 }\end{array}$ & $\begin{array}{l}\text { Vertical Borehole Rock Mass and In-drift Wall } \\
\text { Temperatures }\end{array}$ & SE & U \\
\hline $\begin{array}{l}\text { EBDRD } \\
\text { 3.7.G.3 }\end{array}$ & TSw3 Temperature Limit & SE & U \\
\hline $\begin{array}{l}\text { EBDRD } \\
\text { 3.7.G.4 }\end{array}$ & Ground Surface Temperature Rise Limit & SE & SE \\
\hline $\begin{array}{l}\text { EBDRD } \\
\text { 3.7.G.5 }\end{array}$ & Drift Temperature Limit for Borehole Emplacement & & U \\
\hline
\end{tabular}




\begin{tabular}{|c|c|c|c|}
\hline & $\begin{array}{l}\text { Controlled Design Assumption } \\
\text { Assumption Status Log } \\
\text { As of } \frac{\text { Revision 04. ICN } 3}{\text { EBDRD }}\end{array}$ & & \\
\hline $\begin{array}{l}\text { Assumption } \\
\text { Identifier }\end{array}$ & Assumption Subject & $\begin{array}{l}\text { Responsible } \\
\text { Organization }\end{array}$ & $\begin{array}{c}\text { Status (New, Revised, } \\
\text { Unchanged, } \\
\text { Withdrawn) } \\
\end{array}$ \\
\hline $\begin{array}{l}\text { EBDRD } \\
3.7 .6 .6\end{array}$ & Access Drift Temperature Limit & SE & $\mathrm{U}$ \\
\hline EBDRD 3.7.1.F(W) & Waste Package Information Label & - & $\mathrm{U}$ \\
\hline $\begin{array}{l}\text { EBDRD } \\
3.7 .1 .1 \\
\end{array}$ & Waste Package Substantially Complete Containment & SE & $\mathbf{U}$ \\
\hline $\begin{array}{l}\text { EBDRD } \\
3.7 .1 . J .1 \\
\end{array}$ & Waste Package External Dimensions & WP & $\mathbf{R}$ \\
\hline $\begin{array}{l}\text { EBDRD } \\
3.7 .1 . J .2 \\
\end{array}$ & Waste Package Maximum Mass & WP & $\mathbf{R}$ \\
\hline EBDRD 3.7.1.J.3 & Waste Package Surface Finish & WP & $\mathbf{U}$ \\
\hline $\begin{array}{l}\text { EBDRD } \\
3.7 .1 .1 . \mathrm{F} \\
\end{array}$ & Waste Package Drop Tolerance & WP & $\mathbf{U}$ \\
\hline $\begin{array}{l}\text { EBDRD } \\
3.7 .1 .1 . G(w)\end{array}$ & Postclosure Seismic Loads on Waste Package & WP, SPI & $\mathbf{U}$ \\
\hline
\end{tabular}




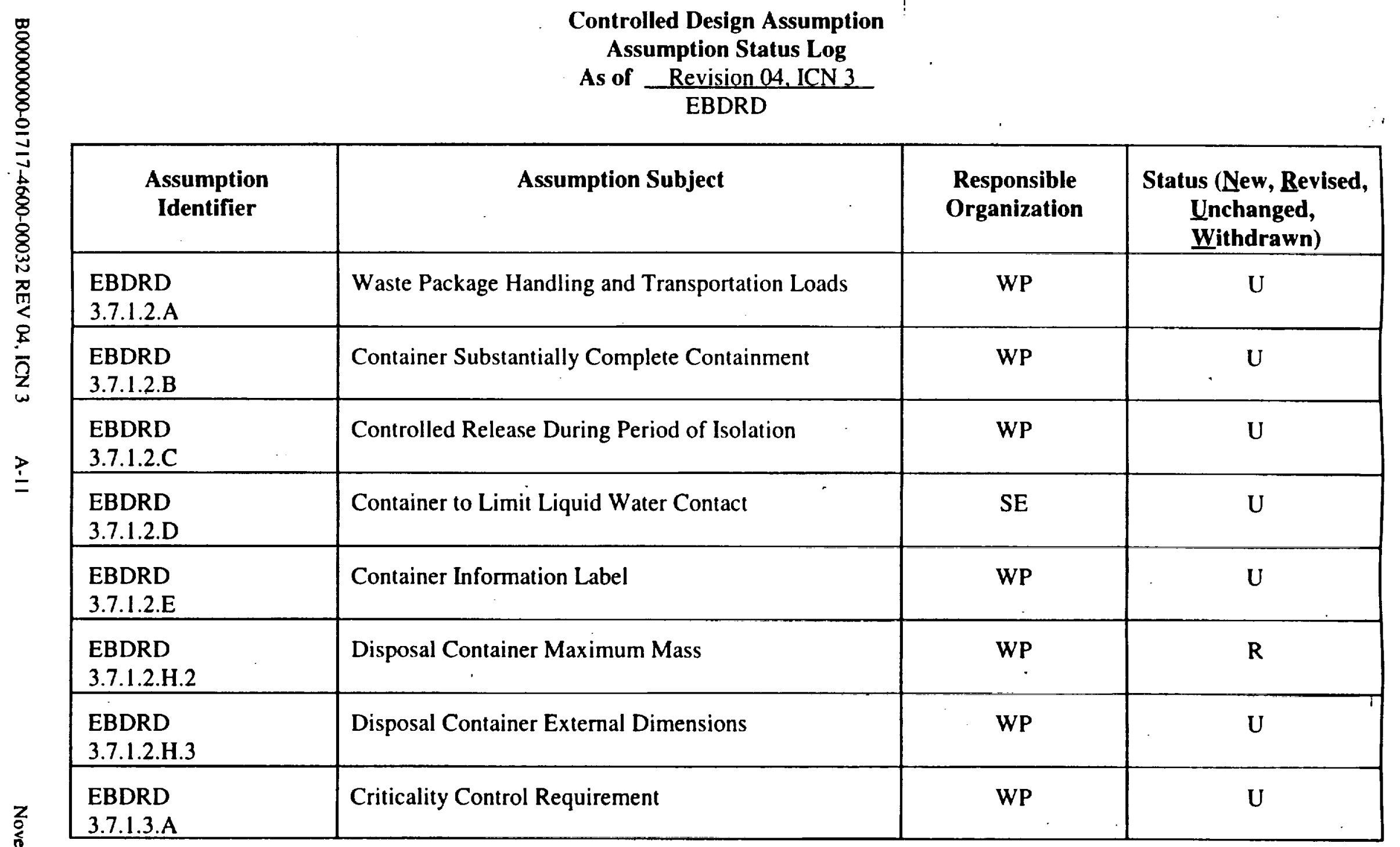




\begin{tabular}{|c|c|c|c|}
\hline \multicolumn{4}{|c|}{$\begin{array}{c}\text { Controlled Design Assumption } \\
\text { Assumption Status Log } \\
\text { As of } \frac{\text { Revision 04. ICN } 3}{\text { EBDRD }}\end{array}$} \\
\hline $\begin{array}{l}\text { Assumption } \\
\text { Identifler }\end{array}$ & Assumption Subject & $\begin{array}{c}\text { Responsible } \\
\text { Organization }\end{array}$ & $\begin{array}{c}\text { Status (New, Revised, } \\
\text { Unchanged, } \\
\text { Withdrawn) }\end{array}$ \\
\hline $\begin{array}{l}\text { EBDRD } \\
\text { 3.7.1.3.D } \\
\end{array}$ & Waste Package Internal Structure Loads & WP & $\mathrm{U}$ \\
\hline EBDRD 3.7.1.4(W) & Waste Container Absorbent Materials & -- & $\mathrm{U}$ \\
\hline $\begin{array}{l}\text { EBDRD } \\
\text { 3.7.2.B } \\
\end{array}$ & Backfill Permeability & WP & u \\
\hline EBDRD 3.7 .3 & Emplacement Hardware Requirements & WP & $\mathrm{u}$ \\
\hline
\end{tabular}




\section{Controlled Design Assumption}

Assumption Status Log

As of Revision 04. ICN 3

RDRD

\begin{tabular}{|l|l|l|l|}
\hline \multicolumn{1}{|c|}{$\begin{array}{c}\text { Assumption } \\
\text { Identifier }\end{array}$} & \multicolumn{1}{|c|}{ Assumption Subject } & $\begin{array}{c}\text { Responsible } \\
\text { Organization }\end{array}$ & $\begin{array}{c}\text { Status (New, } \\
\text { Revised, } \\
\text { Unchanged, } \\
\text { Withdrawn) }\end{array}$ \\
\hline RDRD 3.2.1.2.B & Waste Receiving Schedule & SE \\
\hline RDRD 3.2.1.6.C & $\begin{array}{l}\text { Disposal System Postclosure Performance } \\
\text { (40 CFR 191) }\end{array}$ & SE & U \\
\hline RDRD 3.2.1.6.D & Physical Barriers & S & SS \\
\hline $\begin{array}{l}\text { RDRD } \\
\text { 3.2.3.2.2.A.7 }\end{array}$ & Emplacement Concept & U \\
\hline $\begin{array}{l}\text { RDRD } \\
\text { 3.2.3.2.2.A.11.a }\end{array}$ & Repository Layout to Limit Waste Package - Water Contact & SE & U \\
\hline RDRD 3.2.3.4.B & Non-Potable Water & S & U \\
\hline RDRD 3.2.3.4.D & Telephone Communications & S & S \\
\hline RDRD 3.7.1.C & Special Sources of Groundwater & (Site Investig.) & SS \\
\hline RDRD 3.7.3.5.A.1 & General Underground Lighting & U \\
\hline
\end{tabular}




\begin{tabular}{|c|c|c|c|}
\hline & $\begin{array}{l}\text { Controlled Design Assumption } \\
\text { Assumption Status Log } \\
\text { As of } \frac{\text { Revision 04, ICN } 3}{\text { RDRD }}\end{array}$ & & \\
\hline $\begin{array}{l}\text { Assumption } \\
\text { Identifier }\end{array}$ & Assumption Subject & $\begin{array}{l}\text { Responsible } \\
\text { Organization }\end{array}$ & $\begin{array}{c}\text { Status (New, } \\
\text { Revised, } \\
\text { Unchanged, } \\
\text { Withdrawn) } \\
\end{array}$ \\
\hline RDRD 3.7.3.5.A.2 & Underground Service Facilities Lighting & SS & $\mathbf{U}$ \\
\hline RDRD 3.7.3.9.E & Site-Generated Hazardous Waste & $\mathbf{S}$ & $\mathbf{U}$ \\
\hline RDRD 3.7.4.1.A.2 & Storage Capacity for Waste Receipts & $\mathbf{S}$ & $\mathbf{U}$ \\
\hline RDRD 3.7.4.1.A.3 & Waste Handling Holding Areas & $\mathbf{S}$ & $\mathbf{U}$ \\
\hline RDRD 3.7.5.A.5 & Men-and-Materials Shaft Hoist Limits & SS & $\mathrm{U}$ \\
\hline RDRD 3.7.5.B.6 & Underground Air Supply & SS & $\mathbf{U}$ \\
\hline RDRD 3.7.5.N.1 & Waste Ramp Air Flow & SS & $\mathbf{U}$ \\
\hline RDRD 3.7.5.N.2 & Tuff Ramp Air Flow & SS & $\mathrm{U}$ \\
\hline RDRD 3.7.5.N.5 & Shaft Size & SS & $\underline{U}$ \\
\hline RDRD 3.7.5.0.2 & Men-and-Materials Shaft Usage & SS & $\mathbf{U}$ \\
\hline
\end{tabular}


Controlled Design Assumption

Assumption Status Log

As of Revision 04 ICN 3

DCS

\begin{tabular}{|c|c|c|c|}
\hline $\begin{array}{l}\text { Assumption } \\
\text { Identifier }\end{array}$ & Assumption Subject & $\begin{array}{l}\text { Responsible } \\
\text { Organization }\end{array}$ & $\begin{array}{c}\text { Status (New, Revised, } \\
\text { Unchanged, } \\
\text { Withdrawn) }\end{array}$ \\
\hline DCS-001 & MGDS Operational Center & SE & $\mathrm{U}$ \\
\hline DCS-002(W) & Wet and Dry SNF Handling & -- & $\mathrm{U}$ \\
\hline DCS-003 & Occupational Exposure Limits & $\mathbf{S}$ & $\mathrm{U}$ \\
\hline DCS-004 & ALARA Studies & $\mathbf{S}$ & $\mathrm{U}$ \\
\hline DCS-005(W) & One Waste Handling Building & $\mathbf{S}$ & $\mathrm{U}$ \\
\hline DCS-006(W) & CMF Requirement & -- & $\mathrm{U}$ \\
\hline DCS-007(W) & Waste Treatment Building & -- & $\bar{U}$ \\
\hline DCS-008 & Decontamination Equipment and Space & $\mathbf{S}$ & $\mathrm{U}$ \\
\hline DCS-009(W) & Disposal of Low-Level Radioactive Waste & - & $\mathrm{U}$ \\
\hline DCS-010(W) & Hazardous Waste Disposal & -- & $\mathrm{U}$ \\
\hline DCS-011 & Underground Wạste Generation & SS & $\mathrm{U}$ \\
\hline DCS-012 & No HLW in Waste Treatment Building & $\mathbf{S}$ & $\mathrm{U}$ \\
\hline DCS-013 & Waste Generated by Performance Confirmation Activities & $\mathbf{S}$ & $\mathrm{U}$ \\
\hline DCS-014(W) & Cask Maintenance Operation & -- & $\mathrm{U}$ \\
\hline
\end{tabular}




\section{Controlled Design Assumption}

Assumption Status Log

As of Revision 04 ICN 3

DCS

\begin{tabular}{|l|l|c|c|}
\hline \multicolumn{1}{|c|}{$\begin{array}{c}\text { Assumption } \\
\text { Identifier }\end{array}$} & \multicolumn{1}{|c|}{ Assumption Subject } & $\begin{array}{c}\text { Responsible } \\
\text { Organization }\end{array}$ & $\begin{array}{c}\text { Status (New, Revised, } \\
\text { Unchanged, } \\
\text { Withdrawn) }\end{array}$ \\
\hline DCS-015(W) & Transportation Cask Fleet Inventory & -- & U \\
\hline DCS-016(W) & Transportation Cask Fleet Maintenance Frequency & -- & U \\
\hline DCS-017(W) & WHB Dry Handling & -- & U \\
\hline DCS-018(W) & CMF Wet Handling & -- & U \\
\hline DCS-019 & Support Facilities Design & S & U \\
\hline DCS-020 & WHB WetDry Handling & S & S \\
\hline DCS-021 & Special Tooling & & U \\
\hline
\end{tabular}




\section{Controlled Design Assumption}

Assumption Status Log

As of Revision 04, ICN 3 DCSS

\begin{tabular}{|l|l|c|c|}
\hline \multicolumn{1}{|c|}{$\begin{array}{c}\text { Assumption } \\
\text { Identifier }\end{array}$} & \multicolumn{1}{|c|}{ Assumption Subject } & $\begin{array}{c}\text { Responsible } \\
\text { Organization }\end{array}$ & $\begin{array}{c}\text { Status (New, } \\
\text { Revised, Unchanged, } \\
\text { Withdrawn) }\end{array}$ \\
\hline DCSS-001 & Drift Orientation & SS & U \\
\hline DCSS-002(W) & Repository Horizon & -- & U \\
\hline DCSS-003(W) & Underground Excavation Crown & -- & U \\
\hline DCSS-004(W) & Stand-Off Distance & -- & U \\
\hline DCSS-005 & Drift Excavation Methods & SS & U \\
\hline DCSS-006 & Maximum Excavation Extraction Ratio & SS & U \\
\hline DCSS-007(W) & N/A (Never Issued) & -- & U \\
\hline DCSS-008(W) & N/A (Never Issued) & -- & U \\
\hline DCSS-009 & Maximum Ramp Grade & SS & U \\
\hline DCSS-010 & Repository Material'Handling Equipment & SS & U \\
\hline DCSS-011(W) & N/A (Never Issued) & -- & U \\
\hline DCSS-012(W) & N/A (Never Issued) & -- & U \\
\hline DCSS-013(W) & In-Drift Emplacement & SS & U \\
\hline DCSS-014 & Shaft Excavation Method & U \\
\hline
\end{tabular}




\begin{tabular}{|c|c|c|c|}
\hline & $\begin{array}{l}\text { Controlled Design Assumption } \\
\text { Assumption Status Log } \\
\text { As of } \frac{\text { Revision 04, ICN } 3}{\text { DCSS }}\end{array}$ & . & \\
\hline $\begin{array}{l}\text { Assumption } \\
\text { Identifier }\end{array}$ & Assumption Subject & $\begin{array}{l}\text { Responsible } \\
\text { Organization }\end{array}$ & $\begin{array}{c}\text { Status (New, } \\
\text { Bevised, Unchanged, } \\
\text { Withdrawn) } \\
\end{array}$ \\
\hline DCSS-015 & Ventilated Air Properties & SS & $\mathbf{U}$ \\
\hline DCSS-016 & Maximum Underground Air Velocity & SS & $\mathrm{U}$ \\
\hline DCSS-017 & Minimum Underground Air Velocity & SS & $\mathrm{U}$ \\
\hline DCSS-018 & Minimum Underground Air Volume & SS & $\mathrm{U}$ \\
\hline DCSS-019 & Maximum Underground Air Temperatures - Emplacement Drifts & SS & $\mathbf{U}$ \\
\hline DCSS-020 & Maximum Underground Air Temperatures - Access Mains & SS & $\mathbf{U}$ \\
\hline DCSS-021(W) & Underground Air Quality & SS & $\mathbf{U}$ \\
\hline DCSS-022 & "K" Factor for Ventilation Air Flow & SS & $\mathrm{U}$ \\
\hline DCSS-023 & Maximum Preclosure Rock Surface Temperature & SS & $\mathbf{U}$ \\
\hline DCSS-024(W) & N/A (Never Issued) & -- & $\mathrm{U}$ \\
\hline DCSS-025 & Maximum Zeolite Temperature & $\begin{array}{c}\text { SE } \\
\text { Requirements } \\
\end{array}$ & $\mathrm{U}$ \\
\hline
\end{tabular}


Controlled Design Assumption

Assumption Status Log

As of Revision 04. ICN 3

DCSS

\begin{tabular}{|l|l|c|c|}
\hline $\begin{array}{c}\text { Assumption } \\
\text { Identifier }\end{array}$ & \multicolumn{1}{|c|}{ Assumption Subject } & $\begin{array}{c}\text { Responsible } \\
\text { Organization }\end{array}$ & $\begin{array}{c}\text { Status (New, } \\
\text { Revised, Unchanged, } \\
\text { Withdrawn) }\end{array}$ \\
\hline DCSS-026(W) & Emplacement Drift Backfill & -- & U \\
\hline DCSS-027 & Rock Support Materials - Organic Materials Prohibited & SS & U \\
\hline DCSS-028 & Emplacement Drift, Shafts, Ramps Maintenance Plans & SS & U \\
\hline DCSS-029 & Maximum Underground Air Temperatures - Exhaust Mains & SS & U \\
\hline DCSS-030 & Limit Ground Surface Uplift & SE & U \\
\hline DCSS-031 & Limit Temperatures in PTn & SE & U \\
\hline DCSS-032 & Temporary Surface Facilities for Underground Construction & S, SS & U \\
\hline DCSS-033 & Emplacement Drift Standoff & SS & U \\
\hline DCSS-034 & Emplacement Drift Ground Support & SS & U \\
\hline DCSS-035 & Emplacement and Development Area Ventilation & SS & U \\
\hline DCSS-036 & Emplacement Drift Entrance Doors & SS & U \\
\hline DCSS-037 & Invert Material & SS & U \\
\hline DCSS-038 & Air Monitoring Underground & SS & U \\
\hline DCSS-039 & Ventilation System Pressure Differential & SS & U \\
\hline
\end{tabular}




\begin{tabular}{|c|c|c|c|}
\hline \multicolumn{4}{|c|}{$\begin{array}{l}\text { Controlled Design Assumption } \\
\text { Assumption Status Log }\end{array}$} \\
\hline $\begin{array}{l}\text { Assumption } \\
\text { Identifier }\end{array}$ & Assumption Subject & $\begin{array}{c}\text { Responsible } \\
\text { Organization }\end{array}$ & $\begin{array}{c}\text { Status (New, Revised, } \\
\text { Unchanged, } \\
\text { Withdrawn) } \\
\end{array}$ \\
\hline DCWP-001 & Limit Fuel Cladding Temperature & SE & $\mathrm{U}$ \\
\hline DCWP-002 & Limit HLW Glass Temperature & SE & $\mathrm{U}$ \\
\hline DCWP-003(W) & Alternate Waste Package Disposal Container Materials & -- & $\mathbf{u}$ \\
\hline DCWP-004 & Waste Package Materials & WP & $\mathbf{U}$ \\
\hline DCWP-005(W) & Tentative Co-Disposed DOE SNF WP Dimensions & -- & U \\
\hline DCWP-006(W) & Tentative WP External Dimensions for Canistered SNF & -- & $\mathrm{U}$ \\
\hline
\end{tabular}




\section{Controlled Design Assumption}

Assumption Status Log

As of Revision 04. ICN 3

TDS

\begin{tabular}{|l|l|c|c|}
\hline \multicolumn{1}{|c|}{$\begin{array}{c}\text { Assumption } \\
\text { Identifier }\end{array}$} & \multicolumn{1}{|c|}{ Assumption Subject } & $\begin{array}{c}\text { Responsible } \\
\text { Organization }\end{array}$ & $\begin{array}{c}\text { Status (New, Revised, } \\
\text { Unchanged, } \\
\text { Withdrawn) }\end{array}$ \\
\hline TDS-001 (W) & Fault Displacement, Locations, Attitudes & SPI & U \\
\hline TDS-002 & Topography/Morphology & SPO & U \\
\hline TDS-003 & Soil Properties & SPO & U \\
\hline TDS-004 & Meteorology & SPO & U \\
\hline TDS-005(W) & Seismic Environment & -- & U \\
\hline TDS-006 & Design Basis Tornadoes & SPO & U \\
\hline TDS-007 & Winds (Operating Basis and Standard) & SPO & U \\
\hline TDS-008 & Floods (Design Basis) & -- & UPO \\
\hline TDS-009(W) & Surface Facilities/ALARA - Reclassified as DCS 002 & -- & U \\
\hline TDS-010(W) & ALARA Studies - Reclassified as DCS 004 & -- & U \\
\hline TDS-011(W) & Waste Handling Building - Reclassified as DCS 005 & -- & U \\
\hline TDS-012(W) & $\begin{array}{l}\text { Transportation Cask Maintenance Facility - Reclassified as } \\
\text { DCS 006 }\end{array}$ & -- & U \\
\hline TDS-013(W) & Waste Treatment Building - Reclassified as DCS 007 & - & U \\
\hline TDS-014(W) & Decontamination & - & U \\
\hline TDS-015(W) & Rod Consolidation & & \\
\hline
\end{tabular}




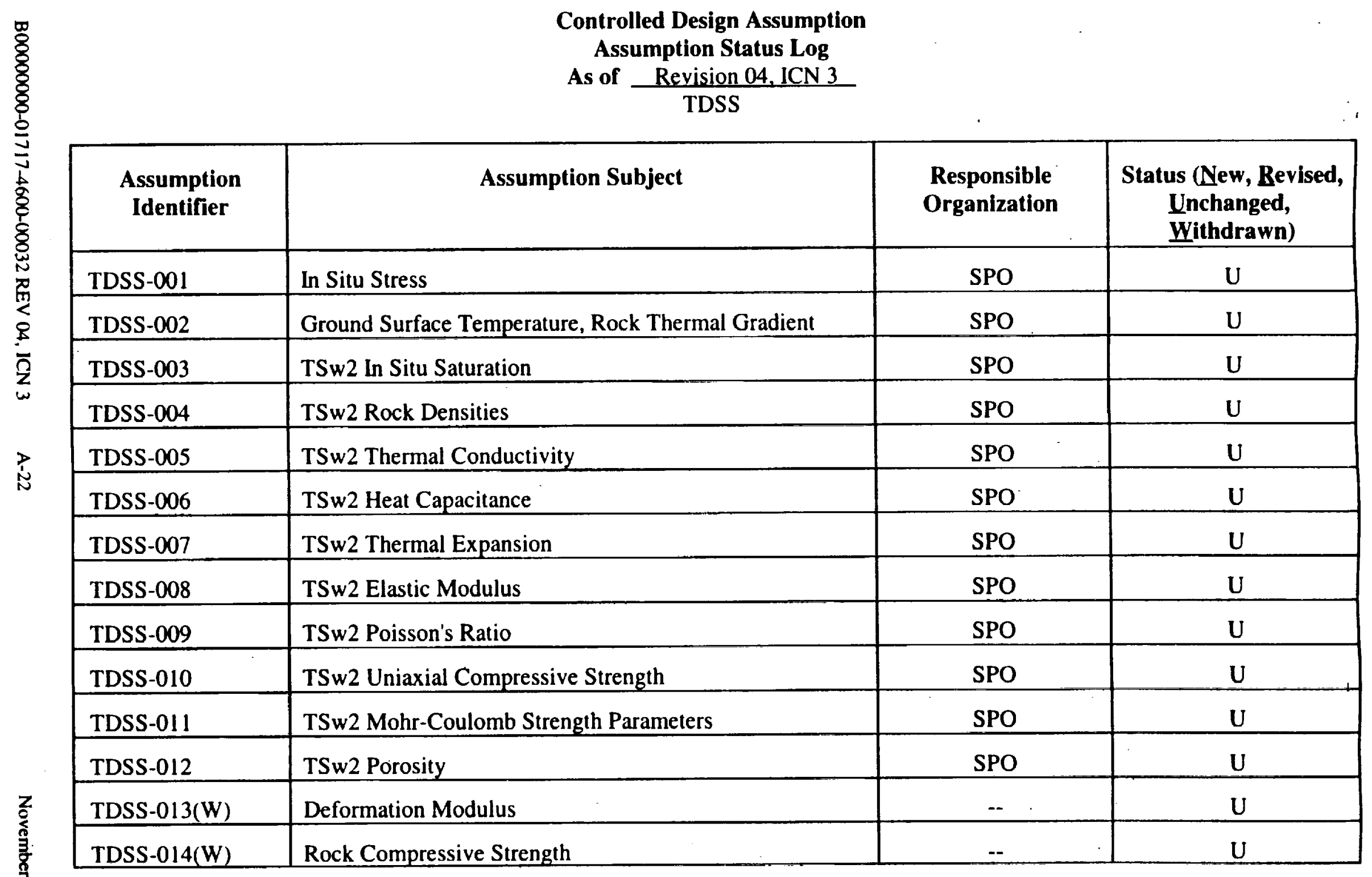




\section{Controlled Design Assumption}

Assumption Status Log

As of Revision 04, ICN 3

TDSS

\begin{tabular}{|l|l|c|c|}
\hline \multicolumn{1}{|c|}{$\begin{array}{c}\text { Assumption } \\
\text { Identifier }\end{array}$} & \multicolumn{1}{|c|}{ Assumption Subject } & $\begin{array}{c}\text { Responsible } \\
\text { Organization }\end{array}$ & $\begin{array}{c}\text { Status (New, Revised, } \\
\text { Unchanged, } \\
\text { Withdrawn) }\end{array}$ \\
\hline TDSS-015(W) & Rock Tensile Strength & -- & U \\
\hline TDSS-016(W) & N/A (Never Issued) & -- & U \\
\hline TDSS-017 & Rock Joint Orientation and Frequency & SPO & U \\
\hline TDSS-018(W) & TSw2 Rock Joint Strength & -- & U \\
\hline TDSS-019(W) & Rock Joint Stiffness & -- & U \\
\hline TDSS-020(W) & Rock Mass Quality Indices & -- & U \\
\hline TDSS-021 & Surface Air Temperature/Humidity & SPO & U \\
\hline TDSS-022 & Wind Intensity & SPO & $\cdot$ \\
\hline TDSS-023(W) & Unsaturated Zone Ground Water Flux & -- & U \\
\hline TDSS-024(W) & Unsaturated Zone Ground Water pH & -- & U \\
\hline TDSS-025 & Unsaturated Zone Ground Water Chemistry & SPO & SPO \\
\hline TDSS-026 & Bounding Water Influx & & U \\
\hline
\end{tabular}




\section{Controlled Design Assumption} Assumption Status Log

As of Revision 04, ICN 3 REQSE

\begin{tabular}{|c|c|c|c|}
\hline $\begin{array}{l}\text { Assumption } \\
\text { Identifier }\end{array}$ & Assumption Subject & $\begin{array}{l}\text { Responsible } \\
\text { Organization }\end{array}$ & $\begin{array}{c}\text { Status (New, Revised, } \\
\text { Unchanged, } \\
\text { Withdrawn) }\end{array}$ \\
\hline REQSE-001(W) & $\begin{array}{r}- \\
-\end{array}$ & - & $\mathrm{U}$ \\
\hline REQSE-002(W) & - & -- & $\mathrm{U}$ \\
\hline REQSE-003(W) & -- & -- & $\mathbf{U}$ \\
\hline
\end{tabular}


INTENTIONALLY LEFT BLANK 
Key 006(W)

Key 007 (W)

Key 012(W)

Key 014(W)

Key 015(W)

Key 018(W)

Key 020(W)

Key 021 (W)

Key 025 (W)

Key 026(W)

Key 029(W)

Key 032(W)

Key 033(W)

Key 034(W)

Key 035(W)

Key $036(W)$

I Key 037 (W)

1 Key $038(W)$

Key 040(W)

Key 041 (W)

Key 042(W)

Key 043(W)

Key 044(W)

Key 045(W)

Key 048(W)

Key 049(W)

Key 050(W)

Key 051(W)

Key 052 (W)

Key 054(W)

Key 056(W)

I Key 062(W)

EBDRD 3.1.5.E(W)

EBDRD 3.2.5.1.2.B.1.a(W)

EBDRD 3.2.5.1.2.B.1.b(W)

EBDRD 3.2.5.1.2.B.1.c(W)

EBDRD 3.2.5.1.2.B.1.d(W)

EBDRD 3.3.9.A(W)

EBDRD 3.3.9.B(W)

EBDRD 3.4.2(W)

EBDRD 3.7.C(W)

EBDRD 3.7.F $(\mathrm{W})$

EBDRD 3.7.1.F(W)

EBDRD 3.7.1.1.G(W)

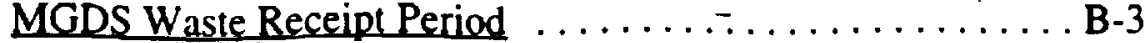

No MPC Repackaging for Heat Load Tailoring $\ldots \ldots \ldots \ldots$ B-4

Use of Robotics $\ldots \ldots \ldots \ldots \ldots \ldots \ldots \ldots \ldots \ldots \ldots$ B-5

Preclosure Monitoring Activities - Robotics . . . . . . . B-6

Remote Handling Systems ..................... B-7

Storage of Retrieved Packages . . . . . . . . . . . . . . B-8

Thermal Load Decisjon Date . . . . . . . . . . . . . . . . . . B-9

Performance Confirmation Areas for Thermal Loads ...... B-10

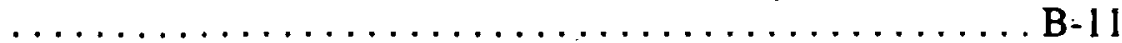

B-12

Technical Baseline Change (Remove Rod Consolidatio .... . B-13

B-14

Individual Waste Package Shielding $\ldots \ldots \ldots \ldots \ldots \ldots$ B-15

B-16

B-17

Substantially Complete Containment (10 CFR 60.113) ... B-17a

Expected Waste Package Lifetime .............. B-17b

Waste Packages Breached at 1000 Years ......... B-17c

Period of Waste Isolation . . . . . . . . . . . . . . . . B- 18

Receipt and Emplacement Rates ................ B-19

Waste Package Materials - High Thermal Load ......... B-20

Waste Package Materials - Low Thermal Load .......... B-21

B-22

Altemative Waste Package Materials $\ldots \ldots \ldots \ldots \ldots \ldots$ B-23

Aluminum Boron in First MPC Procurement . . . . . . . B-24

Aluminum Boron not Acceptable Long Term . . . . . . . B-25

MPC Redesign in Second Procurement ............. B-26

Eirst MPC Procurement Delivery Schedule . . . . . . . . . . B-27

Addition of Filler Material at the Repository ............ B-30

Normal Waste Handling Building Capability

(No Filler Material) $\ldots \ldots \ldots \ldots \ldots \ldots \ldots \ldots \ldots$, B-33

Interim Fuel Storage $\ldots \ldots \ldots \ldots \ldots \ldots \ldots \ldots \ldots \ldots . . .6 \ldots \ldots$

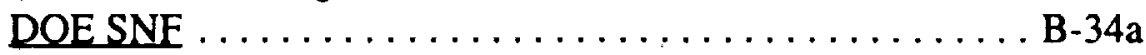

Shielding Allocations $\ldots \ldots \ldots \ldots \ldots \ldots \ldots \ldots \ldots$ B-35

Waste Form Reliability ........................ B-36

Waste Container Reliability .................... B-37

Waste Package Intemal Structure Reliability . . . . . . . . B-38

Waste Package Packing Reliability ............... B-39

Government-Furnished Property ................. B-40

Handling of Govemment-Furmished Property ......... B-41

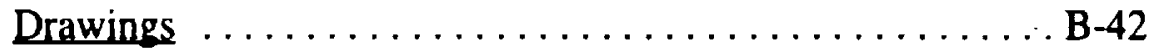

Substantially Complete Containment $\ldots \ldots \ldots \ldots \ldots \ldots$ B-43

Rock-Induced Waste Package Loading $\ldots \ldots \ldots \ldots \ldots$ B-44

Waste Package Information Label ................ B-45

Postclosure Sejsmic Loads onWaste Package .......... B-46 
EBDRD 3.7.1.4(W)

DCS 002(W)

DCS 005(W)

DCS 006(W)

I DCS 007(W)

DCS 009(W)

DCS $010(\mathrm{~W})$

DCS 014 (W)

DCS $015(W)$

DCS $016(\mathrm{~W})$

DCS 017 (W)

DCS $018(\mathrm{~W})$

DCSS 002(W)

DCSS 003(W)

DCSS 004(W)

DCSS 013(W)

DCSS 021 (W)

DCSS 026(W)

DCWP 003 (W)

I DCWP 005 (W)

1 DCWP $006(W)$

TDS 005(W)

TDS 001 (W)

TDS 009(W)

TDS 010(W)

TDS 011(W)

TDS 012(W)

TDS 013(W)

TDS 014(W)

TDS 015(W)

TDSS 013(W)

TDSS 014(W)

TDSS 015(W)

TDSS 018(W)

TDSS 019(W)

TDSS 020(W)

TDSS 023 (W)

TDSS 024 (W)

REQSE 001(W)

REQSE 002(W)

REQSE 003(W)
Waste Container Absorbent Materials . . . . . . . . . . B-47

Wet and Dry SNF Handling . . . . . . . . . . . . . . . B-48

One Waste Handling Building $\ldots \ldots \ldots \ldots \ldots \ldots \ldots \ldots$ B-49

CMF Requirement ........................ B-50

Waste Treatment Building..$\ldots \ldots \ldots \ldots \ldots \ldots \ldots$ B-50a

Disposal of Low-Level Radioactive Waste ........... B-51

Hazardous Waste Disposal $\ldots \ldots \ldots \ldots \ldots \ldots \ldots$ B-5Ia

Cask Maintenance Operations $\ldots \ldots \ldots \ldots \ldots \ldots \ldots$ B-5lb

Transportation Cask Fleet Inventory ............. B-5 Ic

Trans. Cask Fleet Maintenance Frequency $\ldots \ldots \ldots \ldots$ B-51d

WHB Dry Handling $\ldots \ldots \ldots \ldots \ldots \ldots \ldots \ldots \ldots$ B-5le

CMF Wet Handling $\ldots \ldots \ldots \ldots \ldots \ldots \ldots \ldots \ldots$ B-51f

Repository Horizon $\ldots \ldots \ldots \ldots \ldots \ldots \ldots \ldots \ldots$ B-52

Underground Excavation Crown $\ldots \ldots \ldots \ldots \ldots \ldots \ldots$ B-53

Stand-Off Distance $\ldots \ldots \ldots \ldots \ldots \ldots \ldots \ldots \ldots \ldots$ B-54

In-Drift Emplacement $\ldots \ldots \ldots \ldots \ldots \ldots \ldots \ldots \ldots \ldots$ B-55

Underground Air Quality . . . . . . . . . . . . . . . B-56

Emplacement Drift Backfill .................... B-57

Alternate Waste Package Disposal Container Materials .... B-58

Tentative Co-Disposed DOE SNF WP Dimensions ...... B-59a

Tentative WP External Dimensions for Canistered SNF . . . B B-59b

Seismic Environment ...................... B-60

Eault Displacement. Locations, Attitudes .......... B-61

Surface Facilities/ALARA - Reclassified as DCS 002 ...... B-62

ALARA Studies-Reclassified as DCS 004 ............ B-63

Waste Handling Building -Reclassified as DCS 005 ....... B-64

Transportation Cask MaintenanceFacility - Reclassified

as DCS $006 \ldots \ldots \ldots \ldots \ldots \ldots \ldots \ldots \ldots$ B-65

Waste Treatment Building-Reclassified as DCS 007 ..... . B-66

Decontamination ........................ B-67

Rod Consolidation . . . . . . . . . . . . . . . . . . B-68

Deformation Modulus . . . . . . . . . . . . . . . . . . . B-69

Rock Compressive Strength . . . . . . . . . . . . . B-70

Rock Tensile Strength $\ldots \ldots \ldots \ldots \ldots \ldots \ldots \ldots \ldots$ B-71

TSw2 Rock Joint Strength $\ldots \ldots \ldots \ldots \ldots \ldots \ldots \ldots$ B-72

Rock Joint Stiffness . . . . . . . . . . . . . . . . . . . B-73

Rock Mass Quality Indices $\ldots \ldots \ldots \ldots \ldots \ldots \ldots \ldots \ldots \ldots \ldots$

Unsaturated Zone Groundwater Flux . . . . . . . . . . . . . B-74a

Unsaturated Zone Ground water $\mathrm{pH} \ldots \ldots \ldots \ldots \ldots \ldots$. . . 74b

B-75

B-76

B-77 
APPENDIX B

WITHDRA WN ASSUMPTIONS 



\section{WITHDRAWN ASSUMPTIONS}

The list below shows the identification numbers of assumptions that have been withdrawn in previous and current revisions. Assumption Rationale Sheets for these assumptions are contained in this appendix.

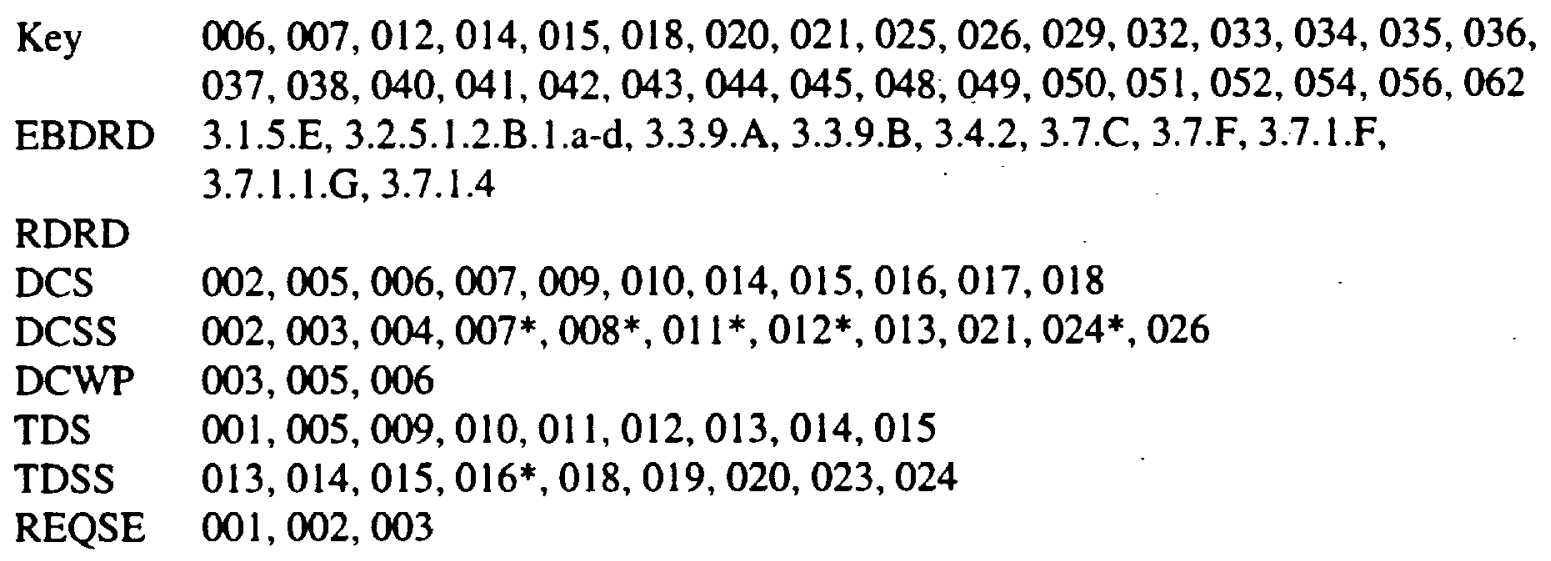

* Never Issued 
INTENTIONALLY LEFT BLANK 


\section{Controlled Design Assumption}

Assumption Rationale Sheet

Assumption Identifier: Key 006(W)

Subject: MGDS Waste Receipt Period

\section{STATEMENT OF ASSUMPTION}

WITHDRAWN - Covered by Key Assumptions 001, 002, 003.

\section{BACKGROUND}

Rev, 00

Waste Type and Quantity

Receipt at MGDS starting 2010 and ending 2033.

Requesting M\&O organization: (X)Surface, (X)Subsurface, (X)Waste Package Development, or Other (specify: Requirements. Systems Analysis and Modeling)

Need for assumption (statement of intended use):

\section{RATIONALE}

Rationale for assumption (source author, date, and report title) or statement of reasoning behind engineering judgment (e.g., midpoint of ranges given in the YMSCP Technical Data Base or Reference Information Base):

In accordance with Nuclear Waste Policy Act, OCRWM Mission Plan, MPC concept, Proposed Program Approach, and MGDS Requirements Document and supporting requirements documents.

\section{RESPONSIBILITY/SUBSTANTIATION/WITHDRAWAL}

Responsible M\&O Organization Systems Engineering

( ) No Substantiation Required

( ) Substantiation Date

(X) Withdrawal Date 4/28/95(Rev.01) 


\section{STATEMENT OF ASSUMPTION}

WITHDRAWN - Consolidated with the Rationale for Key Assumption 003.

\section{BACKGROUND}

Rev. 00

Waste Type and Quantity

No repackaging of MPCs for purposes of heat load tailoring.

Requesting M\&O organization: (X)Surface, ( )Subsurface, (X)Waste Package Development, or Other (specify: Requirements, Systems Analysis and Modeling)

Need for assumption (statement of intended use):

Removes one performance objective to permit MPC and repository design criteria to proceed.

\section{RATIONALE}

Rationale for assumption (source author, date, and report title) or statement of reasoning behind engineering judgment (e.g., midpoint of ranges given in the YMSCP Technical Data Base or Reference Information Base):

In accordance with Nuclear Waste Policy Act, OCRWM Mission Plan, MPC concept, Proposed Program Approach, and MGDS Requirements Document and supporting requirements documents.

\section{RESPONSIBILITY/SUBSTANTIATION/WITHDRAWAL}

Responsible M\&O Organization Systems Engineering

( ) No Substantiation Required

( ) Substantiation Date

(X) Withdrawal Date 4/28/95 (Rev. 01) 


\section{STATEMENT OF ASSUMPTION}

WITHDRAWN. This is a valid statement of design philosophy rather than a design assumption.

Use of robotics and/or remote control will be maximized to achieve the concept of ALARA (as low as reasonably achievable).

\section{BACKGROUND}

Requesting M\&O organization: (X)Surface, (X)Subsurface, ( )Waste Package Development, or Other (specify: Requirements, Systems Analysis and Modeling)

Need for assumption (statement of intended use):

Establishes the need to investigate practical uses of robotics and remote handling in MGDS operations.

\section{RATIONALE}

Rationale for assumption (source author, date, and report title) or statement of reasoning behind engineering judgment (e.g., midpoint of ranges given in the YMSCP Technical Data Base or Reference Information Base):

RDRD (YMP/CM-0023): GROA shall to the extent practicable achieve occupational doses that are ALARA.

\section{RESPONSIBILITY/SUBSTANTIATION/WITHDRAWAL}

Responsible M\&O Organization Subsurface. Surface

( ) No Substantiation Required

( ) Substantiation Date

(X) Withdrawal Date

12/19/95(Rev. 02) 


\section{Controlled Design Assumption}

Assumption Rationale Sheet

Assumption Identifier: Key 014(W) Subject: Preclosure Monitōring Activities - Robotics

\section{STATEMENT OF ASSUMPTION}

WITHDRAWN - Included in Key Assumption 013.

\section{BACKGROUND}

Rev. 00

\section{Surface Robolics}

Robotics may be used to perform routine monitoring activities during the preclosure period.

Requesting M\&O organization: ( )Surface, ( )Subsurface, ( )Waste Package

Development, or Other (specify: Requirements. Systems Analysis and Modeling)

Need for assumption (statement of intended use):

\section{RATIONALE}

Rationale for assumption (source author, date, and report title) or statement of reasoning behind engineering judgment (e.g., midpoint of ranges given in the YMSCP Technical Data Base or Reference Information Base):

Repository Design Requirement Document (RDRD) (YMP/CM-0023): GROA shall, to the extent practical, achieve occupational doses that are as low as reasonably achievable (ALARA).

\section{RESPONSIBILITY/SUBSTANTIATION/WITHDRAWAL}

Responsible M\&O Organization Subsurface

( ) No Substantiation Required

( ) Substantiation Date

(X) Withdrawal Date 4/28/95(Rev. 01) 


\section{STATEMENT OF ASSUMPTION}

WITHDRAWN - Included in Key Assumptions 012 and 013.

\section{BACKGROUND}

Bev. 00

Sub Surface Robotics

Remote handling systems will be used for operations not applicable to robotics and will provide a safe recovery and back up method for robotics systems.

Requesting M\&O organization: ( )Surface, ( )Subsurface, ( )Waste Package Development, or Other (specify: Requirements. Systems Analysis and Modeling)

Need for assumption (statement of intended use):

\section{RATIONALE}

Rationale for assumption (source author, date, and report title) or statement of reasoning behind engineering judgment (e.g., midpoint of ranges given in the YMSCP Technical Data Base or Reference Information Base):

Repository Design Requirement Document (RDRD) (YMP/CM-0023): GROA shall, to the extent practical, achieve occupational doses that are ALARA.

\section{RESPONSIBILITY/SUBSTANTIATION/WITHDRAWAL}

Responsible M\&O Organization Subsurface

( ) No Substantiation Required

( ) Substantiation Date

(X) Withdrawal Date 4/28/95(Rev. 01) 


\section{Controlled Design Assumption}

Assumption Rationale Sheet

Assumption Identifier: Key $018(\mathrm{~W})$

Subject: Storage of Retrieved Packages

\section{STATEMENT OF ASSUMPTION}

WITHDRAWN. Retrieval design assumptions will be made when retrieval plans are specified.

Repository design will allow for the possibility of constructing facilities for temporary or lag storage storing of retrieved waste packages, if required.

\section{BACKGROUND}

Requesting M\&O organization: (X)Surface, ( )Subsurface, ( )Waste Package Development, or Other (specify: Requirements, Systems Analysis and Modeling)

Need for assumption (statement of intended use):

Maintains the possible performance objective and dictates the need to allocate site space for this function.

This allocation should be coordinated with the possibility of an interim storage or thermal lag storage.

III. RATIONALE

Rationale for assumption (source author, date, and report title) or statement of reasoning behind engineering judgment (e.g., midpoint of ranges given in the YMSCP Technical Data Base or Reference Information Base):

Consistent with Program Approach assumptions.

Meets 10 CFR 60 and DOE requirements.

\section{RESPONSIBILITY/SUBSTANTIATION/WITHDRAWAL}

Responsible M\&O Organization Surface

(X ) No Substantiation Required

( ) Substantiation Date

(X) Withdrawal Date

12/19/95(Rev. 02) 


\section{Controlled Design Assumption \\ Assumption Rationale Sheet}

Assumption Identifier: Key 020(W)

Subject: Thērmal Load Decision Date

I. STATEMENT OF ASSUMPTION

WITHDRAWN - See Key Assumption 019.

\section{BACKGROUND}

Rev. 02A

Repository Thermal Load

A preliminary repository operational thermal load decision will be made by 2008 license application update.

Final Thermal Load confirmation will be made during operations.

Requesting M\&O organization: ( )Surface, ( )Subsurface, ( )Waste Package Development, or Other (specify: Requirements. Systems Analysis and Modeling)

Need for assumption (statement of intended use):

\section{RATIONALE}

Rationale for assumption (source author, date, and report title) or statement of reasoning behind engineering judgment (e.g., midpoint of ranges given in the YMSCP Technical Data Base or Reference Information Base):

- Premature to select thermal loading before heater testing complete.

- Proposed Program Approach (PPA) includes decision and confirmation times.

- Provide flexibility and cost effectiveness in repository layout.

- Preliminary analyses indicate a less favorable repository performance at intermediate thermal loads.

\section{RESPONSIBILITY/SUBSTANTIATION/WITHDRAWAL}

Responsible M\&O Organization

( ) No Substantiation Required

( ) Substantiation Date

(X) Withdrawal Date

$4 / 28 / 95(\operatorname{Rev} .01)$ 


\section{Controlled Design Assumption}

Assumption Rationale Sheet

Assumption Identifier: Key $021(\mathrm{~W})$

Subject: Performance Confirmation Areas for Thermal Loads

\section{STATEMENT OF ASSUMPTION}

WITHDRAWN - Assumption is not necessary. Compatibility with Key 019 is understood.

Performance confirmation areas will be designed for the range of thermal loads, consistent with Key Assumption 019.

\section{BACKGROUND}

Requesting M\&O organization: ( )Surface, ( )Subsurface, ( )Waste Package Development, or Other (specify: Requirements. Systems Analysis and Modeling)

Need for assumption (statement of intended use):

Performance confirmation planning must address the range specified in Key Assumption 019.

III. RATIONALE

Rationale for assumption (source author, date, and report title) or statement of reasoning behind engineering judgment (e.g., midpoint of ranges given in the YMSCP Technical Data Base or Reference Information Base):

- Premature to select thermal loading before heater testing complete.

- Program Approach includes decision and confirmation times.

\section{RESPONSIBILITY/SUBSTANTIATION/WITHDRAWAL}

Responsible M\&O Organization Systems Engineering

( ) No Substantiation Required

( ) Substantiation Date

(X) Withdrawal Date 12/19/95(Rev. 02) 
Assumption Identifier: Key $025(\mathrm{~W})$

I. STATEMENT OF ASSUMPTION

WITHDRAWN

\section{BACKGROUND}

Requesting M\&O organization: ( )Surface, ( )Subsurface, ( )Waste Package Development, or Other (specify: Requirements. Systems Analysis and Modeling)

Need for assumption (statement of intended use):

\section{RATIONAL}

Rationale for assumption (source author, date, and report title) or statement of reasoning behind engineering judgment (e.g., midpoint of ranges given in the YMSCP Technical Data Base or Reference Information Base):

IV. RESPONSIBILITY/SUBSTANTIATION/WITHDRAWAL

Responsible M\&O Organization

( ) No Substantiation Required

( ) Substantiation Date

(X) Withdrawal Date 4/28/95(Rev. 01) 
Assumption Identifier: Key 026(W)

\section{STATEMENT OF ASSUMPTION}

WITHDRAWN

\section{BACKGROUND}

Requesting M\&O organization: ( )Surface, ( )Subsurfacé, ( )Waste Package Development, or Other (specify: Requirements. Systems Analysis and Modeling)

Need for assumption (statement of intended use):

\section{RATIONALE}

Rationale for assumption (source author, date, and report title) or statement of reasoning behind engineering judgment (e.g., midpoint of ranges given in the YMSCP Technical Data Base or Reference Information Base):

\section{RESPONSIBILITY/SUBSTANTIATION/WITHDRAWAL}

Responsible M\&O Organization Systems Engineering

( X ) No Substantiation Required

( ) Substantiation Date

(X) Withdrawal Date

4/28/95(Rev, OL) 


\section{Controlled Design Assumption \\ Assumption Rationale Sheet}

Assumption Identifier: Key 029(W)

Subject: Technical Baseline Change (Remove Rod Consolidation)

\section{STATEMENT OF ASSUMPTION}

WITHDRAWN - See Key Assumption 008

\section{BACKGROUND}

Rev, 00

\section{Rod Consolidation}

The option for rod consolidation will be removed from the Technical Baseline.

Requesting M\&O organization: ( )Surface, ( )Subsurface, ( )Waste Package Development, or Other (specify: Requirements, Systems Analysis and Modeling)

Need for assumption (statement of intended use):

\section{RATIONALE}

Rationale for assumption (source author, date, and report title) or statement of reasoning behind engineering judgment (e.g., midpoint of ranges given in the YMSCP Technical Data Base or Reference Information Base):

- The concept of rod consolidation was based on the premise that it would cost less to develop, build and operate the facilities and equipment necessary for consolidation than it would to buy, load and emplace the larger number of waste packages required for intact fuel assemblies.

- Many studies have been conducted to evaluate the economics, and operations and schedule impacts related to rod consolidation.

- Study findings show that fuel disposal without rod consolidation reduces life cycle costs, shortens facility construction schedules, and offers additional operational advantages.

\section{RESPONSIBILITY/SUBSTANTIATION/WITHDRAWAL}

Responsible M\&O Organization

(X ) No Substantiation Required

( ) Substantiation Date

(X) Withdrawal Date

4/28/95 (Rev. 01) 


\section{Controlled Design Assumption \\ Assumption Rationale Sheet}

Assumption Identifier: Key 032(W)

\section{STATEMENT OF ASSUMPTION}

WITHDRAWN

\section{BACKGROUND}

Renumbered prior to CDA, Rev. 00.

Requesting M\&O organization: ( )Surface, ( )Subsurface, ( )Waste Package Development, or Other (specify: Requirements. Systems Analysis and Modeling)

Additional shielding for personnel protection provided on transporter and in surface facilities.

Need for assumption (statement of intended use):

III. RATIONALE

Rationale for assumption (source author, date, and report title) or statement of reasoning behind engineering judgment (e.g., midpoint of ranges given in the YMSCP Technical Data Base or Reference Information Base):

This assumption was combined with Key Assumption 031.

\section{RESPONSIBILITY/SUBSTANTIATION/WITHDRAWAL}

Responsible M\&O Organization

( ) No Substantiation Required

( ) Substantiation Date

(X) Withdrawal Date 4/28/95(Rev. 01) 


\section{Controlled Design Assumption \\ Assumption Rationale Sheet}

Assumption Identifier: Key 033(W)

Subject: Individual Waste Package Shielding

\section{STATEMENT OF ASSUMPTION}

WITHDRAWN - Consolidated with Key Assumption 031.

\section{BACKGROUND}

Rev. 00

Requesting M\&O organization: ( )Surface, ( )Subsurface, ( )Waste Package Development, or Other (specify: Requirements. Systems Analysis and Modeling)

Need for assumption (statement of intended use):

\section{RATIONALE}

Rationale for assumption (source author, date, and report title) or statement of reasoning behind engineering judgment (e.g., midpoint of ranges given in the YMSCP Technical Data Base or Reference Information Base):

- Cost, size, and weight of individually shielded waste packages would be excessive.

- MGDS will meet ALARA requirements.

\section{RESPONSIBILITY/SUBSTANTIATION/WITHDRAWAL}

Responsible M\&O Organization Waste Package

( ) No Substantiation Required

( ) Substantiation Date

(X) Withdrawal Date _4/28/95(Rev. 01) 
Assumption Identifier: Key 034(W)

I. STATEMENT OF ASSUMPTION

WITHDRAWN

\section{BACKGROUND}

Requesting M\&O organization: (' )Surface, ( )Subsurface, ( )Waste Package Development, or Other (specify: Requirements, Systems Analysis and Modeling)

Rev. 00

To the extent practical, locate repository openings to avoid faults that traverse a major portion of the potential emplacement area.

Need for assumption (statement of intended use):

III. RATIONALE

Rationale for assumption (source author, date, and report title) or statement of reasoning behind engineering judgment (e.g., midpoint of ranges given in the YMSCP Technical Data Base or Reference Information Base):

Combined into Key Assumption 023, Rev. 02A.

\section{RESPONSIBILITY/SUBSTANTIATION/WITHDRAWAL}

Responsible M\&O Organization

( X ) No Substantiation Required

( ) Substantiation Date

(X) Withdrawal Date 4/28/95(Rev. O1) 
Assumption Identifier: Key 035(W)

\section{STATEMENT OF ASSUMPTION}

WITHDRAWN

\section{BACKGROUND}

$\operatorname{Rev.00}$

Where avoidance cannot be reasonably achieved, for Type I faults that intersect emplacement drifts, allow 15-m standoff distance of emplaced waste packages from the edges of the fault zone.

Requesting M\&O organization: ( )Surface, ( )Subsurface, ( )Waste Package Development, or Other (specify: Requirements, Systems Analysis and Modeling)

Need for assumption (statement of intended use):

III. RATIONALE

Rationale for assumption (source author, date, and report title) or statement of reasoning behind engineering judgment (e.g., midpoint of ranges given in the YMSCP Technical Data Base or Reference Information Base):

Combined into Key Assumption 023, Rev. 02A.

\section{RESPONSIBILITY/SUBSTANTIATION/WITHDRAWAL}

Responsible M\&O Organization

(X) No Substantiation Required

( ) Substantiation Date

(X) Withdrawal Date

4/28/95(Rev. 01) 


\section{Controlled Design Assumption \\ Assumption Rationale Sheet}

Assumption Identifier: Key 036 (W)

Subject: Substantially Complete Containment

(10 CFR 60.113)

1

\section{STATEMENT OF ASSUMPTION}

1

I Substantially complete containment, as referred to in 10 CFR 60.113, will not be defined I quantitatively.

I

\section{1}

I

I I

I Withdrawal Date: REV 4, ICN 1

- U.S. Department of Energy (DOE) position on definition of substantially complete containment has been given to the Nuclear Regulatory Commission (NRC).

- Consistent with multi-barrier approach to waste package design.

\section{RESPONSIBILITY AND WITHDRAWAL}

Responsible Management and Operating Contractor (M\&O) organization: Systems Engineering

Document(s) Supporting Withdrawal of Assumption: Key 074 


\section{Controlled Design Assumption \\ Assumption Rationale Sheet}

Assumption Identifier: Key $037(W)$

Subject: Expected̄ Waste Package Lifetime

\section{STATEMENT OF ASSUMPTION}

Mean waste package lifetime will be well in excess of 1000 years.

\section{BACKGROUND}

Requesting Management and Operating Contractor (M\&O) organization:

( ) Surface, ( ) Subsurface, ( ) Waste Package Development, (X) Other (specify):

Requirements, Systems Analysis and Modeling

Need for assumption (statement of intended use):

Establishes performance objective to permit development of waste package design criteria consistent with this objective.

\section{RATIONALE}

Rationale for assumption (source author, date, and report title) or statement of reasoning behind engineering judgment:

- Meets 10 CFR 60 requirements for substantially complete containment for 300 to 1000 years, to be later determined by the Nuclear Regulatory Commission (NRC).

- U.S. Department of Energy (DOE) position on definition of substantially complete containment has been given to the Nuclear Regulatory Commission (NRC).

- Consistent with multi-barrier approach to waste package design.

\section{RESPONSIBILITY AND WITHDRAWAL}

Responsible Management and Operating Contractor (M\&O) organization: Waste Package

Document(s) Supporting Withdrawal of Assumption: Key 074

Withdrawal Date: REV 4, ICN 1 


\title{
Controlled Design Assumption \\ Assumption Rationale Sheet
}

\author{
Assumption Identifier: Key 038 (W) \\ Subject: Waste Packagēs Breached at 1000 Years

\section{STATEMENT OF ASSUMPTION} \\ The fraction of waste packages breached at 1000 years shall be less than 1 percent (see Note \\ below).

\section{II. BACKGROUND} \\ I Requesting Management and Operating Contractor (M\&O) organization: \\ Need for assumption (statement of intended use): \\ Establishes performance objective useful in containment probability analysis and waste package \\ design criteria.
}

\section{RATIONALE}

Rationale for assumption (source author, date, and report title) or statement of reasoning behind engineering judgment:

- Meets 10 CFR 60 requirements for substantially complete containment for 300 to 1000 years, to be later determined by the Nuclear Regulatory Commission (NRC).

Note: The Data Source, Thomson, B. H., Waste Package Performance Allocation/ Emplacement Mode System Study (CRWMS M\&O 1994d), recommends that 3000 years is necessary to meet Repository Design Requirements Document (RDRD) (YMP 1994a) Requirement 3.2.1.6.C and Engineered Barrier Design Requirements Document (EBDRD) (YMP 1994b) Requirement 3.2.1.6.B using TSPA-1993 results. The 3000-year value was arrived at primarily due to the C14 release requirements imposed via 40 CFR 19l. However, this standard was remanded. The I current assumption does not take the C-14 issue into consideration; it will be modified when the issue is resolved.

\section{RESPONSIBILITY AND WITHDRA WAL}

I Document(s) Supporting Withdrawal of Assumption: Key 074

1

I Withdrawal Date: REV 4, ICN I 


\section{Controlled Design Assumption \\ Assumption Rationale Sheet}

INTENTIONALLY LEFT BLANK TO ACCOMMODATE ICN PAGES 


\section{Controlled Design Assumption \\ Assumption Rationale Sheet}

Assumption Identifier: Key 040(W)

Subject: Period of Waste Isolation

\section{STATEMENT OF ASSUMPTION}

WITHDRAWN - See Key Assumption 039.

\section{BACKGROUND}

Rev, 02A

\section{Criticality Control Period}

Period of isolation currently 10,000 years.

Requesting M\&O organization: ( )Surface, ( )Subsurface, ( )Waste Package

Development, or Other (specify: Requirements, Systems Analysis and Modeling)

Need for assumption (statement of intended use):

\section{RATIONALE}

Rationale for assumption (source author, date, and report title) or statement of reasoning behind engineering judgment (e.g., midpoint of ranges given in the YMSCP Technical Data Base or Reference Information Base):

- Assumption in accordance with 10 CFR 60.13l(b)(7).

- Period of isolation in accordance with 40 CFR 191.13(a).

- Period of isolation consistent with DOE recommendation to the National Academy of Sciences for the repromulgation of the EPA Standard for Yucca Mountain.

\section{RESPONSIBILITY/SUBSTANTIATION/WITHDRAWAL}

Responsible M\&O Organization Systems Engineering

( ) No Substantiation Required

( ) Substantiation Date

(X) Withdrawal Date 4/28/95(Rev. 01) 


\section{STATEMENT OF ASSUMPTION}

WITHDRAWN - Consolidated with Key Assumptions 001, 002, 003.

\section{BACKGROUND}

Rev.00

Waste Type and Quantity

Receipt and emplacement rate in accordance with MGDS Requirements Document

Table 3-3. Steady state rate $3000 \mathrm{MTU} / \mathrm{yr}$ SNF, $400 \mathrm{MTU} / \mathrm{yr}$ (equivalent) HLW glass.

Requesting M\&O organization: ( X )Surface, ( X )Subsurface, ( X )Waste Package

Development, or Other (specify: Requirements. Systems Analysis and Modeling)

Need for assumption (statement of intended use):

\section{RATIONALE}

Rationale for assumption (source author, date, and report title) or statement of reasoning behind engineering judgment (e.g., midpoint of ranges given in the YMSCP Technical Data Base or Reference Information Base):

In accordance with Nuclear Waste Policy Act, OCRWM Mission Plan, MPC concept, Proposed Program Approach, and MGDS Requirements Document and supporting requirements documents.

\section{RESPONSIBILITY/SUBSTANTIATION/WITHDRAWAL}

Responsible M\&O Organization Systems Engineering

( ) No Substantiation Required

( ) Substantiation Date

(X) Withdrawal Date

4/28/95 (Rev. 01) 


\section{Controlled Design Assumption Assumption Rationale Sheet}

Assumption Identifier: Key 042(W)

Subject: Waste Package Māterials - High Thermal Load

\section{STATEMENT OF ASSUMPTION}

WITHDRAWN because this is a design solution rather than an assumption (see DCWP 003 rationale). Waste Package materials for high thermal load are:

Inner Containment Barrier - UNS N08825 (Alloy 825).

Outer Containment Barrier for SNF packages - UNS G10200 (ASTM A 516).

Outer Containment Barrier for HLW packages - UNS C7I500 (7.0/30 copper-nickel)

\section{BACKGROUND}

Requesting M\&O organization: ( )Surface, ( )Subsurface, ( X )Waste Package Development, or Other (specify: Requirements, Systems Analysis and Modeling)

Need for assumption (statement of intended use):

Establishes probable waste package material to permit development of thermal performance analysis and containment probabilities.

III. RATIONALE

Rationale for assumption (source author, date, and report title) or statement of reasoning behind engineering judgment (e.g., midpoint of ranges given in the YMSCP Technical Data Base or Reference Information Base):

UNS N08825 is highly resistant to general corrosion and in many environments is resistant to localized corrosion. It was chosen as a reasonable compromise between high corrosion resistance and low cost.

USN G10200 is the corrosion allowance material for SNF packages. Although it has an appreciable atmospheric corrosion rate, it is normally not subject to localized corrosion. The material was chosen because it provides predictable corrosion rates and low cost.

UNS C71500 is the outer barrier material for (HLW) glass packages. It provides significant corrosion resistance. An iron-based material was not chosen because there is evidence that active iron-base materials will promote the degradation of the waste glass.

Materials with distinctly different compositions and corrosion mechanisms were chosen for the inner and outer barriers so that protection will be provided over a wide range of environments.

\section{RESPONSIBILITY/SUBSTANTIATION/WITHDRA WAL}

Responsible M\&O Organization Waste Package

( ) No Substantiation Required

( ) Substantiation Date

(X) Withdrawal Date _ 12/19/95(Rev. 02) 


\section{Controlled Design Assumption \\ Assumption Rationale Sheet}

Assumption Identifier: Key $043(W)$

Subject: Waste Package Māterials - Low Themal Load

\section{STATEMENT OF ASSUMPTION}

WITHDRAWN because this is a design solution rather than an assumption (see DCWP 003 rationale). Waste package materials for low thermal load are:

Inner Containment Barrier - UNS N08825 (Alloy 825).

Middle Containment Barrier for SNF packages - UNS G10200 (ASTM A 516).

Middle Containment Barier for HLW packages - UNS C71500 (70/30 copper-nickel).

Outer Containment Barrier - UNS N04400 (Monel 400).

\section{BACKGROUND}

Requesting M\&O organization: ( )Surface, ( )Subsurface, ( X )Waste Package Development, or Other (specify: Requirements, Systems Analysis and Modeling)

Need for assumption (statement of intended use):

Establishes probable waste package material to permit development of thermal performance analysis and containment probabilities.

\section{RATIONALE}

Rationale for assumption (source author, date, and report title) or statement of reasoning behind engineering judgment (e.g., midpoint of ranges given in the YMSCP Technical Data Base or Reference Information Base):

UNS N08825 is resistant to general corrosion in oxidizing and reducing acids. In many environments it is resistant to localized corrosion. It was chosen as a reasonable compromise between high corrosion resistance and low cost.

USN G10200 is the corrosion allowance material for SNF packages. Although it has an appreciable atmospheric corrosion rate, it is normally not subject to localized corrosion. The material was chosen because it provides predictable corrosion rates and low cost.

UNS C71500 is the outer barrier material for (HLW) glass packages. It provides significant corrosion resistance. An iron-based material was not chosen because there is evidence that active iron-base materials will promote the degradation of the waste glass.

UNS N04400 was chosen as an additional corrosion resistant barrier for low thermal load conditions. It is corrosion resistant in various environments including alkalies.

Materials with distinctly different compositions and corrosion mechanisms were chosen for the inner and outer barriers so that protection will be provided over a wide range of environments.

\section{RESPONSIBILITY/SUBSTANTIATION/WITHDRAWAL}

Responsible M\&O Organization Waste Package

( ) No Substantiation Required

( ) Substantiation Date

(X) Withdrawal Date 12/19/95(Rey. 02) 


\section{Controlled Design Assumption \\ Assumption Rationale Sheet}

Assumption Identifier: Key $044(\mathrm{~W})$

I. STATEMENT OF ASSUMPTION

WITHDRAWN

II. BACKGROUND

Renumbered prior to Rev. 00 .

Requesting M\&O organization: ( )Surface, ( )Subsurface, ( )Waste Package Development, or Other (specify: Requirements. Systems Analysis and Modeling)

Need for assumption (statement of intended use):

III. RATIONALE

Rationale for assumption (source author, date, and report title) or statement of reasoning behind engineering judgment (e.g., midpoint of ranges given in the YMSCP Technical Data Base or

Reference Information Base):

- Alloy 825 as corrosion resistant barrier recommended in LLNL survey report.

- Carbon steel (A 516) as corrosion allowance barrier and provide structural and shielding function relatively inexpensively.

- Additional barrier to resist aqueous environments needed for low thermal load case.

- Ability to fabricate and weld materials satisfactorily.

- Other similar materials are being considered as alternatives.

IV. RESPONSIBILITY/SUBSTANTIATION/WITHDRAWAL

Responsible M\&O Organization

(X) No Substantiation Required

( ) Substantiation Date

(X) Withdrawal Date 4/28/95(Rev, 01) 


\section{Controlled Design Assumption \\ Assumption Rationale Sheet}

Assumption Identifier: Key $045(\mathrm{~W})$

Subject: Altemative Waste Package Materials

\section{STATEMENT OF ASSUMPTION}

WITHDRAWN - Required by 10 CFR 60.21.

II. BACKGROUND

$\operatorname{Rev}, 00$

An alternative to each of the component materials indicated will be identified in the CDA document since containment barriers are important to waste isolation.

Requesting M\&O organization: ( )Surface, ( )Subsurface, ( X )Waste Package Development, or Other (specify: Systems Analysis and Modeling)

Need for assumption (statement of intended use):

Identifies a need for flexibility in materials selection for containment barrier design.

III. RATIONALE

Rationale for assumption (source author, date, and report title) or statement of reasoning behind engineering judgment (e.g., midpoint of ranges given in the YMSCP Technical Data Base or Reference Information Base):

Altematives are required by 10 CFR 60 .

IV. RESPONSIBILITY/SUBSTANTIATION/WITHDRA WAL

Responsible M\&O Organization Waste Package

( X ) No Substantiation Required

( ) Substantiation Date

(X) Withdrawal Date 4/28/95(Rev,01) 


\section{Controlled Design Assumption}

Assumption Rationale Sheet

Assumption Identifier: Key 048(W) Subject: Aluminum Boron iñ First MPC Procurement

\section{STATEMENT OF ASSUMPTION}

WITHDRAWN for consistency with programmatic guidance in IOC \#VA.SE.GUR.8/95.016.

Aluminum-boron will be the neutron absorber basket material in the First Procurement MPCs.

\section{BACKGROUND}

\section{Requesting M\&O organization: ( X )Surface, ( )Subsurface, ( X )Waste Package} Development, or Other (specify:

Need for assumption (statement of intended use):

Establishes neutron absorber basket design solution to permit first procurement of MPCs.

\section{RATIONALE}

Rationale for assumption (source author, date, and report title) or statement of reasoning behind engineering judgment (e.g., midpoint of ranges given in the YMSCP Technical Data Base or Reference Information Base):

The MPC Design Procurement Specification contained two possible materials for the SNF basket neutron absorber: Boron or $\mathrm{B}_{4} \mathrm{C}$ finely dispersed in austenitic stainless steel or aluminum alloy matrix. For cost and thermal reasons, it is expected that the First Procurement MPCs will use aluminum-boron (Al-B).

\section{RESPONSIBILITY/SUBSTANTIATION/WITHDRAWAL}

Responsible M\&O Organization Systems Engineering

( ) No Substantiation Required

( ) Substantiation Date

(X) Withdrawal Date 12/19/95(Rev, 02) 


\section{Controlled Design Assumption \\ Assumption Rationale Sheet}

Assumption Identifier: Key 049(W) Subject: Aluminum Boron ñot Acceptable Long Term

\section{STATEMENT OF ASSUMPTION}

WITHDRAWN for consistency with programmatic guidance in IOC \#VA.SE.GUR.8/95.016.

Aluminum-boron is not acceptable as a long-term supplemental neutron absorbing material.

\section{BACKGROUND}

Requesting M\&O organization: ( X )Surface, ( )Subsurface, ( X )Waste Package Development, or Other (specify:

\section{Need for assumption (statement of intended use):}

Defines a performance scenario that establishes Key Assumption 048 as not achieving neutron basket performance objective. This establishes the need for further material study for neutron basket prior to second MPC procurement (see Key Assumption 050). This also establishes need for design analysis to determine remedial criteria for the First Procurement of MPCs (see Key Assumption 051).

\section{RATIONALE}

Rationale for assumption (source author, date, and report title) or statement of reasoning behind engineering judgment (e.g., midpoint of ranges given in the YMSCP Technical Data Base or Reference Information Base):

- As long as the interior of the MPC remains dry or the stainless steel cladding remains intact, the neutron absorber will be protected and no difficulties are expected. However, the interior of the MPC will be filled with water during the SNF loading process and may become wet due to the failure of the disposal container and MPC shell in the presence of water in the repository. If the stainless steel cladding is perforated by corrosion, which is expected, corrosion of the aluminum will occur. Aluminum is passive in neutral solutions, but its solubility increases rapidly as $\mathrm{pH}$ decreases. If nitrogen is present, as is expected if water enters through a breach in the disposal container, radiolysis will produce nitric acid and cause corrosion of the aluminum. Aluminum is thermodynamically very active, and the large available surface area of the stainless steel cladding will make it an excellent cathode for bimetallic corrosion of the aluminum. Corrosion of the aluminum is expected to cause loss of integrity of the neutron absorber, which would allow the remaining boroncontaining material to sift to the bottom of the package where it would no longer be effective for criticality control.

\section{RESPONSIBILITY/SUBSTANTIATION/WITHDRAWAL}

Responsible M\&O Organization Waste Package

( ) No Substantiation Required

( ) Substantiation Date

(X) Withdrawal Date $12 / 19 / 95(\operatorname{Rev}, 02)$ 


\section{Controlled Design Assumption \\ Assumption Rationale Sheet}

Assumption Identifier: Key 050(W)

Subject: MPC Redesign in Second Procurement

\section{STATEMENT OF ASSUMPTION}

WITHDRAWN for consistency with programmatic guidance in IOC \#VA.SE.GUR.8/95.016.

At the completion of the long-term materials testing program and after approval of the revised burnup credit topical report, the second procurement MPC will be redesigned such that the basket, with burnup credit, will achieve long-term criticality control without the need to open the MPC at the Repository.

\section{BACKGROUND}

Requesting M\&O organization: ( X )Surface, ( )Subsurface, ( X )Waste Package Development, or Other (specify:

Need for assumption (statement of intended use):

Establishes the performance objective of eliminating the need to re-open an MPC at the MGDS, thus permitting the development of MPC design criteria to achieve this objective.

\section{RATIONALE}

Rationale for assumption (source author, date, and report title) or statement of reasoning behind engineering judgment (e.g., midpoint of ranges given in the YMSCP Technical Data Base or Reference Information Base):

Based on Key Assumption 049. In order for the repository not to have to open MPCs, both principal isotope burnup credit and supplemental neutron absorbers are expected to be required. After completion of these activities (long-term materials testing and revised burnup credit topical report), there is expected to be an increase in the knowledge in the MGDS requirements applicable to the MPC and an increase in the confidence that the MPC design will be emplaceable. The current MGDS concept of operations for surface facilities does not include the opening of all MPCs. In order for this to be the case, a redesign of the MPC must be planned.

\section{RESPONSIBILITY/SUBSTANTIATION/WITHDRAWAL}

Responsible M\&O Organization Systems Engineering

( ) No Substantiation Required

( ) Substantiation Date

(X) Withdrawal Date $12 / 19 / 95(\operatorname{Rev}, 02)$ 


\section{STATEMENT OF ASSUMPTION}

WITHDRAWN for consistency with programmatic guidance in IOC \#VA.SE.GUR.8/95.016.

The arrival scenario, quantity and type of the First Procurement MPCs will be as shown in the following table.

\section{BACKGROUND}

Requesting M\&O organization: ( X )Surface, ( )Subsurface, ( )Waste Package Development, or Other (specify:

Need for assumption (statement of intended use):

Establishes a waste flow rate upon which remedial performance objectives can be based. Objective is to minimize impact of remedial capacity on Repository Surface Waste Handling facility design.

\section{RATIONALE}

Rationale for assumption (source author, date, and report title) or statement of reasoning behind engineering judgment (e.g., midpoint of ranges given in the YMSCP Technical Data Base or Reference Information Base):

The schedule for resolution of several burnup credit issues is September 1998. The schedule for completion of the long-term materials testing is also September 1998. At that time, there is expected to be an increase in the knowledge in the MGDS requirements applicable to the MPC and an increase in the probability of MPC design being emplaceable. There is also expected to be a three-year time frame to redesign, certify, and procure a second-generation MPC. Based on this and some conservatism, five years worth of MPCs in the first procurement have been used. The source of the table is "Systems Logistics and Waste Stream Data for MGDS CDA Update," CRWMS M\&O Interoffice Correspondence from Jim Davis, Mark Fleming, John King, and Marc Rose, March 28, 1995, VA.SA.JK.03/95.038.

\section{RESPONSIBILITY/SUBSTANTIATION/WITHDRAWAL}

Responsible M\&O Organization Systems Engineering

( ) No Substantiation Required

( ) Substantiation Date

(X) Withdrawal Date 12/19/95(Rev, 02) 
Controlled Design Assumption

Assumption Rationale Sheet

Key 051(W) First MPC Procurement Delivery/Emplacement Scenario

No MRS, 2010 MGDS, OFF (FY95DDAO)

\begin{tabular}{|c|c|c|c|c|c|c|}
\hline \multirow{2}{*}{ Ycar } & \multicolumn{6}{|c|}{ MPCs } \\
\hline & B-LG & P-LG & B-SM & P-SM & B-in-P & Total \\
\hline 2010 & 0 & 0 & 1 & 3 & 0 & 4 \\
\hline 2011 & 0 & 0 & 10 & 3 & 0 & 13 \\
\hline 2012 & 0 & 0 & 20 & 3 & 1 & 24 \\
\hline 2013 & 0 & 3 & 24 & 7 & 1 & 35 \\
\hline 2014 & 8 & 14 & 2 & 3 & 0 & 27 \\
\hline 2015 & 1 & 10 & 2 & 4 & 0 & 17 \\
\hline 2016 & 7 & 17 & 18 & 6 & 0 & 48 \\
\hline 2017 & 1 & 2 & 6 & 6 & 0 & 15 \\
\hline 2018 & 4 & 17 & 5 & 7 & 0 & 33 \\
\hline 2019 & I & 14 & 0 & 5 & 0 & 20 \\
\hline 2020 & 4 & 8 & 4 & 7 & 0 & 23 \\
\hline 2021 & 6 & 25 & 4 & 0 & 0 & 35 \\
\hline 2022 & 3 & 19 & 2 & 4 & 0 & 28 \\
\hline 2023 & 7 & 23 & 2 & 0 & 0 & 32 \\
\hline 2024 & 10 & 28 & 6 & 0 & 0 & 44 \\
\hline 2025 & 2 & 28 & 3 & 0 & 0 & 33 \\
\hline 2026 & 3 & 20 & 0 & 0 & 0 & 23 \\
\hline 2027 & 2 & 12 & 0 & 0 & 0 & 14 \\
\hline 2028 & 2 & 7 & 0 & 0 & 0 & 9 \\
\hline 2029 & 6 & 4 & 0 & 0 & 0 & 10 \\
\hline 2030 & 3 & 0 & 0 & 0 & 0 & 3 \\
\hline 2031 & 0 & 0 & 0 & 0 & 0 & 0 \\
\hline 2032 & 0 & 0 & 0 & 0 & 0 & 0 \\
\hline 2033 & 0 & 0 & 0 & 0 & 0 & 0 \\
\hline Total & 70 & 251 & 109 & 58 & 2 & 490 \\
\hline
\end{tabular}

Key 051(W) 


\section{Controlled Design Assumption \\ Assumption Rationale Sheet}

\section{STATEMENT OF ASSUMPTION}

WITHDRAWN for consistency with removal of multi-purpose canisters from baseline and because filler addition is no longer applicable.

The following table provides a scenario for receipt of First Procurement MPCs. The table may be used to provide an upper bound for abnormal MPCs requiring remedial operations at the repository.

\section{BACKGROUND}

Requesting M\&O organization:

(X) Surface, ( ) Subsurface, ( ) Waste Package Development, or Other (specify: )

Need for assumption (statement of intended use):

Establishes performance objectives permitting the development of design criteria for the MPC First Procurement and the Repository Waste Handling Remedial operations.

III. RATIONALE

Rationale for assumption (source author, date, and report title) or statement of reasoning behind engineering judgment (e.g., midpoint of ranges given in the YMSCP Technical Data Base or Reference Information Base):

Based on programmatic guidance documented in IOC \# VA.SE.GUR.8/95.016, verification assumptions made in that IOC and complete execution of the direction, this assumption should-provide an upper bound on the number of MPCs needing remedial operations at the Repository. The table is based on several considerations: 1) the assumption that five years of MPCs from the first procurement could be deployed and loaded with fuel that may not meet final disposal requirements on MPCs, 2) several criticality control related activities must occur before disposal requirements on MPCs could be finalized, e.g., completion of the Disposal Criticality Control Topical Report, approval of a Bumup Credit Topical report that would include principal isotopes (including some fission products) and completion of basket material corrosion testing, 3) the analysis in the memo indicated below. Based on these assumptions and this analysis, 113 of the first procurement MPCs will require additional criticality control measures. This number was determined by comparing each of the 544 individual MPC $k_{-}$values with an estimated value that reflected the demarcation point between those MPCs that should be opened and those that did not have to be opened. This estimated value, which assumes principle isotope bumup credit and no credit for engineered neutron absorbers, varied depending on whether the MPC being evaluated was large or small, and whether it contained BWR or PWR assemblies. This analysis is described in detail in the memo from M.A. Balady, "Update to Rationale for Selection of First Procurement MPCs to be Opened," CRWMS M\&O Interoffice Correspondence, LV.SEA.MB.04/95.047, April 24, 1995. The reopening of MPCs will be an off-normal operation. Adding filler additives or other reactivity control additives will also be considered an offnormal operation.

\section{RESPONSIBILITY/SUBSTANTIATION/WITHDRA WAL}

Responsible M\&O Organization Systems Engineering

( ) No Substantiation Required

( ) Substantiation Date

(X) Withdrawal Date 9/30/96(Rev.04) 
Controlled Design Assumption

Assumption Rationale Sheet

\begin{tabular}{|c|c|c|c|c|c|c|}
\hline \multirow[t]{3}{*}{$\begin{array}{c}\text { Key } \\
\text { 052(W) }\end{array}$} & \multicolumn{6}{|c|}{$\begin{array}{c}\text { First MPC Procurement Requiring Opening at Repository } \\
\text { No MRS, } 2010 \text { MGDS, OFF (FY95DAO) }\end{array}$} \\
\hline & \multicolumn{5}{|c|}{ MPCs } & \multirow{2}{*}{ Total } \\
\hline & B-LG & P-LG & B-SM & P-SM & B-in-P & \\
\hline 1 & 0 & 0 & 0 & 3 & 0 & 3 \\
\hline 2 & 0 & 0 & 0 & 3 & 0 & 3 \\
\hline 3 & 0 & 0 & 0 & 4 & 0 & 4 \\
\hline 4 & 0 & I & 0 & 7 & 0 & 8 \\
\hline 5 & 0 & 5 & 0 & $I$ & 0 & 6 \\
\hline 6 & 0 & 4 & 0 & 0 & 0 & 4 \\
\hline 7 & 0 & 6 & 0 & 3 & 0 & 4 \\
\hline 8 & 0 & 0 & 1 & 0 & 0 & 1 \\
\hline 9 & 0 & 10 & 0 & 0 & 0 & 10 \\
\hline 10 & 0 & 6 & 0 & $I$ & 0 & 7 \\
\hline 11 & 0 & 1 & 0 & 7 & 0 & 8 \\
\hline 12 & 0 & 18 & 0 & 0 & 0 & 18 \\
\hline 13 & 0 & 6 & 0 & 0 & 0 & 6 \\
\hline 14 & 0 & 1 & 0 & 0 & 0 & 1 \\
\hline 15 & 0 & 1 & 0 & 0 & 0 & 1 \\
\hline 16 & 0 & 9 & 0 & 0 & 0 & 9 \\
\hline 17 & 0 & 8 & 0 & 0 & 0 & 8 \\
\hline 18 & 0 & 4 & 0 & 0 & 0 & 4 \\
\hline 19 & 0 & 4 & 0 & 0 & 0 & 4 \\
\hline 20 & 0 & 3 & 0 & 0 & 0 & 3 \\
\hline 21 & 0 & 0 & 0 & 0 & 0 & 0 \\
\hline 22 & 0 & 0 & 0 & 0 & 0 & 0 \\
\hline 23 & 0 & 0 & 0 & 0 & 0 & 0 \\
\hline 24 & 0 & 0 & 0 & 0 & 0 & 0 \\
\hline Total & 0 & 87 & 1 & 29 & 0 & 117 \\
\hline
\end{tabular}

* Years of MGDS Operation

BASIS (Ref: VA.SA.JK.03/95.038 Memo, 28 Mar 95)

Program Approach Scenario (NO MRS). 


\section{Controlled Design Assumption \\ Assumption Rationale Sheet}

BASIS (Ref: VA.SA.JK.03/95.038 Memo, 28 Mar 95)

- Program Approach Scenario (NO MRS).

- First Procurement MPCs in the five-year period 1998-2002 are loaded with OFF and placed in reactor dry storage.

- Pickup from dry storage is deferred until no fuel older than 10 years remains in spent fuel pools.

- Pickup from only four trucks (no-rail) purchasing utilities are assumed.

- Waste Package heat limit for emplacement is $14.2 \mathrm{~kW}$.

- Transportation Casks are derated as shown.

\section{Cask Derating}

\begin{tabular}{|l||ccrr|}
\hline \multirow{2}{*}{ Operation } & \multicolumn{5}{c|}{ MPC Heat Limits (kW) } \\
\cline { 2 - 5 } & B-LG & P-LG & B-SM & P-SM \\
\hline \multirow{2}{*}{ Storage } & 17.60 & $23.90^{*}$ & 10.56 & 13.68 \\
Transportation & 12.00 & 14.20 & 7.20 & 8.76 \\
Emplacement & 14.20 & 14.20 & 14.20 & 14.20 \\
\hline
\end{tabular}

See Key Assumptions 001 to 003 for Legend

*17.85 kW used at various sites for post-shutdown dry storage 


\section{Controlled Design Assumption \\ Assumption Rationale Sheet}

Key 052 (W)

First Procurement MPCs in the five-year period 1998-2002 are loaded with OFF and placed in reactor dry storage.

Pickup from dry storage is deferred until no fuel older than 10 years remains in spent fuel pools.

Pickup from only four trucks (no-rail) purchasing utilities are assumed.

Waste Package heat limit for emplacement is $14.2 \mathrm{~kW}$.

Transportation casks are derated as shown.

Cask Derating

\begin{tabular}{|l|c|c|c|c|}
\hline \multirow{2}{*}{ Operation } & \multicolumn{4}{|c|}{ MPC Heat Limits (kW) } \\
\cline { 2 - 5 } & B-LG & P-LG & B-SM & P-SM \\
\hline Storage & 17.60 & $23.90^{*}$ & 10.56 & 13.68 \\
\hline Transportation & 12.0 & 14.20 & 7.20 & 8.76 \\
\hline Emplacement & 14.20 & 14.20 & 14.20 & 14.20 \\
\hline
\end{tabular}

See Key Assumptions 001 to 003 for Legend

$* 17.85 \mathrm{~kW}$ used at various sites for post-shutdown dry storage 


\section{Controlled Design Assumption \\ Assumption Rationale Sheet}

\section{Assumption Identifier: Key 054(W) Subject: Normal Waste Hand̄ling Building Capability

\section{STATEMENT OF ASSUMPTION}

WITHDRAWN: Filler material is no longer a consideration in processing commercial SNF.

The design for the Waste Handling Building's (WHB's) standard canister and disposal container handling operations is based on no capability to add filler material to the canistered waste or the disposal container (MPCs) at the repository.

\section{BACKGROUND}

MGDSRD 3.2.3.2.3.1.1.L

The Repository Segment shall have the capability to handle any abnormal disposable canister and other canistered waste forms that require remedial processing. Such processing may include opening the canister, transferring the waste form, adding filler material and resealing. [10CFR60.135(a)(1)] [CRD 3.7.4.2.D]

Requesting Management and Operating Contractor (M\&O) organization:

(X) Surface, ( ) Subsurface, ( ) Waste Package Development, or Other (specify: )

Need for assumption (statement of intended use):

Defines a probable path for continued development of the repository Waste Handling Building (WHB).

\section{RATIONALE}

Rationale for assumption (source author, date, and report title) or statement of reasoning behind engineering judgment:

Programmatic guidance defines an approach where filler material may be unnecessary (IOC \#VA.SE.GUR.8/95.016).

A separate cell for accommodating unusual or off-normal operations is presently planned (see Key Assumption 053). Such limited operations could include performance confirmation examinations, bare fuel assembly handling, and opening damaged waste form canisters.

This assumption complies with the intended interpretation of the MGDS-RD 3.2.3.2.3.1.1.L requirement as found in Section 3.2.3.2.3.1.1.L of the Transportation Site Requirements Document (SRD). The project's position is not to choose the option of adding filler material to a disposable waste canister that does not meet disposal requirements. Instead, the loaded canister will be opened, the spent nuclear fuel (SNF) will be removed, and the canister will be discarded. This modification of the project's approach is a result of the "MPC Policy Change" Baseline Change Proposal (\#BCP 00-96-0002, BCP Rev. 0).

\section{RESPONSIBILITY AND WITHDRAWAL}

Responsible Management and Operating Contractor (M\&O) organization: Surface Document(s) Supporting Withdrawal of Assumption:

Withdrawal Date: (09/30/96) (Rev. 04) 


\section{Controlled Design Assumption \\ Assumption Rationale Sheet}

Assumption Identifier: Key 056(W)

Subject: Interim Fuel Storage

\section{STATEMENT OF ASSUMPTION}

WITHDRAWN: Assumptions regarding interim storage will be deferred until the decision regarding interim storage is made. If there is an ISF, interface requirements are expected to first be established in the CRD.

The Repository will interface with an interim Storage Facility which is located outside the State of Nevada.

\section{BACKGROUND}

Requesting Management and Operating Contractor (M\&O) organization:

( ) Surface, ( ) Subsurface, ( ) Waste Package Development, (X) Other (specify):

Requirements, Systems Engineering

Need for assumption (statement of intended use):

Surface Repository Design

\section{RATIONALE}

Rationale for assumption (source author, date, and report title) or statement of reasoning behind engineering judgment:

Interim storage is a Congressional program requirement.

\section{RESPONSIBILITY AND WITHDRAWAL}

Responsible Management and Operating Contractor (M\&O) organization: Systems Engineering Document(s) Supporting Withdrawal of Assumption:

Withdrawal Date: 09/30/96 (Rev. 04) 


\title{
I. STATEMENT OF ASSUMPTION
}

\author{
WITHDRAWN - Consolidated with Key Assumption 005
}

The direction and assumptions given in BCP-00-96-0005, Implementation of the Program Approach (DOE 1994b) will be used as a basis for Mined Geologic Disposal System (MGDS) design for the U.S. Department of Energy (DOE) spent nuclear fuel (SNF) disposal.

The baseline change proposal (BCP) calls for the disposal at MGDS of 2333 MTHM of mostly canistered DOE SNF, replacing a similar amount out of the $7000 \mathrm{MTHM}$ of high-level waste (HLW) previously planned for the repository. However, the exact fuel characteristics and forms of DOE SNF to be delivered to the repository are not presently known. Therefore, incorporation of the DOE SNF into the MGDS design will be delayed until further information is received. In the interim, Key Assumption 005 (7000 MTU of HLW) will be assumed to hold.

\section{BACKGROUND}

Requesting Management and Operating Contractor (M\&O) organization:

(X) Surface, (X) Subsurface, (X) Waste Package Development, ( ) Other (specify):

Need for assumption (statement of intended use):

Design requirements specific to the DOE SNF needed for repository waste package design do not yet exist in the Mined Geologic Disposal System (MGDS) Design Requirements Documents (DRDs).

\section{RATIONALE}

Rationale for assumption (source author, date, and report title) or statement of reasoning behind engineering judgment:

This key assumption is based on BCP-00-96-0005. Implementation of the Program Approach (DOE 1994b).

Characteristics of most of the fuel are known. However, the characteristics of a few hundred MTU of the DOE waste are not understood as well as the characteristics of the commercial SNF. In addition, the characteristics of another few hundred MTU are not known. Negotiations with $\mathrm{DOE} / \mathrm{EM}$ for characterization of the various SNF are currently underway.

It is further assumed that the acceptability criteria for DOE SNF which is properly conditioned will result in no impact on MGDS Viability Assessment (VA) efforts. For this reason, no attempt was made to incorporate the DOE SNF into the MGDS design at this time.

\section{RESPONSIBILITY AND WITHDRAWAL}

Responsible Management and Operating Contractor (M\&O) organization: Systems Engineering

Document(s) Supporting Withdrawal of Assumption: Key Assumption 005

Withdrawal Date: REV 04, ICN 2 
1 Assumption Identifier: EBDRD 3.1.5.E(W)

Subjēect: Shielding Allocations

\section{STATEMENT OF ASSUMPTION}

\section{WITHDRAWN}

\section{BACKGROUND}

Requesting M\&O organization: ( )Surface, ( )Subsurface, ( )Waste Package Development, or Other (specify: Systems Analysis and Modeling)

Rev. 00

The waste package will not be self-shielded.

Qriginal Version

E. Shielding allocations between the Repository Segment and the Engineered Barrier Segment have not been determined. Currently, the waste package will not be required to be self-shielded. The assumption is that if the waste package is not self-shielded, the repository will provide the required shielding for radiological protection for all modes of facility operation. Shielding allocations will be determined by future trade studies.

Need for assumption (statement of intended use):

Requirement EBDRD 3.1.5.E is written as an "if" statement, and thus provides the design organizations with the opportunity to select from several options.

\section{RATIONALE}

Rationale for assumption (source author, date, and report title) or statement of reasoning behind engineering judgment (e.g., midpoint of ranges given in the YMSCP Technical Data Base or Reference Information Base):

The repository's role in providing shielding is sufficiently covered by Key Assumptions 031 and 033.

\section{RESPONSIBILITY/SUBSTANTIATION/WITHDRAWAL}

Responsible M\&O Organization

(X) No Substantiation Required

( ) Substantiation Date

(X) Withdrawal Date $\overline{4 / 28 / 95(\operatorname{Rev} .01)}$ 


\section{STATEMENT OF ASSUMPTION}

WITHDRAWN - The corresponding EBDRD requirement does not apply to ACD.

\section{BACKGROUND}

\section{Original Version}

\section{EBDRD 3.2.5.1.2}

B. Reliability of the EBS shall be as follows:

1. Waste Package (TBD)

a. Waste Form (TBD)

Requesting M\&O organization: ( )Surface, ( )Subsurface, ( )Waste Package

Development, or Other (specify: Systems Analysis and Modeling)

Need for assumption (statement of intended use):

\section{RATIONALE}

Rationale for assumption (source author, date, and report title) or statement of reasoning behind engineering judgment (e.g., midpoint of ranges given in the YMSCP Technical Data Base or Reference Information Base):

Detail specified in this requirement is too specific for Engineered Barrier requirement. Recommendation to delete this requirement has been forwarded to the Requirements Organization.

\section{RESPONSIBILITY/SUBSTANTIATION/WITHDRAWAL}

Responsible M\&O Organization Waste Package

(X ) No Substantiation Required

( ) Substantiation Date

(X) Withdrawal Date $12 / 19 / 95(\operatorname{Rev} .02)$ 


\section{Controlled Design Assumption \\ Assumption Rationale Sheet}

Assumption Identifier: EBDRD 3.2.5.1.2.B. . . b(W)

Subject: Waste Container Reliability

\section{STATEMENT OF ASSUMPTION}

WITHDRAWN - The corresponding EBDRD requirement does not apply to ACD.

\section{BACKGROUND}

\section{Original Version}

EBDRD 3.2.5.1.2

B. Reliability of the EBS shall be as follows:

1. Waste Package (TBD)

b. Waste Container (TBD)

Requesting M\&O organization: ( )Surface, ( ) Subsurface, ( )Waste Package

Development, or Other (specify: Systems Analysis and Modeling)

Need for assumption (statement of intended use):

III. RATIONALE

Rationale for assumption (source author, date, and report title) or statement of reasoning behind engineering judgment (e.g., midpoint of ranges given in the YMSCP Technical Data Base or Reference Information Base):

Detail specified in this requirement is too specific for Engineered Barrier requirement. Recommendation to delete this requirement has been forwarded to the Requirements Organization.

\section{RESPONSIBILITY/SUBSTANTIATION/WITHDRAWAL}

Responsible M\&O Organization Waste Package

(X) No Substantiation Required

( ) Substantiation Date

(X) Withdrawal Date 


\section{STATEMENT OF ASSUMPTION}

WITHDRAWN - The corresponding EBDRD requirement does not apply to ACD.

\section{BACKGROUND}

Original Version

\section{EBDRD 3.2.5.1.2}

B. Reliability of the EBS shall be as follows:

1. Waste Package (TBD)

c. Internal Structure (TBD)

Requesting M\&O organization: ( )Surface, ( )Subsurface, ( )Waste Package Development, or Other (specify: Systems Analysis and Modeling)

Need for assumption (statement of intended use):

\section{RATIONALE}

Rationale for assumption (source author, date, and report title) or statement of reasoning behind engineering judgment (e.g., midpoint of ranges given in the YMSCP Technical Data Base or Reference Information Base):

Detail specified in this requirement is too specific for Engineered Barrier requirement.

Recommendation to delete this requirement has been forwarded to the Requirements Organization.

\section{RESPONSIBILITY/SUBSTANTIATION/WITHDRAWAL}

Responsible M\&O Organization Waste Package

(X) No Substantiation Required

( ) Substantiation Date

(X) Withdrawal Date $\frac{12 / 19 / 95(\text { Rev. 02) }}{10}$ 


\section{STATEMENT OF ASSUMPTION}

WITHDRAWN - The corresponding EBDRD requirement does not apply to ACD.

\section{BACKGROUND}

\section{Original Version}

EBDRD 3.2.5.1.2

B. Reliability of the EBS shall be as follows:

1. Waste Package (TBD)

d. Packing, shielding, and absorbing materials (TBD)

Requesting M\&O organization: ( )Surface, ( )Subsurface, ( )Waste Package

Development, or Other (specify: Systems Analysis and Modeling)

Need for assumption (statement of intended use):

III. RATIONALE

Rationale for assumption (source author, date, and report title) or statement of reasoning behind engineering judgment (e.g., midpoint of ranges given in the YMSCP Technical Data Base or Reference Information Base):

Detail specified in this requirement is too specific for Engineered Barrier requirement. Recommendation to delete this requirement has been forwarded to the Requirements Organization.

\section{RESPONSIBILITY/SUBSTANTIATION/WITHDRAWAL}

Responsible M\&O Organization Waste Package

(X) No Substantiation Required

( ) Substantiation Date

(X) Withdrawal Date 
Controlled Design Assumption

Assumption Rationale Sheet

Assumption Identifier: EBDRD 3.3.9.A(W)

Subject: Government-Fumished Property

I. STATEMENT OF ASSUMPTION

WITHDRAWN - Resolution of TBD with corresponding EBDRD requirement not required for ACD.

\section{BACKGROUND}

\section{Original Version}

EBDRD 3.3.9 PROPERTY TO BE FURNISHED BY U.S. GOVERNMENT

A. Property to be furnished by the U.S. Government is TBD.

[MGDS-RD 3.3.9.B][CRD 3.3.9.B]

Requesting M\&O organization: ( )Surface, ( )Subsurface, (X )Waste Package

Development, or Other (specify:

Need for assumption (statement of intended use):

III. RATIONALE

Rationale for assumption (source author, date, and report title) or statement of reasoning behind engineering judgment (e.g., midpoint of ranges given in the YMSCP Technical Data Base or Reference Information Base):

This requirement is at a level of detail below that to be addressed during ACD.

\section{RESPONSIBILITY/SUBSTANTIATION/WITHDRAWAL}

Responsible M\&O Organization Waste Package

(X) No Substantiation Required

( ) Substantiation Date

(X) Withdrawal Date 


\section{STATEMENT OF ASSUMPTION}

WITHDRAWN - Resolution of TBD with corresponding EBDRD requirement not required for ACD.

\section{BACKGROUND}

\section{Original Version}

EBDRD 3.3.9

B. Requirements pertaining to the receipt, maintenance, operation, and disposition of Government-furmished property are TBD.

[MGDS-RD 3.3.9.C][CRD 3.3.9.C]

Requesting M\&O organization: ( )Surface, ( )Subsurface, ( )Waste Package Development, or Other (specify: Systems Analysis and Modeling)

Need for assumption (statement of intended use):

\section{RATIONALE}

Rationale for assumption (source author, date, and report title) or statement of reasoning behind engineering judgment (e.g., midpoint of ranges given in the YMSCP Technical Data Base or Reference Information Base):

This requirement is at a level of detail below that to be addressed during ACD.

\section{RESPONSIBILITY/SUBSTANTIATION/WITHDRAWAL}

Responsible M\&O Organization Waste Package

(X) No Substantiation Required

( ) Substantiation Date

(X) Withdrawal Date

$12 / 19 / 95(\operatorname{Rev} .02)$ 


\section{STATEMENT OF ASSUMPTION}

WITHDRAWN - The corresponding EBDRD requirement is deleted.

The details governing design drawing standards have been captured in Quality Assurance procedures per the QARD. The requirement does not need to be repeated in the EBDRD.

\section{BACKGROUND}

Original Version

EBDRD 3.4.2 DRAWINGS

Implementing documents shall be established to ensure that applicable regulatory requirements, design basis requirements, and other requirements as specified herein are correctly translated into drawings. These implementing documents shall ensure that appropriate quality standards are specified and included in design documents and that deviations from these standards are properly controlled. An OCRWM standard for drawings is being developed (TBD) and will be referenced when available.

[MGDS-RD 3.4.2][DOE/RW-0333P]

NOTE: This OCRWM Standard now exists: "OCRWM Engineering Drawings and Associated Lists Requirements," DOE/RW-0461, DI A00000000-00811-5000-00008, Rev. 00, January 1995.

Requesting M\&O organization: ( )Surface, ( )Subsurface, ( )Waste Package Development, or Other (specify:Systems Engineering)

Need for assumption (statement of intended use):

The requirement is not needed as it does not impact design.

\section{RATIONALE}

Rationale for assumption (source author, date, and report title) or statement of reasoning behind engineering judgment (e.g., midpoint of ranges given in the YMSCP Technical Data Base or Reference Information Base):

\section{RESPONSIBILITY/SUBSTANTIATION/WITHDRAWAL}

Responsible M\&O Organization Systems Engineering/Requirements

( ) No Substantiation Required

( ) Substantiation Date

(X) Withdrawal Date 


\section{Controlled Design Assumption \\ Assumption Rationale Sheet}

Assumption Identifier: EBDRD 3.7.C(W)

Subject: Substantially Complete Containment

\section{STATEMENT OF ASSUMPTION}

WITHDRAWN - The corresponding EBDRD requirement is deleted.

The requirement is provided quantitatively by CDA Assumption EBDRD 3.7.D and EBDRD

Requirement 3.7.E.

\section{BACKGROUND}

\section{Original Version}

EBDRD 3.7.C

The EBS shall be designed so that assuming anticipated processes and events: (1) containment of HLW will be substantially complete (TBD) during the period when radiation and thermal conditions in the EBS are dominated by fission product decay (TBD); and (2) any release of radionuclides for the EBS shall be a gradual process that results in small fractional releases (TBD) to the geologic setting over long times.

[Derived][10 CFR 60.113(A)(1)(I)]

Requesting M\&O organization: ( )Surface, ( )Subsurface, ( )Waste Package Development, or Other (specify: Systems Engineering)

Need for assumption (statement of intended use):

\section{RATIONALE}

Rationale for assumption (source author, date, and report title) or statement of reasoning behind engineering judgment (e.g., midpoint of ranges given in the YMSCP Technical Data Base or Reference Information Base):

Note: This assumes the definition of HLW as found in 10 CFR 60 :

High-level radioactive waste or HLW means: (1) irradiated reactor fuel; (2) liquid wastes resulting from the operation of the first cycle solvent extraction system, or equivalent, and the concentrated wastes from subsequent extraction cycles, or equivalent, in a facility for reprocessing irradiated reactor fuel; and (3) solids into which such liquid wastes have been converted.

\section{RESPONSIBILITY/SUBSTANTIATION/WITHDRAWAL}

Responsible M\&O Organization Waste Package

( X ) No Substantiation Required

( ) Substantiation Date

(X) Withdrawal Date 12/19/95(Rev, 02) 


\section{Controlled Design Assumption \\ Assumption Rationale Sheet}

Assumption Identifier: EBDRD 3.7.E(W) Subject: Rock-Inducē̄ Waste Package Loading

\section{STATEMENT OF ASSUMPTION}

WITHDRAWN: The result of a rock fall event is a concentrated dynamic impact load on the waste package. The magnitude of the dynamic impact load depends on the size and the initial height of the rock falling onto the waste package. Since the maximum credible rock size has not yet been determined, this assumption should be withdrawn.

The waste package must be able to withstand a uniform external pressure of $0.50 \mathrm{MPa}$ and a dynamic load of $50 \mathrm{kN}$ and still maintain structural integrity.

\section{BACKGROUND}

Requesting M\&O organization: ( ) Surface, ( ) Subsurface, (X ) Waste Package Development, or Other (specify: System Engineering)

Original Version EBDRD 3.7

F. The EBS shall maintain performance under rock-induced loading.

Need for assumption (statement of intended use):

This assumption is needed to support the design of the waste package.

\section{RATIONALE}

Rationale for assumption (source author, date, and report title) or statement of reasoning behind engineering judgment (e.g., midpoint of ranges given in the YMSCP Technical Data Base or Reference Information Base):

Initial stress calculations have been performed for the multi-barrier waste package with an equivalent wall thickness of $100 \mathrm{~mm}$. These calculations indicate that the multi-barrier waste package can withstand this pressure and load. A pressure of $0.5 \mathrm{MPa}$ includes a factor of safety of 3. A dynamic load value of $50 \mathrm{kN}$ is based on what, at this time, is the expected load from a rock falling onto the waste package. As the ACD design options are further evaluated, the values listed above may change.

\section{RESPONSIBILITY/SUBSTANTIATION/WITHDRAWAL}

Responsible M\&O Organization Waste Package

( ) No Substantiation Required

( ) Substantiation Date

(X) Withdrawal Date $\overline{9 / 30 / 96(\operatorname{Rev} .04)}$ 


\section{Controlled Design Assumption \\ Assumption Rationale Sheet}

Assumption Identifier: EBDRD 3.7.1.E(W)

Subject: Waste Pāckage Information Label

\section{STATEMENT OF ASSUMPTION}

WITHDRAWN - Resolution of the TBD in the corresponding EBDRD requirement not required for ACD.

\section{BACKGROUND}

Original Version

EBDRD 3.7.1.F WASTE PACKAGE INFORMATION LABEL

A label or other means of identification shall be provided for each waste package. The identification shall not impair the integrity of the waste package, shall not damage the waste package, and shall be applied in such a way that the information shall be legible at least to the end of the period of retrievability. Each waste package's identification shall be consistent with the waste package's permanent written records. The information on the label shall be TBD.

[MGDS-RD 3.7.3.3.F][10 CFR 60.135b(0(4)]

Requesting M\&O organization:（ )Surface, ( )Subsurface, ( )Waste Package

Development, or Other (specify:

Need for assumption (statement of intended use):

Not needed for ACD

III. RATIONALE

Rationale for assumption (source author, date, and report title) or statement of reasoning behind engineering judgment (e.g., midpoint of ranges given in the YMSCP Technical Data Base or Reference Information Base):

The requirement is at a level of detail below that to be addressed during ACD.

\section{RESPONSIBILITY/SUBSTANTIATION/WITHDRAWAL}

Responsible M\&O Organization Waste Package

( X ) No Substantiation Required

( ) Substantiation Date

(X) Withdrawal Date

12/19/95(Rev. 02)




\title{
Controlled Design Assumption \\ Assumption Rationale Sheet
}

\author{
Assumption Identifier: EBDRD 3.7.1.1.G(W)
}

Subject: Postçlosure Seismic Loads on

Waste Package

\section{STATEMENT OF ASSUMPTION}

WITHDRAWN: This assumption is superseded by Key Assumption 064.

Waste package seismic design for postclosure (through the substantially complete containment phase) performance shall be compatible with Design Basis Earthquake for surface and subsurface repository. Potential repository peak horizontal accelerations for design are currently estimated at $0.66 \mathrm{~g}$ for surface and subsurface depths. Vertical component of acceleration is assumed to be equal to horizontal component.

\section{BACKGROUND}

Original Verision

EBDRD 3.7.1.1 SPENT NUCLEAR FUEL (SNF) AND HIGH-LEVEL WASTE (HLW) THAT IS EMPLACED IN THE UNDERGROUND FACILITY SHALL MEET THE FOLLOWING CRITERIA:

G. Seismic loads (To Be Determined [TBD]) shall not decrease the postclosure performance of the waste form.

Requesting Management and Operating Contractor (M\&O) organization:

( ) Surface, ( ) Subsurface, (X) Waste Package Development, or Other (specify:

Need for assumption (statement of intended use):

An assumption of the seismic loads is required to evaluate the short- and long-term performance of the waste package under possible dynamic loading conditions after emplacement.

\section{RATIONALE}

Rationale for assumption (source author, date, and report title) or statement of reasoning behind engineering judgment:

The $0.66 \mathrm{~g}$ peak ground acceleration is obtained from the document: Seismic Design Inputs for the Exploratory Studies Facility at Yucca Mountain, BAB000000-01717-5705-00001 REV. 02. Instead of using the reduction factors for changing depth, the subsurface peak ground acceleration is conservatively assumed to be $0.66 \mathrm{~g}$.

\section{RESPONSIBILITY AND WITHDRAWAL}

Responsible Management and Operating Contractor (M\&O) organization:

Waste Package, SPI

Document(s) Supporting Withdrawal of Assumption:

Withdrawal Date: 09/30/96 (Rev. 04) 


\section{Controlled Design Assumption \\ Assumption Rationale Sheet}

Assumption Identifier: EBDRD 3.7.1.4(W) Subject: Waste Contāiner Absorbent Materials

\section{STATEMENT OF ASSUMPTION}

WITHDRAWN - No initial assumptions required for ACD.

\section{BACKGROUND}

\section{Original Version}

EBDRD 3.7.1.4 Specific allocations of requirements to any containers, packages, shielding, and other absorbent materials immediately around an individual waste container will result from trade studies and engineering analyses during ACD.

\section{Requesting M\&O organization: ( )Surface, ( )Subsurface, ( X )Waste Package}

Development, or Other (specify: Developed)

Need for assumption (statement of intended use):

Not required for ACD. Requirement will be reviewed and reissued.

\section{RATIONALE}

Rationale for assumption (source author, date, and report title) or statement of reasoning behind engineering judgment (e.g., midpoint of ranges given in the YMSCP Technical Data Base or Reference Information Base):

As the requirement notes the values will be developed during $A C D$. The values will not directly affect the waste package ACD design.

\section{RESPONSIBILITY/SUBSTANTIATION/WITHDRAWAL}

Responsible M\&O Organization Waste Package

( X ) No Substantiation Required

( ) Substantiation Date

(X) Withdrawal Date $\frac{\overline{12 / 19 / 95(\operatorname{Rev}, 02)}}{2}$ 


\section{Controlled Design Assumption \\ Assumption Rationale Sheet}

Assumption Identifier: DCS 002(W)

Subject: $\overline{\text { Wet and Dry SNF Handling }}$

I. STATEMENT OF ASSUMPTION

WITHDRAWN

II. BACKGROUND

Rev, 02A

Both dry and wet (underwater)concepts will be considered for SNF handling at the MGDS.

Requesting M\&O organization: ( $X$ )Surface, ( )Subsurface, ( )Waste Package Development, or Other (specify:

Need for assumption (statement of intended use):

III. RATIONALE

Rationale for assumption (source author, date, and report title) or statement of reasoning behind engineering judgment (e.g., midpoint of ranges given in the YMSCP Technical Data Base or Reference Information Base):

Some handling steps might be easier, simpler, and safer if they are performed in a fuel basin.

Fuel handling at the utility sites, at reprocessing plants, and other nuclear facilities is usually conducted underwater. This option will be considered in the design of certain surface facilities.

IV. RESPONSIBILITY/SUBSTANTIATION/WITHDRAWAL

Responsible M\&O Organization Surface Facility Design

( ) No Substantiation Required

( ) Substantiation Date

(X) Withdrawal Date $\overline{4 / 28 / 95(\operatorname{Rev} .01)}$ 


\section{Controlled Design Assumption \\ Assumption Rationale Sheet}

Assumption Identifier: DCS 005(W)

Subject: One Waste Handling Building

\section{STATEMENT OF ASSUMPTION}

WITHDRAWN: This assumption is no longer necessary since the consolidation of WHBs 1 and 2 was the result of ACD. This result is documented in the ACD.

Surface Facilities Structures - WHB.

WHBs 1 and 2 in the Site Characterization Plan Conceptual Design Report will be consolidated into a single structure.

\section{BACKGROUND}

Requesting M\&O organization: (X) Surface, ( ) Subsurface, ( ) Waste Package Development, or Other (specify:

Need for assumption (statement of intended use):

\section{RATIONALE}

Rationale for assumption (source author, date, and report title) or statement of reasoning behind engineering judgment (e.g., midpoint of ranges given in the YMSCP Technical Data Base or Reference Information Base):

The need for two WHBs in the SCP/CDR was predicated upon an initial high receipt rate, smaller waste packages, and no MPC. This condition is no longer appropriate.

The WHB will be designed to receive and handle SNF and HLW contained in MPCs, waste packages, and shielded casks. These units are larger and heavier than those used in the SCP/ CDR and require different operations.

\section{RESPONSIBILITY/SUBSTANTIATION/WITHDRAWAL}

Responsible M\&O Organization Surface

( X ) No Substantiation Required

( ) Substantiation Date

(X) Withdrawal Date 9/30/96 (Rev. 04) 


\section{Controlled Design Assumption \\ Assumption Rationale Sheet}

Assumption Identifier: DCS $006(\mathrm{~W})$

Sübject: CMF Requirement

\section{STATEMENT OF ASSUMPTION}

WITHDRAWN. Required in the program approach. See DCS 014.

A Transportation Cask Maintenance Facility (CMF) will be required at the MGDS.

\section{BACKGROUND}

Requesting M\&O organization: ( $\mathrm{X}$ )Surface, ( )Subsurface, ( )Waste Package

Development, or Other (specify:

Need for assumption (statement of intended use):

Identification of Surface Facilities

III. RATIONALE

Rationale for assumption (source author, date, and report title) or statement of reasoning behind engineering judgment (e.g., midpoint of ranges given in the YMSCP Technical Data Base or Reference Information Base):

A CMF is needed to inspect, repair, and maintain transportation casks shipped back to the waste suppliers. This facility will be similar to that designed for the MRS but will be updated to reflect the casks that will be used for shipping currently conceived canisters and waste packages.

The CMF is required at the MGDS as part of the Program Approach. Therefore, it is assumed that this requirement will be carried through to the RDRD and DCS 006, then will no longer be necessary.

\section{RESPONSIBILITY/SUBSTANTIATION/WITHDRAWAL}

Responsible M\&O Organization Surface

(X) No Substantiation Required

( ) Substantiation Date

(X) Withdrawal Date 


\section{Controlled Design Assumption \\ Assumption Rationale Sheet}

Assumption Identifier: DCS 007(W)

Subject: $\overline{\text { Waste Treatment Building }}$

\section{STATEMENT OF ASSUMPTION}

WITHDRAWN - Consolidated with Key Assumption 024.

A Waste Treatment Building (WTB) will be incorporated into the Geologic Repository

Operations Area (GROA) to treat solid and liquid low-level radioactive wastes in preparation for transport to a government approved offsite facility for treatment, storage, and disposal.

\section{BACKGROUND}

Requesting Management and Operating Contractor (M\&O) organization:

(X) Surface, ( ) Subsurface, ( ) Waste Package Development, ( ) Other (specify):

Need for assumption (statement of intended use):

This defines the need to add a facility to the baseline to satisfy Key Assumption 024 .

\section{RATIONALE}

Rationale for assumption (source author, date, and report title) or statement of reasoning behind engineering judgment:

Consistent with revised Key Assumption 024, the facility will provide for treatment and temporary accumulations of low-level waste stream in preparation for transport to offsite facility for disposal.

Some quantities of low-level radioactive waste will be created during the course of repository operations. This waste will include liquid and solid material that will be prepared by concentration or other means for safe offsite disposal. Gaseous process waste will be filtered and treated as needed within the facility in which it is produced. Waste flows and types need to be defined to support License Application (LA) and Environmental Impact Statement (EIS).

\section{RESPONSIBILITY AND WITHDRAWAL}

Responsible Management and Operating Contractor (M\&O) organization: Surface

Document(s) Supporting Withdrawal of Assumption: Key Assumption 024

Withdrawal Date: Rev. 04, ICN 2 
INTENTIONALLY LEFT BLANK TO ACCOMMODATE ICN PAGES 


\section{Controlled Design Assumption \\ Assumption Rationale Sheet}

Assumption Identifier: DCS 009(W)

Subject: Disposal of Low-Level Radioactive Waste

\section{STATEMENT OF ASSUMPTION}

WITHDRAWN. Consolidated with DCS 007.All site-generated, low-level radioactive waste will be disposed of at or near the MGDS site.

\section{BACKGROUND}

This assumption is consistent with Key Assumption 024, which states that this waste will be collected, treated, packaged, and disposed of at the site, but leaves the exact location and method of disposal unspecified.

Requesting M\&O organization: (X )Surface, ( )Subsurface, ( )Waste Package Development, or Other (specify:

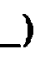

Need for assumption (statement of intended use):

Low-level waste disposal cost estimates need to be based on a preliminary concept until further resolution.

III. RATIONALE

Rationale for assumption (source author, date, and report title) or statement of reasoning behind engineering judgment (e.g., midpoint of ranges given in the YMSCP Technical Data Base or Reference Information Base):

On-site disposal appears to have some advantages (see Key Assumption 024). Further investigation is needed to determine the best on-site or near-by NTS disposal option.

\section{RESPONSIBILITY/SUBSTANTIATION/WITHDRAWAL}

Responsible M\&O Organization Surface

( ) No Substantiation Required

( ) Substantiation Date

(X) Withdrawal Date

$12 / 19 / 95(\operatorname{Rev} .02)$ 


\section{Controlled Design Assumption \\ Assumption Rationale Sheet}

\section{Assumption Identifier: DCS 010 (W) \\ Subject:_Hazardous Waste Disposal \\ I. STATEMENT OF ASSUMPTION \\ WITHDRAWN - Consolidated with Key Assumption 024. \\ Hazardous waste will be accumulated and staged, for up to 90 days, at the source of generation. These wastes will be periodically transported to a Resource Conservation and Recovery Act of 1976 (RCRA) approved offsite treatment, storage, and disposal facility. Subsurface hazardous wastes will be collected at a surface staging area outside the radiologically controlled area (RCA).}

\section{BACKGROUND}

Requesting Management and Operating Contractor (M\&O) organization:

(X) Surface, ( ) Subsurface, ( ) Waste Package Development, ( ) Other (specify):

Need for assumption (statement of intended use):

Hazardous wastes will be generated in both the radiologically controlled area (RCA) and general support areas. An assumption is needed to design the collecting and handling operations for hazardous wastes.

\section{RATIONALE}

Rationale for assumption (source author, date, and report title) or statement of reasoning behind engineering judgment:

Consistent with Key Assumption 024, hazardous wastes will be accumulated, packaged, and transported to a Resource Conservation and Recovery Act of 1976 (RCRA) approved offsite treatment, storage, and disposal facility. To avoid inadvertent creation of mixed wastes, subsurface hazardous wastes will be staged outside the radiologically controlled area (RCA) for transport to an approved offsite facility.

\section{RESPONSIBILITY AND WITHDRAWAL}

Responsible Management and Operating Contractor (M\&O) organization: Surface Document(s) Supporting Withdrawal of Assumption: Key Assumption 024

I Withdrawal Date: Rev. 04 ICN 2 


\section{Controlled Design Assumption \\ Assumption Rationale Sheet}

Assumption Identifier: DCS 014 (W)

Subject: Cask Maintenance Operations

\section{STATEMENT OF ASSUMPTION}

WITHDRAWN - This assumption is superseded by Key Assumption 085.

Cask maintenance facilities may be integrated into related facilities rather than in a separate, stand-alone structure.

Note: This assumption will be updated when cask transportation and maintenance requirements are redefined.

\section{BACKGROUND}

Requesting Management and Operating Contractor $(\mathrm{M} \& \mathrm{O})$ organization:

(X) Surface, ( ) Subsurface, ( ) Waste Package Development, ( ) Other (specify):

Need for assumption (statement of intended use):

Identification of Surface Facilities

\section{RATIONALE}

Rationale for assumption (source author, date, and report title) or statement of reasoning behind engineering judgment:

A Cask Maintenance Facility (CMF) is needed to inspect, repair, and maintain transportation casks shipped back to the waste suppliers. These operations are similar to those designed for the monitored retrievable storage (MRS) but will be updated to reflect the casks that will be used for shipping currently conceived canisters and waste packages.

The MGDS-RD, Rev. 2, (Sections 3.1.5.B and 3.2.3.2.3.1.2.A) requires a Cask Maintenance Facility (CMF) at the Mined Geologic Disposal System (MGDS). However it is assumed that the intent is to require cask maintenance operations without dictating the solution that a standalone facility is necessary.

\section{RESPONSIBILITY AND WITHDRAWAL}

Responsible Management and Operating Contractor (M\&O) organization: Surface

Document(s) Supporting Withdrawal of Assumption: Key Assumption 085

Withdrawal Date: Rev, 04 ICN 2 


\section{Controlled Design Assumption \\ Assumption Rationale Sheet}

\section{Assumption Identifier: DCS $015(\mathrm{~W})$ \\ Subject: Transportāion Cask Fleet Inventory \\ I. STATEMENT OF ASSUMPTION \\ WITHDRAWN - This assumption is superseded by Key Assumption 085. \\ The cask fleet inventory is based on a sealed canister system (disposable canister or dual purpose canister) and consists of a maximum of 12 truck casks and 72 rail casks.}

Note: This assumption will be updated when cask transportation and maintenance requirements are redefined.

\section{BACKGROUND}

Requesting Management and Operating Contractor (M\&O) organization:

(X) Surface, ( ) Subsurface, ( ) Waste Package Development, ( ) Other (specify):

Need for assumption (statement of intended use):

The cask fleet inventory is used to size not only the cask maintenance operations area but also the on-site generated waste treatment operations area. In addition, the cask fleet size could be used in the development of the Total System Life Cycle Cost (TSLCC).

\section{RATIONALE}

Rationale for assumption (source author, date, and report title) or statement of reasoning behind engineering judgment:

The transportation cask fleet inventory was identified in the "Monitored Retrievable Storage Facility Cask Maintenance Facility Design Study Report Final Draft" dated February 28, 1993 as 35 truck and 50 rail casks. This system was based on bare fuel assembly transfers. However, in September 1993, the Monitored Retrievable Storage (MRS) Conceptual Design Report (CDR) was updated. Within this update the above requested assumption was identified as an interface between the Monitored Retrievable Storage and the Transportation System. The above requested assumption can be found in section 3.2.2.4 of the "Multi-Purpose Canister (MPC)

Implementation Program Conceptual Design Phase Report Volume II.C - MPC MRS Facility Conceptual Design Report Final Draft dated September 30, 1993."

\section{RESPONSIBILITY AND WITHDRAWAL}

Responsible Management and Operating Contractor $(\mathrm{M} \& O)$ organization: Surface

Document(s) Supporting Withdrawal of Assumption: Key Assumption 085

Withdrawal Date: Rev. 04 ICN 2 


\section{Controlled Design Assumption Assumption Rationale Sheet}

\section{Assumption Identifier: $\mathrm{DCS} 016$ (W) \\ Subject: Trans. Cask Fleet Maintenance Frequency \\ I. STATEMENT OF ASSUMPTION \\ WITHDRAWN - This assumption is superseded by Key Assumption 085. \\ Maintenance requirements for the transportation fleet (as identified in DCS 015) will be comparable to those for existing casks.}

- Each truck cask is serviced a maximum of three times per year. During one visit the cask system Certificate of Compliance inspection is performed.

- Each rail cask is serviced once per year during the Certificate of Compliance inspection.

Note: This assumption will be updated when cask transportation and maintenance requirements are redefined.

\section{BACKGROUND}

Requesting Management and Operating Contractor (M\&O) organization:

(X) Surface, ( ) Subsurface, ( ) Waste Package Development, ( ) Other (specify):

Need for assumption (statement of intended use):

To properly size the cask maintenance operations area, it is necessary to know the maintenance frequency and requirements of the cask fleet. By assuming comparable requirements for existing casks, it is possible to size a facility and then make incremental changes as cask designs change.

\section{RATIONALE}

Rationale for assumption (source author, date, and report title) or statement of reasoning behind engineering judgment:

Section 3.2.2.4 of the "Multi-Purpose Canister (MPC) Implementation Program Conceptual Design Phase Report Volume II.C - MPC MRS Facility Conceptual Design Report Final Draft dated September 30,1993" assumes that the maintenance requirements for the transportation fleet will be comparable to those for existing casks. In addition, section 4.2.22.22.1 of the above referenced September 30, 1993 report assumes the maintenance frequency for trucks as a maximum of three times per year and rail cars as once per year.

\section{RESPONSIBILITY AND WITHDRA WAL}

Responsible Management and Operating Contractor $(\mathrm{M \& O})$ organization: Surface

Document(s) Supporting Withdrawal of Assumption: Key Assumption 085

Withdrawal Date: Rev. 04 ICN 2 


\section{Controlled Design Assumption \\ Assumption Rationale Sheet}

Assumption Identifier: DCS 017 (W)

Subject: WHB Dry Handling

\section{STATEMENT OF ASSUMPTION}

1

I WITHDRAWN - This assumption is superseded by assumption DCS 020.

1

I The Waste Handling Building (WHB) will use a dry contained hot cell concept for performing

I the waste handling operations.

I

\section{II. BACKGROUND}

I

I Requesting Management and Operating Contractor (M\&O) organization:

(X) Surface, ( ) Subsurface, ( ) Waste Package Development, ( ) Other (specify):

I Need for assumption (statement of intended use):

1

I Clarification that the WHB will use a dry hot cell as opposed to pool.

\section{III. RATIONALE}

I Rationale for assumption (source author, date, and report title) or statement of reasoning behind engineering judgment:

I The use of a dry hot cell as opposed to pool handling is preferred because it promotes a dry canister and container interior and allows for more flexible operations.

I Responsible Management and Operating Contractor (M\&O) organization: Surface

I Withdrawal Date: Rev. 04 ICN 2 


\section{Controlled Design Assumption \\ Assumption Rationale Sheet}

\section{Assumption Identifier: $\mathrm{DCS} 018(\mathrm{~W})$}

Subject: CMF Wet Handling

\section{STATEMENT OF ASSUMPTION}

WITHDRAWN - This assumption is superseded by Key Assumption 085 .

The Cask Maintenance Facility (CMF) will use a small pool for cask maintenance including decontamination and certification.

\section{BACKGROUND}

Requesting Management and Operating Contractor $(\mathrm{M} \& \mathrm{O})$ organization:

(X) Surface, ( ) Subsurface, ( ) Waste Package Development, or ( ) Other (specify):

Need for assumption (statement of intended use):

Clarification that the CMF will use a pool for some of its operations.

\section{RATIONALE}

Rationale for assumption (source author, date, and report title) or statement of reasoning behind engineering judgment:

The CMF will use a pool as a standard practice at the utilities. There is no concern about insuring a dry canister environment, as it is in the WHB.

\section{RESPONSIBILITY AND WITHDRAWAL}

Responsible Management and Operating Contractor $(M \& O)$ organization: Surface Repository Document(s) Supporting Withdrawal of Assumption: Key Assumption 085

Withdrawal Date: Rev, 04 ICN 2 


\section{STATEMENT OF ASSUMPTION}

\section{WITHDRAWN}

\section{BACKGROUND}

Deletion of the corresponding requirement is assumed.

Requesting M\&O organization: ( )Surface, ( X )Subsurface, ( )Waste Package Development, or Other (specify:

Need for assumption (statement of intended use):

\section{RATIONALE}

Rationale for assumption (source author, date, and report title) or statement of reasoning behind engineering judgment (e.g., midpoint of ranges given in the YMSCP Technical Data Base or Reference Information Base):

Limiting the repository horizon to the TSw2 geologic unit is covered by Key Assumption 022.

\section{RESPONSIBILITY/SUBSTANTIATION/WITHDRAWAL}

Responsible M\&O Organization

( ) No Substantiation Required

( ) Substantiation Date

(X) Withdrawal Date

4/28/95(Rev. 01) 


\section{Controlled Design Assumption Assumption Rationale Sheet}

Assumption Identifier: DCSS 003(W)

Subject: Underground Excavation Crown

\section{STATEMENT OF ASSUMPTION}

WITHDRAWN - Potential conflict with Assumption Key 022

The crown of an underground excavation at any given location within the repository block will be: (I) no higher than the contact between the TSwl and TSw2 thermal/mechanical units at that location, and (2) at least $5 \mathrm{~m}$ below rock strata containing significantly greater than $10 \%$ lithophysal cavities at that location.

\section{BACKGROUND}

\section{Requesting M\&O organization: ( X )Surface, ( )Subsurface, ( )Waste Package Development, or Other (specify:}

\section{Need for assumption (statement of intended use):}

Affects verticat and horizontal location of repository. It is being assumed that excavation within the repository block will be within the TSw2 rock unit. There has been considerable discussion as to the definition of the top of the TSw2 unit.

\section{RÄTIONALE}

Rationale for assumption (source author, date, and report title) or statement of reasoning behind engineering judgment (e.g., midpoint of ranges given in the YMSCP Technical Data Base or Reference Information Base):

Criteria for establishing the TSw1/TSw2 contact must consider the nced for a well-defined, mappable contact, as well as the effect of high lithophysal cavity content on rock properties. In regard to mappability, the USGS criteria is used, namely that the TSw $1 / T S w 2$ contact is the gradational contact between the upper lithophysal and middle nonlithophysal zones [Buesch, el.al. (TBD)]. In regard to lithophysal cavities, indications are that the base of strata containing greater than 10\% lithophysal cavities lies above the USGS lithostratigraphic contact, but may be at the contact [Sandia National Laboratories (SNL), (TBD a and b)]. Stability considerations require that there should be about $5 \mathrm{~m}$ of low lithophysal rock between the repository block excavation and the high lithophysal cavity areas. Thus, the need for a two-part assumplion.

Buesch, D.C., R. W. Spengler, T. C. Moyer, and J. K. Geslin (publication date TBD), Revised Stratigraphic Nomenclature and Macroscopic Identification of Lithostratigraphic Units of the Paintbrush Group Exposed at Yucca Mountain, Nevada: USGS Open-File Report.

SNL (TBD a), Data Transmittal Package for Yucca Mountain Site Characterization Project Geology and Rock Structure Log for Drill Hole UE25 NRG-6: DTN: SNF29041993002.006.

SNL (TBD b), Data Transmittal Package for Yucca Mountain Site Characterization Project Geology and Rock Struciure Log for Drill Hole UE25NRG-7/7A: DTN: TBD.

\section{RESPONSIBILITY/SUBSTANTIATION/WITHDRAWAL}

Responsible M\&O Organization Subsurface

( ) No Substantiation Required

( ) Substantiation Date

(X) Withdrawal Date $12 / 18 / 95(\operatorname{Rev}, 02)$ 


\section{STATEMENT OF ASSUMPTION}

\section{WITHDRAWN}

\section{BACKGROUND}

Deletion of the corresponding requirement is assumed.

Requesting M\&O organization: ( )Surface, ( X )Subsurface, ( X )Waste Package Development, or Other (specify:

Need for assumption (statement of intended use):

III. RATIONALE

Rationale for assumption (source author, date, and report title) or statement of reasoning behind engineering judgment (e.g., midpoint of ranges given in the YMSCP Technical Data Base or Reference Information Base):

Revision 00 was an attempt at interpreting the configuration required to comply with DCSS 025 . The repository floor standoff distance will be whatever is needed to comply with DCSS 025 . DCSS 025 is sufficient by itself.

\section{RESPONSIBILITY/SUBSTANTIATION/WITHDRAWAL}

Responsible M\&O Organization

(X) No Substantiation Required

( ) Substantiation Date

(X) Withdrawal Date 4/28/95(Rev.01) 
Assumption Identifier: DCSS 013(W)

Subject: In-Drift Emplacement

I. STATEMENT OF ASSUMPTION

WITHDRAWN

\section{BACKGROUND}

Deletion of the corresponding requirement is assumed.

Requesting M\&O organization: ( )Surface, ( X )Subsurface, ( X )Waste Package Development, or Other (specify:

Need for assumption (statement of intended use):

III. RATIONALE

Rationale for assumption (source author, date, and report title) or statement of reasoning behind engineering judgment (e.g., midpoint of ranges given in the YMSCP Technical Data Base or Reference Information Base):

In-drift emplacement of waste packages is covered by Key Assumption 011 .

\section{RESPONSIBILITY/SUBSTANTIATION/WITHDRAWAL}

Responsible M\&O Organization

( ) No Substantiation Required

( ) Substantiation Date

(X) Withdrawal Date 4/28/95(Rev,01) 


\section{Controlled Design Assumption \\ Assumption Rationale Sheet}

Assumption Identifier: DCSS 021 (W)

Subject: Underground Air Quality

\section{STATEMENT OF ASSUMPTION}

WITHDRAWN: Cooling power requirement has been deleted from the Exploratory Studies Facility Design Requirements, and is inherently covered by DCSS 020 . Oxygen content and TLV values both come from 30 CFR 57 and are to be implemented through program/project decision to comply with 30 CFR 57.

Underground air quality in drifts occupied by personnel during:

Construction: $\mathrm{O}_{2} \geq 19.5 \%$, air cooling power $\geq 260 \mathrm{~W} / \mathrm{m}^{2}$, contaminants $<\mathrm{TLV}$ values Operations: $\mathrm{O}_{2} \geq 19.5 \%$, air cooling power $\geq 260 \mathrm{~W} / \mathrm{m}^{2}$, contaminants $<T L V$ values Caretaker: $\quad \mathrm{O}_{2} \geq 19.5 \%$, air cooling power $\geq 260 \mathrm{~W} / \mathrm{m}^{2}$, contaminants $<\mathrm{TLV}$ values Retrieval: $\quad \mathrm{O}_{2} \geq 19.5 \%$, air cooling power $\geq 260 \mathrm{~W} / \mathrm{m}^{2}$, contaminants $<T L V$ values Backfilling: $\mathrm{O}_{2} \geq 19.5 \%$, air cooling power $\geq 260 \mathrm{~W} / \mathrm{m}^{2}$, contaminants $<T L V$ values

\section{BACKGROUND}

Requesting M\&O organization: ( )Surface, ( X )Subsurface, ( )Waste Package Development, or Other (specify:

Need for assumption (statement of intended use):

Affects ventilation system design.

III. RATIONALE

Rationale for assumption (source author, date, and report title) or statement of reasoning behind engineering judgment (e.g., midpoint of ranges given in the YMSCP Technical Data Base or Reference Information Base):

Oxygen content from 30 CFR 57.5015.

Cooling power from ESFDR 3.2.5.5.4.K.

TLV values from 30 CFR 57.5001 .

IV. RESPONSIBILITY/SUBSTANTIATION/WITHDRAWAL

Responsible M\&O Organization Subsurface

( X ) No Substantiation Required

( ) Substantiation Date

(X) Withdrawal Date 9/30/96(Rev, 04) 


\section{STATEMENT OF ASSUMPTION}

\section{WITHDRAWN}

\section{BACKGROUND}

Deletion of the corresponding requirement is assumed.

Requesting M\&O organization: ( )Surface, ( X )Subsurface, ( X )Waste Package

Development, or Other (specify:

Need for assumption (statement of intended use):

\section{RATIONALE}

Rationale for assumption (source author, date, and report title) or statement of reasoning behind engineering judgment (e.g., midpoint of ranges given in the YMSCP Technical Data Base or Reference Information Base):

Key Assumption 046 states that emplacement drifts will not be backfilled. The need to maintain the option for backfilling of emplacement drifts is part of the substantiation effort for Key Assumption 046.

\section{RESPONSIBILITY/SUBSTANTIATION/WITHDRAWAL}

Responsible M\&O Organization

( ) No Substantiation Required

( ) Substantiation Date

(X) Withdrawal Date $\overline{4 / 28 / 95(\operatorname{Rev}, 01)}$ 


\section{Controlled Design Assumption Assumption Rationale Sheet}

Assumption Identifier: DCWP $003(\mathrm{~W})$

Subject: Ältemate Waste Package Disposal Container Materials

\section{STATEMENT OF ASSUMPTION}

WITHDRAWN: Reference materials for Viability Assessment design have been documented in a design analysis, Waste Package Materials Selection Analysis, DI: BBA000000-01717-0200-00020 REV. 00.

Alternate waste package disposal container materials:

Comosion allowance materials:

UNS G10200 (ASTM A 516 Grade 55)

UNS J02501 (ASTM A 27 Grade 70-40)

UNS K21590 (ASTM A 387 Grade 22)

Moderately comosion resistant materials:

UNS C70600 (ASTM B 171)

UNS C71500 (ASTM B 171)

UNS N04400 (ASTM B 127) (Monel 400)

Corrosion resistant materials:

UNS N06022 (ASTM B 575, AWS ERNiCrMo-10)

UNS N06030 (ASTM B 582, AWS ERNiCrMo-II)

UNS N06455 (ASTM B 575)

UNS N06985 (ASTM B 582, AWS ERNiCrMo-9)

UNS N08065 (AWS ERNiFcCr-1)

UNS N08221 (ASTM B 424) (not in commercial production)

UNS N08825 (ASTM B 424)

UNS R53400 (ASTM B 265 Grade 12, AWS ERTi-12)

Titanium Grade 16

\section{BACKGROUND}

Requesting Management and Operating Contractor (M\&O)organization:

( ) Surface, ( ) Subsurface, (X) Waste Package Development, or Other (specify: )

Need for assumption (statement of intended use):

The primary materials recommended for the inner and outer containment barriers of multi-barrier waste package are identified to focus the designer's attention to the list provided.

\section{RATIONALE}

Rationale for assumption (source author, date, and report title) or statement of reasoning behind engineering judgment:

The list includes all materials mentioned in the Updated Candidate List for Engineered Barrier Materials

(September, 1994, milestone MOL0I, attachment to letter LLYMP94 12023 from W. L. Clarke to Robert M. Nelson, November 30, 1994) or in Report on Preliminary Selection of Waste Package Materials (BBA000000-01717-570500007 REV 00. July 21, 1995). The ASTM specifications apply to wroughi products, except for ASTM A 27, which is for cast products. The AWS grades apply to welding electrodes.

Current baseline waste package materials are:

Inner Containment Barrier - UNS N08825 (Alloy 825).

Outer Containment Barrier for SNF packages - UNS G10200 (ASTM A 516).

Outer Containment Barrier for DHLW packages - UNS C71500 (70/30 copper-nickel).

Alternative waste package materials for low thermal load are:

Inner Containment Barrier - UNS N08825 (Alloy 825).

Outer Containment Barrier for SNF packages - UNS G10200 (ASTM A 516).

Outer Containment Barrier for DHLW packages - UNS C71500 (70/30 copper-nickel). 


\section{Controlled Design Assumption}

Assumption Rationale Sheet

\section{RESPONSIBILITY AND WITHDRA WAL}

Responsible Management and Operating Contractor (M\&O) organization: Waste Package Document(s) Supporting Withdrawal of Assumption:

Withdrawal Date: 09/30/96 (Rev. 04) 


\section{Controlled Design Assumption \\ Assumption Rationale Sheet}

Assumption Identifier: DCWP 005 (W)

Subject: Tentative Co-Disposed

DOE SNF WP Dimensions

\section{STATEMENT OF ASSUMPTION}

WITHDRAWN - This assumption is superseded by and incorporated in assumption EBDRD 3.7.1.J.1

This assumption is pending coordination and resolution of BCP-00-96-0005 implementation issues. The designs are recent and have not been reconciled with other assumptions in this version of the CDA.

The external dimensions of the waste package containing DOE SNF that is co-disposed with defense HLW shall not exceed:

Outer Diameter: $1970 \mathrm{~mm}$

Outer Length: $\quad 5350 \mathrm{~mm}$

\section{BACKGROUND}

Requesting Management and Operating Contractor (M\&O) organization:

(X) Surface, (X) Subsurface, (X) Waste Package Development, or ( ) Other (specify):

Need for assumption (statement of intended use):

Needed to focus MGDS design.

\section{RATIONALE}

Rationale for assumption (source author, date, and report title) or statement of reasoning behind engineering judgment:

Current dimensions for the largest waste package are based on IOC \# LV.WP.WEW. 9/96 - 227 by Wayne Wallin.

\section{RESPONSIBILITY AND WITHDRA WAL}

Responsible Management and Operating Contractor (M\&O) organization: Waste Package

Document(s) Supporting Withdrawal of Assumption: Assumption EBDRD 3.7.1.J.1

Withdrawal Date: Rev 04, ICN 2 


\section{Controlled Design Assumption \\ Assumption Rationale Sheet}

Assumption Identifier: DCWP 006 (W)

Subject: Tentative WP Extemal

Dimensions for Canistered SNE

\section{STATEMENT OF ASSUMPTION}

WITHDRAWN - This assumption is superseded by and incorporated in assumption EBDRD 3.7.1.J.1

This assumption is pending coordination and resolution of BCP-00-96-0005 implementation issues. The designs are recent and have not been reconciled with other assumptions in this version of the CDA.

The external dimensions of the waste package for commercial SNF that is canistered and not repackaged (based on vendor development) shall not exceed:

Outer Diameter: $1950 \mathrm{~mm}$

Outer Length: $\quad 5850 \mathrm{~mm}$

\section{BACKGROUND}

Requesting Management and Operating Contractor $(\mathrm{M} \& \mathrm{O})$ organization:

(X) Surface, (X) Subsurface, (X) Waste Package Development, or ( ) Other (specify):

Need for assumption (statement of intended use):

Needed to focus MGDS design.

\section{RATIONALE}

Rationale for assumption (source author, date, and report title) or statement of reasoning behind engineering judgment:

Current dimensions for the largest wast package are based on IOC \# LV.WP.WEW. 9/96 - 227

by Wayne Wallin.

\section{RESPONSIBILITY AND WITHDRAWAL}

Responsible Management and Operating Contractor $(M \& O)$ organization:

Document(s) Supporting Withdrawal of Assumption: Assumption EBDRD 3.7.1.J.I

Withdrawal Date: Rev 04, ICN2 
Assumption Identifier: TDS 005(W)

Subjēct: Seismic Environment

\section{STATEMENT OF ASSUMPTION}

WITHDRAWN -- The information in the RIB has been superseded by "Seismic Design Inputs for the Exploratory Studies Facility at Yucca Mountain," May 20, 1994 (DI BAB000000-017175705-00001, Rev. 02A).

\section{BACKGROUND}

Rev. 00

The Surface Facilities Seismic Environment which includes the ground motion design basis, the ground motion probability, and earthquake characteristics that will be used for calculations for Design Base Earthquake, Operating Base Earthquake, and Standard Earthquake is defined in section 1.22 of the RIB.

Requesting M\&O organization: ( X )Surface, ( )Subsurface, ( )Waste Package

Development, or Other (specify:

Need for assumption (statement of intended use):

The assumption is needed to establish the seismic design features of the surface facilities and associated equipment.

III. RATIONALE

Rationale for assumption (source author, date, and report title) or statement of reasoning behind engineering judgment (e.g., midpoint of ranges given in the YMSCP Technical Data Base or Reference Information Base):

This material is found directly in the RIB.

\section{RESPONSIBILITY/SUBSTANTIATION/WITHDRAWAL}

Responsible M\&O Organization SPI

( ) No Substantiation Required

( ) Substantiation Date

(X) Withdrawal Date

4/28/95(Rev, OD) 


\section{Controlled Design Assumption \\ Assumption Rationale Sheet}

Assumption Identifier: TDS 001 (W)

Subject: Fault Displacēnent, Locations, Attitudes

\section{STATEMENT OF ASSUMPTION}

WITHDRAWN: Seismic design is covered by Key Assumption 064.

The Surface Facilities fault displacements, fault locations, and fault attitudes shall be as described in Section 1.23 of the Reference Information Base (RIB).

\section{BACKGROUND}

Requesting Management and Operating Contractor (M\&O) organization:

(X) Surface, ( ) Subsurface, ( ) Waste Package Development, ( ) Other (specify):

Need for assumption (statement of intended use):

The assumption is needed as input to surface facilities seismic design and site layout.

\section{RATIONALE}

Rationale for assumption (source author, date, and report title) or statement of reasoning behind engineering judgment:

The information in this section of the Reference Information Base (RIB) includes a litany of data sources that reflect the current knowledge of the seismic characteristics of the site.

This assumption affects:

Design Basis Earthquake, Operating Basis Earthquake, and Standard Earthquake design requirements related to the fault locations.

\section{RESPONSIBILITY AND WITHDRA WAL}

Responsible Maragement and Operating Contractor $(\mathrm{M} \& O)$ organization: SPI

Document(s) Supporting Withdrawal of Assumption:

Withdrawal Date: 9/30/96 (Rev.04) 


\section{Controlled Design Assumption \\ Assumption Rationale Sheet}

Assumption Identifier: TDS 009(W)

Subject: Surface Facilities/ALARA -

Reclassified as DCS 002

\section{STATEMENT OF ASSUMPTION}

WITHDRAWN - Reclassified as DCS 003, Rev. 00.

\section{BACKGROUND}

Requesting M\&O organization: ( $X$ )Surface, ( )Subsurface, ( )Waste Package Development, or Other (specify:

Need for assumption (statement of intended use):

This assumption provides the allowable exposure allowed for occupational dose and is the basis for calculations involving radiological safety.

III. RATIONALE

Rationale for assumption (source author, date, and report title) or statement of reasoning behind engineering judgment (e.g., midpoint of ranges given in the YMSCP Technical Data Base or Reference Information Base):

TDS 009, Rev. 00 was a Design Concept Assumption.

IV. RESPONSIBILITY/SUBSTANTIATION/WITHDRAWAL

Responsible M\&O Organization IDM

( X ) No Substantiation Required

( ) Substantiation Date

(X) Withdrawal Date 
Assumption Identifier: $\operatorname{TDS} 010(\mathrm{~W})$

\section{STATEMENT OF ASSUMPTION}

WITHDRAWN - Reclassified as DCS 004, Rev. 00.

\section{BACKGROUND}

Requesting M\&O organization: ( X )Surface, ( )Subsurface, ( )Waste Package Development, or Other (specify:

Need for assumption (statement of intended use):

ALARA is a requirement that is established to ensure that radiological safety is adhered to in the design and operation of nuclear facilities.

\section{RATIONALE}

Rationale for assumption (source author, date, and report title) or statement of reasoning behind engineering judgment (e.g., midpoint of ranges given in the YMSCP Technical Data Base or Reference Information Base):

TDS 010, Rev. 00 was a Design Concept Assumption.

\section{RESPONSIBILITY/SUBSTANTIATION/WITHDRAWAL}

Responsible M\&O Organization

( X ) No Substantiation Required

( ) Substantiation Date

(X) Withdrawal Date 


\section{Controlled Design Assumption \\ Assumption Rationale Sheet}

Assumption Identifier: TDS OL1(W)

Subject: $\underline{\text { Waste Handling Building- }}$

Reclassified as DCS 005

\section{STATEMENT OF ASSUMPTION}

WITHDRAWN - Reclassified as DCS 005, Rev. 00.

\section{BACKGROUND}

Requesting M\&O organization: (X)Surface, ( )Subsurface, ( )Waste Package

Development, or Other (specify:

Rev. 00

The WHBs 1 and 2 in the SCP/CDR will be consolidated into a single structure.

Need for assumption (statement of intended use):

The need for two WHBs in the SCP/CDR was predicated upon an initial high receipt rate, smaller waste packages, and no MPC. This condition is no longer appropriate.

\section{RATIONALE}

Rationale for assumption (source author, date, and report title) or statement of reasoning behind engineering judgment (e.g., midpoint of ranges given in the YMSCP Technical Data Base or Reference Information Base):

TDS 011 was a Design Concept Assumption.

\section{RESPONSIBILITY/SUBSTANTIATION/WITHDRAWAL}

Responsible M\&O Organization

(X) No Substantiation Required

( ) Substantiation Date

(X) Withdrawal Date $\overline{4 / 28 / 95(\operatorname{Rev} \text {. OU) }}$ 
Controlled Design Assumption

Assumption Rationale Sheet

Assumption Identifier: TDS 012(W)

Subject: Transportation Cask Maintenance

Eacility - Reclassified as DCS 006

I. STATEMENT OF ASSUMPTION

WITHDRAWN - Reclassified as DCS 006, Rev. 00.

\section{BACKGROUND}

Requesting M\&O organization: ( $X$ )Surface, ( )Subsurface, ( )Waste Package

Development, or Other (specify:

$\operatorname{Rev} 00$

A transportation CMF will be required at the MGDS.

Need for assumption (statement of intended use):

Identification of Surface Facilities.

III. RATIONALE

Rationale for assumption (source author, date, and report title) or statement of reasoning behind engineering judgment (e.g., midpoint of ranges given in the YMSCP Technical Data Base or Reference Information Base):

TDS 012, Rev. 00 was a Design Concept Assumption.

IV. RESPONSIBILITY/SUBSTANTIATION/WITHDRAWAL

Responsible M\&O Organization

(X) No Substantiation Required

( ) Substantiation Date

(X) Withdrawal Date 


\section{STATEMENT OF ASSUMPTION}

WITHDRAWN - Reclassified as DCS 007, Rev. 00.

\section{BACKGROUND}

Requesting M\&O organization: ( $X$ )Surface, ( )Subsurface, ( )Waste Package Development, or Other (specify:

Rev. 00

A waste treatment building will be incorporated into the Geologic Repository Operations area.

Need for assumption (statement of intended use):

The facility will be used to prepare low level waste materials generated at the MGDS for disposal at a designated on-site disposal area.

\section{RATIONALE}

Rationale for assumption (source author, date, and report title) or statement of reasoning behind engineering judgment (e.g., midpoint of ranges given in the YMSCP Technical Data Base or Reference Information Base):

TDS 013, Rev. 00 was a Design Concept Assumption.

\section{RESPONSIBILITY/SUBSTANTIATION/WITHDRAWAL}

Responsible M\&O Organization

(X ) No Substantiation Required

( ) Substantiation Date

(X) Withdrawal Date $\overline{4 / 28 / 25(\operatorname{Rev}, 01)}$ 


\section{Controlled Design Assumption \\ Assumption Rationale Sheet}

Assumption Identifier: TDS 014(W)

Subject: Decontamination

I. STATEMENT OF ASSUMPTION

WITHDRAWN - Reclassified as DCS 008, Rev. 00.

\section{BACKGROUND}

Requesting M\&O organization: ( X )Surface, ( )Subsurface, ( )Waste Package

Development, or Other (specify:

Need for assumption (statement of intended use):

Decontamination activities will be conducted in area as close to the source of contamination as possible using conventional decontamination techniques.

III. RATIONALE

Rationale for assumption (source author, date, and report title) or statement of reasoning behind engineering judgment (e.g., midpoint of ranges given in the YMSCP Technical Data Base or Reference Information Base):

TDS 014, Rev. 00 was a Design Concept Assumption.

\section{RESPONSIBILITY/SUBSTANTIATION/WITHDRAWAL}

Responsible M\&O Organization

(X) No Substantiation Required

( ) Substantiation Date

(X) Withdrawal Date $\overline{4 / 28 / 95(\operatorname{Rev}, 01)}$ 


\section{STATEMENT OF ASSUMPTION}

\section{WITHDRAWN}

\section{BACKGROUND}

Requesting M\&O organization:（）Surface, ( )Subsurface, ( )Waste Package

Development, or Other (specify:

Rev, 00

Rod consolidation will not be performed at the MGDS.

Need for assumption (statement of intended use):

Rod consolidation has been considered as a way to reduce the size and weight of waste containers and thus reduce the cost of shielding and handling. Many studies have indicated that rod consolidation does not, in fact, accomplish these objectives and does have opposite impacts.

III. RATIONALE

Rationale for assumption (source author, date, and report title) or statement of reasoning behind engineering judgment (e.g., midpoint of ranges given in the YMSCP Technical Data Base or Reference Information Base):

Assumption already appears as Key 008 in this document.

\section{RESPONSIBILITY/SUBSTANTIATION/WITHDRAWAL}

Responsible M\&O Organization Surface

( ) No Substantiation Required

( ) Substantiation Date

(X) Withdrawal Date 
Assumption Identifier: TDSS 013(W)

Subject: Deformation Modulus

I. STATEMENT OF ASSUMPTION

WITHDRAWN

\section{BACKGROUND}

Requesting M\&O organization: ( )Surface, (X )Subsurface, ( )Waste Package

Development, or Other (specify:

Need for assumption (statement of intended use):

III. RATIONALE

Rationale for assumption (source author, date, and report title) or statement of reasoning behind engineering judgment (e.g., midpoint of ranges given in the YMSCP Technical Data Base or Reference Information Base):

Following review, the deformation of rock modulus data were rejected for inclusion in the RIB.

IV. RESPONSIBILITY/SUBSTANTIATION/WITHDRAWAL

Responsible M\&O Organization

(X) No Substantiation Required

( ) Substantiation Date

(X) Withdrawal Date $\overline{4 / 28 / 95(\operatorname{Rev} .01)}$ 
Controlled Design Assumption

Assumption Rationale Sheet

Assumption Identifier: TDSS 014(W)

Subject: Rök Compressive Strength

\section{STATEMENT OF ASSUMPTION}

WITHDRAWN

\section{BACKGROUND}

Requesting M\&O organization: ( )Surface, ( $\mathrm{X}$ )Subsurface, ( )Waste Package

Development, or Other (specify:

Need for assumption (statement of intended use):

III. RATIONALE

Rationale for assumption (source author, date, and report title) or statement of reasoning behind engineering judgment (e.g., midpoint of ranges given in the YMSCP Technical Data Base or Reference Information Base):

Following review, the compressive strength of rock mass data were rejected for inclusion in the RIB.

\section{RESPONSIBILITY/SUBSTANTIATION/WITHDRAWAL}

Responsible M\&O Organization

( X ) No Substantiation Required

( ) Substantiation Date

(X) Withdrawal Date 
Assumption Identifier: TDSS 015(W)

Subject: Rock Tensile Strength

\section{STATEMENT OF ASSUMPTION}

WITHDRAWN

\section{BACKGROUND}

Requesting M\&O organization: ( )Surface, (X )Subsurface, ( )Waste Package

Development, or Other (specify:

Need for assumption (statement of intended use):

\section{RATIONALE}

Rationale for assumption (source author, date, and report title) or statement of reasoning behind engineering judgment (e.g., midpoint of ranges given in the YMSCP Technical Data Base or Reference Information Base):

Following review, the tensile strength of rock mass data were rejected for inclusion in the RIB.

IV. RESPONSIBILITY/SUBSTANTIATION/WITHDRAWAL

Responsible M\&O Organization

(X) No Substantiation Required

( ) Substantiation Date

(X) Withdrawal Date $\overline{4 / 28 / 95(\operatorname{Rev} .01)}$ 
Assumption Identifier: TDSS 018(W)

Subject: TSw2 Rock Joint Strength

\section{STATEMENT OF ASSUMPTION}

WITHDRAWN - For same reasons as for TDSS 019 and TDSS 020.

\section{BACKGROUND}

Rev.00

Rock Joint Strength - TSw2.

Rock Mass Quality Category

Cohesion (MPa) $\frac{1}{2} \frac{3}{0.01} \frac{4}{0.04} \frac{5}{0.08} \quad 0.14 \quad 0.18$

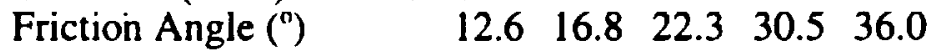

Requesting M\&O organization: ( )Surface, ( X )Subsurface, ( )Waste Package

Development, or Other (specify:

Need for assumption (statement of intended use):

Needed for rock mass stability and deformation calculations.

III. RATIONALE

Rationale for assumption (source author, date, and report title) or statement of reasoning behind engineering judgment (e.g., midpoint of ranges given in the YMSCP Technical Data Base or Reference Information Base):

From SAND89-0837, Table 12-11.

\section{RESPONSIBILITY/SUBSTANTIATION/WITHDRAWAL}

Responsible M\&O Organization SPI

( ) No Substantiation Required

( ) Substantiation Date

(X) Withdrawal Date 
Assumption Identifier: TDSS 019(W)

Subject: Rock Joint Stiffness

\section{STATEMENT OF ASSUMPTION}

WITHDRAWN

\section{BACKGROUND}

Requesting M\&O organization: ( )Surface, ( X )Subsurface, ( )Waste Package Development, or Other (specify:

Need for assumption (statement of intended use):

\section{RATIONALE}

Rationale for assumption (source author, date, and report title) or statement of reasoning behind engineering judgment (e.g., midpoint of ranges given in the YMSCP Technical Data Base or Reference Information Base):

Following review, the rock joint stiffness parameters were rejected for inclusion in the RIB.

IV. RESPONSIBILITY/SUBSTANTIATION/WITHDRAWAL

Responsible M\&O Organization

( X ) No Substantiation Required

( ) Substantiation Date

(X) Withdrawal Date $\overline{4 / 28 / 95(\operatorname{Rev}, 01)}$ 


\section{Controlled Design Assumption \\ Assumption Rationale Sheet}

Assumption Identifier: TDSS 020(W)

Subject: Rock Mass Quality Indices

\section{STATEMENT OF ASSUMPTION}

WITHDRAWN

\section{BACKGROUND}

Requesting M\&O organization: ( )Surface, (X )Subsurface, ( )Waste Package

Development, or Other (specify:

Need for assumption (statement of intended use):

III. RATIONALE

Rationale for assumption (source author, date, and report title) or statement of reasoning behind engineering judgment (e.g., midpoint of ranges given in the YMSCP Technical Data Base or Reference Information Base):

Following review, the rock mass quality indices for thermal/mechanical rock units were rejected for inclusion in the RIB.

\section{RESPONSIBILITY/SUBSTANTIATION/WITHDRAWAL}

Responsible M\&O Organization

(X) No Substantiation Required

( ) Substantiation Date

(X) Withdrawal Date

4/28/95(Rev.01) 


\section{Controlled Design Assumption}

Assumption Rationale Sheet

\section{Assumption Identifier: TDSS $023(\mathrm{~W})$ \\ I. STATEMENT OF ASSUMPTION}

Subject: Unsaturatē̄ Zone Groundwater Flux

Groundwater annual flux estimates at the proposed repository horizon are:

$\begin{array}{llll}\text { Matrix: } & 0.1 & -1 & \mathrm{~mm} \\ \text { Fractures: } & 1 & -5 & \mathrm{~mm} \\ \text { Fast Paths: } & 0.1 & -50 & \mathrm{~mm}\end{array}$

\section{BACKGROUND}

Requesting Management and Operating Contractor (M\&O) organization:

( ) Surface, ( ) Subsurface, (X) Waste Package Development, or (X) Other (specify): Scientific Program Operations

Need for assumption (statement of intended use):

Needed for waste package design and repository design.

\section{RATIONALE}

Rationale for assumption (source author, date, and report title) or statement of reasoning behind engineering judgment:

Values based on

Development and Calibration of the Three-Dimensional Site-Scale Unsaturated Zone Model of Yucca Mountain, Nevada, August 1996, by G. S. Bodvarsson and T. M. Bandurraga;

Summary Report of Chlorine-36 Studies: Sampling, Analysis, and Simulation of Chlorine-36 in the Exploratory Studies Facility (Draft), August 29, 1996, by J. Fabryka-Martin, et al. (LA-CSTTIP-96-002);

Site Scale Unsaturated Zone Flow and Transport Model (Draft), 8/29/96, by Bruce A. Robinson, et al.;

Summary Report of Chlorine-36 Studies (Draft), August 30, 1996, by J. Fabryka-Martin, et al. (LA-CST-TIP-96-003).

\section{RESPONSIBILITY AND WITHDRAWAL}

Responsible Management and Operating Contractor (M\&O) organization: Scientific Program Operations

Document(s) Supporting Withdrawal of Assumption: The old flux assumption is being deleted and a new flux assumption is being added (See TDSS 026). The previous flux specification and references will be preserved in the withdrawn section.

Withdrawal Date: REV 4 ICN 1 


\section{STATEMENT OF ASSUMPTION}

Groundwater $\mathrm{pH}$ values at the proposed repository horizon are:

$$
\begin{array}{lr}
\text { Typical: } & 7.4 \\
\text { Extreme: } & 2 \text { to } 12
\end{array}
$$

\section{BACKGROUND}

Requesting Management and Operating Contractor (M\&O) organization:

( ) Surface, ( ) Subsurface, (X) Waste Package Development, or (X) Other (specify): Scientific Program Operations

Need for assumption (statement of intended use):

Needed for waste package design.

\section{RATIONALE}

Rationale for assumption (source author, date, and report title) or statement of reasoning behind engineering judgment:

Values are based on

Volume II: Near Field and Altered-Zone Environment Report (UCRL-LR-124998), August 23, 1996, by Dale G. Wilder.

\section{RESPONSIBILITY AND WITHDRA WAL}

Responsible Management and Operating Contractor (M\&O) organization: Scientific Program Operations

Document(s) Supporting Withdrawal of Assumption: The old unsaturated zone ground water $\mathrm{pH}$ assumption is now covered by the revised TDSS 025 assumption.

Withdrawal Date: REV 4 ICN 1 
Assumption Identifier: REQSE 001(W)

\section{STATEMENT OF ASSUMPTION}

WITHDRAWN

\section{BACKGROUND}

Requesting M\&O organization: ( )Surface, ( )Subsurface, ( )Waste Package

Development, or Other (specify: Systems Analysis and Modeling)

Need for assumption (statement of intended use):

To limit the predicted thermal and thermomechanical response of the host rock and surrounding strata, and groundwater system, the Engineered Barrier Segment configuration and loading shall:

Limit temperatures in the Calico Hills nonwelded $(\mathrm{CHn})$ unit to less than $115^{\circ} \mathrm{C}$.

III. RATIONALE

Rationale for assumption (source author, date, and report title) or statement of reasoning behind engineering judgment (e.g., midpoint of ranges given in the YMSCP Technical Data Base or Reference Information Base):

Assumption covered by DCSS 025, Rev. 02A.

\section{RESPONSIBILITY/SUBSTANTIATION/WITHDRAWAL}

Responsible M\&O Organization

( X ) No Substantiation Required

( ) Substantiation Date

(X) Withdrawal Date $\overline{4 / 28 / 95(\operatorname{Rev}, 01)}$ 
Assumption Identifier: REQSE 002(W)

I. STATEMENT OF ASSUMPTION

WITHDRAWN - Reclassified as DCSS 030, Rev. 00.

\section{BACKGROUND}

Requesting M\&O organization: ( )Surface, ( )Subsurface, ( )Waste Package Development, or Other (specify: System Analysis and Modeling)

Rev. 00

Limit surface uplift to less than $0.5 \mathrm{~cm} / \mathrm{yr}$ and relative motion of the top of TSw 1 to less than $1 \mathrm{~m}$ with no intact rock failure and no continuous slip.

Need for assumption (statement of intended use):

III. RATIONALE

Rationale for assumption (source author, date, and report title) or statement of reasoning behind engineering judgment (e.g., midpoint of ranges given in the YMSCP Technical Data Base or Reference Information Base):

Items such as this that may become requirements are provided as design goals in the CDA, hence the reclassification of this item to a design concept.

\section{RESPONSIBILITY/SUBSTANTIATION/WITHDRAWAL}

Responsible M\&O Organization

( X ) No Substantiation Required

( ) Substantiation Date

(X) Withdrawal Date 4/28/95(Rev.01) 
Assumption Identifier: REQSE 003(W)

\section{STATEMENT OF ASSUMPTION}

WITHDRAWN - Reclassified as DCSS 031, Rev. 00.

\section{BACKGROUND}

Rev. 00

Limit temperatures PTn in (Upper Paint Brush non-welded) to less than $115^{\circ} \mathrm{C}$.

Requesting M\&O organization: ( )Surface, ( )Subsurface, ( )Waste Package Development, or Other (specify System Analysis and Modeling)

Need for assumption (statement of intended use):

III. RATIONALE

Rationale for assumption (source author, date, and report title) or statement of reasoning behind engineering judgment (e.g., midpoint of ranges given in the YMSCP Technical Data Base or Reference Information Base):

Items such as this that may become requirements are provided as design goals in the CDA, hence the reclassification of this item to a design concept.

\section{RESPONSIBILITY/SUBSTANTIATION/WITHDRAWAL}

Responsible M\&O Organization

(X) No Substantiation Required

( ) Substantiation Date

(X) Withdrawal Date $\overline{4 / 28 / 95(\operatorname{Rev} .01)}$ 


\begin{abstract}
APPENDIX C
CONTROLLED DESIGN ASSUMPTIONS FOR VIABILITY ASSESSMENT ISSUES
\end{abstract}




\section{Appendix C. Controlled Design Assumptions for Viability Assessment Issues}

Design and systems engineering related issues important to the Viability Assessment (VA) milestone were briefed to the DOE in May 1997 (CRWMS M\&O 1997g). These issues are related to tradeoffs or decisions with significant, potential impacts for the OCRWM Program.

A reference concept for each of the VA issues has been defined as presented in the middle column of Table C-1. The controlled design assumptions in the body of this CDA Document have been updated to reflect those reference concepts. Table C-2 identifies the assumptions with the primary relationships to the reference concepts for the VA issues. Legend for Table C-2 is as follows:

$X$ - Assumption is applicable to the reference concept for the specific VA issue and requires no modification.

M - Assumption was modified in CDA Document Rev. 04, ICN 2 for applicability to the reference concept for the specific VA issue.

A - Assumption was added in CDA Document Rev. 04, ICN 2 for applicability to the reference concept for the specific VA issue.

W - Assumption was withdrawn in CDA Document Rev. 04, ICN 2 because it is no longer applicable as a result of other assumption modifications or additions.

m - Assumption was modified in CDA Document Rev. 04, ICN 3.

a - Assumption was added in CDA Document Rev. 04, ICN 3.

Table C-2 includes an extra column to identify other changes made in CDA Document Rev. 04, ICN 2 for updating purposes unrelated to the specific VA issues.

One or more alternate concepts have been defined for most of the VA issues. These are also described in Table C-1. Table C-3 identifies the assumptions that would be modified, added, or withdrawn for each of the alternate concepts. Table C-3 uses similar legends to that defined above for Table C-2, except that each entry is preceded by a number to identify the alternate concept to which it is applicable. Appendix D presents the new and modified assumptions that are contingent on the alternate assumptions. See the note on the cover page for Appendix $D$ that the alternate assumptions in Appendix D are not part of the controlled design assumptions applicable to the reference design. Also, see the discussion of alternate concepts and assumptions in Section 1.3 and the caution that the assumptions in Appendix D should not be used other than to help understand the alternate concepts and the potential impacts that they would have on the reference system design assumptions. 


\begin{tabular}{|c|c|c|}
\hline VA Issue & Relerence Concept & Alternate Concepts \\
\hline 1. Thermal Loading Range & $\begin{array}{l}\text { High thermal load concept with Areal Mass Loading } \\
\text { (AML) at a specitic value within the 19.8-24.7 } \\
\mathrm{kgU} / \mathrm{m}^{2} \text { (80-100 MTU/acre) range. Layout geometry } \\
\text { will be similar to that in the ACD Report, commonly } \\
\text { lermed "point load." Commercial SNF WPs will be } \\
\text { assigned area according to their individual mass } \\
\text { content, while HLW and other low or no-heat WPs } \\
\text { are placed between commercial SNF WPs without } \\
\text { accounting for their mass content. Dritt spacing will } \\
\text { be maximized within the constraints of providing WP } \\
\text { spacing for specified mass per area and maintaining } \\
\text { the ability to emplace the other WPs between the } \\
\text { large commercial SNF WPs. The overall thermal } \\
\text { management concepts for the reference case } \\
\text { include loading waste into WPs in approximalely the } \\
\text { order in which received (within the limit specified } \\
\text { elsewhere on initial heat output and criticality). } \\
\text { emplacing the WPs in drifts in the order received } \\
\text { from the surface facility (which is the order in which } \\
\text { they are loaded), and only minimal ventilation in } \\
\text { each emplacement dritt after emplacement is } \\
\text { completed tor the dritt. }\end{array}$ & $\begin{array}{l}\text { A lower mass loading alternative will be considered, as will other } \\
\text { thermal management techniques that can be used independently or } \\
\text { in combination. } \\
\text { 1) A lower AML at a specific value within the range of } 6.2-8.9 \\
\text { kgU/m² (25-36 MTU/acre) will be considered as an alternative for LA } \\
\text { with the potential lor improvement in total system pertormance. } \\
\text { 2) A layout, commonly termed "line load," with wider dritt spacing } \\
\text { and WP spacing determined by package length (within handling } \\
\text { constraints) and not adjusted for individual mass content will be } \\
\text { considered if design basis modeling predicts that MGDS } \\
\text { pertormance is improved without imposing unacceptable operational } \\
\text { constraints on the design. The AML value for the line load would be } \\
\text { defined on the basis of the mass content of an entire drit, since WP } \\
\text { spacing would not be adjusted to measure mass per area for } \\
\text { individual WPs. } \\
\text { 3) Emplacing waste in order different trom that in which received } \\
\text { by sequencing of CSNF assemblies into WPs (using either waste } \\
\text { handling building storage or other surface lag storage capabilities) } \\
\text { and/or sequencing of WPs into the emplacement dritts (using } \\
\text { surface or subsurface lag storage capabilities) will be considered if } \\
\text { design basis modeling predicts that MGDS performance is improved } \\
\text { without imposing unacceptable operational constraints on the } \\
\text { design. } \\
\text { 4) Forced ventilation of emplacement dritts for sevieral decades } \\
\text { will be considered if design basis modeling predicts that MGDS } \\
\text { performance is improved without imposing unacceptable operational" } \\
\text { consiraints on the design. }\end{array}$ \\
\hline
\end{tabular}
constraints on the design. 
Table C-1. Reference and Alternate Concepts for VA Issues (continued)

\begin{tabular}{|c|c|c|}
\hline VA Issue & Reference Concept & Alternate Concepts \\
\hline $\begin{array}{l}\text { 2. EBS Performance } \\
\text { Enhancements }\end{array}$ & $\begin{array}{l}\text { No backfill is required but would not be precluded } \\
\text { from being stowed in the emplacement dritts. }\end{array}$ & 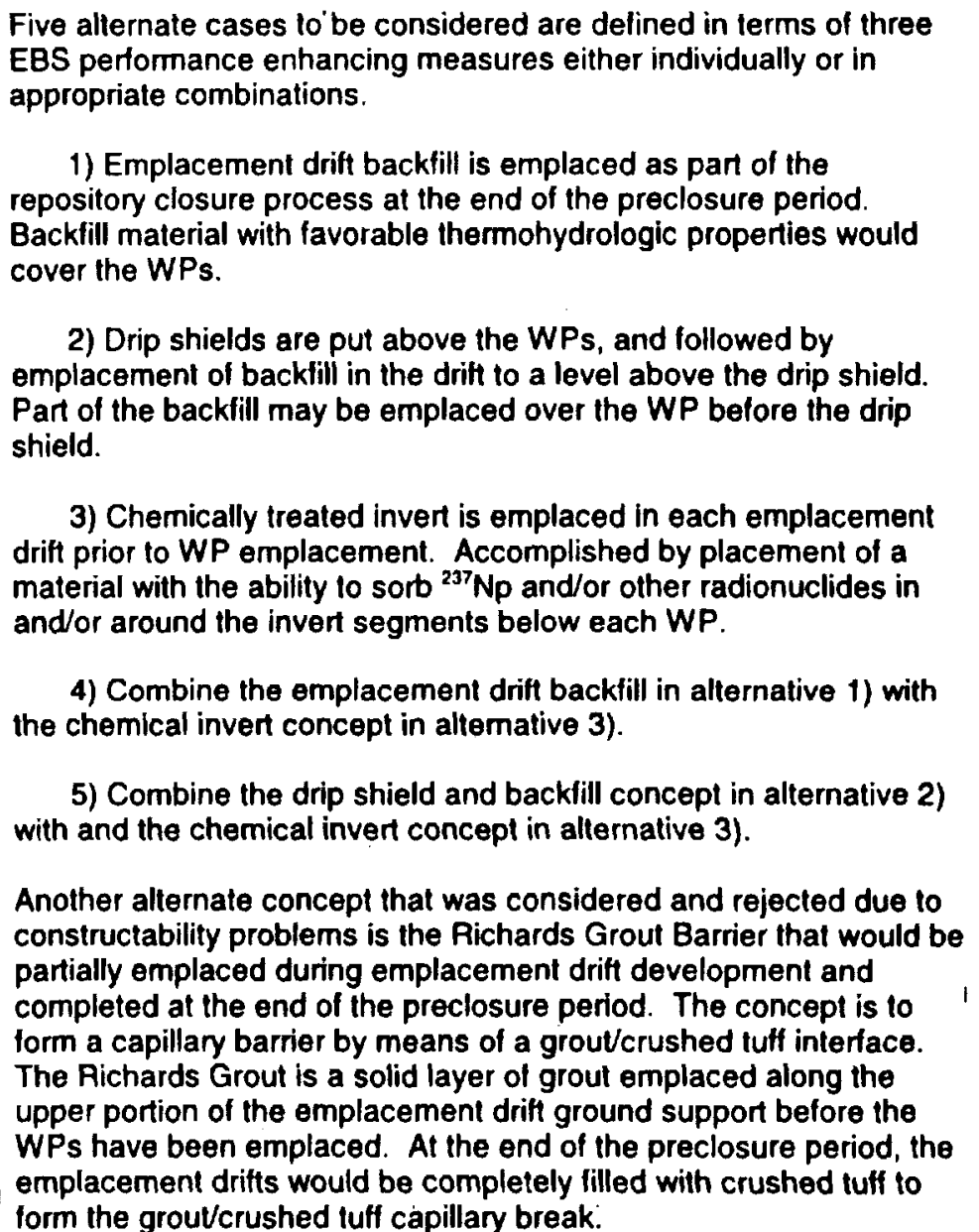 \\
\hline
\end{tabular}


Table C-1. Reference and Alternate Concepts for VA Issues (continued)

\begin{tabular}{|c|c|c|}
\hline VA Issue & Reference Concepl & Alternate Concepts \\
\hline 3. Criticality Control & $\begin{array}{l}\text { Criticality Control Methodology - } \\
\text { The disposal criticality analysis methodology will use } \\
\text { probabilistic risk analysis and disposal burnup credit } \\
\text { for evaluating disposal criticality control. } \\
\text { Criticality Control Design - } \\
\text { CSNF WP design will use principle isolope burnup } \\
\text { credit and take credit for neutron absorber material } \\
\text { in control panels in the lollowing WPs: } \\
\text { a) Main PWR WP design ( } 21 \text { PWR } \\
\text { uncanistered fuel assemblies) } \\
\text { b) Main BWR WP design (44 BWR } \\
\text { uncanistered fuel assemblies) } \\
\text { c) South Texas Fuel WP design (12 PWR S.Tx } \\
\text { uncanistered fuel assemblies) } \\
\text { Will also use and take credit for neutron absorber } \\
\text { material in control rods in PWR WP design. } \\
\text { DHLW WP design allows limiled fissile loading of } \\
\text { canisters. }\end{array}$ & $\begin{array}{l}\text { Criticality Control Methodology - } \\
\text { No alternates to be considered. } \\
\text { Criticality Control Design - } \\
\text { If needed, the CSNF WP designs for PWR and BWR WPs will } \\
\text { use and receive credit for additional concepts as follows: } \\
\text { 1) Iron Shot Filler Material } \\
\text { For PWR WPs (Main \& South Texas) and BWR WPs } \\
\text { 2) Depleled Uranium Filler Material } \\
\text { For PWR WPs (Main \& South Texas) and BWR WPs }\end{array}$ \\
\hline
\end{tabular}


Table C-1. Reference and Alternate Concepts for VA Issues (continued)

\begin{tabular}{|c|c|c|}
\hline VA Issue & Reference Concept & Alternate Concepts \\
\hline $\begin{array}{l}\text { 4. Emplacement Drift Ground } \\
\text { Support }\end{array}$ & $\begin{array}{l}\text { Install precast concrete segmental lining in } \\
\text { emplacement drifts that are not to be mapped, and } \\
\text { install cast-in-place concrele lining in emplacement } \\
\text { drifts that are to be mapped in accordance with the } \\
\text { reference mapping strategy defined in the reference } \\
\text { concept for issue \#9. } \\
\text { The precast concrele segmental lining will be } \\
\text { installed as the initial and only ground support in } \\
\text { emplacement drifts that do not require mapping. } \\
\text { This is the preferred ground support method from an } \\
\text { engineering perspective because it can be rapidly } \\
\text { installed and can be fabricated under controlled } \\
\text { conditions to enhance quality. However, mapping is } \\
\text { not safely performed before installation nor } \\
\text { adequately performed after installation. Thus, in } \\
\text { emplacement drifts that requires mapping, cast-in- } \\
\text { place concrete lining will be installed atter the initial } \\
\text { installation of support such as rockbolts and the } \\
\text { subsequent mapping. }\end{array}$ & $\begin{array}{l}\text { 1) Install cast-in-place concrete lining after initial installation of } \\
\text { support such as rockbolts. This method is the second preference } \\
\text { from an engineering perspective and would allow mapping, if } \\
\text { necessary, after the initial installation of rockbolts and before the } \\
\text { installation of the concrete lining. If the alternate mapping strategy } \\
\text { for issue \#9 is imposed to require mapping of all emplacement drifts, } \\
\text { this would become the preferred ground support concept. } \\
\text { 2) Install steel sets with steel lagging. This method is the third } \\
\text { preference from an engineering perspective and allows steel lagging } \\
\text { to be installed in slages at different times. It allows mapping, if } \\
\text { necessary. It could be used if mapping of all emplacement drifts } \\
\text { were required and concrete were found to be unacceptable. }\end{array}$ \\
\hline $\begin{array}{l}\text { 5. Performance Confirmation } \\
\text { Concept }\end{array}$ & $\begin{array}{l}\text { Performance Confirmation requirements in } \\
\text { accordance with controlled design assumptions Key } \\
061,063 \text {, and } 067 \text {. }\end{array}$ & $\begin{array}{l}\text { None defined. An enhanced case for Performance Confirmation } \\
\text { requirements, as defined in Performance Conlirmation Concepls } \\
\text { Sludy Report (CRWMS M\&O, 1996e), might be considered in a } \\
\text { future CDA update. }\end{array}$ \\
\hline 6. Retrievability Concept & $\begin{array}{l}\text { WP retrieval equipment concepts are equivalent to } \\
\text { those for WP. emplacement (see related issue \#11). } \\
\text { Emplacement \& retrieval of WPs will utilize Gantries } \\
\text { without carry-over capability. }\end{array}$ & $\begin{array}{l}\text { Emplacement \& retrieval of WPs will utilize a carry-over Gantry that } \\
\text { will facilitate selective retrieval of WPs. }\end{array}$ \\
\hline
\end{tabular}


Table C-1. Reference and Alternate Concepts for VA Issues (continued)

\begin{tabular}{|c|c|c|}
\hline VA Issue & Reference Concept & Alternate Concepts \\
\hline $\begin{array}{l}\text { 7. Confirmation of Waste } \\
\text { Handling Capability }\end{array}$ & $\begin{array}{l}\text { A combination of wet and dry operations will be } \\
\text { used in the Waste Handling Building (WHB). It will } \\
\text { include three identical lines to transler SNF } \\
\text { assemblies from a shipping cask or dual-purpose } \\
\text { canister (DPC) to a disposal container (DC) and two } \\
\text { lines to transler disposable canisters of HLW or SNF } \\
\text { from a shipping cask to a DC. Each SNF assembly } \\
\text { transler line will use a fuel pool to open the casks } \\
\text { and DPCs, remove the assemblies, and place them } \\
\text { in baskets tor transfer to a hot cell where the } \\
\text { assemblies will be loaded into a DC. All operations } \\
\text { other than SNF assembly unloading will be } \\
\text { conducted dry. (See "wet handling concept" in } \\
\text { Waste Handling Systems Configuration Analysis, } \\
\text { CRWMS M\&O 1997b, for additional description). } \\
\text { Lag storage within the WHB will include an } \\
\text { additional storage pool to stage CSNF assemblies } \\
\text { that would accumulate as a resull of surges in } \\
\text { shipments. An external parking area will be } \\
\text { designed to stage shipping casks, but an external } \\
\text { lag storage lacility for interim storage is not required } \\
\text { with waste receipt to begin concurrent with } \\
\text { emplacement. } \\
\text { Waste will be loaded for emplacement in approxi- } \\
\text { mately the order in which it is received. }\end{array}$ & $\begin{array}{l}\text { The reference concept of combining wet and dry operations is the } \\
\text { selected design concept applicable to all of the following } \\
\text { alternatives: } \\
\text { 1) Receive waste (starting in 2007) before emplacement begins (in } \\
2010 \text { ) and include an external lag storage facility to accommodale } \\
\text { the amount of waste received prior to start of emplacement. Waste } \\
\text { handling facilities would be phased. First phase would provide an } \\
\text { ISF style storage facility with storage area and storage modules } \\
\text { designed to house large welded canisters and a structure for } \\
\text { transferring DPCs from shipping casks to storage modules. Second } \\
\text { phase would include front end of the WHB to provide facility to } \\
\text { transter CSNF assemblies from a shipping cask to a welded canister } \\
\text { and lransport it to an outside storage module. Third phase would } \\
\text { complete the WHB similar to that in the reference design. } \\
\text { 2) Sequence waste into DCs for emplacement in an order different } \\
\text { rrom that in which received for purposes of thermal management. } \\
\text { Additional capacity for staging pool for CSNF assemblies is } \\
\text { anticipated. }\end{array}$ \\
\hline $\begin{array}{l}\text { 8. Disposal of Site- } \\
\text { Generaled Waste }\end{array}$ & $\begin{array}{l}\text { Treat and package radioactive low level waste } \\
\text { (LLW) at the repository and ship for disposal at the } \\
\text { Nevada Test Site (NTS). Package and ship } \\
\text { hazardous and mixed wastes to approved, off-site } \\
\text { facilities lor treatment and disposal after less than } \\
90 \text { days storage at the repository. }\end{array}$ & $\begin{array}{l}\text { Alternatives to the reference concept for disposal of LLW follow: } \\
\text { 1) Dispose of LLW at an off-site DOE or commercial facility. } \\
\text { 2) Dispose of LLW at the repository at a surface location to be } \\
\text { identified. }\end{array}$ \\
\hline
\end{tabular}


Table C-1. Reference and Alternate Concepts for VA Issues (continued)

\begin{tabular}{|c|c|c|}
\hline VA Issue & Relerence Concept & Alternate Concepts \\
\hline $\begin{array}{l}\text { 9. Strategy for Mapping } \\
\text { Repository }\end{array}$ & $\begin{array}{l}\text { Map completely a portion (1 in } 10) \text { of the } \\
\text { emplacement drifts prior to installing the primary } \\
\text { ground support. Essentially all other dritts in the } \\
\text { repository horizon also will be mapped completely. } \\
\text { including perimeter drifts, PC dritts, ventilation dritts, } \\
\text { and possibly selected drifts within the emplacement } \\
\text { dritt pattern that are excluded from emplacement. }\end{array}$ & $\begin{array}{l}\text { 1) Map completely all emplacement drifts. Essentially all other } \\
\text { dritts in the repository horizon also will be mapped completely, } \\
\text { as in the reference concept. } \\
\text { 2) Map none of the emplacement dritts if a grid of about } 300 \text { by } 600 \\
\text { meters is determined to provide appropriale mapping coverage } \\
\text { and this grid can be achieved by fully mapping all other drifts in } \\
\text { the repository horizon. }\end{array}$ \\
\hline $\begin{array}{l}\text { 10. Postclosure Performance } \\
\text { Standards }\end{array}$ & $\begin{array}{l}\text { Use interim postclosure requirement and goal } \\
\text { provided by DOE (YMP 1997) as a planning basis } \\
\text { for VA Design and postclosure pertormance } \\
\text { assessment of the repository. }\end{array}$ & $\begin{array}{l}\text { No alternate concepts are defined in terms of changes to the } \\
\text { assumed postclosure standard. Nevertheless, Performance } \\
\text { Assessment is planning to conduct modeling that will provide } \\
\text { analysis relevant to potential changes to the reference concept. } \\
\text { Performance Assessment is planning to analyze the repository long- } \\
\text { term pertormance with sensitivity analyses of the expected annual } \\
\text { dose to an average individual in a critical group at different distances } \\
\text { from the repository (varying from } 5 \mathrm{~km} \text { to } 30 \mathrm{~km} \text { ) and for time periods } \\
\text { up to and beyond } 10,000 \text { years to support the goal described in Key } \\
\text { Assumption } 060 \text {. Analyses are planned for system designs with } \\
\text { alternative EBS performance enhancements identified above for VA } \\
\text { Issue } \# 2 \text {. The results will allow predicted long term performance to } \\
\text { be compared to potential dose limits. }\end{array}$ \\
\hline
\end{tabular}


Table C-1. Reference and Alternate Concepts for VA Issues (continued)

\begin{tabular}{|c|c|c|}
\hline VA Issue & Relerence Concept & Alternate Concepts \\
\hline $\begin{array}{l}\text { 11. Viability of Underground } \\
\text { Piemote Control Concepts }\end{array}$ & $\begin{array}{l}\text { WP emplacement operations are to be } \\
\text { accomplished primarily by remole systems, } \\
\text { including remotely operated mobile emplacement } \\
\text { gantries, gantry carriers, and transporters, remote } \\
\text { loading and unloading mechanisms, and } \\
\text { locomotives that can be both manually and remotely } \\
\text { operated. } \\
\text { Normal WP retrieval process, if necessary, will } \\
\text { tililize essentially the same equipment used during } \\
\text { emplacement. Off-normal retrleval will employ a } \\
\text { variety of remotely operated vehicles that can be } \\
\text { used to extricate WPs from various off-normal } \\
\text { situations. These include remotely operated multi- } \\
\text { purpose mini-excavating equipment, load-haul-dump } \\
\text { vehicles, inclinable plattorms \& towing equipment. } \\
\text { Shielded manually-operated concepts may be used. } \\
\text { Performance Confirmation program will utilize } \\
\text { remole sensors and instrumentalion to monitor and } \\
\text { acquire exhaust air and borehole data. A mobile } \\
\text { remotely operated inspection gantry will be used to } \\
\text { inspect emplacement drifts and WPs, and to } \\
\text { emplace and recover test coupons. }\end{array}$ & $\begin{array}{l}\text { Emplacement/Retrieval - 1) Alternale design concepts considered } \\
\text { for routine emplacement/retrieval have included emplacement on rail } \\
\text { cars, by non-rail based wheeled or track driven vehicles, using air } \\
\text { pallet technology, or using rollers \& turn tables. } \\
\text { 2) Alternate concepts for off-normal retrieval of WPs include various } \\
\text { designs of remote excavalion \& hauling equipment and also portable } \\
\text { shielding and shielded equipment that allows direct manual } \\
\text { operation. } \\
\text { Performance Conflirmation - 3) Alternatives being considered that } \\
\text { relate to degree \& type of coverage of remote } \\
\text { sensors/instrumentation. } \\
\text { 4) Enhancements to role \& functionality of the basic remole } \\
\text { inspection gantry, e.g., periodic thermal \& radiological mapping of } \\
\text { emplacement dritts, air sampling, chemical sensing, dritt } \\
\text { convergence measurement, and placemenVretrieval of temporary in- } \\
\text { drift monitoring equipment. } \\
\text { 5) Reliance on available borehole monitoring coverage with no direct } \\
\text { in-drift monitoring. } \\
\text { 6) Periodic removal of WPs from individual dritts allowing personnel } \\
\text { access for non-remole inspection/monitoring. } \\
\text { 7) Other alternate concepts may be developed, including: remote } \\
\text { systems for minor emplacement drift maintenance, emergency } \\
\text { response and mitigation, and applications related to regulalory } \\
\text { monitoring, site security and salety. }\end{array}$ \\
\hline 12. Bumup Credit & $\begin{array}{l}\text { NOTE: Work on this issue has been suspended } \\
\text { pending results of overlapping Issue } \$ 3 \text {, which will } \\
\text { consider burnup credit in the resolution of criticality } \\
\text { control methodology and concepts. Burnup credit } \\
\text { will not be addressed as a separate issue in the } \\
\text { update of the Controlled Design Assumptions } \\
\text { Document. }\end{array}$ & \\
\hline
\end{tabular}


Table C-1. Reference and Alternate Concepts for VA Issues (continued)

\begin{tabular}{|c|c|c|}
\hline VA Issue & Pelerence Concept & Alternate Concepts \\
\hline $\begin{array}{l}\text { 13. Repository Seals } \\
\text { Requirements \& Concepts }\end{array}$ & $\begin{array}{l}\text { Seals will be put in the ramps, shafts, and boreholes } \\
\text { from the surface to ensure no preferential pathways } \\
\text { exist for water ingress and gaseous flow and which } \\
\text { would increase the release of radionuclides to the } \\
\text { accessible environment. }\end{array}$ & $\begin{array}{l}\text { None defined; without seals, preferential pathways would exist. } \\
\text { Activities underway for this issue involve development of design } \\
\text { requirements for components of the sealing system. These are not } \\
\text { being treated as alternate concepts. }\end{array}$ \\
\hline 14. RSAISF Interface & $\begin{array}{l}\text { Regional Service Agents (RSAs) will be delivering } \\
\text { SNF to the repository under a privatization concept } \\
\text { in which they will be providing and maintaining the } \\
\text { shipping casks. NOTE: Initial interface assumptions } \\
\text { will be included in future CDA update after release } \\
\text { of the final RFP for RSA. }\end{array}$ & $\begin{array}{l}\text { Repository will be collocated with an ISF-style storage facility. This } \\
\text { will include early receipt of SNF at the ISF but will not necessarily be } \\
\text { consistent with alternate concept } 1 \text { for VA issue } \# 7 \text {. The RSA role in } \\
\text { the relerence concept would expand to include responsibility for } \\
\text { providing the storage modules for use at the facility. Legislation is } \\
\text { being monitored and could dictate the manner in which the concept } \\
\text { should be defined in the fulure. }\end{array}$ \\
\hline 15. Additional Wasle Forms & $\begin{array}{l}\text { Waste receipts will include a tolal of } 70,000 \text { MTU } \\
\text { equivalent comprised of } 63,000 \text { for commercial SNF, } \\
4,667 \text { for HLW, and } 2,333 \text { for DOE SNF. The } \\
\text { receipts are defined by the waste streams } \\
\text { documented in Key assumptions } 001,002,004, \\
005 \text {, and } 062 \text { and developed in the Waste Quantity, } \\
\text { Mix and Throughput Study Report, Rev. 00, March } \\
31,1997 \text { (CRWMS M\&O 1997c). }\end{array}$ & $\begin{array}{l}\text { Relain the total } 70,000 \text { MTU equivalent limit and the } 63,000 \text { for } \\
\text { commercial SNF, but include all the DOE SNF of about } 2,600 \mathrm{MTU} \\
\text { by reducing the HLW to equivalent of } 4,400 \mathrm{MTU} \text {. }\end{array}$ \\
\hline $\begin{array}{l}\text { 16. Waste Package Sizes \& } \\
\text { Weights }\end{array}$ & $\begin{array}{l}\text { Thirteen different waste packages of varying } \\
\text { dimensions are included to accommodate the } \\
\text { different waste forms and special cases that are } \\
\text { anticipated. For commercial SNF, these include } \\
\text { large and small waste packages for both PWR and } \\
\text { BWR and a waste package for canistered SNF. } \\
\text { Additional waste packages are included for co- } \\
\text { disposal of HLW and DOE SNF and for disposal of } \\
\text { other special waste forms such as Navy SNF. }\end{array}$ & $\begin{array}{l}\text { None defined. Size and weight could change to reflect alternate } \\
\text { concepts that might be considered for waste package materials. }\end{array}$ \\
\hline
\end{tabular}


Table C-1. Reference and Alternate Concepts for VA Issues (continued)

\begin{tabular}{|c|c|c|}
\hline VA Issue & Reference Concept & Alternate Concepts \\
\hline 17. Waste Package Materials & $\begin{array}{l}\text { The outer barrier is made of carbon steel (ASTM A } \\
516 \text { ), a corrosion allowance material. This barrier } \\
\text { corrodes at a slow, predictable rate. The inner } \\
\text { barrier is made of Alloy } 625 \text { (ASTM B 443), a } \\
\text { corrosion resistant material. The outer barrier } \\
\text { corrodes slowly enough that the near-field } \\
\text { temperature is low before this barrier is exposed to } \\
\text { the environment. Low temperatures contribute to } \\
\text { controlling localized corrosion of the Alloy } 625 \text {. The } \\
\text { near-field geochemical environment is not } \\
\text { sufficiently aggressive that significant localized } \\
\text { corrosion occurs. }\end{array}$ & $\begin{array}{l}\text { Under the assumption that the percolation flux is large, the waste } \\
\text { packages will be exposed to humid or wet environments earlier than } \\
\text { would otherwise be expected. Early exposure of the corrosion } \\
\text { allowance barrier to corrosive conditions may lead to early breaching } \\
\text { of this barrier and exposure of the corrosion resistant barrier to high- } \\
\text { temperature corrodents. To provide extra corrosion resistance, the } \\
\text { inner barrier material is changed to Alloy } 622 \text { (a.k.a. C-22, ASTM B } \\
575 \text { N06022). }\end{array}$ \\
\hline 18. Design Basis Model & $\begin{array}{l}\text { NOTE: Reference and alternate concepts are not } \\
\text { established because this issue addresses timely } \\
\text { product development: Can a design basis model be } \\
\text { used to provide timely and effective design guidance } \\
\text { in preparation for VA? }\end{array}$ & \\
\hline $\begin{array}{l}\text { 19. Subsurface Design } \\
\text { Development }\end{array}$ & $\begin{array}{l}\text { NOTE: Relerence and alternate concepts are not } \\
\text { established because this issue addresses timely } \\
\text { product development: Can design documentation } \\
\text { consistent with the resolution of the key design } \\
\text { issues be produced in time for the VA submittal? }\end{array}$ & \\
\hline $\begin{array}{l}\text { 20. Surface Design } \\
\text { Development }\end{array}$ & $\begin{array}{l}\text { NOTE: Reference and alternate concepts are not } \\
\text { established because this issue addresses timely } \\
\text { product development: Can design documentation } \\
\text { consistent with the resolution of the key design } \\
\text { issues be produced in time for the VA submittal? }\end{array}$ & 1 \\
\hline 21. Site Design Development & $\begin{array}{l}\text { NOTE: Reference and alternate concepts are not } \\
\text { established because this issue addresses timely } \\
\text { product development: Can design documentation } \\
\text { consistent with the resolution of the key design } \\
\text { issues be produced in time for the VA submittal? }\end{array}$ & . \\
\hline
\end{tabular}


Table C-2. CDA Assumptions Related to Reference Concepts for VA Issues

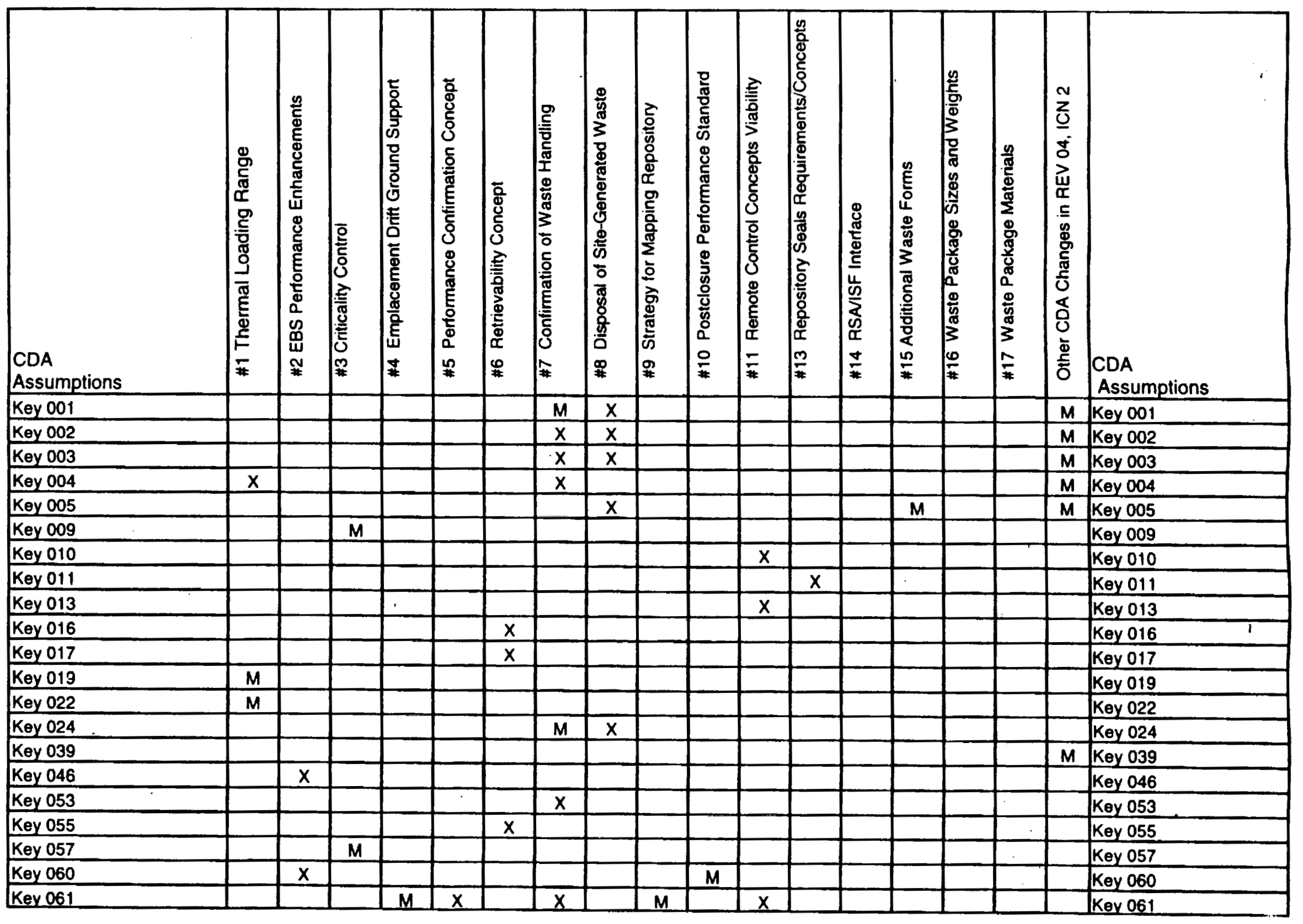


Table C-2. CDA Assumptions Related to Reference Concepts for VA Issues (continued)

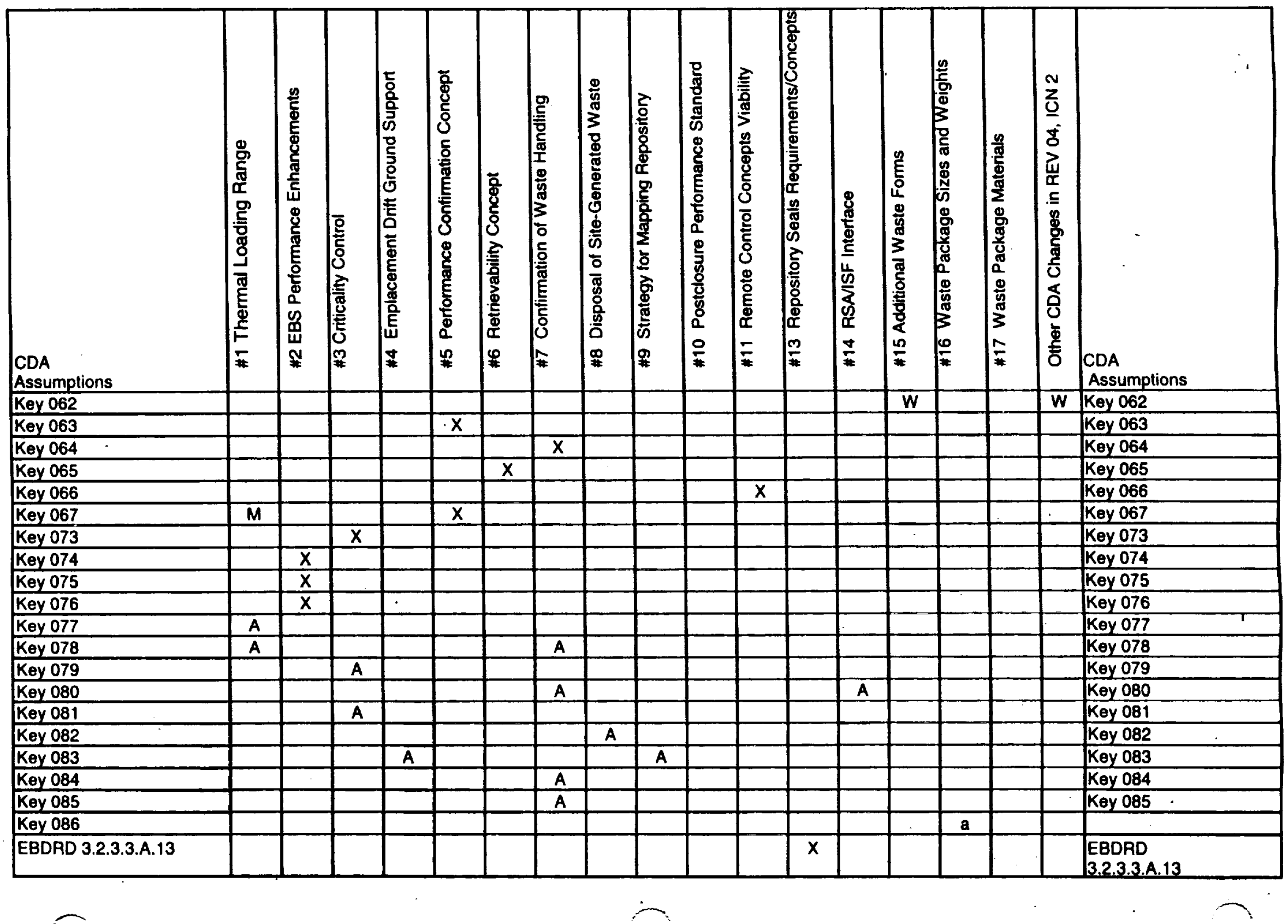


Table C-2. CDA Assumptions Related to Relerence Concepts for VA Issues (continued)

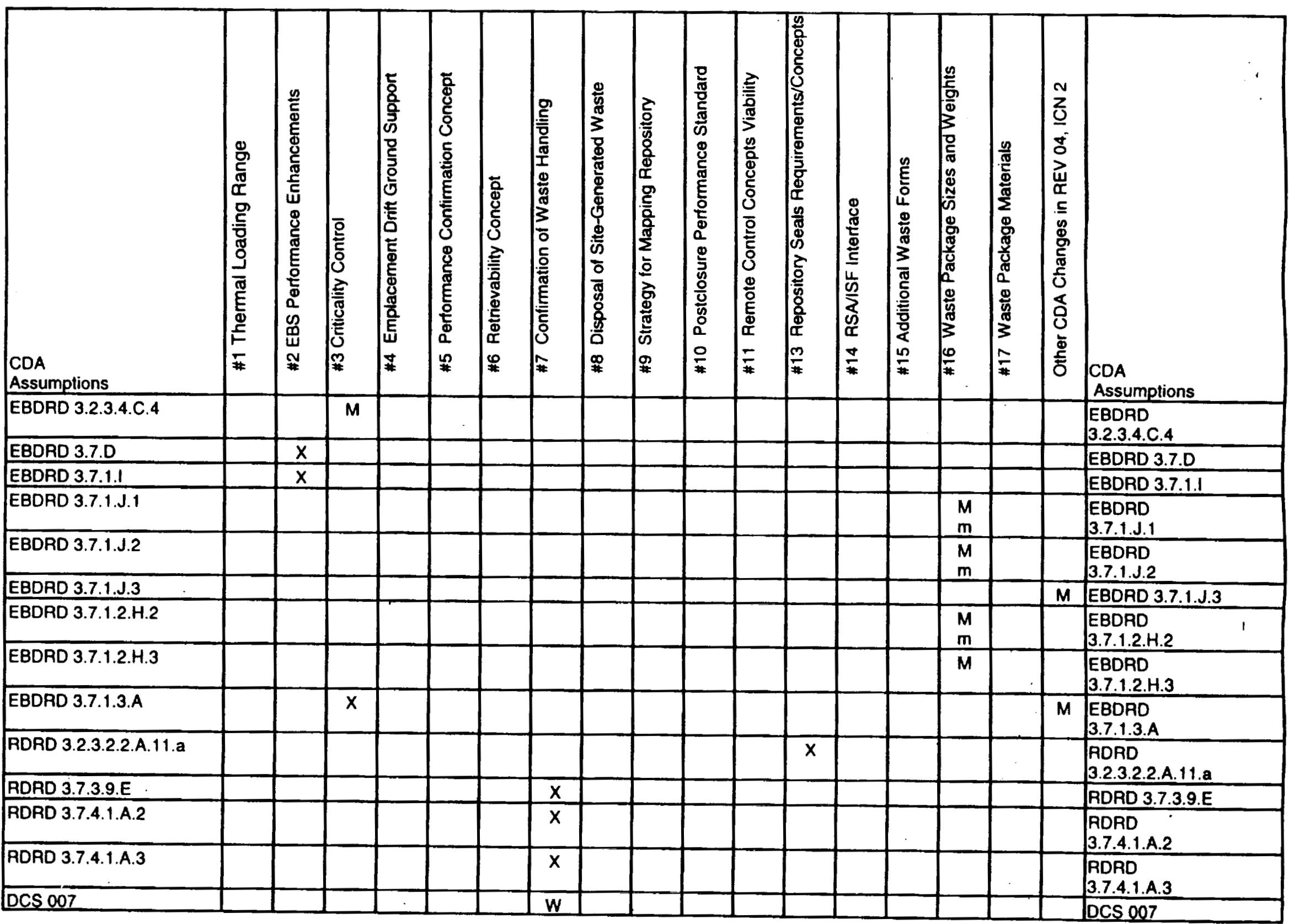


Table C-2. CDA Assumptions Related to Reference Concepts for VA Issues (continued)

\begin{tabular}{|c|c|c|c|c|c|c|c|c|c|c|c|c|c|c|c|c|c|c|}
\hline $\begin{array}{l}\text { CDA } \\
\text { Assumptions }\end{array}$ & 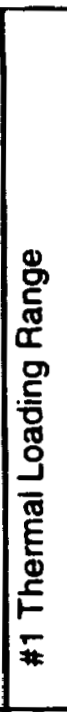 & 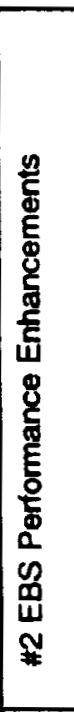 & 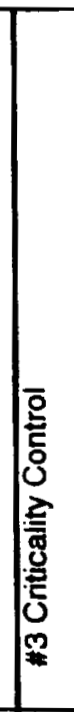 & 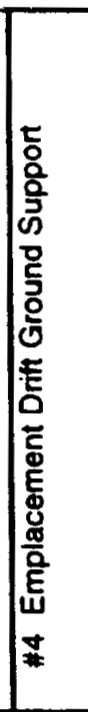 & 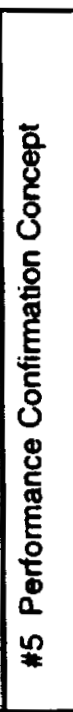 & 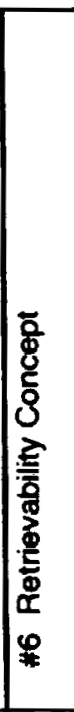 & 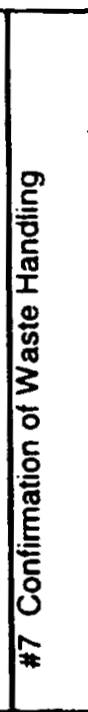 & 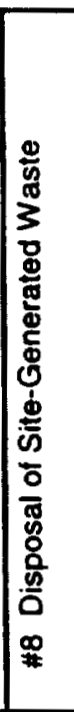 & 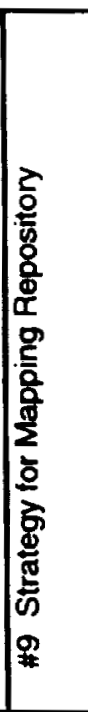 & 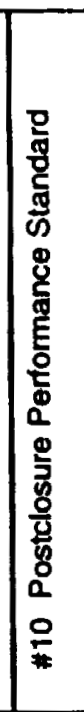 & 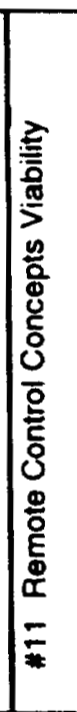 & 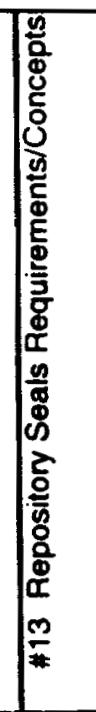 & 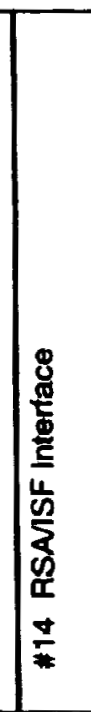 & 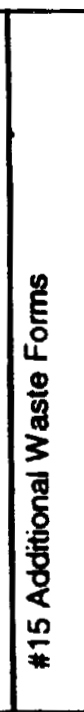 & 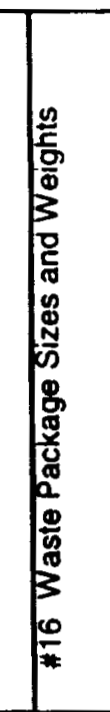 & 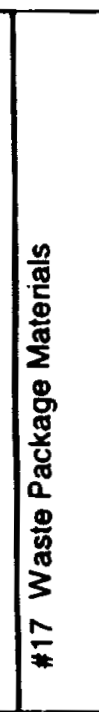 & 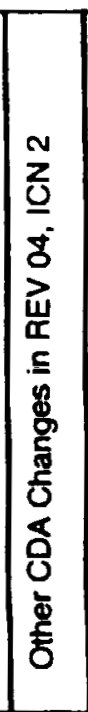 & $\begin{array}{l}\text { CDA } \\
\text { Assumptions }\end{array}$ \\
\hline DCs 010 & & & & & & & $w$ & & & & & & & & & 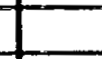 & & DCS 010 \\
\hline DCS 014 & & & & & & & $w$ & & & & & & & & & & & DCS 014 \\
\hline DCS 015 & & & & & & & $w$ & & & & & & & & & & & DCs 015 \\
\hline DCS 016 & & & & & & & $w$ & & & & & & & & & & & DCS 016 \\
\hline DCS 017 & & & & & & & $w$ & & & & & & & & & & & DCS 017 \\
\hline DCS 018 & & & & & & & $w$ & & & & & & & & & & & DCS 018 \\
\hline DCs 020 & & & & & & & A & & & & & & & & & & & DCS 020 \\
\hline DCS 021 & & & & & & & $A$ & & & & & & & . & & & & DCS 021 \\
\hline DCSS 009 & & & & . & & & & & & & & $x$ & & & & - & & DCSS 009 \\
\hline DCSS 025 & & & & & & & & & & & & & & & & & $M$ & DCSS 025 \\
\hline DCSS 027 & & & & $x$ & & & & & & & & & & & & & & DCSS 027 \\
\hline DCSS 034 & & & & $x$ & & & & & $x$ & & & & & & & & & DCSS 034 \\
\hline DCWP 004 & & & & & & & & & & & & & & & & $x$ & & DCWP 004 \\
\hline DCWP 005 & & & & & & & & & & & & & & & $w$ & & & DCWP 005 \\
\hline DCWP 006 & & & & & & & & & & & & & & & $w$ & & & DCWP 006 \\
\hline TDSS 001-012\& 017 & & & & & & & & & & & & $x$ & & & & & & TDSS $001.012 \& 017$ \\
\hline TDSS 025 & & & & & & & & & & & & & & & & $x$ & & TDSS 025 \\
\hline TDSS 026 & & $x$ & & & & & & & & & & $\bar{x}$ & & & & $x$ & & TDSS 026 \\
\hline
\end{tabular}


Table C-3. CDA Assumptions Related to Alternate Concepts for VA Issues

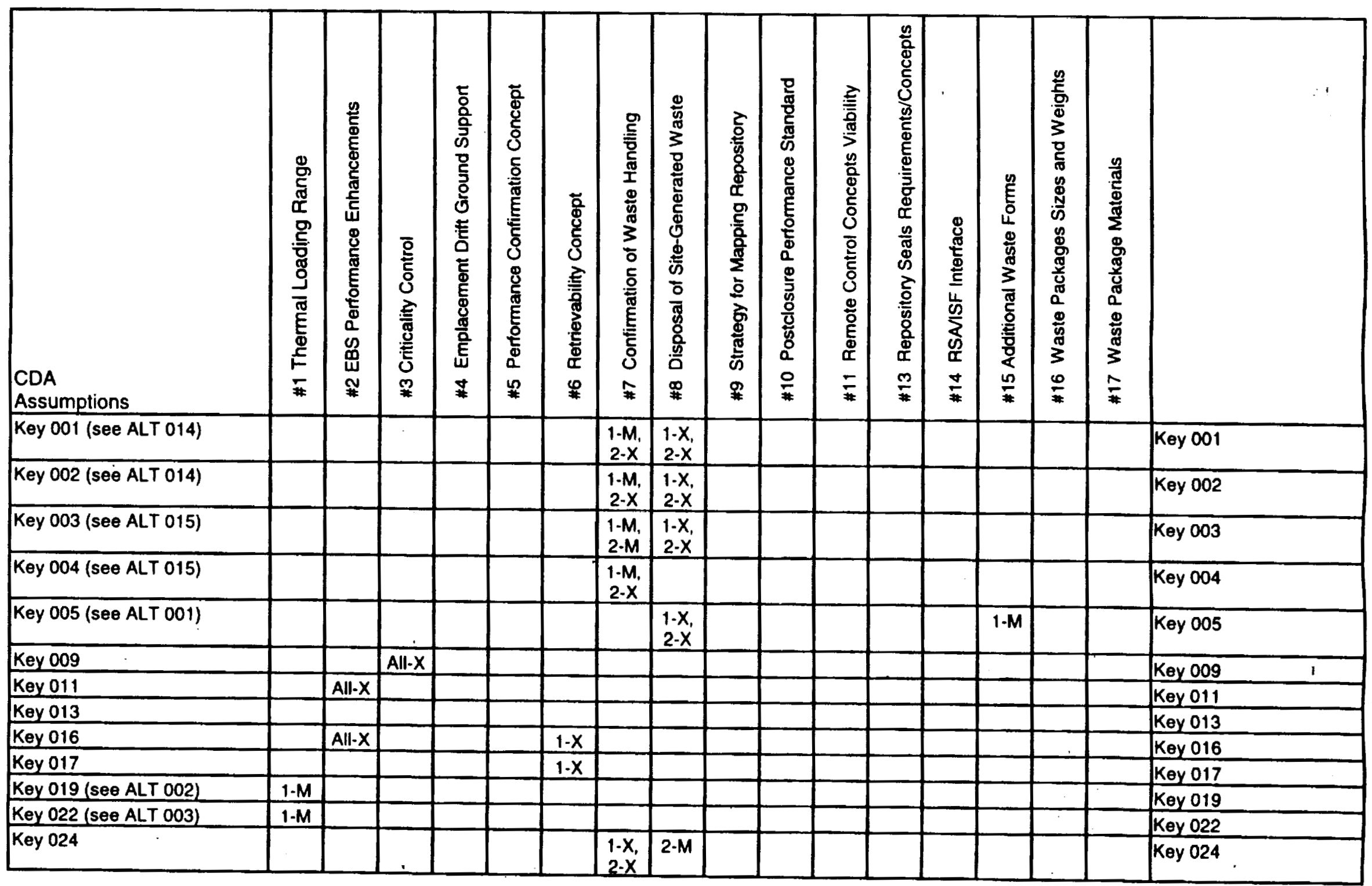


Table C-3. CDA Assumptions Related to Alternate Concepts for VA Issues (continued)

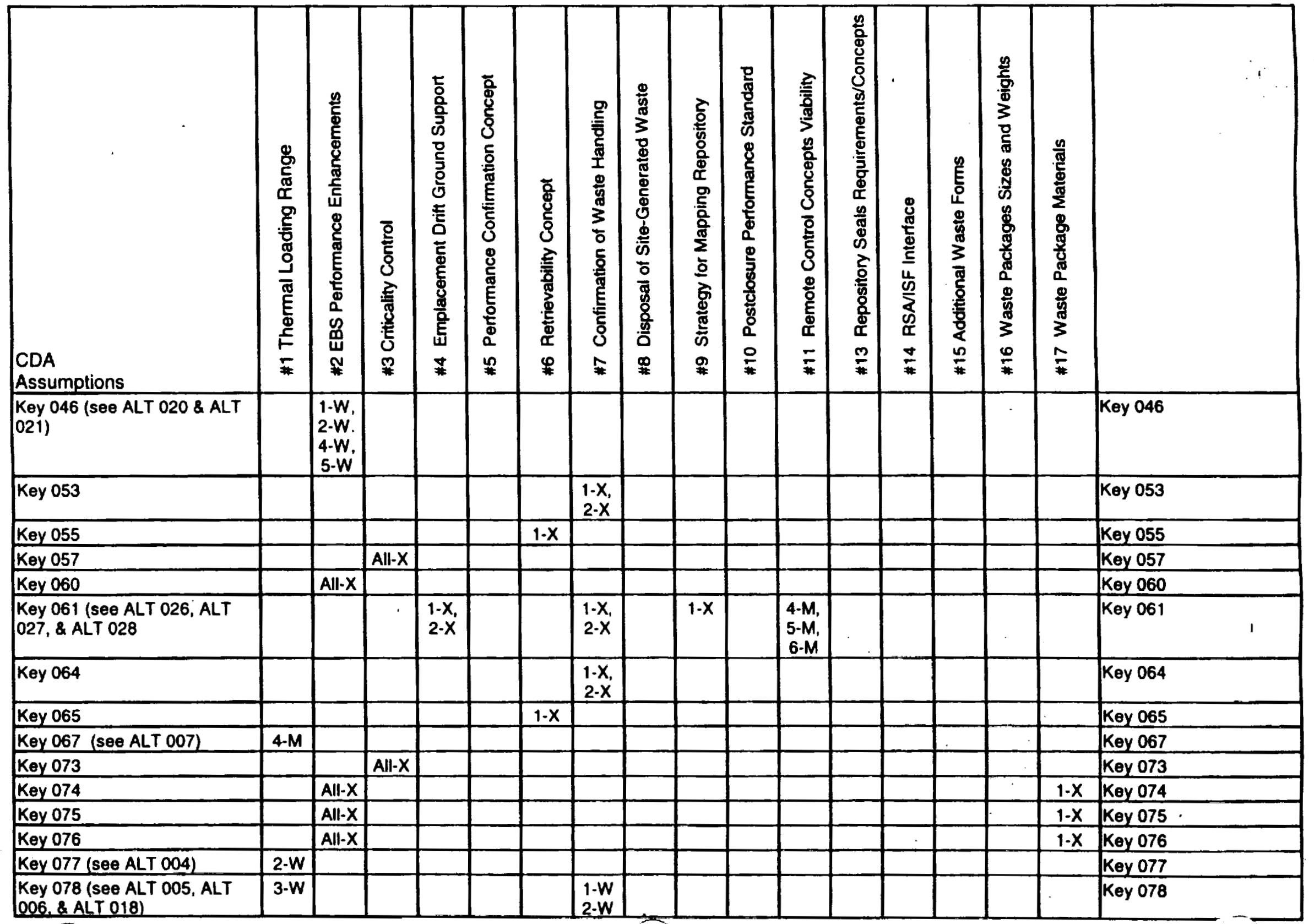




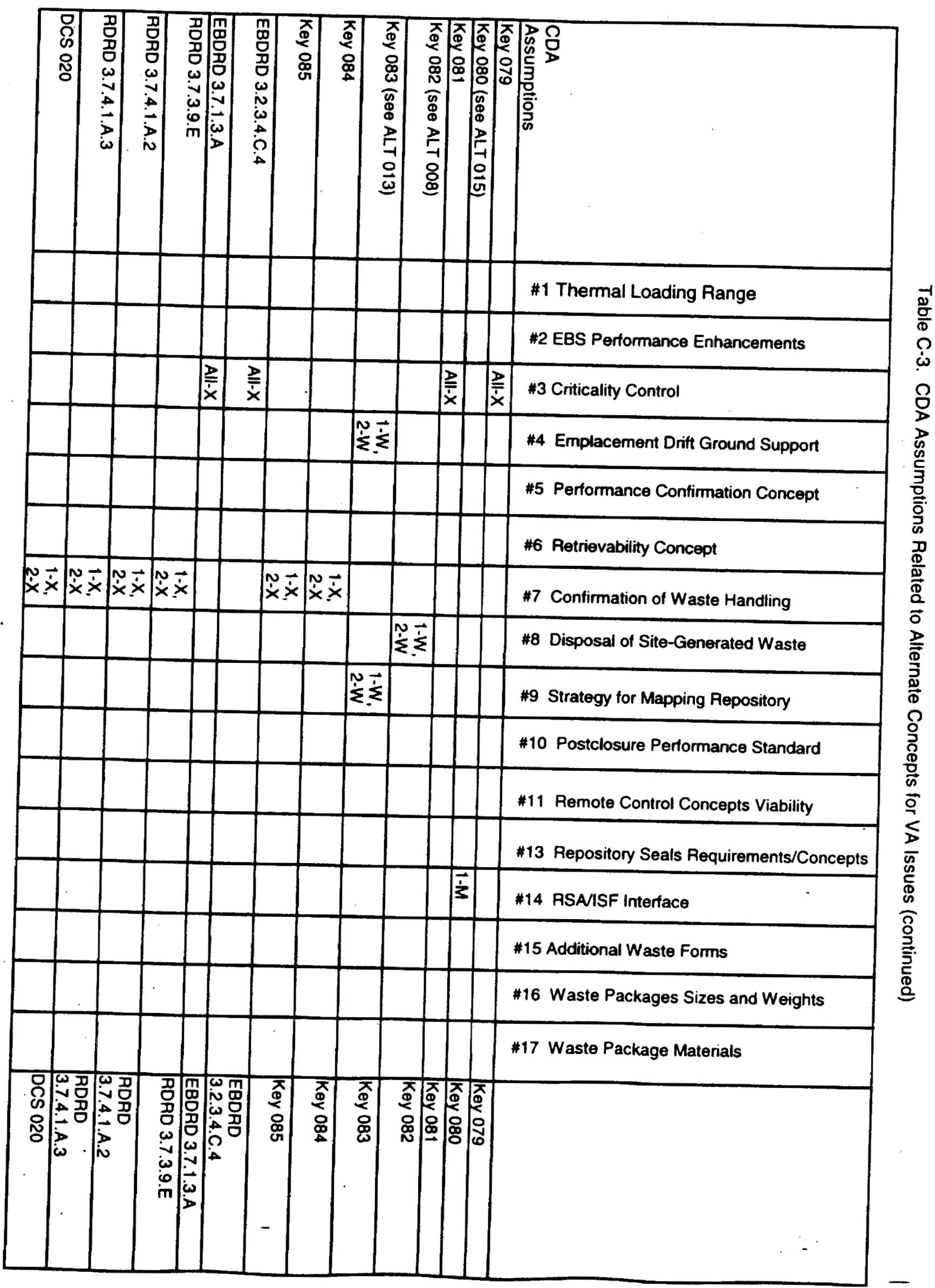


Table C-3. CDA Assumptions Related to Alternate Concepts for VA Issues (continued)

\begin{tabular}{|c|c|c|c|c|c|c|c|c|c|c|c|c|c|c|c|c|c|c|}
\hline $\begin{array}{l}\text { CDA } \\
\text { Assumptions }\end{array}$ & 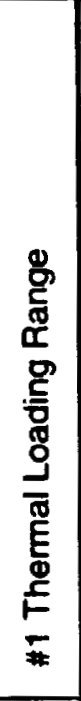 & 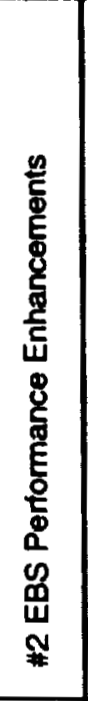 & 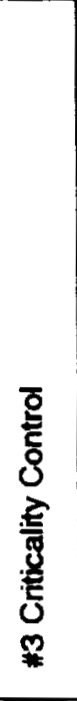 & 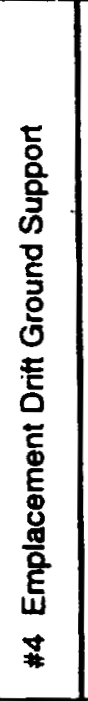 & 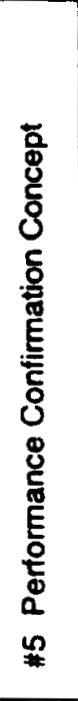 & 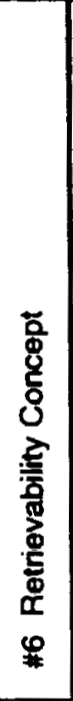 & 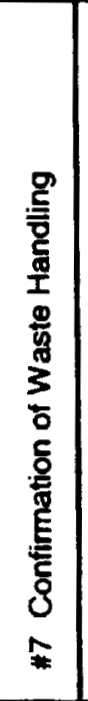 & 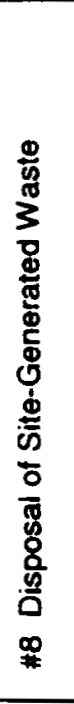 & 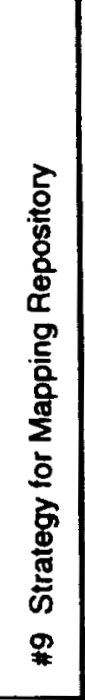 & 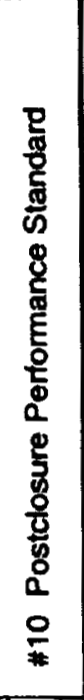 & 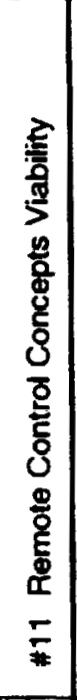 & 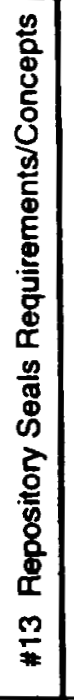 & 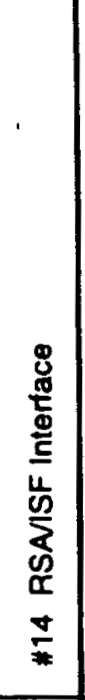 & 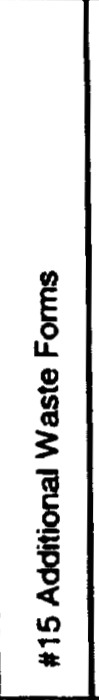 & 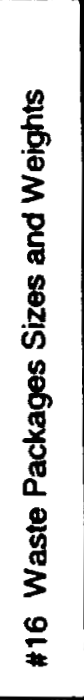 & 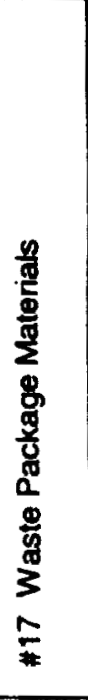 & & \\
\hline DCS 021 & & & . & & & & $\begin{array}{l}1-x \\
2-x\end{array}$ & & & & & & & & & & DCS 021 & \\
\hline DCSS 027 (see ALT 011) & & & & $\begin{array}{l}1-X \\
2-M\end{array}$ & & & & & & & & & & & & & DCSS 027 & \\
\hline DCSS 034 (see ALT 012) & & & & $\begin{array}{l}1-X_{1} \\
2-M^{2}\end{array}$ & & & & & & & & & & & & & DCsS 034 & \\
\hline DCWP 001 & & $\begin{array}{l}1-x_{1} \\
2 \cdot x \\
4-x \\
5 \cdot x \\
\end{array}$ & & & & & & & & & & & & & & & DCWP 001 & \\
\hline DCWP 004 (see ALT 025) & & & & & & & & & & & & & & & & $1-M$ & DCWP 004 & 1 \\
\hline TDSS 025 & & & & & & & & & & & & & & & & $1 \cdot x$ & TOSS 025 & \\
\hline TOSS 026 & & $\begin{array}{l}1-x \\
2-x \\
4-x \\
5-x \\
\end{array}$ & & & & & & & & & & & & & & $1-x$ & TDSS 026 & \\
\hline ALT 001 (Key 005 mod.) & & & & & & & & & & & & & & 1.A & & & ALT 001 & \\
\hline ALT 002 (Key 019 mod.) & $1-A$ & & & & & & & & & & & & & & & & ALT 002 & \\
\hline ALT 003 (Key 022 mod.) & $1-A$ & & & & & & & & & & & & & & & & ALT 003 & \\
\hline ALT 004 (Key 077 mod.) & $2-A$ & & $\therefore$ & & & & & & & & & & & & & & ALT 004 & \\
\hline ALT 005 (Key 078 mod.) & 3-A & & & & & & 2-A & & & & & & & & & & ALT 005 & \\
\hline ALT 006 (Key 079 mod.) & 3-A & & & & & & 2-A & & & & & & & & & & ALT 006 & \\
\hline ALT 007 (Key $067 \mathrm{mod}$ ) & 4-A & & & & & & & & & & & & & & & & ALT 007 & \\
\hline
\end{tabular}


Table C-3. CDA Assumptions Related to Alternate Concepts for VA Issues (continued)

CDA

Assumptions ALT 008 (Key 082 mod.) ALT 009

ALT 010

ALT 011 (DCSS 027 mod.)

ALT 012 (DCSS 034 mod.) ALT 013 (Key 083 mod.)

ALT 014 (Key 083 mod.)

ALT 015 (Key 080 mod.)

ALT 016 (Key 001, 002, \& 004 mod.)

ALT 017

ALT 018 (Key 078 mod.)

ALT 019

ALT 020 (Key 046 mod.)

1

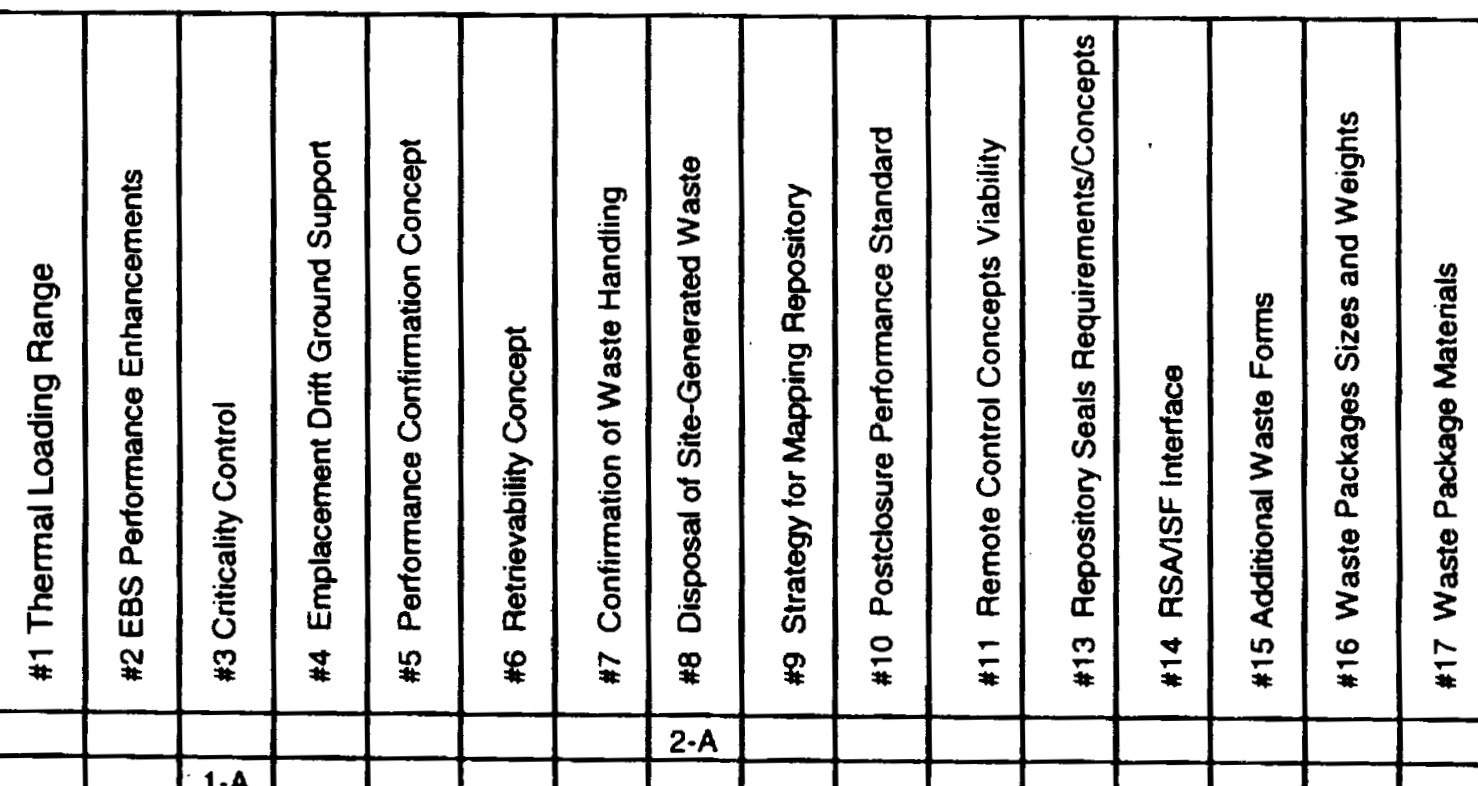

$10 \mid \frac{1 \cdot A}{2-A}$

$+2$

\begin{tabular}{|l|l|}
\hline & \\
\hline $1-A$ & \\
\hline
\end{tabular}

\begin{tabular}{lll|l|l|l|l|l|l|l}
\hline & & & & & & \\
\hline
\end{tabular}

ALT 008 ALT 009 ALT 010 ALT 011 ALT 012 ALT 013

\begin{tabular}{ll|l|l|l|l|l|l|l}
$1-A$ & & & & & & & \\
\hline
\end{tabular}

ALT 014 ALT 015 ALT 016

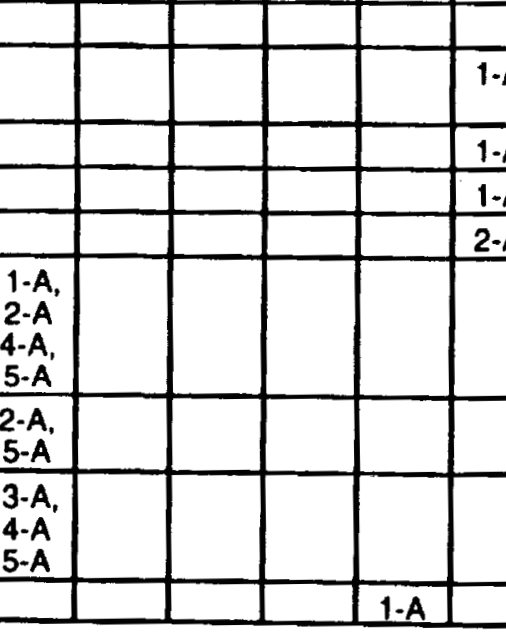

1-A

1-A

1.A

\begin{tabular}{ll|l|l|l|l}
\hline & & & \\
\hline
\end{tabular}

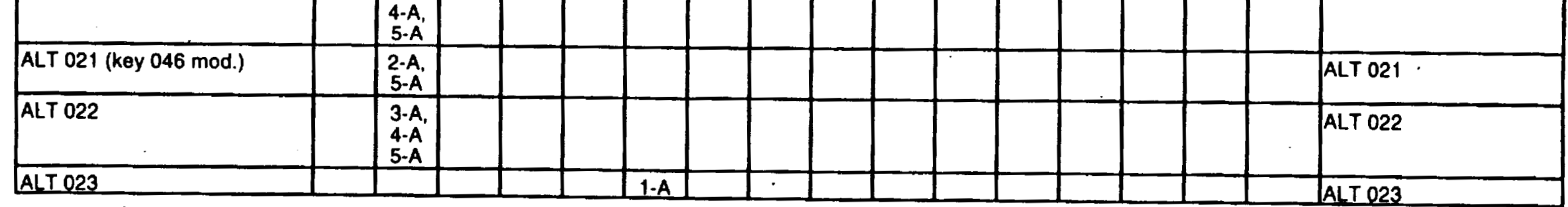


Table C-3. CDA Assumplions Related to Alternate Concepts for VA Issues (continued)

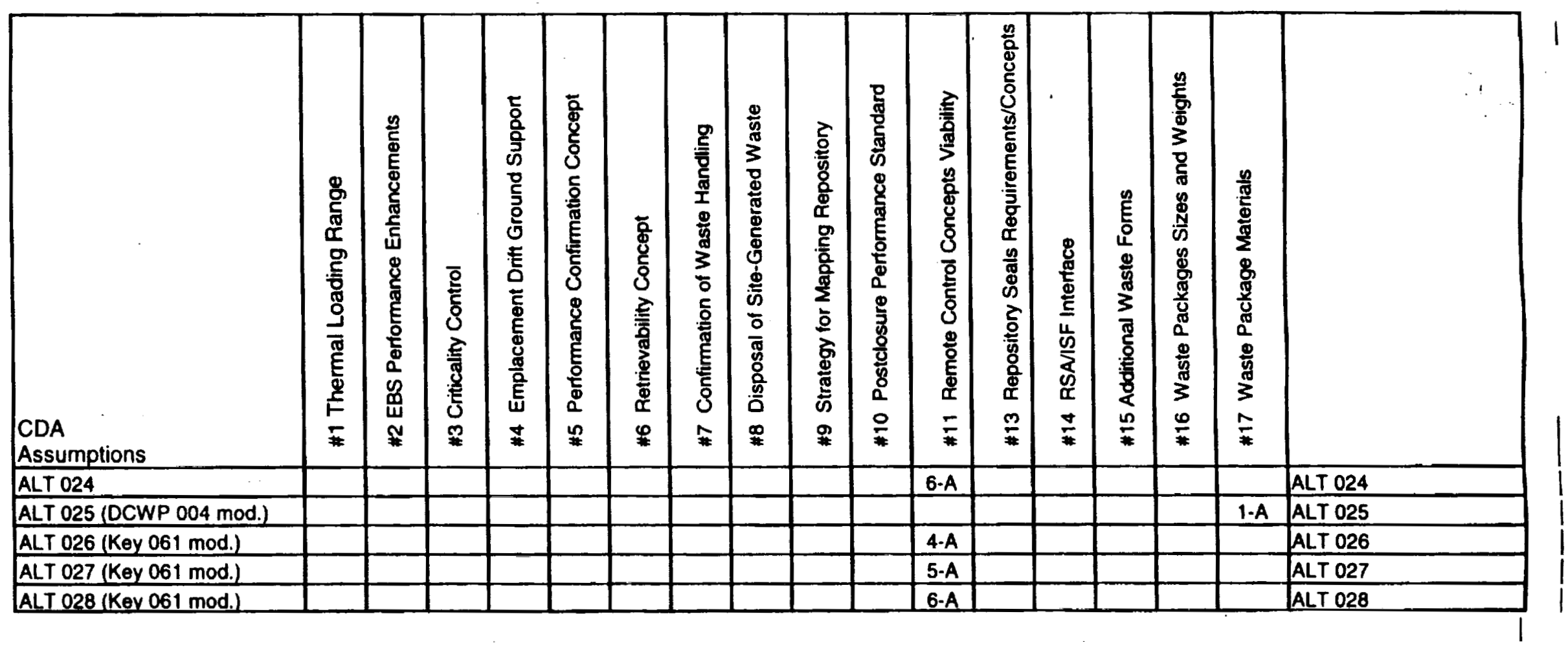




\section{APPENDIX D}

\section{ALTERNATE ASSUMPTIONS}

NOTE: The "ALT" assumptions in Appendix D are not part of the controlled design assumptions applicable to the reference design but only show how new or modified assumptions might look if alternate concepts for VA issues (as identified in the right column of Table C-1) were adopted. Any ALT assumption would have to be converted into one of the assumption categories defined in Attachment II of NLP-3-32 (CRWMS M\&O 1997h), with its prefix changed accordingly, before it could be added to the applicable assumptions in the body of the CDA Document. 


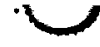




\section{Controlled Design Assumption \\ Alternate Assumption Rationale Sheet}

Assumption Identifier: ALT 001

Subject: HLW and DOE SNF

\section{STATEMENT OF ASSUMPTION}

The quantities of high-level waste (HLW) and U.S. Department of Energy (DOE) spent nuclear fuel (SNF) within the combined $7000 \mathrm{MTU}$ equivalent to be disposed of in the repository will be modified to take all of the anticipated DOE SNF of approximately 2600 MTU equivalent by reducing the HLW to 4400 MTU equivalent.

All HLW and most DOE SNF will be received in disposable canisters. At the repository, these canisters will be packaged for disposal, and the waste packages emplaced in the subsurface facility. Many of the DOE SNF canisters will be co-disposed in waste packages with the HLW canisters, and the remaining DOE SNF canisters will be disposed in separate waste packages. A small amount (approximately $50 \mathrm{MT}$ ) of DOE SNF may be received uncanistered if it meets the repository waste acceptance criteria and has acceptable characteristics so that it can be handled and processed in the same facilities as the commercial SNF.

The data on HLW and DOE SNF casks, canisters, and waste packages in Tables 3-4, 3-8, and 3-9 of Key Assumptions 001, 002, and 003, respectively, would have to be modified to reflect the change in the relative portions of the 7000 MTU equivalent allocated to HLW and DOE SNF. See Table 3-4 for the yearly streams of transportation cask arrivals. See Table 3-8 for the numbers of canisters of HLW and DOE SNF to be received each year. The DOE SNF canisters to be disposed in separate waste packages are shown separately from those to be co-disposed in HLW waste packages. Table 3-9 shows the number of co-disposal waste packages with five HLW canisters and one DOE SNF canister and the number of separate-disposal waste packages containing varying numbers of DOE SNF canisters. 1

\section{BACKGROUND}

Requesting Management and Operating Contractor (M\&O) organization:

( ) Surface, ( ) Subsurface, ( ) Waste Package Development, (X) Other (specify): Systems Engineering

Need for assumption (statement of intended use):

\section{RATIONALE}

Rationale for assumption (source author, date, and report title) or statement of reasoning behind engineering judgment:

This assumption is a replacement for Key Assumption 005 and is applicable to VA issue \#15 alternate concept. 


\section{Controlled Design Assumption Alternate Assumption Rationale Sheet}

I Assumption Identifier: ALT 001 (continued)

Subject: HLW and DOE SNF

1 The increase in DOE SNF from one-third of the combined 7000 MTU equivalent (2333 MTU equivalent of DOE SNF) to the total amount of DOE SNF of approximately $2600 \mathrm{MTU}$

equivalent is a relatively small increase and only reduces the quantity of HLW to go into the I repository by about 6 percent.

1

IV. RESPONSIBILITY/SUBSTANTIATION/WITHDRAWAL

I Responsible Management and Operating Contractor (M\&O) organization: Systems Engineering I

I Document(s) Supporting Withdrawal of Assumption:

1

I Withdrawal Date:

I 


\section{Controlled Design Assumption \\ Alternate Assumption Rationale Sheet}

Assumption Identifier: ALT 002

Subject: Areal Mass Loading

\section{STATEMENT OF ASSUMPTION}

A lower mass loading in the range of 6.2 to $8.9 \mathrm{kgU} / \mathrm{m}^{2}$ (25 to $36 \mathrm{MTU} / \mathrm{acre}$ ) will be considered as an alternative for License Application (LA) purposes and will be evaluated with regard to potential improvement in total system performance.

\section{BACKGROUND}

Requesting Management and Operating Contractor (M\&O) organization:

( ) Surface, ( ) Subsurface, ( ) Waste Package Development, (X) Other (specify): Project Engineering

Need for assumption (statement of intended use):

Establishes a design range permitting Mined Geologic Disposal System (MGDS) and waste package design options to proceed with criteria to achieve these objectives.

\section{RATIONALE}

Rationale for assumption (source author, date, and report title) or statement of reasoning behind engineering judgment:

This assumption is a replacement for Key Assumption 019 and is applicable to VA issue \#I alternate concept 1 .

A lower mass loading will be evaluated in the LA process as an appropriate alternative for potential improvement in total system performance. The alternative could be adopted if it provides the appropriate performance enhancement and the reference mass loading in Key Assumption 019 is determined to be unacceptable.

\section{RESPONSIBILITY/SUBSTANTIATION/WITHDRAWAL}

Responsible Management and Operating Contractor (M\&O) organization: Systems Engineering Document(s) Supporting Withdrawal of Assumption:

Withdrawal Date: 


\section{Controlled Design Assumption \\ Alternate Assumption Rationale Sheet}

Assumption Identifier: ALT 003

Subject: Repository Horizon and Location

\section{STATEMENT OF ASSUMPTION}

The repository horizon will be located mainly in the TSw2 geologic unit within the primary area. If additional area is needed due to a lower mass loading than the reference range given in Assumption 019 or due to portions of the primary area being unusable, the initial expansion area will be to the north of the primary area.

If additional expansion areas are found to be suitable, such as in the lower block or across Solitario Canyon, they may be considered as needed after first developing north of the primary area.

\section{BACKĠROUND}

Requesting Management and Operating Contractor $(\mathrm{M \& O})$ organization:

( ) Surface, ( ) Subsurface, ( ) Waste Package Development, (X) Other (specify): Project Engineering

Need for assumption (statement of intended use):

\section{RATIONALE}

Rationale for assumption (source author, date, and report title) or statement of reasoning behind engineering judgment:

This assumption is a replacement for Key Assumption 022 and is applicable to VA issue \# I alternate concept 1 .

Additional area beyond the primary area could be required due to a lower mass loading such as defined in alternate assumption ALT 002 or if portions of the primary area are unusable. Expansion to the north is preferred for subsurface design.

\section{RESPONSIBILITY/SUBSTANTIATION/WITHDRAWAL}

Responsible Management and Operating Contractor (M\&O) organization: Subsurface

Document(s) Supporting Withdrawal of Assumption:

Withdrawal Date: 


\section{Controlled Design Assumption \\ Alternate Assumption Rationale Sheet}

Assumption Identifier: ALT 004

Subject: Waste Package and Drift Spacing

\section{STATEMENT OF ASSUMPTION}

A layout, commonly termed "line load," with wider drift spacing and the waste package (WP) spacing determined by package length (within handling constraints) instead of mass content will be considered if design basis modeling predicts that MGDS performance is improved without imposing unacceptable operational constraints on the design. The areal mass loading value would be implemented on the basis of the mass content of an entire drift, as opposed to a unit WP basis.

\section{BACKGROUND}

Requesting Management and Operating Contractor $(\mathrm{M} \& \mathrm{O})$ organization:

( ) Surface, ( ) Subsurface, ( ) Waste Package Development, or (X) Other (specify): Project Engineering

Need for assumption (statement of intended use):

Establishes a thermal loading layout geometry permitting subsurface design to proceed once the mass loading per acre has been selected.

\section{RATIONALE}

Rationale for assumption (source author, date, and report title) or statement of reasoning behind engineering judgment:

This assumption is a replacement for Key assumption 077 and is applicable to VA issue \#1 alternate concept 2 .

A change from point load to line load will be considered if MGDS performance is predicted to improve without imposing unacceptable operational constraints on the design. The line load concept puts WPs as close as practical to each other within handling constraints, and does not adjust the WP spacing (and thus the area) of an individual WP for its mass content. Hence, the average mass per area is computed over the entire drift. The line load concept is predicted on the basis of an expectation that if WPs are pushed closed enough together, they will radiate well into each other and result in a fall in temperature that would allow the WPs to be closer together for a given AML value. 

1
Controlled Design Assumption
Alternate Assumption Rationale Sheet

I Assumption Identifier: ALT 004 (continued)

Subject: Waste Package and Drift Spacing

\section{IV. RESPONSIBILITY/SUBSTANTIATION/WITHDRAWAL}

I

I Responsible Management and Operating Contractor $(\mathrm{M} \& O)$ organization: Subsurface

1

1 Document(s) Supporting Withdrawal of Assumption:

1

I Withdrawal Date: 


\section{Controlled Design Assumption \\ Alternate Assumption Rationale Sheet}

Assumption Identifier: ALT 005

Subject: Sequencing Waste Package Emplacement

\section{STATEMENT OF ASSUMPTION}

Sequencing of waste packages into the emplacement drifts (using surface or subsurface lag storage capabilities) will be considered if design basis modeling predicts that MGDS performance is improved without imposing unacceptable operational constraints on the design.

\section{BACKGROUND}

Requesting Management and Operating Contractor (M\&O) organization:

(X) Surface, ( ) Subsurface, ( ) Waste Package Development, or (X) Other (specify): Project Engineering

Need for assumption (statement of intended use):

Affects surface and subsurface design.

\section{RATIONALE}

Rationale for assumption (source author, date, and report title) or statement of reasoning behind engineering judgment:

This assumption would partially replace Key Assumption 078 and is applicable to VA issue \# I alternate concept 3 and VA issue \#7 alternate concept 2.

The sequencing of waste package emplacement will be considered as part of the overall thermal management strategy if MGDS performance is predicted to improve without imposing unacceptable operational constraints on the design.

\section{RESPONSIBILITY/SUBSTANTIATION/WITHDRAWAL}

Responsible Management and Operating Contractor (M\&O) organization: Subsurface

Document(s) Supporting Withdrawal of Assumption:

Withdrawal Date: 


\section{Controlled Design Assumption \\ Alternate Assumption Rationale Sheet}

Assumption Identifier: ALT 006

Subject: Sequencinḡ Waste Package Loading

\section{STATEMENT OF ASSUMPTION}

Sequencing of spent fuel assemblies into waste packages (using either waste handling building storage or surface lag storage capabilities) will be considered if design basis modeling predicts 1 that MGDS performance is improved without imposing unacceptable operational constraints on I the design.

I Withdrawal Date: 


\section{Controlled Design Assumption \\ Alternate Assumption Rationale Sheet}

Assumption Identifier: ALT 007

Subject: Empläcement Drift Ventilation

\section{STATEMENT OF ASSUMPTION}

Forced ventilation of emplacement drifts for several decades will be considered if design basis modeling predicts that MGDS performance is improved without imposing unacceptable operational constraints on the design.

\section{BACKGROUND}

Requesting Management and Operating Contractor (M\&O) organization:

( ) Surface, ( ) Subsurface, ( ) Waste Package Development, or (X) Other (specify): Project Engineering

Need for assumption (statement of intended use):

Affects design and operation of subsurface ventilation system.

\section{RATIONALE}

Rationale for assumption (source author, date, and report title) or statement of reasoning behind engineering judgment:

This assumption will replace Key assumption 067 and is applicable to VA issue \#1 alternate concept 4.

Forced ventilation will be considered as part of the overall thermal management strategy if MGDS performance is predicted to improve without imposing unacceptable operational constraints on the design.

\section{RESPONSIBILITY/SUBSTANTIATION/WITHDRAWAL .}

Responsible Management and Operating Contractor (M\&O) organization: Subsurface

Document(s) Supporting Withdrawal of Assumption:

Withdrawal Date: 


\section{Controlled Design Assumption \\ Alternate Assumption Rationale Sheet}

Assumption Identifier: ALT 008

Subject: On-site LLW Disposal

\section{STATEMENT OF ASSUMPTION}

If off-site LLW disposal facilities are not available or do not provide a cost-effective means for disposing of site-generated radiological low level waste ( $L L W$ ) from the repository, the LLW will be disposed at a surface location to be identified at the repository site outside the geologic repository operations area.

\section{BACKGROUND}

Requesting Management and Operating Contractor (M\&O) organization:

( ) Surface, ( ) Subsurface, ( ) Waste Package Development, (X ) Other (specify): Systems

Engineering

Need for assumption (statement of intended use):

\section{RATIONALE}

Rationale for assumption (source author, date, and report title) or statement of reasoning behind engineering judgment:

This assumption is a replacement for Key Assumption 082 and is applicable to VA issue \#8 alternate concept 2 .

If the NTS and other approved off-site facilities were not available for disposal of site-generated LLW, locations at the repository site could be examined for acceptability for establishment of a LLW disposal facility for this LLW from the repository.

\section{RESPONSIBILITY/SUBSTANTIATION/WITHDRAWAL}

Responsible Management and Operating Contractor (M\&O) organization: Systems Engineering

Document(s) Supporting Withdrawal of Assumption:

Withdrawal Date: 


\section{Controlled Design Assumption Alternate Assumption Rationale Sheet}

Assumption Identifier: ALT 009

Subject: Iron Shot Filler Material

\section{STATEMENT OF ASSUMPTION}

Will be able to take credit for criticality control purposes for moderator displacing iron shot filler material placed inside waste packages.

\section{BACKGROUND}

Requesting Management and Operating Contractor (M\&O) organization:

(X) Surface, ( ) Subsurface, (X) Waste Package Development, ( ) Other (specify):

Need for assumption (statement of intended use):

Would affect waste package design if need to take credit for filler material for criticality control.

\section{RATIONALE}

Rationale for assumption (source author, date, and report title) or statement of reasoning behind engineering judgment:

This assumption is applicable to VA issue \#3 altemate concept 2. This assumption would not necessarily impact Key Assumption 073 which indicates that disposable canisters arriving at the repository loaded with SNF would not have to be opened to add filler material.

The results reported in the Advance Conceptual Design Report (CRWMS M\&O 1996a) indicate filler material my provide the necessary criticality control.

\section{RESPONSIBILITY/SUBSTANTIATION/WITHDRAWAL}

Responsible Management and Operating Contractor (M\&O) organization: Waste Package Development

Document(s) Supporting Withdrawal of Assumption:

Withdrawal Date: 


\section{Controlled Design Assumption \\ Alternate Assumption Rationale Sheet}

Assumption Identifier: ALT 010

Subjject: DU Filler Material

\section{STATEMENT OF ASSUMPTION}

Will be able to take credit for criticality control purposes for moderator displacing depleted uranium (DU) filler material placed inside waste packages for criticality control.

\section{BACKGROUND check}

Requesting Management and Operating Contractor (M\&O) organization:

(X ) Surface, ( ) Subsurface, (X) Waste Package Development, ( ) Other (specify):

Need for assumption (statement of intended use):

Would affect waste package design if need to take credit for filler material for criticality control.

\section{RATIONALE}

Rationale for assumption (source author, date, and report title) or statement of reasoning behind engineering judgment:

This assumption is applicable to VA issue \#3 alternate concept 3 . This assumption would not necessarily impact Key Assumption 073 which indicates that disposable canisters arriving at the repository loaded with SNF would not have to be opened to add filler material.

The results reported in the Advance Conceptual Design Report (CRWMS M\&O 1996a) indicate filler material may provide the necessary criticality control. The dilution provided by DU could provide additional far-field criticality control.

\section{RESPONSIBILITY/SUBSTANTIATION/WITHDRAWAL}

Responsible Management and Operating Contractor (M\&O) organization: Waste Package

Development

Document(s) Supporting Withdrawal of Assumption:

Withdrawal Date: 


\section{Controlled Design Assumption \\ Alternate Assumption Rationale Sheet}

Assumption Identifier: ALT 011

Subject: Rock Support Material Restrictions

\section{STATEMENT OF ASSUMPTION}

Concrete materials and organic materials (e.g., epoxy resin, timber) are restricted for use as rock support and other postclosure permanent materials in all openings.

Steel is an allowable preclosure construction material in all openings.

\section{BACKGROUND}

Requesting Management and Operating Contractor (M\&O) organization:

( ) Surface, (X) Subsurface, ( ) Waste Package Development, ( ) Other (specify):

Need for assumption (statement of intended use):

Affects rock support design and possibly other underground work.

\section{RATIONALE}

Rationale for assumption (source author, date, and report title) or statement of reasoning behind engineering judgment:

These restrictions are necessary to minimize the impact of subsurface construction on waste isolation. The use of organic and specific cementitious materials should be approved by the Determination of Importance (DI) group. As indicated in Assumption EBDRD 3.2.3.3.A.13, performance evaluations are needed to determine any adverse impacts to waste isolation.

This is a modified assumption for DCSS 027 if concrete were determined to be unacceptable and is applicable to VA issue \#4 alternate concept 2.

IV. RESPONSIBILITY/SUBSTANTIATION/WITHDRAWAL

Responsible Management and Operating Contractor (M\&O) organization: Subsurface

Document(s) Supporting Withdrawal of Assumption:

Withdrawal Date: 


\section{Controlled Design Assumption \\ Alternate Assumption Rationale Sheet}

Assumption Identifier: ALT 012

Subject: Emplacement Drift Ground Support

I A single ground support type consisting of steel sets with steel lagging will be used in I emplacement drifts.

Rationale for assumption (source author, date, and report title) or statement of reasoning behind engineering judgment:

1 Document(s) Supporting Withdrawal of Assumption:

Using a single ground support type greatly simplifies design and construction by eliminating field decisions regarding ground classification and support type to be installed.

A single ground support type allows for efficient application of materials, emphasis on longevity, and minimization of maintenance.

This is a modified assumption for DCSS 034 if concrete were determined to be unacceptable and is applicable to VA issue \#4 alternate concept 2.

\section{RESPONSIBILITY/SUBSTANTIATION/WITHDRAWAL}

Responsible Management and Operating Contractor (M\&O) organization: Subsurface 


\section{Controlled Design Assumption \\ Alternate Assumption Rationale Sheet}

Assumption Identifier: ALT 013

Subject: Map All Emplacement Drifts ।

\section{STATEMENT OF ASSUMPTION}

All emplacement drifts as well as all non-emplacement drifts are to be mapped.

\section{BACKGROUND}

Requesting Management and Operating Contractor (M\&O) organization:

( ) Surface, ( ) Subsurface, ( ) Waste Package Development, ( X ) Other (specify): Systems Analysis and Modeling

Need for assumption (statement of intended use):

\section{RATIONALE}

Rationale for assumption (source author, date, and report title) or statement of reasoning behind engineering judgment:

This assumption is a replacement for Key Assumption 083 that is applicable to the altemate concept for VA issue \# 9.

\section{RESPONSIBILITY/SUBSTANTIATION/WITHDRAWAL}

Responsible Management and Operating Contractor (M\&O) organization: Systems Analysis and Modeling

Document(s) Supporting Withdrawal of Assumption:

Withdrawal Date: 


\section{Controlled Design Assumption \\ Alternate Assumption Rationale Sheet}

\section{Assumption Identifier: ALT 014}

Subject: Mā̄ No Emplacement Drifts

\section{STATEMENT OF ASSUMPTION}

All non-emplacement drift repository subsurface facilities are to be mapped. The grid of mapping coverage in the repository horizon will be 300 by 600 meters, and the arrangement of the non-emplacement drifts will accommodate this mapping coverage such that none of the emplacement drifts will have to be mapped.

\section{BACKGROUND}

Requesting Management and Operating Contractor (M\&O) organization:

( ) Surface, ( X ) Subsurface, ( ) Waste Package Development, ( ) Other (specify):

Need for assumption (statement of intended use):

\section{RATIONALE}

Rationale for assumption (source author, date, and report title) or statement of reasoning behind engineering judgment:

This assumption is a replacement for Key Assumption 083 that is applicable to VA issue \#9 alternate concept 2 . The importance to postclosure performance of the thermal-hydrological and radionuclide transport properties of faults should be better understood through the investigation of the extent of lateral diversion of flow within hydrogeological units. As this better understanding is obtained, it might be determined that the required grid of mapping coverage in Key Assumption 083 is more conservative than necessary. If assumed grid of mapping coverage in this alternate assumption proves adequate, the non-emplacement drifts may be arranged to I provide the necessary coverage by mapping less than 1 in 10 , and possibly, no emplacement I drifts. Hence, it is being carried as an alternate concept.

1 Responsible Management and Operating Contractor (M\&O) organization: Systems Analysis and I Modeling 1

I Withdrawal Date: 


\section{Controlled Design Assumption \\ Alternate Assumption Rationale Sheet}

Assumption Identifier: ALT 015

Subject: $\bar{R} S A$ Interface with an ISF

\section{STATEMENT OF ASSUMPTION}

Regional Service Agents (RSAs), under contract to the DOE, will be responsible for arranging and providing waste acceptance and transportation services to deliver the commercial SNF to a Federal facility which might be the repository or an Interim Storage Facility (ISF). This will include responsibility for providing and maintaining the transportation casks in which the SNF will be received at the Federal facility and the storage modules in which canistered SNF will be stored at the ISF.

\section{BACKGROUND}

Requesting Management and Operating Contractor $(\mathrm{M} \& O)$ organization:

( ) Surface, ( ) Subsurface, ( ) Waste Package Development, (X ) Other (specify): Systems Engineering

Need for assumption (statement of intended use):

Interfaces need to be defined to focus MGDS design, particularly in the surface facility waste handling systems.

\section{RATIONALE}

Rationale for assumption (source author, date, and report title) or statement of reasoning behind engineering judgment:

This assumption is a replacement for Key Assumption 080 that is applicable to VA issue \#14 alternate concept if it is determined that there should be early receipt of waste beginning in advance of the start of waste emplacement.

A draft Request for Proposals (RFP) was released by DOE in December 1996 to solicit organizations interested in becoming RSAs. The expressed objective by DOE is to maximize use of private industry and reduce OCRWM involvement in the waste acceptance, storage and transportation of SNF. The final RFP will be used as the basis for developing an initial set of interface assumptions for inclusion in the CDA Document.

\section{RESPONSIBILITY/SUBSTANTIATION/WITHDRAWAL}

Responsible Management and Operating Contractor (M\&O) organization: Systems Engineering Document(s) Supporting Withdrawal of Assumption:

Withdrawal Date: 


\section{Controlled Design Assumption \\ Alternate Assumption Rationale Sheet}

Assumption Identifier: ALT 016

Subject: Early Receipt

\section{STATEMENT OF ASSUMPTION}

Receive commercial SNF beginning 2007 without advancing the start of emplacement in 2010.

An external lag storage facility will be collocated near the North Portal with a capacity of about 11,000 MTHM of commercial SNF. This facility will include a storage area with storage modules design to house large welded canisters and a structure for transferring dual purpose canisters from shipping casks to storage modules. This facility is to accommodate the early receipt concept and would be established in conjunction with the phased startup of the waste handling building in assumption ALT 017.

\section{BACKGROUND}

Requesting Management and Operating Contractor (M\&O) organization:

(X) Surface, ( ) Subsurface, ( ) Waste Package Development, ( ) Other (specify):

Need for assumption (statement of intended use):

\section{RATIONALE}

Rationale for assumption (source author, date, and report title) or statement of reasoning behind engineering judgment:

This assumption is applicable to VA issue \#7 alternate concept I and VA issue \#14 alternate concept. The assumption would modify the waste streams defined in Key Assumptions 001, 002 , and 004. Replacements for the tables in these key assumptions must be provided to implement this assumption.

If the early-receipt concept were adopted, a facility would be required for storage prior to beginning the packaging for disposal and the start of emplacement. Legislation would have to accommodate the collocation of facilities.

\section{RESPONSIBILITY/SUBSTANTIATION/WITHDRAWAL}

Responsible Management and Operating Contractor (M\&O) organization: Surface

Document(s) Supporting Withdrawal of Assumption:

Withdrawal Date: 


\section{STATEMENT OF ASSUMPTION}

Under the early-receipt assumption defined in ALT 016, the waste handling building (WHB) will be similar to the reference design, except the facility would be designed for phased startup. The first phase would be capable of transferring assemblies from a shipping cask to a welded canister, and transporting the canister to an outside storage module. The second phase would add the hot cells for loading, welding and transferring disposal containers for transport to the subsurface emplacement area.

\section{BACKGROUND}

Requesting Management and Operating Contractor (M\&O) organization:

(X) Surface, ( ) Subsurface, ( ) Waste Package Development, ( ) Other (specify):

Need for assumption (statement of intended use):

\section{RATIONALE}

Rationale for assumption (source author, date, and report title) or statement of reasoning behind engineering judgment:

This assumption is applicable to VA issue \#7 alternate concept 1 .

If the early-receipt concept in assumption ALT 016 was adopted and a facility was established for storage prior to the start of emplacement, the waste handling facilities should be phased to initially support the ISF-style facility and subsequently to accomplish the packaging for disposal to facilitate the start of waste emplacement.

\section{RESPONSIBILITY/SUBSTANTIATION/WITHDRAWAL}

Responsible Management and Operating Contractor $(\mathrm{M} \& O)$ organization: Surface

Document(s) Supporting Withdrawal of Assumption:

Withdrawal Date: 


\section{Controlled Design Assumption \\ Alternate Assumption Rationale Sheet}

\section{Assumption Identifier: ALT 018 \\ Subject: Adjūsted Emplacement Order \\ I. STATEMENT OF ASSUMPTION \\ Under the early-receipt assumption defined in ALT 018, the SNF temporarily stored in the ISF- style facility can be used to modify to some extent the order in which SNF is loaded into disposal containers and thereby provide some adjustment to the order of waste emplacement for thermal management purposes.}

\section{BACKGROUND}

Requesting Management and Operating Contractor (M\&O) organization:

(X) Surface, ( ) Subsurface, ( ) Waste Package Development, ( ) Other (specify):

Need for assumption (statement of intended use):

\section{RATIONALE}

Rationale for assumption (source author, date, and report title) or statement of reasoning behind engineering judgment:

This assumption is a modification of Key Assumption 078 and is applicable to VA issue \#7 alternate concept 1 .

The availability of SNF in storage would allow some adjustment in the order of waste emplacement relative to the order of receipt if beneficial for thermal management purposes even if the more extensive sequencing covered in assumptions ALT 005 and 006 is not imposed.

\section{RESPONSIBILITY/SUBSTANTIATION/WITHDRAWAL}

Responsible Management and Operating Contractor (M\&O) organization: Surface

Document(s) Supporting Withdrawal of Assumption:

Withdrawal Date: 


\section{Controlled Design Assumption \\ Alternate Assumption Rationale Sheet}

Assumption Identifier: ALT 019

Subject: Additional SNF-Assembly Lag Storage I

\section{STATEMENT OF ASSUMPTION}

In conjunction with the alternate assumptions ALT 005 and ALT 006 to sequence the loading and emplacement of SNF differently than the approximate order in which received, techniques such as fuel blending or surface cooling would be facilitated by establishing additional lag storage for SNF assemblies, which would likely be achieved with an additional fuel staging pool between planned assembly transfer pools in the WHB.

\section{BACKGROUND}

Requesting Management and Operating Contractor $(M \& O)$ organization:

(X) Surface, ( ) Subsurface, ( ) Waste Package Development, ( ) Other (specify):

Need for assumption (statement of intended use):

\section{RATIONALE}

Rationale for assumption (source author, date, and report title) or statement of reasoning behind engineering judgment:

This assumption is applicable to VA issue \# 7 alternate concept 2 and would be used in conjunction with VA issue \#1 alternate 3 . The assumption is a companion to alternate assumptions ALT 005 and ALT 006.

\section{RESPONSIBILITY/SUBSTANTIATION/WITHDRAWAL}

Responsible Management and Operating Contractor $(\mathrm{M} \& O)$ organization: Subsurface

Document(s) Supporting Withdrawal of Assumption:

Withdrawal Date: 


\section{Controlled Design Assumption \\ Alternate Assumption Rationale Sheet}

Assumption Identifier: ALT 020

Subject: Backfill in Emplacement Drifts

\section{STATEMENT OF ASSUMPTION}

Backfill is required in the emplacement drifts. The specification for the emplacement drift envelope shall accommodate: 1) level single layer backfill material composed of quartz sand or other material of similar favorable thermohydrologic properties and 2) the waste packages should initially be covered with at least 0.6 meters of backfill material. It is further assumed that the I material/chemical interactions between the backfill and the waste package do not accelerate I degradation of the waste package relative to the no-backfill case.

\section{BACKGROUND}

Requesting Management and Operating Contractor (M\&O) organization:

( ) Surface, ( ) Subsurface, ( ) Waste Package Development, (X) Other (specify): Systems Engineering

Need for assumption (statement of intended use):

Establishes a scenario that constrains aspects of the waste package, surface facilities, and subsurface facilities dèsigns.

\section{RATIONALE}

Rationale for assumption (source author, date, and report title) or statement of reasoning behind engineering judgment:

This assumption is a replacement for Key Assumption 046 that is applicable to VA issue \#2 alternate concepts 1 and 4 .

It is expected that Total System Performance Assessment calculations conducted employing the higher infiltration fluxes currently thought plausible at the repository horizon could substantially reduce the performance margin relative to the Interim Postclosure Standard. The currently assessed performance margin is documented in the Engineered Barrier System Performance Requirements Systems Study Report (CRWMS M\&O 1996d). Substantial reduction in the performance margin may sufficiently impact the reasonable assurance argument to necessitate the addition of a barrier (e.g., backfill or other barriers such as dripshields or a ceramic coating that rely on backfill for protection) to enhance EBS performance. Further information regarding the performance benefits can be found in the referenced EBS Performance Requirements Study.

\section{RESPONSIBILITY AND WITHDRA WAL}

Responsible Management and Operating Contractor (M\&O) organization: Systems Engineering

Document(s) Supporting Withdrawal of Assumption:

Withdrawal Date: 


\section{Controlled Design Assumption \\ Alternate Assumption Rationale Sheet}

Assumption Identifier: ALT 021

Subject: D̄rip Shields and Backfill

in Emplacement Drifts

\section{STATEMENT OF ASSUMPTION}

Drip shields above the waste packages and under or within the backfill are required in the emplacement drifts. The specification that the emplacement drift envelope shall accommodate is TBD. It is further assumed that the material/chemical interactions between the backfill and the waste package do not accelerate degradation of the waste package relative to the no-backfill case.

\section{BACKGROUND}

Requesting Management and Operating Contractor $(\mathrm{M} \& O)$ organization:

( ) Surface, ( ) Subsurface, ( ) Waste Package Development, (X) Other (specify): Systems Engineering

Need for assumption (statement of intended use):

Establishes a scenario that constrains aspects of the waste package, surface facilities, and subsurface facilities designs.

\section{RATIONALE}

Rationale for assumption (source author, date, and report title) or statement of reasoning behind engineering judgment:

This assumption is a replacement for Key Assumption 046 that is applicable to VA issue \#2 alternate concepts 2 and 5 .

It is expected that Total System Performance Assessment calculations conducted employing the higher infiltration fluxes currently thought plausible at the repository horizon could substantially reduce the performance margin relative to the Interim Postclosure Standard. The currently assessed performance margin is documented in the Engineered Barrier System Performance Requirements Systems Study Report (CRWMS M\&O 1996d). Substantial reduction in the performance margin may sufficiently impact the reasonable assurance argument to necessitate the addition of barriers (drip shield and backfill) to enhance EBS performance. Although a drip shield was discounted in the EBS Performance Requirements System Study as a means of improving total systems performance over a million-year time frame, it may be a feasible approach over a 10,000-year time frame for a repository that experiences high flux.

\section{RESPONSIBILITY AND WITHDRAWAL}

Responsible Management and Operating Contractor (M\&O) organization: Systems Engineering Document(s) Supporting Withdrawal of Assumption:

Withdrawal Date: 


\section{Controlled Design Assumption \\ Alternate Assumption Rationale Sheet}

\section{Assumption Identifier: ALT 022}

Subject: C̄hemically Treated Invert

\section{STATEMENT OF ASSUMPTION}

Sedimentary apatite ore, or a material with similar ability to sorb ${ }^{237} \mathrm{~Np}$ and/or other radionuclides, shall be placed in and/or around the emplacement drift invert segments below each waste package, and the amount of this material needed to sorb a significant amount of the ${ }^{2.37} \mathrm{~Np}$ in a large SNF WP is sufficiently small that it can be reasonably placed under a WP. It is further assumed that the infiltration rate at the repository horizon will not cause the chemicals in the emplacement drift inverts to be washed away prior to the time of their usefulness when the waste packages breach.

\section{BACKGROUND}

Requesting Management and Operating Contractor (M\&O) organization:

\section{( ) Surface, ( ) Subsurface, ( ) Waste Package Development, (X) Other (specify): Systems} Engineering

Need for assumption (statement of intended use):

Establishes a scenario that constrains aspects of the waste package, surface facilities, and subsurface facilities designs.

\section{RATIONALE}

Rationale for assumption (source author, date, and report title) or statement of reasoning behind engineering judgment:

This assumption is applicable to VA issue \#2 alternate concepts 3,4 , and 5 .

The use of material to sorb ${ }^{237} \mathrm{~Np}$ would be adopted to enhance the capability of the EBS to severely retard the transport of ${ }^{2.37} \mathrm{~Np}$ for 10,000 years after closure of the repository. The function of the material would not required until waste packages have breached.

\section{RESPONSIBILITY AND WITHDRA WAL}

Responsible Management and Operating Contractor (M\&O) organization: Systems Engineering Document(s) Supporting Withdrawal of Assumption:

Withdrawal Date: 
Assumption Identifier: ALT 023

Sub̄ject: Selective Retrieval

\section{STATEMENT OF ASSUMPTION}

To facilitate selective waste package retrieval (or recovery) from an emplacement drift the emplacement gantry shall have the capability to carry waste packages over emplaced packages and to travel the length of the emplacement drift with the waste package in the carryover mode.

\section{BACKGROUND}

Requesting Management and Operating Contractor (M\&O) organization:

( ) Surface, (X) Subsurface, ( ) Waste Package Development, ( ) Other (specify):

Need for assumption (statement of intended use):

Current assumptions and requirements for retrieval do not specify selective retrieval. This assumption applies to an alternate concept only.

\section{RATIONALE}

Rationale for assumption (source author, date, and report title) or statement of reasoning behind engineering judgment:

This assumption is applicable to the alternate concept for VA issue \#6.

If selective retrieval is determined to be necessary, then:

- A gantry with carryover capability would facilitate selective retrieval of waste packages by lifting and carrying the target packages over emplaced packages. Without this capability waste packages between the emplacement drift entrance and the target package(s) would first have to be removed.

- The carryover capability simplifies the task and shortens the time needed for selective retrieval operations and, hence, reduces the cost of this activity.

\section{RESPONSIBILITY/SUBSTANTIATION/WITHDRAWAL}

Responsible Management and Operating Contractor (M\&O) organization: Subsurface Document(s) Supporting Withdrawal of Assumption:

Withdrawal Date: 


\section{Controlled Design Assumption \\ Alternate Assumption Rationale Sheet}

\section{Assumption Identifier: ALT 024}

\section{STATEMENT OF ASSUMPTION}

Repository performance confirmation operations will provide for periodic removal and relocation of all waste packages within selected drifts to provide temporary access of personnel for in-drift inspection activities.

\section{BACKGROUND}

Requesting Management and Operating Contractor (M\&O) organization:

( ) Surface, ( X ) Subsurface, ( ) Waste Package Development, ( ) Other (specify):

Need for assumption (statement of intended use):

Current assumptions and requirements preclude personnel entry and depend on remote inspection capabilities.

\section{RATIONALE}

Rationale for assumption (source author, date, and report title) or statement of reasoning behind engineering judgment:

This alternate assumption is applicable to the VA issue \#11 alternate concept 6. This assumption would be applied in conjunction with assumption ALT 028.

Removing waste packages to allow personnel entry is an alternative to the reference concept that would preclude personnel access and use remotely controlled inspection equipment.

\section{RESPONSIBILITY/SUBSTANTIATION/WITHDRA WAL}

Responsible Management and Operating Contractor (M\&O) organization: Subsurface

Document(s) Supporting Withdrawal of Assumption:

I

I Withdrawal Date: 


\section{Controlled Design Assumption \\ Alternate Assumption Rationale Sheet}

Assumption Identifier: ALT 025

Subject: Waste Package Materials

\section{STATEMENT OF ASSUMPTION}

The following materials will be used in future waste package (WP) design work:

\begin{tabular}{|l|l|}
\hline \multicolumn{1}{|c|}{ Component } & \multicolumn{1}{|c|}{ Material } \\
\hline Corrosion allowance barrier for SNF waste forms & ASTM A 516 Grade 55 or 70 \\
\hline Corrosion resistant barrier for SNF waste forms & C-22, ASTM B 575 N06022 (Alloy 622) \\
\hline Fuel basket tubes for SNF waste forms & ASTM A 516 Grade 55 or 70 \\
\hline Fuel basket plates for SNF waste forms & Neutronit A 978 or equivalent \\
\hline Waste container fill gas for SNF waste forms & Helium \\
\hline Basket guides for SNF waste forms & ASTM A 516 Grade 55 or 70 \\
\hline Corrosion allowance barrier for HLW glass & ASTM A 516 Grade 55 or 70 \\
\hline Corrosion resistant barrier for HLW glass & C-22, ASTM B 575 N06022 (Alloy 622) \\
\hline Canister guide for HLW glass & ASTM A 516 Grade 55 or 70 \\
\hline
\end{tabular}

HLW - High-Level Waste, SNF - Spent Nuclear Fuel

Where a choice is indicated (ASTM A 516 Grade 55 or 70), either of these materials could be used; a choice between them will require additional engineering analysis.

\section{BACKGROUND}

Requesting Management and Operating Contractor (M\&O) organization:

( ) Surface, ( ) Subsurface, (X) Waste Package Development, or ( ) Other (specify):

Need for assumption (statement of intended use):

\section{RATIONALE}

Rationale for assumption (source author, date, and report title) or statement of reasoning behind engineering judgment:

This alternate assumption is a modification of assumption DCWP 004 that is applicable to the alternate concept for VA issue \#17.

Materials for the reference concept were selected in Waste Package Material Selection Analysis (BBA000000-01717-0200-00020 REV 00). The concept includes an outer barrier of corrosion allowance material that corrodes as a slow, predictable rate, and an inner barrier of a corrosion resistant material. To provide extra corrosion resistance, the inner barrier for the alternate concept is changed to Alloy 622 (a.k.a. C-22, ASTM B 575 N06022). Under the assumption that 


\section{Controlled Design Assumption Alternate Assumption Rationale Sheet}

I Assumption Identifier: ALT 025 (continued)

Subject: Waste Package Materials

I the percolation flux is large, the waste packages will be exposed to humid or wet environments

1 earlier than would otherwise be expected. Early exposure of the corrosion allowance barrier to

1 corrosive conditions may lead to early breaching of this outer barrier and exposure of the

1 corrosion resistant barrier to high-temperature corrodents.

I

\section{RESPONSIBILITY AND WITHDRAWAL}

1

I Responsible Management and Operating Contractor (M\&O) organization: Waste Package

1

I Document(s) Supporting Withdrawal of Assumption:

I

I Withdrawal Date:

I 


\section{Controlled Design Assumption \\ Alternate Assumption Rationale Sheet}

Assumption Identifier: ALT 026

Subject: Pērformance Confirmation

Requirements (1996)

\section{STATEMENT OF ASSUMPTION}

The following set of requirements is based on the FY 96 Performance Confirmation Concept Study Report (CRWMS M\&O 1996e) with a modification to reflect enhancements to the role and functionality of the basic remote inspection gantry for use in emplacement drifts. This assumption is a modification of Key Assumption 061 that will be used as a basis for Mined Geologic Disposal System (MGDS) Performance Confirmation planning and design if VA issue \#11 alternate concept 4 is adopted.

1. Repository design and operation shall provide facilities, access, instrumentation, recording, maintenance, and support for measuring/monitoring the performance confirmation parameters identified in Appendix D of the FY 96 Performance Confirmation Concept Study Report (CRWMS M\&O 1996e).

2. The performance confirmation monitoring and measuring system shall have a maintainable service life of 125 years ( 100 years plus the duration of initial construction plus the duration of final closure plus any time period during site characterization for which the system must be operable). Specific equipment and components shall have maintainable service lives dependent upon their identified function. These service lives are to be determined (TBD).

3. Planning of repository design and operations for performance confirmation test facilities and support shall consider the performance confirmation concepts identified in Section 5 of the Performance Confirmation Concept Study Report (CRWMS M\&O 1996e) as a point of departure.

4. The performance confirmation system shall be planned to permit availability of TBD percent.

5. Test locations/environments, samples, and specimens, onsite and offsite, shall be representative of the Repository environments and design elements.

6. Performance confirmation staff, measurement and monitoring hardware and software, shall be available to support the variable demand for analysis, assessment, and periodic reporting throughout the Performance Confirmation Program.

7. Surface-based boreholes shall be provided for monitoring unsaturated zone hydrology and shall avoid underground excavations.

8. At least one alcove shall be provided for testing and monitoring the Ghost Dance Fault prior to and following waste emplacement.

9. Monitoring of at least two percent of the thermal rock mass behavior (to be related to the number of emplacement drifts) shall be performed; a portion of the rock mass to be monitored should be near the first emplacement drifts to contain waste.

10. The Repository Subsurface Facilities shall provide underground openings (drifts, alcoves, boreholes, and ancillary excavations), access, data acquisition, and test support to implement performance confirmation monitoring and test recommendations including interface and coordination with Site Investigation Testing, Repository Testing, Waste 


\section{Controlled Design Assumption \\ Alternate Assumption Rationale Sheet}

\section{Assumption Identifier: ALT 026 (continued)}

Subject: Performance Confirmation

Requirements (1996)

Package Testing, and Surface Support. These operations are to include, but are not to be limited to, capabilities for:

a. Any ground support system (i.e., shotcrete or concrete) that covers the repository subsurface opening rock wall surface shall not be installed until after necessary rock mapping is complete.

b. TBD samples of rock core shall be acquired following emplacement drift excavation.

c. Placement and recovery of material coupons or specimens in the emplacement drift or other underground locations shall be performed at least once every 10 years.

d. Recovery of selected or malfunctioning waste packages shall be performed on a nonroutine basis, as required.

e. The design, excavation, and ground support of emplacement drifts shall permit installation of and access to test/monitoring instrumentation, and observation drift instrumentation, and provide access for remotely operated vehicles or mobile inspection platforms to obtain measurements.

f. Excavation of at least one permanent observation drift above the repository horizon shall be developed in support of thermal monitoring.

g. At least one alcove shall be prepared for underground monitoring of seismic activities.

h. The air temperature, relative humidity, and gaseous radioactive emissions of all emplacement drifts shall be monitored through the drift ventilation.

i. The ventilation monitoring system shall be capable of identifying the specific drifts that are sources of gaseous radioactive emissions, if any, within TBD hours of detection of such emission.

j. The provision and use of remotely operated vehicles or movable inspection platform for monitoring emplacement drift environments and effects shall be considered in support of the following requirements:

- Personnel access into emplacement drifts shall not be permitted except for emergencies or if waste packages have been removed from the drift.

- Remote inspections of TBD emplacement drifts shall be performed annually to:

- Measure and map radiological and thermal emplacement drift conditions

- Visually monitor for possible rockfalls and inspect for deformation and convergence in excess of TBD $\mathrm{mm}$ in drift walls and near-field rock mass

- Collect samples of water inflow for laboratory analysis 


\section{Controlled Design Assumption \\ Alternate Assumption Rationale Sheet}

\section{Assumption Identifier: ALT 026 (continued)}

Subject: Performance Confirmation

Requirements (1996)

- Collect wipe samples of dust from surfaces for laboratory analysis

- Emplace and recover temporary in-drift monitoring instrumentation

- Obtain small samples of drift liners or near-field geology

- Inspect waste package integrity using ultrasonic, eddy-current sensors or other implementable technology

- Monitor waste package corrosion

- Obtain in-drift air/gas sampling at specific locations.

- Remote inspection equipment may also be used to provide support for in-drift operational, maintenance and regulatory activities not encompassed specifically within PC Program, i.e., response to off-normal events and anomalies, debris removal, and other ad hoc applications.

k. Subsurface facilities operations shall have a program to inspect for significant water inflow and, if detected, for measuring

- Groundwater inflow quantities,

- Temperature, and

- Chemical composition.

Measurements shall be made by:

- Direct measurement on a recurring basis prior to closure for all underground openings except emplacement drifts,

- Direct measurement during construction and prior to waste emplacement for emplacement drifts, and

1. Drift diameter changes shall be monitored periodically to track excavation convergence. These measurements are required:

- In Permanent Observation Drifts, and may be monitored directly or remotely.

- In selected drifts, as indicated by rockfall activities.

m. Alcoves or drifts shall be provided to support backfill performance and constructability experiments and tests.

n. Alcoves shall be provided to support seal performance and constructability tests.

o. Subsurface Facilities shall provide facilities and test support as required by Site Investigation Thermal Testing to characterize and monitor thermal interaction effects 


\section{Controlled Design Assumption \\ Alternate Assumption Rationale Sheet}

Assumption Identifier: ALT 026 (continued)

Subject: Pērformance Confirmation

Requirements (1996)
while heating and while cooling and as required by Waste Package Testing for materials in situ tests.

11. The Repository Surface Facilities shall have the capability to support Performance Confirmation surface operations, equipment, and tests including, but not limited to:

a. The capability to receive, handle, store, examine, test, and return to the underground waste packages, material coupons, and other specimens recovered from underground emplacement. This capability is to be exercised on a non-routine basis for malfunctioning radioactive waste packages, if any.

b. Handling to include transferring and opening the disposal container and canistered and uncanistered waste forms, removing of samples, and repackaging, resealing, and decontaminating the disposal container.

c. The capability for routine and non-routine non-destructive testing of sealed or resealed waste packages prior to emplacement or after recovery.

d. The capability to receive, decontaminate, manage, temporarily store, and ship material coupons or specimens, retrieved from the emplacement drift, for offsite testing.

e. The capability to receive, manage, temporarily store, and ship rock samples for offsite testing.

f. The capability to transfer, automatically acquire, record, process, and communicate instrumentation data from surface and subsurface monitoring equipment and tests.

g. The capability to support and protect continuous and periodic surface monitoring and tests operations.

h. The facilities and equipment to support performance confirmation operations such as test monitoring and control, data processing, record management and communication, limited laboratory tests, analysis and evaluations.

\section{BACKGROUND}

Requesting Management and Operating Contractor (M\&O) organization:

(X) Surface, (X) Subsurface, (X) Waste Package Development, (X) Other (specify): Systems Engineering

Need for assumption (statement of intended use):

Performance confirmation requirements are needed for design and planning and do not yet exist in the Mined Geologic Disposal System (MGDS) design requirements documents. 


\section{Controlled Design Assumption \\ Alternate Assumption Rationale Sheet}

I Assumption Identifier: ALT 026 (continued)

Subject: Përformance Confirmation Requirements (1996)

\section{RATIONALE}

Rationale for assumption (source author, date, and report title) or statement of reasoning behind engineering judgment:

Requirements were recommended in the Performance Confirmation Concept Study Report (CRWMS M\&O 1996e). The recommended requirements as presented in Key Assumption 061 have been modified in paragraph $10 \mathrm{~J}$ of this alternate assumption to identify enhancements to the role and functionality of the basic remote inspection gantry that are applicable to VA issue \#11 alternate concept 4.

\section{RESPONSIBILITY AND WITHDRAWAL}

Responsible Management and Operating Contractor (M\&O) organization: Systems Engineering

Document(s) Supporting Withdrawal of Assumption:

Withdrawal Date: 


\section{Controlled Design Assumption \\ Alternate Assumption Rationale Sheet}

Assumption Identifier: ALT 027

Subject: Pērformance Confirmation

\section{STATEMENT OF ASSUMPTION}

Requirements (1996)

The following set of requirements is based on the FY 96 Performance Confirmation Concept Study Report (CRWMS M\&O 1996e) with a modification to reflect reliance on available borehole monitoring coverage with no direct in-drift monitoring in emplacement drifts. This assumption is a modification of Key Assumption 061 that will be used as a basis for Mined Geologic Disposal System (MGDS) Performance Confirmation planning and design if VA issue $\# 11$ alternate concept 5 is adopted.

1. Repository design and operation shall provide facilities, access, instrumentation, recording, maintenance, and support for measuring/monitoring the performance confirmation parameters identified in Appendix D of the FY 96 Performance Confirmation Concept Study Report (CRWMS M\&O 1996e).

2. The performance confirmation monitoring and measuring system shall have a maintainable service life of 125 years ( 100 years plus the duration of initial construction plus the duration of final closure plus any time period during site characterization for which the system must be operable). Specific equipment and components shall have maintainable service lives dependent upon their identified function. These service lives are to be determined (TBD).

3. Planning of repository design and operations for performance confirmation test facilities and support shall consider the performance confirmation concepts identified in Section 5 of the Performance Confirmation Concept Study Report (CRWMS M\&O 1996e) as a point of departure.

4. The performance confirmation system shall be planned to permit availability of TBD percent.

5. Test locations/environments, samples, and specimens, onsite and offsite, shall be representative of the Repository environments and design elements.

6. Performance confirmation staff, measurement and monitoring hardware and software, shall be available to support the variable demand for analysis, assessment, and periodic reporting throughout the Performance Confirmation Program.

7. Surface-based boreholes shall be provided for monitoring unsaturated zone hydrology and shall avoid underground excavations.

8. At least one alcove shall be provided for testing and monitoring the Ghost Dance Fault prior to and following waste emplacement.

9. Monitoring of at least two percent of the thermal rock mass behavior (to be related to the number of emplacement drifts) shall be performed; a portion of the rock mass to be monitored should be near the first emplacement drifts to contain waste.

10. The Repository Subsurface Facilities shall provide underground openings (drifts, alcoves, boreholes, and ancillary excavations), access, data acquisition, and test support to implement performance confirmation monitoring and test recommendations including interface and coordination with Site Investigation Testing, Repository Testing, Waste 


\section{Controlled Design Assumption \\ Alternate Assumption Rationale Sheet}

Assumption Identifier: ALT 027 (continued)

Subject: Performance Confirmation

Requirements (1996)

Package Testing, and Surface Support. These operations are to include, but are not to be limited to, capabilities for:

a. Any ground support system (i.e., shotcrete or concrete) that covers the repository subsurface opening rock wall surface shall not be installed until after necessary rock mapping is complete.

b. TBD samples of rock core shall be acquired following emplacement drift excavation.

c. Recovery of selected or malfunctioning waste packages shall be performed on a nonroutine basis, as required.

d. The design, excavation, and ground support of emplacement drifts shall permit installation of and access to test/monitoring instrumentation, and observation drift instrumentation.

e. Excavation of at least one permanent observation drift above the repository horizon shall be developed in support of thermal monitoring.

f. At least one alcove shall be prepared for underground monitoring of seismic activities.

g. The air temperature, relative humidity, and gaseous radioactive emissions of all emplacement drifts shall be monitored through the drift ventilation.

h. The ventilation monitoring system shall be capable of identifying the specific drifts that are sources of gaseous radioactive emissions, if any, within TBD hours of detection of such emission.

i. Subsurface facilities operations shall have a program to inspect for groundwater inflow and, if detected, for measuring

- Groundwater inflow quantities,

- Temperature, and

- Chemical composition.

Measurements shall be made by:

- Direct measurement for all underground openings except emplacement drifts,

- Direct measurement during construction and prior to waste emplacement for emplacement drifts, and

j. Drift diameter changes shall be monitored periodically to track excavation convergence. These measurements are required:

- In Permanent Observation Drifts.

- In selected drifts, as indicated by rockfall activities. 


\section{Controlled Design Assumption \\ Alternate Assumption Rationale Sheet}

Assumption Identifier: ALT 027 (continued)

Subject: Performance Confirmation

Requirements (1996)

k. Alcoves or drifts shall be provided to support backfill performance and constructability experiments and tests, if backfill in emplacement drifts is required.

1. Alcoves shall be provided to support seal performance and constructability tests.

m. Subsurface Facilities shall provide facilities and test support as required by Site Investigation Thermal Testing to characterize and monitor thermal interaction effects while heating and while cooling and as required by Waste Package Testing for materials in situ tests.

11. The Repository Surface Facilities shall have the capability to support Performance

Confirmation surface operations, equipment, and tests including, but not limited to:

a. The capability to receive, handle, store, examine, test, and return to the underground waste packages, material coupons, and other specimens recovered from underground emplacement. This capability is to be exercised on a non-routine basis for malfunctioning radioactive waste packages, if any.

b. Handling to include transferring and opening the disposal container and canistered and uncanistered waste forms, removing of samples, and repackaging, resealing, and decontaminating the disposal container.

c. The capability for routine and non-routine non-destructive testing of sealed or resealed waste packages prior to emplacement or after recovery.

d. The capability to receive, decontaminate, manage, temporarily store, and ship material coupons or specimens, retrieved from the emplacement drift, for offsite testing.

e. The capability to receive, manage, temporarily store, and ship rock samples for offsite testing.

f. The capability to transfer, automatically acquire, record, process, and communicate instrumentation data from surface and subsurface monitoring equipment and tests.

g. The capability to support and protect continuous and periodic surface monitoring and tests operations.

h. The facilities and equipment to support performance confirmation operations such as test monitoring and control, data processing, record management and communication, limited laboratory tests, analysis and evaluations.

\section{BACKGROUND}

Requesting Management and Operating Contractor (M\&O) organization:

(X) Surface, (X) Subsurface, (X) Waste Package Development, (X) Other (specify): Systems Engineering

Need for assumption (statement of intended use): 


\section{Controlled Design Assumption \\ Alternate Assumption Rationale Sheet}

Assumption Identifier: ALT 027 (continued)

Subject: Performance Confirmation

Requirements (1996)

Performance confirmation requirements are needed for design and planning and do not yet exist in the Mined Geologic Disposal System (MGDS) design requirements documents.

\section{RATIONALE}

Rationale for assumption (source author, date, and report title) or statement of reasoning behind engineering judgment:

Requirements were recommended in the Performance Confirmation Concept Study Report (CRWMS M\&O 1996e). The recommended requirements as presented in Key Assumption 061 have been modified to reflect reliance on available borehole monitoring coverage with no direct in-drift monitoring in emplacement drifts. Changes to Key Assumption 061 include: deletion of paragraph 10.c, modification of paragraph 10.e (new 10.d), deletion of paragraph 10.j, and modification of paragraph 10.1 (new paragraph $10 . \mathrm{j}$ ). These changes are applicable to VA issue \#11 alternate concept 5.

\section{RESPONSIBILITY AND WITHDRAWAL}

Responsible Management and Operating Contractor (M\&O) organization: Systems Engineering

Document(s) Supporting Withdrawal of Assumption:

Withdrawal Date: 


\section{Controlled Design Assumption \\ Alternate Assumption Rationale Sheet}

\section{Assumption Identifier: ALT 028}

Subject: Pērformance Confirmation

\section{STATEMENT OF ASSUMPTION}

Requirements (1996)

The following set of requirements is based on the FY 96 Performance Confirmation Concept Study Report (CRWMS M\&O 1996e) with a modification to reflect periodic removal of waste packages from individual drifts to allow personnel access for non-remote inspection/monitoring. This assumption is a modification of Key Assumption 061 that will be used as a basis for Mined Geologic Disposal System (MGDS) Performance Confirmation planning and design if VA Issue $\# 11$ alternate concept 6 is adopted.

1. Repository design and operation shall provide facilities, access, instrumentation, recording, maintenance, and support for measuring/monitoring the performance confirmation parameters identified in Appendix D of the FY 96 Performance Confirmation Concept Study Report (CRWMS M\&O 1996e).

2. The performance confirmation monitoring and measuring system shall have a maintainable service life of 125 years ( 100 years plus the duration of initial construction plus the duration of final closure plus any time period during site characterization for which the system must be operable). Specific equipment and components shall have maintainable service lives dependent upon their identified function. These service lives are to be determined (TBD).

3. Planning of repository design and operations for performance confirmation test facilities and support shall consider the performance confirmation concepts identified in Section 5 of the Performance Confirmation Concept Study Report (CRWMS M\&O 1996e) as a point of departure.

4. The performance confirmation system shall be planned to permit availability of TBD percent.

5. Test locations/environments, samples, and specimens, onsite and offsite, shall be representative of the Repository environments and design elements.

6. Performance confirmation staff, measurement and monitoring hardware and software, shall be available to support the variable demand for analysis, assessment, and periodic reporting throughout the Performance Confirmation Program.

7. Surface-based boreholes shall be provided for monitoring unsaturated zone hydrology and shall avoid underground excavations.

8. At least one alcove shall be provided for testing and monitoring the Ghost Dance Fault prior to and following waste emplacement.

9. Monitoring of at least two percent of the thermal rock mass behavior (to be related to the number of emplacement drifts) shall be performed; a portion of the rock mass to be monitored should be near the first emplacement drifts to contain waste.

10. The Repository Subsurface Facilities shall provide underground openings (drifts, alcoves, boreholes, and ancillary excavations), access, data acquisition, and test support to implement performance confirmation monitoring and test recommendations including interface and coordination with Site Investigation Testing, Repository Testing, Waste 


\section{Controlled Design Assumption \\ Alternate Assumption Rationale Sheet}

Assumption Identifier: ALT 028 (continued)

Subject: Performance Confirmation Requirements (1996)

Package Testing, and Surface Support. These operations are to include, but are not to be limited to, capabilities for:

a. Any ground support system (i.e., shotcrete or concrete) that covers the repository subsurface opening rock wall surface shall not be installed until after necessary rock mapping is complete.

b. TBD samples of rock core shall be acquired following emplacement drift excavation.

c. Placement and recovery of material coupons or specimens in the emplacement drift or other underground locations shall be performed at least once every 10 years.

d. Recovery of selected or malfunctioning waste packages shall be performed on a nonroutine basis, as required.

e. The design, excavation, and ground support of emplacement drifts shall permit installation of and access to test/monitoring instrumentation, and observation drift instrumentation, and provide access for remotely operated vehicles or mobile inspection platforms to obtain measurements.

f. Excavation of at least one permanent observation drift above the repository horizon shall be developed in support of thermal monitoring.

g. At least one alcove shall be prepared for underground monitoring of seismic activities.

h. The air temperature, relative humidity, and gaseous radioactive emissions of all emplacement drifts shall be monitored through the drift ventilation.

i. The ventilation monitoring system shall be capable of identifying the specific drifts that are sources of gaseous radioactive emissions, if any, within TBD hours of detection of such emission.

j. The provision and use of remotely operated vehicles or movable inspection platform for monitoring emplacement drift environments and effects shall be considered in support of the following requirements:

- Personnel access into emplacement drifts shall not be permitted except for emergencies or if waste packages have been removed from the drift.

- Remote inspections of emplacement drifts at least once every ten years shall be performed to monitor rockfall, and visually inspect and thermally image waste packages.

k. Subsurface facilities operations shall have a program to inspect for groundwater inflow and, if detected, for measuring

- Groundwater inflow quantities,

- Temperațure, and 


\section{Controlled Design Assumption \\ Alternate Assumption Rationale Sheet}

Assumption Identifier: ALT 028 (continued)

Subject: Pērformance Confirmation

Requirements (1996)

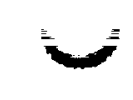

- Chemical composition.

Measurements shall be made by:

- Direct measurement for all underground openings except emplacement drifts,

- Direct measurement during construction and prior to waste emplacement for emplacement drifts, and

- Indirect or remote measurement in emplacement drifts after waste emplacement.

1. Emplacement drift diameter changes shall be monitored periodically to track excavation convergence. These measurements are required:

- In Permanent Observation Drifts, and may be monitored directly or remotely.

- In selected drifts, as indicated by rockfall activities.

m. Alcoves or drifts shall be provided to support backfill performance and constructability experiments and tests, if backfill in emplacement drifts is required.

n. Alcoves shall be provided to support seal performance and constructability tests.

o. Subsurface Facilities shall provide facilities and test support as required by Site Investigation Thermal Testing to characterize and monitor thermal interaction effects while heating and while cooling and as required by Waste Package Testing for materials in situ tests.

11. The Repository Surface Facilities shall have the capability to support Performance Confirmation surface operations, equipment, and tests including, but not limited to:

a. The capability to receive, handle, store, examine, test, and return to the underground waste packages, material coupons, and other specimens recovered from underground emplacement. This capability is to be exercised on a non-routine basis for malfunctioning radioactive waste packages, if any.

b. Handling to include transferring and opening the disposal container and canistered and uncanistered waste forms, removing of samples, and repackaging, resealing, and decontaminating the disposal container.

c. The capability for routine and non-routine non-destructive testing of sealed or resealed waste packages prior to emplacement or after recovery.

d. The capability to receive, decontaminate, manage, temporarily store, and ship material coupons or specimens, retrieved from the emplacement drift, for offsite testing.

e. The capability to receive, manage, temporarily store, and ship rock samples for offsite testing. 


\section{Controlled Design Assumption Alternate Assumption Rationale Sheet}

Assumption Identifier: ALT 028 (continued)

Subject: Performance Confirmation

Requirements (1996)

f. The capability to transfer, automatically acquire, record, process, and communicate instrumentation data from surface and subsurface monitoring equipment and tests.

g. The capability to support and protect continuous and periodic surface monitoring and tests operations.

h. The facilities and equipment to support performance confirmation operations such as test monitoring and control, data processing, record management and communication, limited laboratory tests, analysis and evaluations.

\section{BACKGROUND}

Requesting Management and Operating Contractor $(\mathrm{M} \& \mathrm{O})$ organization:

(X) Surface, (X) Subsurface, (X) Waste Package Development, (X) Other (specify): Systems Engineering

Need for assumption (statement of intended use):

Performance confirmation requirements are needed for design and planning and do not yet exist in the Mined Geologic Disposal System (MGDS) design requirements documents.

\section{RATIONALE}

Rationale for assumption (source author, date, and report title) or statement of reasoning behind engineering judgment:

Requirements were recommended in the Performance Confirmation Concept Study Report (CRWMS M\&O 1996e). The recommended requirements, as presented in Key Assumption 061, have been modified in paragraph $10 . \mathrm{J}$ of this alternate assumption to acknowledge that waste packages might be removed from an emplacement drift to allow personnel access. This modification is applicable to VA issue \#11 alternate concept 6 . This assumption would be applied in conjunction with assumption ALT 024.

\section{RESPONSIBILITY AND WITHDRAWAL}

Responsible Management and Operating Contractor (M\&O) organization: Systems Engineering Document(s) Supporting Withdrawal of Assumption:

Withdrawal Date: 


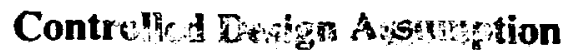
Alternate Assumgiogs sationale Sheet

\section{INTENTIONALL.Y LEFT BLANK}

